\title{
Long-term clinical and genetic studies in myotonic dystrophy
}

Citation for published version (APA):

de Die-Smulders, C. E. M. (2000). Long-term clinical and genetic studies in myotonic dystrophy. [Doctoral Thesis, Maastricht University]. Datawyse / Universitaire Pers Maastricht.

https://doi.org/10.26481/dis.20000323cd

Document status and date:

Published: 01/01/2000

DOI:

$10.26481 /$ dis.20000323cd

Document Version:

Publisher's PDF, also known as Version of record

\section{Please check the document version of this publication:}

- A submitted manuscript is the version of the article upon submission and before peer-review. There can be important differences between the submitted version and the official published version of record.

People interested in the research are advised to contact the author for the final version of the publication, or visit the DOI to the publisher's website.

- The final author version and the galley proof are versions of the publication after peer review.

- The final published version features the final layout of the paper including the volume, issue and page numbers.

Link to publication

\footnotetext{
General rights rights.

- You may freely distribute the URL identifying the publication in the public portal. please follow below link for the End User Agreement:

www.umlib.nl/taverne-license

Take down policy

If you believe that this document breaches copyright please contact us at:

repository@maastrichtuniversity.nl

providing details and we will investigate your claim.
}

Copyright and moral rights for the publications made accessible in the public portal are retained by the authors and/or other copyright owners and it is a condition of accessing publications that users recognise and abide by the legal requirements associated with these

- Users may download and print one copy of any publication from the public portal for the purpose of private study or research.

- You may not further distribute the material or use it for any profit-making activity or commercial gain

If the publication is distributed under the terms of Article $25 \mathrm{fa}$ of the Dutch Copyright Act, indicated by the "Taverne" license above, 


\section{LONG-TERM CLINICAL AND GENETIC STUDIES IN MYOTONIC DYSTROPHY}


C C.E.M. de Die-Smulders, Maastricht 2000

ISBN: 9052782733

Printing: Datawyse, Maastricht

Omslagfoto: Alex Zeguers en Jan de Die

The research described in this thesis was supported by grants from the Beatrixfonds and the Clinical Genetics Center South-East Netherlands 


\title{
LONG-TERM CLINICAL AND GENETIC STUDIES IN MYOTONIC DYSTROPHY
}

\author{
PROEFSCHRIFT \\ ter verkrijging van de graad van doctor \\ aan de Universiteit Maastricht, \\ op gezag van de Rector Magnificus, \\ Prof. Dr. A. C. Nieuwenhuijzen Kruseman \\ volgens het besluit van het College van Decanen \\ in het openbaar te verdedigen op \\ donderdag 23 maart 2000 om 16.00 uur
}

door

Christine Elisabeth Maria de Die-Smulders

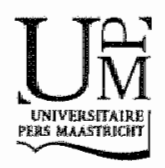




\section{Promotores:}

Prof. dr. J.P.M. Geraedts

Prof. dr. J.P. Fryns

\section{Co-promotor:}

Dr. C.J. Höweler

\section{Beoordelingscommissie:}

Prof. dr. J. Troost (voorzitter)

Prof. dr. C.E. Blanco

Prof. dr. H.G. Brunner (Katholieke Universiteit Nijmegen)

Prof. dr. P.S. Harper (University of Wales College of Medicine, U.K.)

Prof. dr. J.G. Nijhuis 


\section{Contents}

General introduction

\section{Part I: Clinical studies}

Chapter 1 Myotonic dystrophy: a clinical perspective 11

Chapter 2 The childhood type of myotonic dystrophy 23

2.1 The childhood type of myotonic dystrophy: clinical and genetic aspects 25

2.2 Emotional and behavioural profile and child psychiatric diagnosis in the childhood type of myotonic dystrophy

2.3 A study of the cognitive and psychological profile in 16 children with congenital or juvenile myotonic dystrophy

Chapter 3 Age and causes of death in adult onset myotonic dystrophy

\section{Part II: Genetic studies}

Chapter 4 Trinucleotide repeat disorders

Chapter 5 Genetic aspects of myotonic dystrophy

Chapter 6 Epidemiology and origin of the myotonic dystrophy mutation

Chapter 7 Anticipation resulting in elimination of the myotonic dystrophy gene: a follow up study of one extended family

Chapter 8 Paternal transmission of the myotonic dystrophy gene

8.1 Paternal transmission of congenital myotonic dystrophy

8.2 Reverse mutation in myotonic dystrophy

Chapter 9 General discussion

Summary

Samenvatting

Dankwoord

Curriculum vitae

Publications 



\section{General introduction}

Myotonic dystrophy (DM), also known as dystrophia myotonica or Steinert's disease, is the most frequent, heritable neuromuscular disease in adults. Unique among the muscular dystrophies, it is characterised by myotonia, accompanied by muscle weakness and multiple systemic complications. DM was first recognised as a clinical entity in the beginning of the 20th century (Batten and Gibb, 1909; Steinert, 1909). The clinical features were thoroughly studied in the following decades and the involvement of organs outside muscle, such as the eyes and the endocrine system, became obvious. Also the occurrence of mental changes and cardiorespiratory problems appeared to be of main importance. In the sixties the severe congenital presentation was recognised (Vanier, 1960).

From a clinical point of view DM is one of the most variable disorders known, and patients with myotonic dystrophy can be seen and treated not only by neurologists but by a wide variety of other clinicians. The diagnosis is not difficult to make in patients presenting with myotonia, in conjunction with weakness and wasting. However, patients may also present with systemic complaints, such as cataract, dysphagia and abdominal complaints, or with developmental delay and in that case the diagnosis is often fairly delayed. This occurrence of abnormalities outside muscle is perhaps the most characteristic feature of DM.

Age at onset is the most important factor determining the clinical picture. Therefore, it is useful for clinical practice to divide patients in disease types: late onset (mild) type, adult-onset, childhood and congenital onset type. The core symptoms differ per disease type. In the mild type, with age at onset $>50$ years, cataract is often the only sign. The most frequent adult type represents the "classical" presentation with myotonia, weakness and systemic complications. Mental retardation is the principal feature in the childhood and congenital onset types, in the latter preceded by neonatal muscular weakness.

The course of DM is one of slow progression. Muscular weakness increases gradually and only in a late phase of the disease mobility becomes impaired. The extramuscular features are also progressive and usually determine the prognosis for life. Due to the slow progression of the disease, long-term follow-up studies are difficult to perform and most data are derived from transversal observations or from 2-3 generation families. Therefore, little is known on the course of the disease, on the features in advanced cases and on the life expectancy of patients. It is reasonable to assume that the disease type is one of the factors determining the prognosis, but this has not been studied extensively. 
It is already known since the beginning of this century that DM follows a pattern of autosomall dominant inheritance. However some atypical features are observed in the transmission. Firstly, the disease usually presents at progressively earlier age in successive generations. This phenomenon, called anticipation, has been debated for decades, but the careful clinical study of Höweler et al. $(1986,1989)$ provided convincing evidence for the existence of anticipation in DM. Other remarkable genetic issues are the almost exclusive maternal transmission of congenital DM and the predominant paternal origin of minimally affected cases (Harper, 1989; Brunner et al., 1993). Many of the puzzling clinical and genetic features of DM are now explained by the genetic instability consequent on trinucleotide repeat expansion (Harper et al., 1992). However, the mechanism by which the mutational change influences the clinical expression still remains an enigma. Also, we still lack understanding on questions such as: what are the consequences of ongoing repeat expansion for families? Will the mutated gene, as a consequence of anticipation, been eliminated from families, due to the low reproductive fitness of severely affected patients in the youngest generations? If this is true, why is the disease still. relatively frequent in the population? Moreover, the explanations for the differences between maternal and paternal inheritance are still incomplete.

The present study aimed to determine the long-term clinical and genetic consequences of myotonic dystrophy. We had a unique opportunity for a longitudinal study because 45 years ago, $85 \mathrm{DM}$ patients from 15 families, all living in the Southern part of Limburg (the Netherlands), were examined and described in detail by de Jong, who presented his thesis on this subject in 1955 (de Jong, 1955). The collection of data was continued by the Jong, and since 1970 by the next generation of neurologists, working in the three regional hospitals in Maastricht, Heerlen and Sittard. After 1987 the series of family records were collated by the Department of Clinical Genetics and extended to the more Northern parts of Limburg and the South-Eastern part of Brabant. For the present study we had the data of $370 \mathrm{DM}$ patients from 65 families at our disposal. Medical records of all patients were reviewed and updated, and if possible patients were examined personally. Data on age at onset, age at death, disease type, course of the disease and major complications, results of DNA examination and genealogical studies were documented. This approach enabled us to gather long-term follow-up information on a large number of DM patients and their families. In the course of the study we noticed a lack of knowledge of the clinical features, in particular of the behavioural phenotype, and of the prospects of children with DM. 
By combining these clinical and genetic data we gained insight into:

- the symptomology of DM in the different age of onset groups, particularly in the childhood-onset type

- the course and prognosis of the childhood and adult onset types

- the long-term consequences of anticipation in one extended family

- aspects of the irregular inheritance of the DM gene, especially the sex differences in transmission

The first part of this thesis (chapters 1-3) concerns the clinical studies, while the second part (chapters 4-8) deals with the genetic aspects of the disease. In chapter 1 a review of the clinical features is given. Clinical, genetic and prognostic aspects of the childhood type of DM are described in chapter 2, completed with cognitive, behavioural and child-psychiatric data. Chapter 3 addresses the results of a study on age and causes of death in the adult-onset type of DM. An overview of the trinucleotide repeat disorders is given in chapter 4 . Literature data on the genetics of DM are summarised in chapter 5 . Chapter 6 comprises a summary on the literature on the origin of the DM mutation. Chapter 7 concerns a follow-up study of a large DM family, in which the consequences of anticipation are studied. Finally in chapter 8 a rare case of paternal transmission of congenital DM and the reverse mutation of a paternally inherited DM gene are reported.

\section{References}

Batten FE, Gibb HP. Myotonia atrophica (dystrophia myotonica). Brain 1909;32:187-205.

Brunner HG, Brüggenwirth HT, Nillisen W, Jansen G, Hamel BCJ, Hoppe RLE, de Die CEM, Höweler CJ, van Oost BA, Wieringa B, Ropers HH, Smeets HMM. Influence of sex of the transmitting parent as well as of parental allele size on the $C T G$ expansion in myotonic dystrophy. Am J Hum Genet 1993;53:1016-1023.

Harper PS. Myotonic dystrophy, 2nd edn. WB Saunders, London and Philadelphia, 1989.

Harper PS, Harley HG, Reardon W, Shaw DJ. Anticipation in myotonic dystroplay: new light on an old problem. Am J Hum Genet 1992;51:10-16.

Höweler CJ. A clinical and genetic study in myotonic dystrophy. Thesis, University of Rotterdam, 1986.

Höweler CJ, Busch HFM, Geraedts JPM, Niermeijer MF, Staal A. Anticipation in myotonic dystrophy: fact or fiction? Brain 1989;1 12:779-797.

Jong de JGY. Dystrophia myotonica, paramyotonia and myotonia congenita. Thesis, University of Utrecht, 1955.

Steinert H. Myopathologische Beitrage I. Uber das klinische and anatomische Bild des Muskelschwunds der Myotoniker. Dtsch Z Nervenheilkd 1909;37:58-104. 
Vanier TM. Dystrophia myotonica in childhood. Br Med J1960;2:1284-1288. 
Chapter 1

\section{Myotonic dystrophy: a clinical perspective}

\subsection{Introduction}

1.2 The disease types

1.3 A closer look at the muscular problems

1.4 Systemic complications

1.5 Disease progression and prognosis

1.6 General management

1.7 Social activities, daily living and working

Adapted from: de Die-Smulders CEM, Höweler CJ. Myotone dystrofie. Begeleiding in de verschillende levensfasen. Myonet, Nieuwsbrief neuromusculaire ziekten 1996;3. http://www.vsn/myo43.htm 


\subsection{Introduction}

The combination of a characteristic pattern of muscle involvement in conjunction with myotonia and multiple systemic complications places myotonic dystrophy in a unique position among the inherited muscular dystrophies. Muscle weakness especially involves the facial, jaw, throat and neck muscles and the muscles of the forearm and lower legs. A variety of organs outside the muscles may also be affected resulting in problems such as cataract, cardiac arrhythmias, mental slowness, loss of initiative and infertility in males (Harper, 1989). There is considerable variation in the age at onset, presentation and severity of symptoms amongst patients, ranging from the isolated development of cataract later on in life to life-threatening muscle weakness at birth (Harper, 1989). In 1992 the mutational basis of the disease was found to be an unstable trinucleotide repeat, namely a CTG repeat in the 3' untranslated region of the DMPK gene. There is a broad positive correlation between length of the CTG repeat and age at onset (Brook et al., 1992; Harley et al., 1992; Harley et al.,1993).

\subsection{The disease types}

The severity of DM is extremely variable and related to the age at onset and duration of symptoms. Different classifications have been used. Dyken (1969) defined three clinical "syndromes", the "mildest", starting in middle or old age, "classical" DM seen in adolescence and adulthood, and the "congenital or childhood" presentation with onset at birth. In practice only the term congenital myotonic dystrophy (CMD) was widely accepted. In the eighties children with $\mathrm{DM}$, but an uneventful neonatal history were described (O'Brien and Harper, 1984). This childhood presentation was distinguished as a separate disease type, different from the congenital type, only recently (Koch et al., 1991). Classification of patient groups by age of onset is nowadays common (table 1) (Koch et al., 1991; Harley et al., 1993). For clinical practice this subdivision is useful, because core symptoms and prognosis differ per onset-group and also the length of the CTG expansion correlates broadly with these groups. In the mild type, with age at onset $>50$ years, cataract is the principal clinicall feature, sometimes accompanied by myotonia and mild muscular weakness. The adult-onset (classical) type, with the age at onset between puberty and the age of 50 , is characterised by slowly progressive muscular weakness and myotonia. Systemic complications usually occur in a later phase, exceptionally they are the 
presenting symptom. In the childhood-onser type, with age at onset between 1 and 12 years, mental retardation is the most obvious symptom, muscle weakness is often mild. In the absence of specific signs or symptoms, the diagnosis DM is often difficult to make in these children, especially if the disease is not (yet) known in one of the parents or other family members (O'Brien and Harper, 1984; Koch et al., 1991).

Table 1 The 4 types of myotonic dystrophy, age at onset, most important early and later symptoms and number of CTG triplet repeats.

\begin{tabular}{|c|c|c|c|c|}
\hline Type & $\begin{array}{l}\text { Age at } \\
\text { onset }\end{array}$ & Early symptoms & Later symptoms & $\begin{array}{l}\text { Number of CTO } \\
\text { triplat repeats }\end{array}$ \\
\hline Mild & $>50$ & Cataract & $\begin{array}{l}\text { Myotonia, } \\
\text { mild weakness }\end{array}$ & $40-80$ \\
\hline Adult & $12-50$ & $\begin{array}{l}\text { Myotonia, } \\
\text { muscle weakness }\end{array}$ & $\begin{array}{l}\text { Increased weakness, } \\
\text { cataract, } \\
\text { slowness/apathy, } \\
\text { organ complications }\end{array}$ & $100->1000$ \\
\hline Chilldhood & $1-12$ & $\begin{array}{l}\text { Learning difficulties, } \\
\text { speech difficulties }\end{array}$ & $\begin{array}{l}\text { Bowel problems } \\
\text { tiredness, myotonia, } \\
\text { muscle weakness, } \\
\text { as in the adult type }\end{array}$ & $500->2000$ \\
\hline Congenital & Birth & $\begin{array}{l}\text { Hypotonia, } \\
\text { respiratory and } \\
\text { swallowing problems, } \\
\text { club feet }\end{array}$ & $\begin{array}{l}\text { Learning and speech } \\
\text { difficulties, } \\
\text { as in the childhood } \\
\text { type }\end{array}$ & $1000->5000$ \\
\hline
\end{tabular}

In the congenital type severe muscle weakness (floppy baby) is already present at birth. During pregnancy there is often an excess of amniotic fluid (because the baby does not swallow) and the mother experiences feeble fetal movements. Affected neonates show profound hypotonia with facial weakness, frequently of severe degree, and contractures, most often talipes. Two-thirds of these babies show feeding difficulties, such as inability to suck, choking and regurgitation. Respiratory problems are a frequent cause of death (Pearse and Höweler, 1979; Hageman et al., 1993). If these children survive, the muscle weakness will improve considerably during the first years of $\|$ ife. However, they do retain a facial diplegia with the characteristic tent-shaped mouth. Bowel complaints (colics, cramps and constipation) often occur as well as recurrent ear infections. They all have a retarded motor and mental development, and speech problems dre common (Hageman et al., 1993; Roig et al., 1994). In adulthood congenitally affected patients develop 
myotonia and muscle weakness, as in the adult onset type.

\subsection{A closer look at the muscular problems}

The diagnosis. The muscle weakness begins gradually and can be present for years before the patient visits a doctor. Significantly, patients with DM hardly ever complain which is why the diagnosis is often made at a late stage of the disease. Others have vague complaints such as tiredness, lack of energy, weakness, loss of initiative, stomach complaints or swallowing problems and in these cases the diagnosis DM will not be considered. The diagnosis of myotonic dystrophy can be made by the neurologist, based on the combination of myotonia, the typical distribution of muscle weakness and the presence of characteristic myotonic discharges, and should be confirmed by DNA testing.

Muscle weakness. In the initial phase of the disease muscle weakness is mild and on examination diminished power of eye closure, weakness of the neck muscles and of the dorsiflexors of the feet can be found. Facial muscle involvement occurs early on in the disease: due to weakness of the levator palpebrae muscles the eyelids start to droop (ptosis) and whilst the patient is asleep part of the whites of the eyes remain visible. It is no longer possible to laugh properly. Speech becomes indistinct with a nasal tune. Wasting of the jaw muscles causes hollowed cheeks and shrinkage of the temples. These facial features are termed "facies myopathica". Due to weakness and atrophy of the flexor muscles of the neck (especially the sternocleidomastoid muscle) patients cannot lift their head up whilst lying down. Gradually distal limb involvement becomes more obvious. Weakness of the forearm and hand muscles, together with the myotonia causes manual clumsiness. Reduced dorsiflexion of the muscles in the lower legs means that the patient starts shuffling, trips up easily and falls more frequently. Weakness is slowly progressive and proximal limb weakness occurs only in late stages of the disease (Mathieu et al., 1992).

Myotonia. The clinical symptom of myotonia is a slowing of relaxation of a normal muscle contraction (Harper, 1994). Myotonia is a painless muscle cramp, which typically affects the hands, especially after a firm grip. The cramp or "stiffness" disappears spontaneously after a short period of time. Cold can provoke myotonia or make it worse. Complaints are: difficulties in letting things go, for instance, a door-handle or after shaking hands, and cramp when wringing a cloth out, especially in wintertime. Myotonia is commonly most marked in those patients with relatively minor muscle weakness and wasting. In cases with advanced muscle wasting it may 
diminish (Harper, 1989). Myotonia is usually clinically undetectable in young children. Most patients are only slightly affected by myotonia and are not likely to complain about it spontaneously.

\subsection{Systemic complications}

DM is usually classified as a muscle disease, but it actually affects several organ systems. Table 2 shows a synopsis of the systemic complications. One individual patient can experience these complications in various combinations and at different moments in the course of the disease. Whereas the muscular problems usually follow a relatively benign course, the complications of the internal organs may be life-threatening.

Cardiac involvement is common and can already occur in early stages of the disease, it is thus certainly not confined to severely disabled patients. Conduction disturbance, in particular first degree heart block, is the most common abnormality, but atrial flutter and ventricular arrhythmias can also occur. Cardiomyopathy is unusual. Cardiac arrhythmias can cause loss of consciousness and are also a frequent cause of sudden death. Subclinical cardiac involvement in DM is very common and the majority of patients show electrocardiographic defects. These electrocardiographic changes are progressive with time and are often the predictor of development of cardiac symptomatology. Therefore regular ECG (electrocardiogram) control is warranted (Philips and Harper, 1997). It was shown in pathological studies that the underlying abnormality of these cardiac rhythm disturbances is a selective degeneration of the conducting system (Nguyen et al., 1988).

Respiratory problems are the result of a combination of involvement of diaphragmatic and other respiratory muscles, alveolar hypoventilation due to abnormal cerebral regulation of respiration and swallowing problems causing choking and subsequent aspiration pneumonia. Particularly in those patients with severe proximal muscle involvement aspiration pneumonia may be fatal (Mathieu et al., 1997).

Smooth muscle involvement accounts for the gastrointestinal problems. The most prevalent symptoms are abdominal pain, constipation or diarrhoea, dysphagia, emesis, coughing while eating and anal incontinence. Gastrointestinal symptoms are often considered to be a very disabling consequence of the disease. They may be the initial symptoms in adults and are especially common in children with DM 
(Rönnblom et al., 1996).

Obstetric complications are frequently observed and therefore pregnant women with DM need intensive monitoring and should be advised to deliver in centres with perinatal facilities. There is a marked increase of polyhydramnios and preterm labour in gestations with congenitally affected foetuses. Also abnormal placentation (placenta praevia), failure to progress during labour and postpartum haemorrhage are more frequent. The higher complication rate after anaesthesia for a caesarean section should be kept in mind (Rudnik-Schöneborn et al., 1998).

Mental problems can also be present, and are due to involvement of the central nervous system. Hypersomnia, the need to sleep more, is the commonest nonmuscular symptom. There is a broad correlation with the overall severity of the disease, but it may be the presenting complaint. Methylphenidate is an effective treatment for hypersomnia (Thornton, 1999). In a small percentage of patients nocturnal hypoventilation, with or without obstructive sleep apnoea, is the cause of excessive daytime sleepiness (Hilton-Jones, 1997). The frequent occurrence of apathy, drowsiness and lack of initiative exert a strong influence on the daily life of the people concerned, especially on spouses and children. The resulting social decline and poor living circumstances may be accepted by the patient with indifference. MRI studies of the brain showed cerebral atrophy and focal white matter abnormalities in adult DM patients (Censori et al., 1994; Ashizawa, 1998). When the disease starts at a young age mental retardation, usually mild to moderate in degree, is the rule (Harper, 1989; Roig et al., 1994). The brains of children with the congenital type often show atrophy and ventricular dilatation at birth (Tanabe et al., 1992; Hashimoto et al., 1995).

DM patients have an increased risk of developing complications if they undergo general anaesthesia and subsequent surgery. These problems are most likely to occur if the anaesthesist and surgeon do not know preoperatively that the patient has DM. The combination of a cerebral hypersensitivity to anaesthetic drugs, cardiac rhythm disturbances and lung problems, especially aspiration pneumonia, can lead to complications both during and immediately after operation as well as in the postoperative period (Aldridge, 1985; Harper, 1989). The complications during and immediately after operation are usually drug-related, prolonged apnoea (presumably due to the administration of thiopentone or opiates) being the most frequent complication (Aldridge, 1985). Later postoperative complications are chest infections and cardiovascular problems (Aldridge, 1985). In a recent study the overall frequency of complications after surgery was $8.2 \%$. The risk of (pulmonary) complications was significantly higher in patients over the age of 40 years, patients 


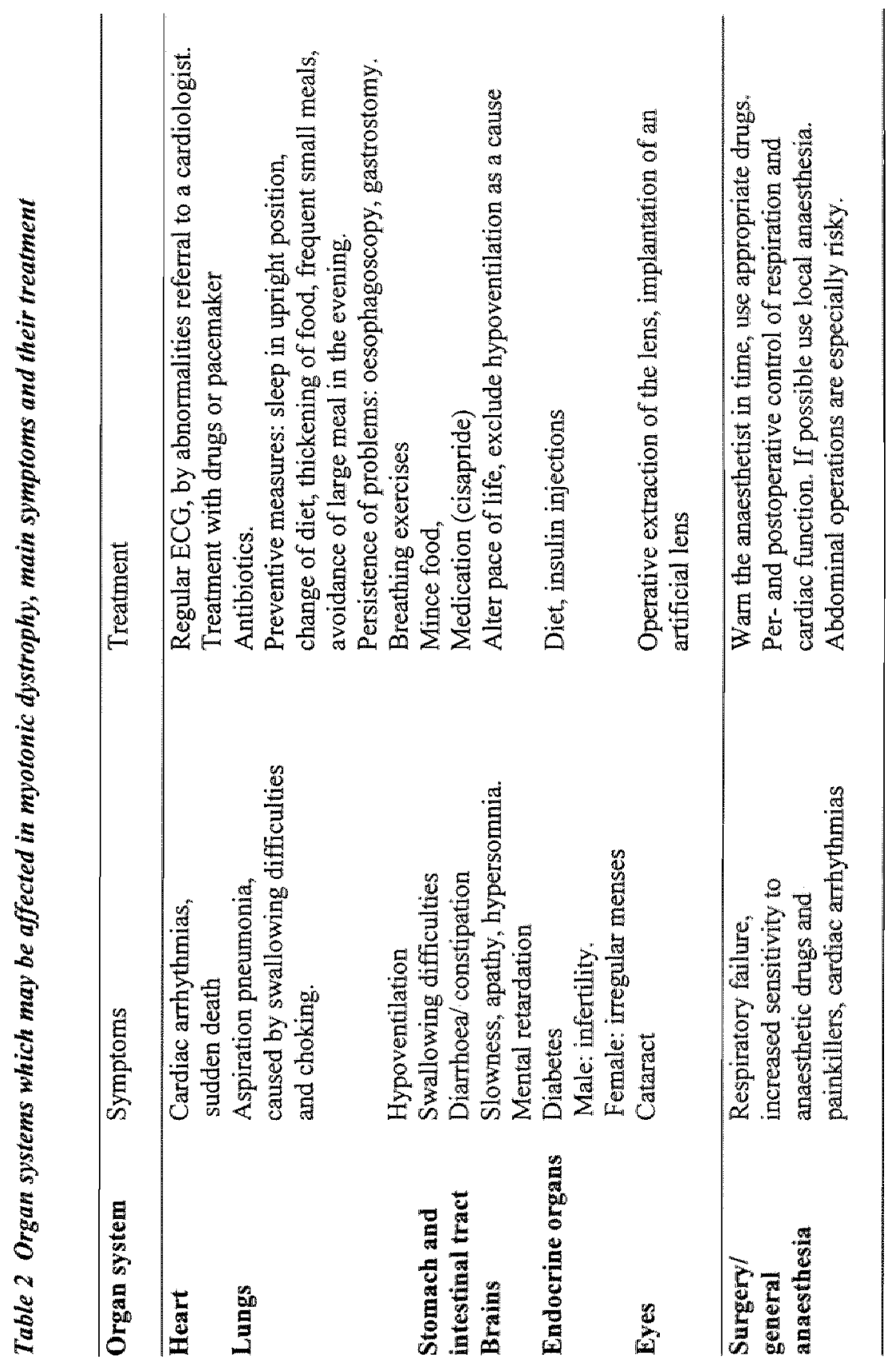


with severe and proximal muscular weakness, and after upper abdominal surgery (Mathieu et all., 1997).

Endocrine abnormalities, such as diabetes, can exist in DM, but the most significant abnormality is testicular atrophy, with decreased fertility. The incidence is probably as high as $60-80 \%$ of affected males. Pathological studies have shown that the principal changes are atrophy, hyalinisation and fibrosis of the seminiferous tubules, with reduced spermatogenesis, and a relative hypertrophy of Leydig cells. The basal level of follicle stimulating hormone (FSH) is elevated, with normal or slightly reduced testosterone levels (Harper, 1989; Harper, 1996).

\subsection{Disease progression and prognosis}

To give an accurate prognosis in DM is no easy task and there has not been much research done into the way in which the disorder progresses. One may suppose that course and prognosis are related to the age at onset and hence to the disease type. Generally, the course of the disease is one of slow progression. The spread of the muscle weakness to the upper arms and legs often only occurs 20 to 30 years after the start of the disease. Most patients remain mobile for a long time, although their action radius becomes gradually restricted to the home. In a transversal study only $4 \%$ of patients appeared to be wheelchair dependent (Mathieu et al., 1992). The natural history of DM has only been studied for the congenital type. Mental and behavioural disturbances mainly influence the long-term management. A variety of cluronic medical problems, such as recurrent otitis, gastrointestinal features, and cardiac rhythm disturbances, was observed (O'Brien and Harper, 1984; Reardon et al., 1993, Roig et al., 1994).

Owing to the lack of long-term studies in DM, also little information exists on age and causes of death. Most studies on age at death were retrospective and made no distinction between the various disease types. They showed mean ages of death between 44 and 53 years (Bell ,1948; Thomasen, 1948; Klein, 1958; Grimm, 1975). Reardon et al. (1993) showed that for congenitally affected patients the risk of dying before the age of 30 was $\pm 50 \%$. Recently, Mathieu et al. (1999) found a greatly reduced life expectancy in a 10 years follow-up research on a group of $367 \mathrm{DM}$ patients with different disease types. Total mortality in DM was 7.3 times higher than in an age-matched reference population. Mortality was particularly high in those with proximal muscular involvement, and presumably long standing disease. Nearly half of the patients died of respiratory problems, and $30 \%$ of cardiac disease 
or sudden death.

\subsection{General management}

Several different health care professionals may come into contact with myotonic dystrophy patients. At present there are no drugs available which can significantly alter the natural course of the disease. Effective help and support is of paramount importance to these patients. In particular it is very important to consider the treatment possibilities for several of the systemic complications. The comments below are based mainly on the monograph of Harper (1989) and on personal experience with our own large group of patients with DM. The treatment options will be discussed by age group.

Neonatal period. When a DM affected woman is pregnant, careful observation is mandatory. The delivery should be managed in hospital. If it becomes obvious, during pregnancy, that the baby has the congenital type of DM (an excess of amniotic fluid and reduced fetal movements), then adequate care for the new-born baby must be organised before the delivery. Respiratory insufficiency often occurs, due to the combination of weakness of the respiratory muscles, eventually complicated by lunghypoplasia. Artificial ventilation is often necessary.

From infant to adolescent. The muscle weakness seen in the congenitally affected children improves, without therapy, during the first few years of life, due to further maturation of the muscles. If the hypotonia persists, a special chair or pram/pushchair may be needed. Club feet should be treated with plaster casts, and sometimes by surgical correction. Physiotherapy is needed for children with delayed motor development. All children learn to walk sooner or later. The children with the congenital type learn to talk and to look after themselves, but they usually do not learn to read and write properly. The mental retardation is an important characteristic of the congenital type (IQ mostly 50-80) (Harper, 1989; Roig et al., 1994). It is important to test the child in time and to choose the right school based on the test results. Most of these children need special schooling. Care must be taken not to underestimate the ability of the child. Factors such as facial muscle weakness with resulting expressionless face, speech difficulties, poor hearing and slowness may influence this. In the childhood type learning difficulties may be the only symptom, without any physical complaints. Affected children may also have social problems e.g. difficulty integrating with other children. Help from a child education specialist or psychologist is recommended. The speech difficulties in congenital and 
childhood DM result from a combination of problems, such as weakness of the palate, other muscle problems and the general delayed development. Speech therapy is then required. Medical problems such as abdominal pain, recurrent ear infections and squinting should be treated in the usual way. It is advisable to involve a paediatrician or child neurologist in the co-ordination of the care of the child with DM.

Adulthood. In adulthood the emphasis is on organ complications (table 2, last column). If cardiac abnormalities are diagnosed, treatment by a cardiologist with drugs or a pacemaker is recommended. The management for the bowel complaints is as for irritable bowel syndrome in general. However certain drugs (e.g. cisapride) have a tendency to increase the risk of cardiac arrhythmias (Wysowski and Bacsanyi, 1996).

The myotonia responds well to treatment with conventional antimyotonic medications, such as phenytoin or mexilitene but most of the patients do not seem to need to use them. Furthermore, cardiac rhythm disturbances can be provoked by these drugs, which may be especially risky for DM patients (Durelli et al., 1985). The role of physiotherapy in maintaining or improving muscle power and mobility is limited. Recent research from a rehabilitation specialist, showed that exercises to strengthen the muscles hardly affect the power in the legs, but it does not do any harm either (Lindeman, 1996). If a patient trips or stumbles frequently due to weakness of the lower leg muscles, it is advisable to refer the patient to a rehabilitation specialist for fitting of special shoes or a calliper. A walker or shopping-cart (rollator) can be very useful for patients with widespread muscle weakness and problems with walking. In later stages of the disease the (outdoor) use of a wheelchair may be necessary (Mathieu et al., 1992). Good headrests in chairs and especially in the car are important for support of the head when the neck muscles are weakened. In severe cases a neck collar may be necessary.

\subsection{Social activities, daily living and working}

Many patients are able to function independently in the family for a long time. In time, as muscle weakness spreads to the proximal muscles, adaptations may have to be made to the house and a lift can be installed. The drowsiness and lack of initiative can cause problems. This can be particularly difficult for the partner and other family members. The patient is often not aware of these problems him/herself and this can cause nerves to be stretched in the family. At work these symptoms can 
also create problems. Many patients may continue to work for a long time if they are able to adjust their work tempo and if their employer and colleagues understand the situation and are prepared to give support. If this is not possible then sheltered employment may be the solution. Many women are able to do their housekeeping independently for a long time if other family members are prepared to help where necessary. Sometimes adjustments in the kitchen are useful. Because of the complexity of the problems which can occur in many cases it is recommended that the organisation of support be co-ordinated by a (child)neurologist, paediatrician or rehabilitation specialist. If necessary psychosocial assistance (for instance by a social worker) can be organised. If the patient is mentally handicapped, they may not be able to function independently. At an adult age the patient can be admitted to a day-care centre, a sheltered home or an institution for mentally disabled people.

\section{References}

Aldridge LM. Anaesthetic problems in myotonic dystrophy. Br J Anaesth 1985;57:1119-1130. Ashizawa T. Myotonic dystrophy as a brain disorder. Arch Neurol 1998;55:291-293.

Bell J. Dystrophia myotonica and allied diseases. In: Treasury of human inheritance 4, part V. Cambridge University Press, Cambridge, 1948.

Brook JD, Mc Currach ME, Harley HG, Buckler AJ, Church D, Aburatani H, Hunter KI, Stanton VP, Thirion J-P, Hudson $T$, Sohn $\mathbb{R}$, Zemelman B, Snell RG, Rundle SA, Crow S, Davies $J$, Shelbourne P, Buxton J, Jones C, Juvonen V, Johnson K, Harper PS, Shaw DJ, Housman DE. Molecular basis of myotonic dystrophy: expansion of a trinucleotide (CTG) repeat at the $3^{\text {end }}$ of a transcript encoding a protein kinase family member. Cell 1992;68:799-808.

Censori B, Provinciali L, Danni $\mathrm{M}_{3}$ Chiaramoni L. Brain involvement in myotonic dystrophy: MRI features and their relationship to clinical and cognitive conditions. Acta Neurol Scand $1994,3: 211-217$.

Durelli L, Mutani R, Sechi GP, Monaco $\mathbb{E}$, Glorioso N, Gusmaroli G. Cardiac side effects of phenytoin and carbamazepine. A dose-related phenomenon? Arch Neurol 1985;42:1067-1068. Dyken PR. The changing syndromes of dystrophia myotonica. Neurology 1969;19:292.

Grimm $T$. The age of onset and the age at death in patients with dystrophia myotonica. J Génét Hum 1975; 23:301-308.

Hageman ATM, Gabreèls FJM, Liem KD, Renkawek K, Boon JM. Congenital myotonic dystrophy; a report on thirteen cases and a review of the literature. I Neurol Sciences 1993; 115:95-101.

Harley HG, Brooi JD, Rundle SA, Crow S, Reardon W, Buckler AJ, Harper PS, Housman DE, Shaw DJ. Expansion of an unstable DNA region and phenotypic variation in myotonic dystrophy. Nature $1992 ; 355: 545-546$

Harley HG, Rundle SA, MacMillan JC, Myring J, Brook JD, Crow S, Reardon W, Fenton I, Shaw DJ, Harper PS. Size of the unstable repeat sequence in relation to phenotype and parental transmission in myotonic dystrophy. Am J Hum Genet 1993;52:1164-1174.

Harper PS. Myotonic dystrophy, 2nd edn. WB Saunders, London and Philadelphia, 1989. 
Harper PS. Myotonic dystrophy. In: Rimoin DL, Comor JM, Pyeritz RE (eds). Emery and Rimoin's principles and practice of medical genetics. Churchill Livingstone, New York. 1996. Harper PS, Radel R. Myotonic dystrophy. In: Engel A. Franzini-Amistrong C (eds). Myology. McGraw-Hill, New York, 1994.

Hashimoto $T$, Tayama M, Miyazaki $M_{3}$ Murakawa $K$, Kawail $H$, Nishitani $H$, Kuroda $Y$. Neuroimaging study of myotonic dystrophy. I. Magnetic resonance imaging of the brain. Brain Dev 1995:17:24-27.

Hilton-Jones D. Myotonic dystrophy-forgotten aspects of an often neglected condition. Current Opinion in Neurology 1997:10:300-401.

Klein D. La dystrophie myotonique (Steinert) et la myotonie congénitale (Thomsen) en Suisse: étude clinique, génétique et démographique. J Génét Hum 1958;7 Suppl:1-328.

Koch MC, Grimm T, Harley HC, Harper PS. Genetic risks for children of women with myotonic dystrophy. Am J Hum Genet 1991;48:1084-1091.

Lindeman E. Strength and effects of training in myotonic dystrophy and HMSN. Thesis, Maastricht University, 1996.

Mathieu J, De Braekeleer M, Prévost C, Boily C. Myotonic dystrophy: chinical assessment of muscular disability in an isolated population with presumed homogeneous mutation. Neurology $1992 ; 42: 203-208$.

Mathieu J, Allard P, Gobeil G, Girard M, De Braekeleer M, Bégin P. Anaesthetic and surgical complications in 219 cases of myotonic dystrophy. Neurology 1997;49:1646-1650.

Mathieu J, Allard P, Potvin L, Prévost C, Bégin P. A 10-year study of mortality in a cohort of patients with myotonic dystrophy. Neurology 1999;52:1658-1662.

Nguyen HH, Wolfe JT, Holmes DR Ir, Edwards WD. Pathology of the cardiac conduction system in myotonic dystrophy: a study of 12 cases. I Am Coll Cardiol 1988;11:662-671.

O'Brien TA, Harper PS. Course, prognosis and complications of childhood-onset myotonic dystrophy. Dev Med Child Neurol 1984;26:62-67.

Pearse RG, Howweler CJ. Neonatal form of dystrophia myotonica. Five cases of preterm babies and review of earlier reports. Arch Dis Child 1979;54:331-338.

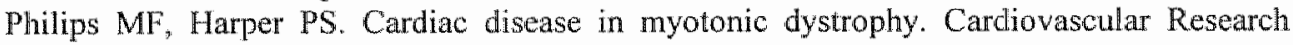
1997;33:13-22.

Reardon W, Newcombe R, Fenton I, Sibert J. Harper PS. The natural history of congenital myotonic dystrophy: mortality and long term clinical aspects. Arch Dis Child 1993;68:177-181. Roig M, Ballieu P-R, Navarro C, Brugera R, Losada M. Presentation, clinical course and outcome of the congenital form of myotonic dystrophy. Pediatr Neurol 1994;11:208-213.

R.önnblom A. Forsberg $H$, Danielsson $A$. Gastrointestinal symptoms in myotonic dystrophy. Scan J Gastroenterol 1996;31:654-657.

Rudnik-Schonebom S, Nicholson GA, Morgan G, Röhrig D, Zerres K. Different patterns of obstetric complications in myotonic dystrophy in relation to the disease status of the fetus. Am J Med Genet 1998;80:314-321.

Tanabe Y, Iai M, Tamai $K$, Fujimoto N, Sugita $K$. Neuroradiological findings in children with congenital myotonic dystrophy. Acta Paediatr 1992;81:613-617.

Thomasen E. Myotonia. Universitetsforlaget, Aarhus, 1948.

Thornton C. The myotonic dystrophies. Semin Neurol 1999;19:25-33.

Wysowski DK, Bacsanyi J. Cisapride and fatal arrhythmia. New Engl J Med 1996;335:290-291. 
Chapter 2

\section{The childhood type of myotonic dystrophy}

2.1 The childhood type of myotonic dystrophy: clinical and genetic aspects (submitted)

2.2 Emotional and behavioural profile and child psychiatric diagnosis in the childhood type of myotonic dystrophy (submitted)

2.3 A study of the cognitive and psychological profile in 16 children with congenital or juvenile myotonic dystrophy

(Clin Genet 1997;52:135-141) 
Chapter 2.1

\section{The childhood type of myotonic dystrophy : clinical and genetic aspects}

Christine E.M. de Die-Smulders', Chris J. Höweler ${ }^{2}$, Jan-Frans Mirandolle ${ }^{3}$, Jean G.P.L.E. Steyaert ${ }^{4}$, Dian Willekens ${ }^{4}$, Els Goossens ${ }^{4}$, Patty Nelemans ${ }^{5}$, Hubert J.M. Smeets ${ }^{1}$, Joep P.M. Geraedts' ${ }^{1}$, Jean-Pierre Fryns ${ }^{4}$

Departments of ${ }^{1}$ Molecular Cell Biology and Genetics and ${ }^{2}$ Neurology and ${ }^{5}$ Epidemiology, Maastricht University, Maastricht, the Netherlands, ${ }^{3}$ Department of Neurology, Atrium Medical Centre, Heerlen, the Netherlands ${ }^{4}$ Center for Human Genetics, Leuven, Belgium

Submitted 


\section{Abstract}

Myotonic dystrophy (DM) is a progressive multisystem disorder with a wide clinical variability. Because of this variation in symptomology and prognosis, which is determined by the age at onset, it is considered useful in clinical practice, to divide patients into disease types. The length of the CTG repeat expansion in the DMPK gene also correlates broadly with these types. Initially, three disease types were recognised: mild (late onset), adult-onset and congenital type. Recently, a fourth disease type has been proposed, the childhood type, with age at onset between 1 and 10 year. A systematic study was performed on the childhood type of DM, and we report on 52 patients ( 20 children and 32 adults). Only patients with learning problems at an early age, but without congenital symptoms, were included. The 20 children were clinically examined and their intelligence quotients were measured. Symptoms in early childhood were that of an indistinct speech and clumsiness. In later childhood most patients were borderline or mildly mentally retarded. Chronic fatigue, slowness and abdominal complaints were additional symptoms, whilst on examination dysarthria and mild facial weakness were found, but not the "tented mouth" which is typical for the congenital type. Walking problems were infrequent. The adult patients were rarely able to live independently and to hold down a job, due to their mental retardation. In most patients mobility was relatively normal until the age of 40 years, with gradual deterioration after this age. Dysarthria was a frequent, serious and progressive problem. The prognosis for life for childhood onset DM patients was shown to be better than that for congenitally affected patients. The mother transmitted the disease in $57 \%$ of cases, the father in $43 \%$, which is in contrast to the almost exclusive maternal transmission of congenital DM. Most parents suffered from adult-onset disease, but one-third of the parents were only mildly affected or even asymptomatic. For genetic counselling it is important to realise that DM affected parents of either sex may have mentally retarded offspring. We conclude that the observed characteristics in clinical presentation, outcome and transmission pattern warrant delineation of childhood onset DM as a separate disease type. The frequency of the childhood type is similar to that of the congenital type. 


\section{Introduction}

Myotonic dystrophy (DM) is an autosomal dominant muscular dystrophy. Characteristic features in adults are myotonia and slowly progressive muscle weakness of the facial and distal limb muscles, and additionally multiple systemic complications (Harper, 1989). The inheritance of $D M$ is characterised by anticipation, the earlier onset of the disease in subsequent generations (Höweler et al., 1989). The genetic basis underlying DM is an expansion of a CTG trinucleotide repeat in the DMPK gene on the long arm of chromosome 19. The CTG repeat increases in length with transmission, and this size increase is the molecular explanation for anticipation (Brook et al., 1992).

The severity of the disease is extremely variable and related to the age at onset and duration of symptoms. Initially, clinical studies led to the recognition of three clearly defined disease types based on age at onset and core symptoms: mild (late onset) type, adult onset (classical) type and congenital type (Dyken and Harper, 1973; Höweler, 1986; Harper, 1989). In the mild type, with age at onset $>50$ years, cataract is the principal clinical feature. The adult-onset (classical) type, with the age at onset between puberty and 50 years, is characterised by a slowly progressive muscular weakness and myotonia. The clinical picture of congenital DM differs with the age of presentation. In the neonatal period it is characterised by hypotonia and muscle weakness and in severe cases, respiratory and swallowing problems (Pearse and Höweler, 1979; Hageman et al., 1993). The muscular weakness is caused by delayed maturation of the muscles and improves in the first two years, owing to the catch up growth of the muscles (Sarnat and Silbert, 1976). Congenitally affected children eventually learn to walk, but they remain mentally retarded and have a striking facial weakness with a typical "tented mouth" and indistinct speech.

However, DM may also occur in childhood without neonatal symptoms. (O'Brien and Harper, 1984; Harper, 1989). These children have a normal early motor development and they usually present with learning difficulties at school age, without the typical facial appearance of the congenital type. Koch et al. (1991) classified this presentation in childhood as a separate disease type, different from the congenital type. They defined the childhood type as follows: age at onset between 1 and 10 years, uneventful pre- and postnatal history with normal development in the first year of life, increasing problems as toddlers, variable degree of mental retardation and muscle hypotonia. However, a systematic study of the clinical features and the natural history of this proposed childhood type has not been 
performed. Genetic studies do not discriminate between childhood and congenital DM, as CTG repeat sizes are in the same range (Harley et al., 1993, Redman et al., 1993). The congenital type is transmitted almost exclusively by affected mothers, whilst extensive data on the parent of transmission of the childhood type are not available (Koch et al., 1991).

Here we report the first systematic study on the proposed childhood type. 52 Patients, 20 younger than 18 years and 32 adults, with onset of DM in childhood without obvious neonatal symptorns, were studied. The purpose of this study was to delineate in detail the clinical features at different ages. The long term prognosis was studied in the older patients. Finally we collected information concerning the sex and disease type of the transmitting parents.

\section{Patients and methods}

The study population consisted of 52 patients with childhood onset DM, ascertained from two sources. Group A comprised of 20 young patients between 7 and 18 years old. They were children of members of the Dutch patient organisation for Myotonic Dystrophy patients and were recruited by way of a call for patients. They were included in the study on the following basis: clinical diagnosis of DM with onset between 1 and 12 years, and learning difficulties, severe enough to cause failure at primary school level, as well as absence of congenital features. Group B comprised of 32 older patients with ages between 22 and 69 years. They were selected from a register of myotonic dystrophy patients in the South-Eastern part of the Netherlands. This register was set up in 1950 and data collection has been continued ever since then (de Die-Smulders et al., 1994; de Die-Smulders et al., 1998). Data on disease type, major complications and results of DNA examination have been documented. Selection criteria for the group B patients were a diagnosis DM made on clinical grounds, with mental retardation before the age of 12 as main symptom, but without signs or symptoms in the neonatal period or first year of life.

The 20 group A children came from 18 families. A structured questionnaire, especially designed for this study, was completed by the parents in order to obtain detailed information on pregnancy, delivery, the neonatal period, the early development and the current problems of their affected children. All children were clinically examined by the first author and their medical records were reviewed. Intelligence was tested with the Wechsler intelligence scales (WISC-R for patients under 16 years, and WAIS for the three patients older than 16 years). 
The 32 patients of group $B$, belonging to 18 families, were clinically evaluated by one of the authors between 1988 and 1998. Their medical records were reviewed and updated, information was collected with particular attention being paid to walking and speech ability, social situation and long term medical complications. The information concerning the early years of the group B patients was mainly obtained from their parents or healthy siblings.

All the parents of the group A patients and six of the 25 affected parents of the group B patients were still alive at the time of study. All living parents were personally examined and information was collected from their specialists. The medical records of all the deceased parents were carefully reviewed. The parents were classified as: asymptomatic, mild or adult-onset type DM.

DNA studies were possible in all 20 group A children and their parents. Molecular data were available for 27 of the 32 group B patients and for 6 of their parents. Genomic DNA was isolated from peripheral blood cells and Southern blot analysis was performed according to methods previously described (Mahadevan et al., 1992). In the samples where smears were detected, the middle of the smear was sized. All expansions are expressed in terms of kilobases of additional. DNA. Expansions $<0.35 \mathrm{~kb}$ were also sized on polyacrylamide gels, after PCR amplification using primers flanking the CTG repeat.

\section{Results}

The general characteristics of the patients are given in table 1 .

Table 1 General characteristics of the patients $(n=52)$

\begin{tabular}{lll}
\hline & Group A & Group B \\
\hline$n$ & 20 & 32 \\
Males & 11 & 13 \\
Females & 9 & 19 \\
Age at time of study & & \\
$\quad$ Mean (years, range) & $13.6(7-1.8)$ & $40.2(22-69)$ \\
Age at diagnosis & $10.7(3-16)$ & $24.3(6-43)$ \\
\hline
\end{tabular}


The age at the time of study differed considerably for group $A$ and $B$, due to the different ascertainment. Seven of the 20 group A children were aged between 7 and 12 years old, and 13 subjects were between 12 and 18 years old. Sixteen of the 32 group B patients were younger than 40 years old, whilst the other 16 were older than 40 at the time of study. The age at diagnosis also clearly differed between group A and group B patients. In group $A$ the age at diagnosis was relatively young (mean 10.7 years), due to the fact that all the subjects in this group were included in the study because they were diagnosed in childhood. In group B patients the mean age at diagnosis was 24.3 years. Most of these patients had been mentally retarded since an early age, without a cause for their retardation having been known. In the majority (26/32) of them the diagnosis DM was not considered until the diagnosis of classical DM had been made in a family member. Only six group B patients were diagnosed before the age of 18 , due to the fact that they had muscular symptoms.

\section{Clinical features at different ages (group A)}

Gestational and neonatal data (table 2). The pregnancies were largely unremarkable, except for 2 reports of a mild excess of amniotic fluid. All children were born at term and their birthweights were within the normal limits. Although there were no serious problems reported in the neonatal period, minor problems were reported six times: two children were floppier in comparison with their healthy siblings and four were "slow suckers", but did not require nasogastric feeding.

Table 2 Symptons in young children, reported by parents of group A subjects $(n=20)$

$n \%$

\begin{tabular}{lrr}
\hline Gestational and neonatal period & & \\
Large amount of amniotic fluid & 2 & 10 \\
Twin pregnancy & 1 & 5 \\
Breech delivery & 1 & 5 \\
Caesarean section & 1 & 5 \\
Floppier than siblings & 2 & 10 \\
Slow suckers & 4 & 20 \\
Early childhood (S6 years) & & \\
Delayed motor milestones & 2 & 10 \\
Clumsiness & 8 & 40 \\
Delayed mental development & 4 & 20 \\
Indistinct speech & 15 & 75 \\
Recurrent ENT infections & 4 & 20 \\
Strabismus & 2 & 10 \\
& & \\
\hline
\end{tabular}


Early childhood (1-6 years) (table 2). Most of the children had no major problems as toddlers. Mild motor problems were reported in half of them: two children had some motor delay, and did not walk independently before the age of two and three years respectively; eight children experienced mild motor dysfunction including clumsiness, frequent stumbling and falling, and/or difficulty with running. Most of the children (16/20) showed no cognitive delay before school age. In only four of the children it was apparent before the age of six that they were mentally retarded, due to the fact that there was a delay in their cognitive and language development. Indistinct speech with poor articulation was a frequent problem (75\%). One child therefore had an unsuccessful velopharyngoplasty at the age of five.

Later childhood and adolescence (7-18 years) (table 3). The most frequent symptom reported in $80 \%$ of the children, was chronic fatigue with tiredness especially after physical exercise. These children could not take part in sport and some were not able to even participate in any of the school activities because of their tiredness. Slowness was reported in fourteen children, which meant that they had problems with finishing their school work on time.

Table 3 Clinical symptoms, signs and cognitive data in children $7-18$ years (Group $A, n=20$ )

\begin{tabular}{|c|c|c|}
\hline & $n$ & $\%$ \\
\hline \multicolumn{3}{|l|}{ Symptoms } \\
\hline Fatigue & 16 & 80 \\
\hline Slowness & 14 & 70 \\
\hline Reduced initiative & 2 & 10 \\
\hline Hypersomnia & 4 & 20 \\
\hline Dysphagia & 5 & 25 \\
\hline Abdominal symptoms & 6 & 30 \\
\hline \multicolumn{3}{|l|}{ Signs } \\
\hline Mild facial weakness & 20 & 100 \\
\hline Weakness of neck muscles & 9 & 45 \\
\hline Lower limb weakness & 3 & 15 \\
\hline Dysarthria & 16 & 80 \\
\hline Myotonia & 14 & 70 \\
\hline \multicolumn{3}{|l|}{ Cognitive datta } \\
\hline Mean intelligence quotient & \multicolumn{2}{|c|}{71 (range $48-94$ ) } \\
\hline Normal $(\mathrm{IQ}>80)$ & 2 & 10 \\
\hline Borderline $(\mathrm{IQ} 70-85)$ & 10 & 50 \\
\hline Mild mental retardation (1Q 55-70) & 6 & 30 \\
\hline Moderate mental retardation $(\mathbb{I Q}<55)$ & 2 & 10 \\
\hline Able to read and write & 16 & 80 \\
\hline
\end{tabular}


Markedly reduced initiative was reported in another two children and hypersomnia in four. Five children complained of swallowing difficulties. Six children suffered from abdominal symptoms, consisting of recurrent abdominal pain with constipation and diarrhoea. Coloscopy was performed in two children, without pathological findings. Faecal soiling, which is often seen in congenital DM, did not occur (Harper, 1989). Mild facial weakness was found in all cases, but none of them showed the severe facial diplegia with the typical "tented mouth" as seen in the congenital type. Most children had a somewhat expressionless face (Fig 1). Formal examination showed diminished power of eye closure in all. Although this facial weakness caused no major probiems, the children were often told that they "looked like a drip". Weakness of the anterior neck muscles was present in nine children. Mild dysarthria, consisting of indistinct and poorly formed speech with poor articulation and a nasal quality, was present in $80 \%$ of the children. Fifteen children $(75 \%)$ had had speech therapy for this reason. Only three children suffered from a disabling weakness of the legs. One 15-year-old boy had weakness of both his distal and his proximal muscles, which necessitated him to use a wheelchair for longer distances. One 16-year-old girl and one 12 year-old boy complained of tripping and stumbling, due to distal leg weakness. Clinical myotonia was present in 14 children, the youngest age at onset was eight years. One mentally retarded boy presented at the age of 13 years with cardiac arrhythmia, in the form of a ventricular flutter. The mean intelligence quotient (IQ) of the children was 71 (range 48-94).

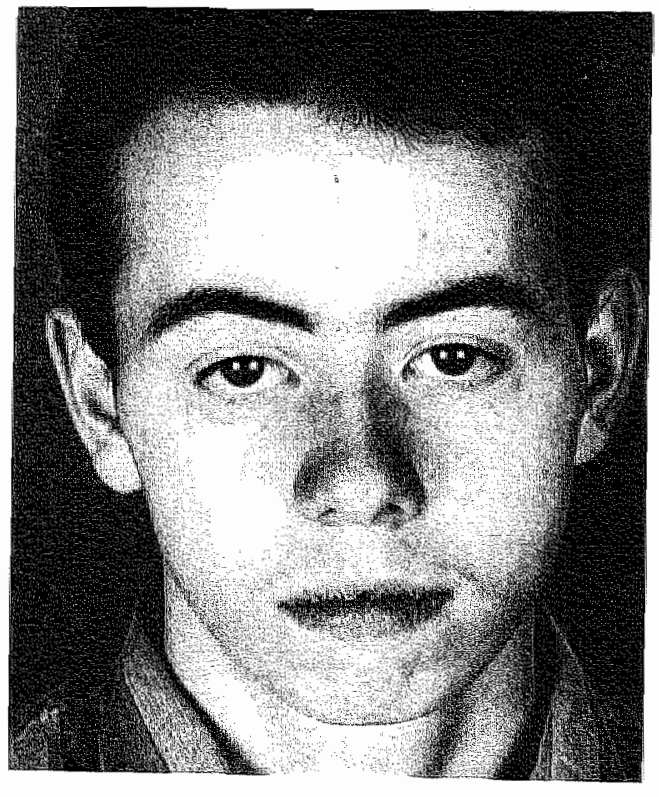

Figure 1 16-years old boy with childhood onset myotonic dystrophy. Note the expressionless face with slight ptosis, but the absence of tented upper lip. His father was the gene transmitting parent with age at onset around the age of 45 . 
Half of the children were in the category borderline (IQ: 70-85), mild mental retardation (IQ: 55-70) was present in six children. Two children were moderately mentally retarded $(\mathrm{IQ}<55)$ and two children were in the normal range $(\mathrm{IQ}>90)$. Sixteen of the 20 children ( $80 \%$ ) required special education. Three children, aged 9,11 and 12 years were attending normal schools, but needed special assistance. One 17-year-old boy worked in sheltered employment. In general all the children had learning difficulties, due to a combination of a low IQ and/or slowness and fatigue.

Moreover, an indistinct speech and somatic complaints, such as abdominal pain, aggravated their problems. Walking problems due to weakness were present in a minority. The children and their parents experienced great problems in coping with the combination of learning difficulties, chronic fatigue and the somatic complaints. Most children had little contact with their peer groups, and lived socially isolated.

\section{Problems in later life (group B)}

Group B especially provided information on the problems later in life and the long term outcome. Parents or siblings did not report major problems in the neonatal period and early childhood years. In all the patients, learning difficulties became apparent in the first years of school. Most of them required special schooling but some remained in normal primary school because special schools were not yet available in rural communities. Early speech problems were also frequently reported. In most patients mobility was normal until adulthood.

Sociodemographic and cognitive data (table 4). The majority of the subjects (87\%) were not able to live independently. Twelve were cared for by their parents, siblings or other family members, 10 subjects lived in a group home and 5 lived in an institution for the mentally handicapped. The three women and two men who lived on their own, needed help from family members or social workers, in carrying out their daily activities. Only four of the patients, all females, were married. Three were housewives, but were not able to do their housekeeping independently and needed help from their husbands and/or their mothers. Three of them had offspring: one woman had had two congenitally affected children who had died in the neonatal period, two had one healthy child each. They had problems with taking care of their child, one child was brought up by her grandmother, the other boy relied mostly on help from his father. None of the subjects had a regular job. Ten subjects worked in sheltered employment and nineteen visited day care services or were unemployed. The intelligence of the subjects of group B was not tested for this study. However, retrospective data on IQ testing with heterogeneous methods and at different ages, were available for 9 subjects (table 4). Their mean IQ was 68 (range 39-89). 
Table 4 Sociodemographic atd cognitive data (Group $B, n=32$ )

\begin{tabular}{|c|c|c|}
\hline & $n$ & 9 \\
\hline \multicolumn{3}{|l|}{ Housing } \\
\hline Indeperident & 5 & 12.5 \\
\hline With farnily & 12 & 37.5 \\
\hline Group home & 9 & 31 \\
\hline Institution & 6 & 19 \\
\hline \multicolumn{3}{|l|}{ Social status } \\
\hline Married & 4 & 13 \\
\hline Single & 28 & 87 \\
\hline \multicolumn{3}{|l|}{ Employment } \\
\hline Sheltered work & 10 & 31 \\
\hline $\begin{array}{l}\text { Day care service or } \\
\text { unemployed }\end{array}$ & 19 & 59 \\
\hline Housewife & 3 & 10 \\
\hline \multicolumn{3}{|l|}{ Cognitive data } \\
\hline Learning probllems & 32 & 100 \\
\hline Able to read and write & 14 & 44 \\
\hline Mean intelligence quotient & \multicolumn{2}{|c|}{68 (range $39-89)(n=9)$} \\
\hline
\end{tabular}

Mobility and speech impairment (table 5). As DM is a progressive disorder, walking ability and speech problems are categorised by age. Mobility is scored on a 4 point scale (Hoffer et al., 1973, de Die-Smulders et al., 1998). In patients younger than 40 years, walking was unrestricted $(75 \%)$ or only mildly restricted $(25 \%)$. Most of the patients between 40 and 50 years were community ambulators but needed a wheelchair for long distances. The six patients older than 50 years of age were all partially or completely wheelchair bound. Dysarthria was found to be a frequent, serious and progressive problem. The severity of dysarthria was scored on a four point scale, designed for the purpose of this study. Most of the patients between 18 and 39 years had mild dysarthria, whilst moderate to severe dysarthria was found in most of the patients over the age of 40 years.

Systemic complications (table 6). A variety of systemic complications was identified. As some patients had more than one problem, the data are not mutually exclusive. Of the twelve patients with abdominal complaints, six had recurrent constipation with diarrhoea, four had recurrent abdominal pain and two suffered from a combination of these problems. Twelve patients $(38 \%)$ had symptomatic cataract, and 10 of them had undergone surgery. The mean age at diagnosis for symptomatic cataract was 39.9 years (range 18-62 year). Symptomatic cardiac 
arrhythmia was present in 9 patients (28\%), asymptomatic ECG abnormalities in another 14 patients $(44 \%)$. Four patients suffered from recurrent pneumonia, presumably due to aspiration. Twenty-one patients underwent surgery at adult age. The indications for surgery are also given in table 6 . Six women were operated on because of a benign tumour (two adenoma of the parotid gland, four cystadenoma of the ovary). None of the patients had died from postoperative complications.

Table 5 Mobility and speech problems categorised by age $($ Group $B, n=32)$

\begin{tabular}{|c|c|c|c|c|}
\hline \multirow[b]{3}{*}{$n$} & \multicolumn{2}{|c|}{ Age at time of study } & \multirow{3}{*}{$\begin{array}{l}>50 \text { years } \\
6\end{array}$} & \multirow{3}{*}{$\begin{array}{l}\text { All patients } \\
32\end{array}$} \\
\hline & $18-39$ & $40-49$ & & \\
\hline & 16 & 10 & & \\
\hline \multicolumn{5}{|l|}{ Mobility } \\
\hline -No restrictions & 12 & 1 & - & 13 \\
\hline $\begin{array}{l}\text {-Community ambulator } \\
\text { (able to walk }>100 \text { m outside } \\
\text { without assistance, wheelchair } \\
\text { needed for long distances) }\end{array}$ & 4 & 6 & - & 10 \\
\hline $\begin{array}{l}\text { - Household ambulator } \\
\text { (able to walk indoors, } \\
\text { wheelchair needed outdoors) }\end{array}$ & - & 1 & 4 & 5 \\
\hline Completely wheelchair bound & - & 2 & 2 & 4 \\
\hline \multicolumn{5}{|l|}{ Speech } \\
\hline -Normal & 2 & 1 & - & 3 \\
\hline $\begin{array}{l}\text { - Mild dysarthria } \\
\text { (comprehensible for family } \\
\text { and strangers in private conwersation) }\end{array}$ & 8 & 2 & 1 & 11 \\
\hline $\begin{array}{l}\text {-Moderate dysarthria } \\
\text { (comprehensible for family, } \\
\text { difficult to understand for strangers) }\end{array}$ & 5 & 6 & 2 & 13 \\
\hline $\begin{array}{l}\text { - Severe dysarthria } \\
\text { (difficult to understand for familly) }\end{array}$ & 1 & 1 & 3 & 5 \\
\hline
\end{tabular}

Age and causes of death. Twenty five of the 32 group B patients were still alive at the time of the survey (July 1998), seven patients had died between 1988 and 1998. Their mean age at death was 43.6 years (range 21-70 years). Five patients died suddenly and unexpected, presumably due to cardiac arrhythmias, two of them despite the presence of a pacemaker. Pneumonia was the cause of death in another two patients. An autopsy, performed in 3 patients, confirmed the clinical diagnosis in the two patients with pneumonia, no specific cause was found on autopsy in one patient who had died suddenly. 
Table 6 Loug term systewic problems (Group $B, n=32$ )

\begin{tabular}{lrr}
\hline & $n$ & $\%$ \\
\hline Abdominal symptoms & 12 & 40 \\
Recurrent pneumonia & 5 & 16 \\
Cataract & 12 & 40 \\
Symptomatic cardiac anrhythmia & 9 & 28 \\
Asymptomatic ECG abnormalities & 14 & 44 \\
Hypersomnia & 13 & 43 \\
Surgery & & 21 \\
Ptosis & & 4 \\
Cataract & & 10 \\
Ears & & 2 \\
Jaw & & 1 \\
Adenoma of the parotid gland & & 2 \\
Pacemaker implantation & & 2 \\
Cystadenoma ovarii & 4 \\
Uterus extirpation & \\
Urological & & 2 \\
Ileus & & 1 \\
Fractures &
\end{tabular}

\section{Inheritance}

The sex and disease types of the transmitting parents, combined for group A and B, are given in table 7 . The mother was the transmitting parent in $57 \%$, the father in $43 \%$. The observed difference between maternal and paternal transmission is not statistically different from the expected distribution of $50 \%$ for both sexes $(95 \% \mathrm{CI}$ $0.42-0.70, \mathrm{p}=0.87$ ). Most parents suffered from adult onset DM. However, $31 \%$ of the mothers and $23 \%$ of the fathers were asymptomatic or only mildly affected.

Table 7 Sex and disease type of gene transwitting parent (group $A$ and $B, n=51$, I wnknawn)

Disease type of transmitting parent

\begin{tabular}{lllll} 
& Total & $\begin{array}{l}\text { Asymp- } \\
\text { tomatic }\end{array}$ & Mild & $\begin{array}{c}\text { Adult } \\
\text { onset }\end{array}$ \\
\hline Mothers $n(\%)$ & $29(57 \%)$ & $5(17 \%)$ & $4(14 \%)$ & $20(69 \%)$ \\
Fathers $n(\%)$ & $22(43 \%)$ & $3(14 \%)$ & $2(9 \%)$ & $17(77 \%)$
\end{tabular}




\section{Molecular data}

The molecular data are given in fig. 2 and table 8. Mean repeat size of all offspring (group $A$ and $B$ combined) was $2.5 \mathrm{~kb}$. In all but one parent-child pair (fatherdaughter) the repeat size of the child was larger than the parental repeat size. The increase in size of the repeat was greater in maternal transmission than in paternal transmission, although not significantly. The mean repeat size of the DM allele transmitting parents was $1.0 \mathrm{~kb}$. The repeat size of the affected mothers did not differ significantly from that of the affected fathers. Four parents ( 2 fathers and 2 mothers) had a small mutation ( $<100 \mathrm{CTG}$ repeats). Mean repeat sizes of group B patients and their parents were larger than that for group $\mathrm{A}$.

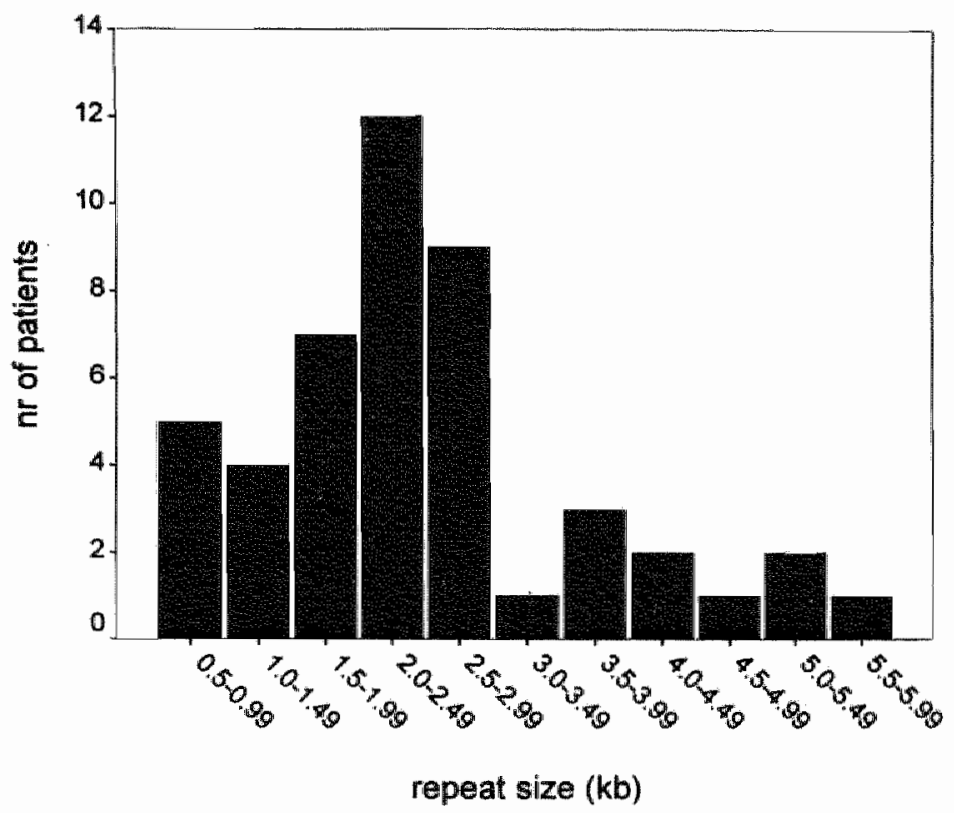

Figure 2 Distribution of repeat sizes of the 52 patients with childhood-onset DM

\section{Discussion}

We report on 52 patients, aged 7 - 69 years, with childhood-onset DM. The clinical features at young age were studied in 20 subjects younger than 18 years and the long term outcome was studied in 32 older patients. The principal feature in all patients were learning problems at primary school level and none of them had symptoms compatible with congenital DM. The young children had a nearly normal development within the first years, apart from non- specific problems as toddlers 


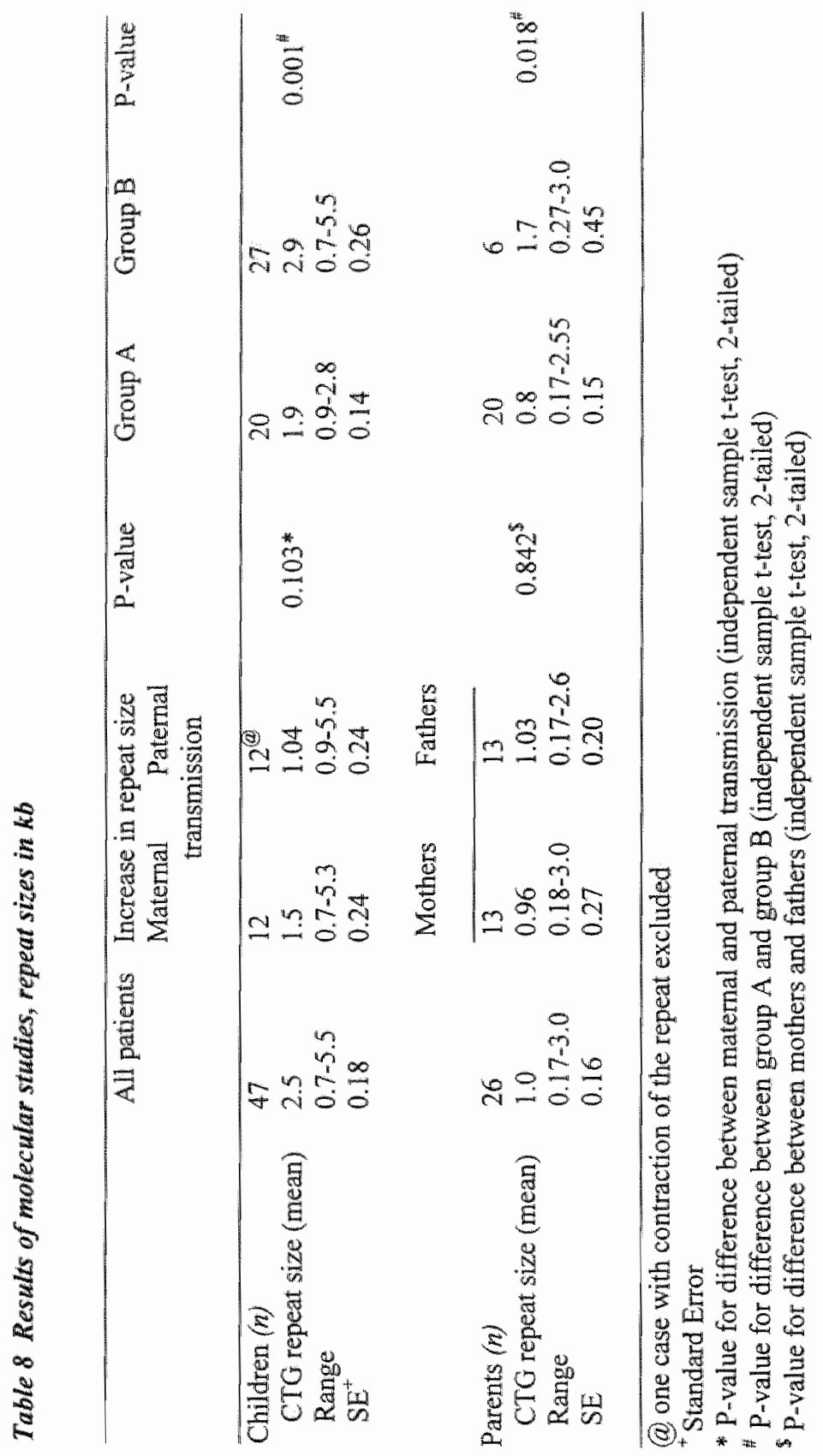


such as an indistinct speech and clumsiness. At school age mental retardation, usually borderline or mild, became apparent and speech problems became more obvious. On examination, mild facial weakness was present in all children, but without the striking facial diplegia and "tented mouth", which is typical for the congenital type. Chronic fatigue and slowness were frequent symptoms, and dysphagia and abdominal symptoms were present in a minority. The long term outlook was mainly determined by their inability for independent living and employment, due to mental retardation. Disabling muscular problems, especially impairment of mobility, usually became obvious after the age of 40 years, and all patients older than 50 years were partially or completely wheelchair bound. Dysarthria was moderate to severe in more than half of the adult patients and therefore communication was often seriously hindered.

A comparison of our data with previous studies on congenital and childhood DM is difficult for several reasons (Dyken and Harper, 1973; Harper, 1975a; Harper, 1975b; O'Brien and Harper, 1984; Harper, 1989; Hageman et al., 1993; Reardon et al., 1993; Roig et al., 1994). The nomenclature of DM in children is confusing. For patients with symptoms during the first years the name childhood or early onset DM has been used, without distinction between onset in the neonatal period (congenital type) and onset in later childhood. Childhood-onset DM without neonatal symptoms was only recently separated as a disease type (Koch et al., 1991). Furthermore, many studies on congenital DM have focused on the diagnosis and management during the new-born period and early years of childhood and there is a scarcity of reports on long term sequelae. In table 9, we compare the clinical characteristics of congenital and childhood. Muscle problems in congenital DM are present at birth and remain more severe in later life, in comparison with the childhood type. In both types mental retardation is a core symptom at young age and is the determining factor for long term outcome with respect to independent living and working. The prognosis for life for childhood-onset DM patients is considerably better than for congenitally affected patients. Our data showed that 27 of the 32 older patients ( $84 \%$ ) were over the age of 35 , whereas only $50 \%$ of congenitally affected patients survives into the mid thirties (Reardon et al., 1993). Mathieu et al. (1999) found a mean age at death of 44.7 years for the childhood type. Cardiac arrhythmia was a frequent cause of death in our patients as it is in congenitally affected and adult onset cases (Reardon et al., 1993; de-Die-Smulders et al., 1998). The mental retardation distinguishes the congenital and childhood types from other DM types and is probably related to impaired cerebral development. Although serious anatomical brain defects are not a constant finding, malformations of the 
Table 9 Comparison of characteristics of the childhood type DM and the congenital type

\begin{tabular}{|c|c|c|}
\hline & Congenital type & Childhood type* \\
\hline \multicolumn{3}{|l|}{ Gestational and neonatal period } \\
\hline Polyhydramnion & $25-50 \%$ & $10 \%$ (mild) \\
\hline Hypotonia & $70-100 \%$ & $10 \%$ (mild) \\
\hline Facial weakness & $82-100 \%$ & - \\
\hline Talipes & $50-85 \%$ & - \\
\hline Respiratory distress & $47-66 \%$ & - \\
\hline Weeding problems & $50-60 \%$ & $20 \%$ (mild) \\
\hline \multicolumn{3}{|l|}{ Carly childhood } \\
\hline Motor delay & $65-100 \%$ & $10 \%$ \\
\hline Cognitive delay & $63-100 \%$ & $20 \%$ \\
\hline \multicolumn{3}{|l|}{ Later childhood } \\
\hline Mental retardation & $75-100 \%$ & $90 \%$ \\
\hline Indistinct speech & $80-100 \%$ & $80 \%$ \\
\hline Severe facial weakness & $80-100 \%$ & $=$ \\
\hline Strabismus & $50 \%$ & $10 \%$ \\
\hline Abdominal symptoms & $34 \%$ & $30 \%$ \\
\hline \multicolumn{3}{|l|}{ Adulthood } \\
\hline Unemployed or sheltered work & $87 \%$ & $90 \%$ \\
\hline Severe walking problems $<40$ years & $30 \%$ & $15 \%$ \\
\hline Serious dysarthria $>40$ years & $?$ & $75 \%$ \\
\hline
\end{tabular}

* References: Dyken and Harper, 1973; Harper 1975a, Harper 1975b; Harper, 1989; Hageman et al., 1996; Reardon et al., 1993; Roig et al., 1994.

** References: O'Brien and Harper, 1984; Steyaert et al., 1997, this study.

cerebral cortex were reported in a neuropathological study of 2 patients with presumed childhood onset DM (Rosman and Kakulas, 1966). Ventricular dilatation and hypoplasia of the corpus callosum were found in an MRI study on congenital DM (Hashimoto et al., 1995). An important question is why the development of the brain as well as the muscles is involved in the congenital type, whilst muscle maturation is relatively normal in the childhood type. A difference in repeat length of blood cells is not essential (Harley et al, 1993; Redman et al., 1993). Somatic heterogeneity of repeat expansion between brain and muscle tissue may be considered (Jansen et al., 1994; Martorell et al., 1997; Wong et al.,1997).

Somatic instability starts prenatally, presumable at 16 weeks gestation in a tissue dependent fashion (Groenen and Wieringa, 1998). Alternative hypotheses are, a differential influence of the CTG repeat on expression of neighbouring genes, such as DMPK, DMR-N9 and DMAHP, or altered processing of CUG-containing mRNA's in the different tissues. (Groenen and Wieringa, 1998; Timchenko, 
1999).

There are also remarkable genetic differences between childhood and congenital DM. In childhood DM the sex ratio of the transmitting parents is almost equal and a quarter of the parents is asymptomatic or mildly affected. This is in contrast with the congenital type, which is almost always transmitted by a mother with clear symptoms of the disease. These observations demonstrate again that the parent of transmission somehow influences the disease type of the affected child (Brunner et al., 1993). Repeat sizes of parent and/or child, mitochondrial inheritance or genomic imprinting are unlikely to play a decisive role (de Die-Smulders et al., 1997). One of the factors involved might be a yet unknown difference in behaviour of the CTG repeat, dependent on transmission via the male or female germ line. The old suggestion of a maternal environmental factor should still be kept in mind (Harper and Dyken, 1972).

This is the first systematic study on childhood-onset DM and we present data on clinical features, prognosis and transmission pattern. Nevertheless we acknowledge some limitations. Firstly, by taking learning disabilities as inclusion criterion, we may have missed other presentations of DM beginning in childhood. DNA testing and follow-up of all offspring of DM affected parents would be more reliable, but is ethically and practically impossible. Secondly, the two groups of patients studied were ascertained in different ways. The young patients were ascertained by way of a call for patients, which may have resulted in bias to more severely affected patients applying. The older patients of group B were included at adult age and therefore it was more difficult to obtain detailed information on their neonatal period. The fact that the mean CTG repeat length in the older patients of group $B$ was larger than in the younger patients of group A may indicate a difference between the two groups but may also be explained by increasing repeat expansion with age, as was shown by Martorell et al. (1998).

In our opinion, our data justify the recognition of childhood-onset DM without neonatal symptoms, as a separate "childhood" disease type. The distinction between congenital and childhood DM is important for clinical practice due to the differences in presentation, prognosis and transmission pattern between the two types. However, DM in children is probably a continuous spectrum from severely affected congenital cases who present with life threatening respiratory and feeding problems, to patients with "mild" congenital DM, to cases with onset in later childhood, who come under attention because of speech and learning difficulties. The childhood presentation is probably not rare. In our register, $12 \%$ of subjects had the childhood type, compared with $9 \%$ with the congenital type. This is similar to 
Matthieu et al., who registered $6 \%$ congenital affected cases and $10 \%$ for the childhood type (Mathieu et al., 1999).

The diagnosis of chilldhood type DM is difficult in a sporadic mentally retarded child because of the absence of specific signs and symptoms. The speech problems and the mild faciall weakness are the most helpful clinical signs in recognising the disease. Furthermore, a careful family history is important, as other family members may have more characteristic DM signs. Molecular studies should be carried out to confirm or exclude the diagnosis, and clinical and DNA analysis of both parents of an affected child is recommended. For genetic counselling it is important to realise that DM affected parents of either sex may have mentally retarded offspring.

\section{Acknowledgements}

We are very grateful to all families who took part in the study. We would also like to thank the VSN (Vereniging Spierziekten Nederland) for their help in collecting the young patients, Rini Eekermans for help in psychological testing, Prof. Dr. F. Jennekens and Prof. Dr. H. Busch for their critical comment, Lori Tierney and Ann Hilton for the English corrections, Dr. A. wagemans, Dr. A.M. Ypma-Verhulst, Dr. S. Dykstra and Dr. G. Pennings and others colleagues for providing data on several patients, Wil Loots and Jeroen Nijland for molecular work, and Francis van der Lubbe for the skilliful photographic work.

\section{References}

Brook JD, Mc Currach ME, Harley HG, Buckler AJ, Church D, Aburatani H, et al. Molecular basis of myotonic dystrophy: expansion of a trinucleotide (CTG) repeat at the $3^{t}$ end of a transcript encoding a protein kinase family member. Cell 1992;68: 799-808.

Brunner $\mathrm{HO}_{s}$ Brüggenwirth HT, Nillisen W, Jansen G, Hamel BCJ, Hoppe RLE, et al. Influence of sex of the transmitting parent as well as of parental allele size on the CTG expansion in rnyotonic dystrophy. Am J Hum Genet 1993;53:1016-1023.

de Die-Smulders CEM, Höweler CJ, Mirandolle JF, Brunner HG, Hovers V, Brüggenwirth H, et al. Anticipation resulting in elimination of the myotonic dystrophy gene: a follow up study of one extended family. J Med Genet 1994;31:595-601.

de Die-Smulders CEM, Smeets HJM, Loots W, Anten HBM, Mirandolle JF, Geraedts JPM, et al. Paternal transmission of congenital myotonic dystrophy. J Med Genet 1997;34:930-933.

de Die-Smulders CEM, Höweler CJ, Thijs C, Mirandolle JF, Anten HB, Smeets HJM, et al. Age and causes of death in adult onset myotonic dystrophy. Brain 1998; 121:1557-1563.

Dyken PR, Harper PS. Congenital dystrophia myotonica. Neurology 1973; 23: 465-473.

Groenen P, Wieringa B. Expanding complexity in myotonic dystrophy. BioEssays 1998;20:901- 
912.

Hageman ATM, Gabreäls FJM, Liem KD, Renkawek K, Boon IM. Congenital myotonic dystrophy; a report on thirteen cases and a review of the literature. I Neurol Sciences $1993 ; 115: 95-101$.

Harley HG, Rundle SA, MacMillan JC, Myring J, Brook JD, Crow $\mathrm{S}$, et all. Size of the unstable repeat sequence in relation to phenotype and parental tranmission in myotonic dystrophy. Am J Hum Genet 1993;52:1164-1174.

Harper PS, Dyken PR. Early onset dystrophia myotonica-evidence supporting a maternal environmental factor. Lancet 1972;2:53-55.

Harper PS. Congenital myotonic dystrophy in Britain. I Clinical aspects. Arch Dis Childh $1975 a ; 50: 505-513$.

Harper PS. Congenital myotonic dystrophy in Britain. II Genetic basis. Arch Dis Childh $1975 b ; 50: 514-521$.

Harper PS. Myotonic dystrophy, 2nd edn. WB Saunders, London and Philadelphia. 1989.

Hashimoto $T$, Tayama M, Miyazaki $M$, Murakawa K, Kawai H, Nishitani $H$, Kuroda $Y$. Neuroimaging study of myotonic dystrophy. I. Magnetic resonance imaging of the brain. Brain Dev 1995; 17:24-27.

Hoffer MM, Feiwell E, Perry R, Perry J, Bonnett C. Functional ambulation in patients with myelomeningocele. I Bone \& Joint Surg 1973;55A:137-141.

Höweler CJ. A clinical and genetic study in myotonic dystrophy. Thesis, University of Rotterdam, 1986.

Höweler CJ, Busch HFM, Geraedts JPM, Niermejer MF, Staal A. Anticipation in myotonic dystrophy: fact or fiction? Brain 1989;112:779-797.

Jansen $\mathrm{G}$, Willems $\mathrm{P}$, Coerwinkel M, Nillesen W, Smeets $\mathbb{H}$, Vits L, et al. Gonosomal mosaicism in myotonic dystrophy patients: involvement of mitotic events in (CTG) repeat variation and selection against extreme expansion in sperm. Am J Hum Genet 1994;54:575-585.

Koch MC, Grimm T, Harley HG, Harper PS. Genetic risks for children of women with myotonic dystrophy. Am J Hum Genet 1991;48:1084-1091.

Mahadevan M, Tsilfidis C, Sabouri L, Shutler G, Amemiya C, Jansen G, et al. Myotonic dystrophy mutation: an unstable CTG repeat in the $3^{\prime}$ untranslated region of the gene. Science 1992:255:1253-1255.

Martorell L, Johnson K, Boucher CA, Baiget M. Somatic instability of the myotonic dystrophy (CTG)n repeat during human fetal development. Hum Molec Genet 1997; 6:877-880.

Martorell L, Monckton DG, Gamez J, Johnson KJ, Gich I, Lopez de Munain A, et al. Progression of somatic CTG repeat length heterogeneity in the blood calls of myotonic dystrophy patients. Hum Molec Genet 1998;7:307-312.

Mathieu J, Allard P, Potvin L, Prévost C, Bégin P. A 10-year study of mortality in a cohort of patients with myotonic dystrophy. Neurology $1999 ; 52, " 1658-1662$.

O'Brien TA, Harper PS. Course, prognosis and complications of childhood-onset myotonic dystrophy. Dev Med Child Neurol 1984;26:62-67.

Pearse RG, Höweler CJ. Neonatal form of dystrophia myotonica. Five cases of preterm babies and review of earlier reports. Arch Dis Child 1979;54:331-338.

Reardon W, Newcombe R, Fenton $\mathbb{1}$, Sibert J, Harper PS. The natural history of congenital myotonic dystrophy; mortality and long term clnical aspects. Arch Dis Child 1993;68:177-181. Redman JB, Fenwick Jr RG, Fu YH, Pizzuti A, Caskey T. Relationship between parental trinucleotide $\mathrm{GCT}$ repeat length and severity of myotonic dystrophy in ofspring. JAMA $1993 ; 269: 1960-1965$.

Roig M, Balliu P-R, Navarro C, Brugera R, Losada M. Presentation, clinical course and outcome 
of the congenital form of myotonic dystrophy. Pediatr Neurol 1994;11:208-213.

Rosman NP, Kakulas BA. Mental deficiency associated with muscular dystrophy. A neuropathological study. Brain 1966;89:769-787.

Sarnat HB, Silbert SW. Maturational arrest of fetal muscle in neonatal myotonic dystrophy. Arch Neurol 1976;33:459-465.

Steyaert J, Umans $\mathrm{S}$, Willekens D, Legius E, Pijkels E, de Die-Smulders CEM, et al. A study of the cognitive and psychological profile in 16 children with congenital or juvenile myotonic dystrophy. Clin Genet 1997;52:135-141.

Timchenko LT. Myotonic dystrophy: the role of RNA CUG triplet repeats. Am J Hum Genet $1999 ; 64: 360-364$.

Wong L-JC, Ashizawa T. Instability of the (CTG)n repeat in congenital myotonic dystrophy. Am J Hum Genet 1997;61:1445-1448. 
Chapter 2.2

\section{Emotional and behavioural profile and child psychiatric diagnosis in the childhood type of myotonic dystrophy}

Goossens E. ${ }^{1}$, Steyaert J. ${ }^{2,3}$, de Die-Smulders C. ${ }^{3}$, Willekens D. ${ }^{2}$, Fryns J.P. ${ }^{2,3}$

${ }^{1}$ Department of Child and Adolescent Psychiatry, University of Leuven, Belgium, ${ }^{2}$ Centre for Human Genetics, University of Leuven, Belgium, ${ }^{3}$ Department of Clinical Genetics, Academic Hospital Maastricht, The Netherlands

Submitted 


\begin{abstract}
We report data on behaviour and possibly associated psychopathology in 24 children and adolescents between 9 and 22 years of age, with the childhood type of myotonic dystrophy. The patients were recruited through a patients association, as family members from patients with myotonic dystrophy (DM). In $41 \%$ of the subjects a score in the clinical abnormal range was found on the Child Behaviour Checklist (completed by parents and by teachers). In $62 \%$ of the subjects, a child psychiatric diagnosis was found using a standardised psychiatric interview. The most frequent child psychiatric diagnoses were Attention Deficit with Hyperactivity Disorder and Anxiety Disorder.
\end{abstract}




\section{Introduction}

Myotonic dystrophy (DM) is an autosomal dominant neuromuscular disease, characterised by myotonia and progressive muscular weakness. Other symptoms can be present depending on the affected organ system: smooth muscle disturbances (swallowing problems, spastic colon, diarrhoea), cataract, gonadal dysfunction in males (subfertility), cardiac conduction defects. In adults hypersomnia, loss of initiative and apathy are among the most common systemic complications. When the disease starts at young age mental retardation, usually mild to moderate in degree, is the rule. DM is caused by an expanded and unstable CTG repeat sequence in the 3 ' untranslated region of the DMPK gene on the long arm of chromosome 19 (Harper, 1998). Four disease types can be distinguished based on the age of onset and predominant symptoms (Koch et al., 1991): 1.The mild type with cataract and minimal or no neuromuscular symptoms in middle or older age. 2. The classical or adult type with neuromuscular symptoms in adolescence or early adult life (age at onset $12-50$ years). 3. The childhood type with symptoms before the age of 12 years and an uneventful pre- and neonatal history and normal development within the first year of life. Learning disabilities are often prominent, while neuromuscular symptoms are rather mild or sometimes even absent (Koch et al., 1991). 4. The congenital type with clinical symptoms present in utero (reduced fetal movements and history of polyhydramnios) or from birth (hypotonia, facial diplegia, often skeletal deformities, respiratory and/ or feeding problems). Mild to moderate developmental delay is seen in survivors.

Psychopathology in patients with myotonic dystrophy has been documented in several studies. In adults a variety of problems was described, such as a high incidence of avoiding personality, and a medication-responsive major depressive disorder (Brumback et al., 1983; Colombo et al., 1992; Delaporte, 1998). However, others did not find anxio-depressive symptomatology or other significant psychiatric morbidity (Cuthill et al., 1988; Bungener et al., 1998). Disturbances of mood and affect, a depressive attitude with a somatic concern, difficulties in social life or an emotional deficit and changes in character are also described (Cuthill et al., 1988; Franzese et al., 1991; Bungener et al., 1998). Ambrosini and Numberg (1979) mentioned clinical evidence for an altered mental functioning as a basic feature of DM, rather than a reactive or secondary phenomenon, due to a possible difficult adaptation to the threatening implications of the disease. His hypothesis 
was that thalamic dysfunction causes the (neuro)psychopathologic changes (e.g. changes in diurnal rhythm, narcolepsia, hypersomnia, disorientation, confabulation, somnolence and akinetic mutism). Primary cerebral involvement in DM patients was confirmed by the presence of abnormalities in neuro-imaging studies, such as cerebral atrophy and focal white matter lesions (Censori et al., 1994; Damian et al., 1994a,b; Ashizawa, 1998). Some cerebral lesions seem to be characteristic of the disease, while others are similar to the age related alterations (Censori et al., 1994). Damian et al. (1994a) concluded that the cognitive impact of brain lesions depends on the distribution as well as the total extent of white matter lesions, e.g. subcortical lesions have more impact on cognitive functioning than periventricular lesions and are responsible for attention problems, not for deficit in intelligence. Furthermore cerebral hypoperfusion on single photon emission computed tomography (SPECT) and an altered cerebral metabolism have been documented (Fiorelli et al., 1992; Chang et al., 1993; Chang et al., 1998). Neuropathological examination of brains of adult DM patients found intracytoplasmatic inclusions, neurofibrillary tangles containing pathological tau protein and neuronal loss (Ashizawa, 1998).

In affected children the central nervous manifestations may be much more conspicuous than those seen in adults, as mental retardation is a major feature in the congenital as well as in the childhood type (Ashizawa, 1998; de Die-Smulders et al., 1999). Although serious anatomical brain defects are not a constant finding, ventricular dilatation and hypoplasia of the corpus callosum were found in an MRI study on congenital DM and malformations of the cerebral cortex were reported in a neuropathological study of 2 patients with presumed childhood onset DM (Rosman and Kakulas, 1966; Hashimoto et al., 1995). However psychopathology in DM affected children and adolescents is scarcely documented. Blondis et al. (1996) described a 10-years-old DM affected gir with Asperger syndrome. In a pilot study Steyaert et al. (1997) showed that more than half of the children with childhood onset DM shows signs of psychopathology and that most subjects have some form of cognitive impairment. The present study is an extension of the latter study. It is part of a research project where we assess the clinical features, cognitive functioning, neuropsychological impairments and psychopathology in children with childhood DM (de Die-Smulders et al., 1999). 


\section{Subjects}

We studied a group of 24 children and adolescents, between the age of 9 and 22 years, 14 boys and 10 girls. they were children of members of the Dutch patient organisation for myotonic dystrophy patients and were recruited by way of a call for patients. They were included in the study on the following basis: clinical diagnosis of DM with onset between 1 and 12 years, and learning difficulties, severe enough to cause failure at primary school level, as well as absence of congenital features. All subjects had been diagnosed with DM prior to the study, the diagnosis of DM was confirmed by molecular studies. In most participants the parents worried about possibly neurological and or learning problems in their child. The patients came from 23 families (one sibpair). Twenty one of the subjects attend school: 4 subjects were in a normal school programme, 17 subjects were in a special education programme (11 for the mildly mentally retarded, 3 for children with specific learning disabilities, 2 for motor disabled persons and 1 for moderate mental retarded children). One subject works in a sheltered workshop.

The subjects were tested with the Wechsler Intelligence Scale for Children, revised version (WISC-R) (Vander Steene et al., 1986) or the Wechsler Adult Intelligence Scale (WAIS) (Stinissen et al., 1970) in the adolescents older than 16 years. Full scale IQ (FSIQ) varied between 50 and 97. The mean FSIQ is 72.25 with a SD of 14 . There is no significant difference between verbal and performance IQ .

\section{Methods}

The Dutch versions of Achenbach's Child Behaviour Checklist (CBCL) and the Teacher Report Form (TRF) (Verhulst et al., 1996) are well-vallidated checklists to assess behaviour and emotional problems in children. These checklists have been standardised for children between 4 and 18 years old. The parents complete the CBCL; the teacher completes the TRF. In this study the CBCL was completed by the parents in all subjects. A Teacher Report Form (TRF) was completed by the teacher in 13 of the 24 subjects.

The results of these checklists are transformed into a total problem score and into two subscores for, respectively, the internalising and externalising problem 
behaviour. This total problem score and the two subscores are transformed into Tscores. A T-score higher than $63\left(>90^{\text {th }}\right.$ centile) is found to discriminate between normal children and children with emotional and/or behavioural problems who would benefit from care. A T-score of 70 or higher $\left(>97^{\text {th }}\right.$ centile) is found in children with severe emotional and/or behavioural problems (Verhulst et al., 1996). The results are also transformed into eight clusters of specific problem behaviour: withdrawn, somatic complaints, anxious/depressed, social problems, thought problems, attention problems, delinquent behaviour and aggressive behaviour. Each of these are transformed into a T-score (mean $=50, S . D .=10)$. A T-score higher than $67\left(>95^{\text {th }}\right.$ centile $)$ is considered to be of concern. A T-score of 70 or higher $\left(>97^{\text {th }}\right.$ centile) is considered to be in the clinical abnormal range.

A structured child psychiatric interview with the parents has been used to find out a possible child psychiatric syndrome. We used the Dutch version (ADIKA) of the Diagnostic Interview for Children and Adolescents (DICA) (Welner et al., 1987; Kortenbout Van der Sluijs et al., 1993). This interview is based on the criteria of the DSM-III-R classification (American Psychiatric Association, 1987). As the DSM-III-R criteria for the diagnosis Attention Deficit Disorder with Hyperactivity (ADHD) are quite different from the DSM-IV criteria for ADHD, we used an adaptation of the ADIKA that includes the new DSM-IV criteria (American Psychiatric Association, 1994; Célestin-Westreich and Ponjaert, 1998). For the diagnosis of autism, which is not included in the structured interview, we adapted the ADIKA, based on the DSM-IV criteria.

Differences between intelligence scales were assessed using Student's t-test. The probability of finding a particular number of child psychiatric diagnoses or abnormal findings on the scales of the CBCL was estimated using a test for probability of binomial distributions. For each measured variable, the number of abnormal findings was compared to the expected proportion of abnormal findings in the general population, e.g. when we used the cut-off for abnormality at the $95^{\text {th }}$ centile in the $C B C L$, the findings in the studied subjects were compared to a frequency of abnormality of $5 \%$.

\section{Results}




\section{Behavioural and emotional problems: CBCL (Table 1)}

Using the $\mathrm{CBCL}$, we found a total problem score in the clinical range in $10 / 24$ subjects $(42 \%)$. This is significantly $(p<0.001)$ above the expected number of subjects considering that we set the threshold at the 90 th centile, as recommended by Verhulst et al. (Verhulst et al., 1996). Nine subjects $(37.5 \%)$ score in the clinical range for internalising problems $(p<0.001)$ and 2 subjects $(8 \%)$ score in the clinical range for externalising problems $(p=0.564)$. Nine children also scored in the clinical range in the problem domain "somatic complaints".

Table I Results of the CBCL and TRF. Number of subjects with a score in the clinical range for the several scales and problem domains of the Child Behaviour Checklist and Teacher Report Form of the CBCL

\begin{tabular}{|lcc|cc|}
\hline & \multicolumn{2}{c|}{ CBCL Parents } & \multicolumn{2}{c|}{ TRF } \\
\hline & $\begin{array}{c}\text { Number in } \\
\text { clinical range } \\
(\mathrm{n}=24)\end{array}$ & $\begin{array}{c}\text { Probability to } \\
\text { find this } \\
\text { prevalence }\end{array}$ & $\begin{array}{c}\text { Number in } \\
\text { clinical range } \\
(\mathrm{n}=13)\end{array}$ & $\begin{array}{c}\text { Probability to } \\
\text { find this } \\
\text { prevalence }\end{array}$ \\
\hline Total problem & 10 & $<0.001$ & 3 & 0.134 \\
Internalising & 9 & 0.003 & 5 & 0.006 \\
Externalising & 2 & 0.564 & 0 & 0.254 \\
Withdrawn & 7 & $<0.001$ & 3 & 0.024 \\
Somatic complaints & 9 & $<0.001$ & 4 & 0.003 \\
Anxious depressed & 3 & 0.116 & 3 & 0.024 \\
Social problems & 13 & $<0.001$ & 5 & $<0.001$ \\
Thought problems & 6 & $<0.001$ & 2 & 0.135 \\
Attention problems & 9 & $<0.001$ & 1 & 0.487 \\
Delinquent behaviour & 1 & 0.661 & 0 & 0.513 \\
Aggressive & 2 & 0.339 & 0 & 0.513 \\
Behaviour & & & & \\
\hline
\end{tabular}

Using the TRF, 3 of 13 subjects (23\%) had a total score in the clinical range ( $\mathrm{p}<$ $0.09), 5$ others $(38 \%)$ had an internalising score in the clinical range $(\mathrm{p}=0.003)$ and none of the subjects had a score for externalising problems in the clinical range. The specific problem scales show that the subjects have most problems in the areas "withdrawn", "social interaction" and "inattention" (Table 1).

2. Child Psychiatric syndromes (Table 2)

Using the ADIKA we found out that 15 of the 24 subjects $(63 \%)$ had a child 
psychiatric diagnosis. 11 Subjects $(45.8 \%)$ had one diagnosis, 3 subjects thad 2 diagnoses and 1 subject had 4 diagnoses. Looking at the whole group, we found Attention Deficit Hyperactivity Disorder (ADHD) in 8 subjects (33\%): 6 have the combined type, 2 have the predominantly inattentive type. Two subjects $(8 \%)$ had symptoms of ADHD but did not fulfil the diagnostic DSM-IV criteria for duration or for age of onset. In 6 subjects (25\%) we found some form of anxiety disorder as first or as second diagnosis: separation anxiety disorder in 4 , generalised anxiety disorder in 1 and specific phobia in 1 .

Table 2 Child psychiatric diagnoses (ADIKA). Number of children with a particular diagnosis on the child psychiatric interwiew ADIKA. A number of ctildren have more than one diagnosis

\begin{tabular}{|lc|}
\hline Diagnosis on ADIKA & Number of subjects with this diagnosis \\
\hline No diagnosis & 9 \\
Attention Deficit Hyperactivity Disorder & 8 \\
Separation anxiety disorder & 4 \\
Generalised anxiety disorder & 1 \\
Simple phobia & 1 \\
All anxiety disorders combined & 6 \\
Dysthymic disorder & 2 \\
Encopresis & 1 \\
Enuresis & 1 \\
Adjustment disorder & 4 \\
\hline
\end{tabular}

In 2 subjects $(8.3 \%)$ a mood disorder was found as first or as second diagnosis. In 1 subject ( $4 \%$ ) we found encopresis as the fourth diagnosis and in 1 subject (4\%) we found enuresis as the fourth diagnosis. Four subjects $(16 \%)$ have signs of an adjustment disorder.

\section{Discussion}

We studied a group of 24 children and adolescents with the childhood type of DM. As this category of DM patients is not known to have important neurological symptoms or motor impairment, the subjects in this study were not clinical patients. We found an important number of subjects with a child psychiatric diagnosis, mostly ADHD and Anxiety Disorder. ADHD has a significantly high 
prevalence in this group, considering that in DSM-IV (American Psychiatric Association, 1994) the prevalence of ADHD in the general population is estimated between 2 and $5 \%(\mathrm{p}<0.001$ for a population prevalence of $5 \%)$. The statistical significance of the number of children with anxiety disorders in the DM group is not clear, as the prevalence of anxiety disorders in children is not well documented. However, the prevalence of $25 \%$ in this childhood DM group is likely to be unusually high.

With this larger group we confirm the findings of Steyaert et al. (1997), who documented an unexpected prevalence of psychiatric disorders in children with DM. Van Spaendonck et al. (1995) concluded that there is evidence for poor cognitive control of behaviour in adult patients with DM, and attention deficits and vigilance problems are frequent problems in subjects with an early onset type of DM (Harper, 1989). Therefore, it is not unexpected to find ADHD in children and adolescents with DM, as attention problems and poor cognitive control are key features of ADHD. We did not observe a higher prevalence of mood disorders in children and adolescents with childhood type DM, in contrast with the finding of Cuthill et al. (1988) that adults with DM having more depressions.

Not much is known about the causal mechanisms of psychopathology in children with DM, and this study falls short of clarifying these. The first possibility is that of a brain disorder, in which the molecular defect underlying DM directly affects the brain, and thus affects the psychological development of the subjects. Secondly, one might assume a rather reactive mechanism, according to which these children might have a high prevalence of psychopathology as maladjustment to the mental stress of having a chronic and progressive disorder. This latter hypothesis is less likelly, as the cognitive and behavioural symptoms often occur well before the diagnosis has been made, at a time that the physical signs are mild or absent and the children have no muscle impairment. Though the possibility of reactive behavioural problems should not be ruled out, three arguments are in favour of the hypothesis of a brain disorder leading to developmental problems. The first is that brain-imaging studies demonstrated functional brain anomalies in congenitally affected children and adults with DM (Hashimoto et al., 1995; Ashizawa, 1998). One may assume that these brain anomalies are also present in childhood onset DM. The second argument is that as a group, children with childhood onset DM have a significantly lower intelligence level. As they do not present significant motor impairment in childhood, it is likely that the lower IQ has a primarily central 
origin. $\mathrm{A}$ third argument is the high prevalence of $\mathrm{ADHD}$ in these children. $\mathrm{ADHD}$ is generally considered as a form of psychopathology arising from a dysfunction in brain development rather than as a reactive pattem of psychopathology. In order to clarify further the mechanisms of psychopathology in children with DM, it will be necessary to analyse the psychopathology in these subjects more thoroughly. In this perspective an important question is which central neurological differences exist between DM subjects with different psychopathology, or without problems. A first hypothesis is that in DM, there is a progressive dysfunction of at least the frontal lobes. This could explain both the apathy in advanced DM subjects and the problems of impulse inhibition and attention seen in the young patients with childhood DM and ADHD.

In conclusion, the results of this sample of 24 children and adolescents with childhood onset DM reveal an unexpected high incidence of different child psychiatric syndromes (mainly ADHD and anxiety disorders). Although we do not know how representative they are for the whole population of children with DM, they are a group with important risks for emotional and behaviourall problems. This study underlines the importance of accurate neurological and/or genetic investigation of children, admitted to child and adolescent psychiatry units with learning disabilities, $\mathrm{ADHD}$, or other behavioural and/or emotional problems. Finding the underlying somatic diagnosis may have major implications for their treatment and long-term prognosis.

\section{References}

American Psychiatric Association (APA). Diagnostic and statistical manual for mental disorders,

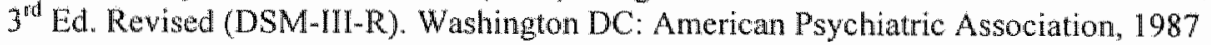

American Psychiatric Association (APA). Diagnostic and statistical manual for mental disorders, $4^{\text {th }}$ Ed.(DSM-IV). American Psychiatric Association, Washington DC, 1994.

Ambrosini PJ, Nurnberg HG. Psychopathology: a primary feature of myotonic dystrophy. Psychosomatics 1979;6:393-399.

Ashizawa T. Myotonic dystropliy as a brain disorder. Arch Neurol 1998;55:291-293.

Blondis TA, Cook E, Koza-Taylor P, Finn T.Asperger syndrome associated with Steinert's myotonic dystrophy. Dev Med Child Neurol 1996;9:840-847.

Brumback RA, Carlson KM, Wilson H, Staton RD. Psychiatric disorder in myotonia. Biol Psychiatry $1983 ; 5: 603-604$.

Bungener $\mathrm{C}$, Jouvent $\mathrm{R}$, Delaporte C. Psychopathological and emotional deficits in myotonic dystrophy. INeurol Neurosurg Psychiatry 1998:3:353-356. 
Célestin-Westreich S, Ponjaert. Adaptation of the "Amsterdams Diagnostisch Interview voor Kinderen en Adolescenten" (ADKA) to the DSM-IV. Intemal report. Brussel: Department Development and Lifespan Psychology. Vrije Universiteit Brussel, 1998.

Censori $B$, Provinciali $L$, Danni $M$, Chiaramoni $L$. Brain involvement in myotonic dystrophy: MRI features and their relationship to clinical and cognitive conditions. Acta Neurol Scand 1994;3:211-217.

Chang L, Anderson T, Migneco OA, Boone K. Cerebrall abnormalities in myotonic dystrophy: Cerebral blood flow, magnetic resonance imaging and neuropsychological tests. Arch Neurol 1993;9:917-923.

Chang L, Emst T, Osborn D, Seltzer W, Leonido-Yee M, Poland RE. Proton spectroscopy in myotonic dystrophy. Arch Neurol 1998;55:305-311.

Colombo G, Perini GI, Miotti MV, Armani M. Cognitive and psychiatric evaluation of 40 patients with myotonic dystrophy. Ital J Neurol Sci 1992;1:53-58.

Cuthill J, Gattereau A, Viguie F. Myotonic dystrophy of Steinert: Are anxiety and depression necessarily concomitants? Can J Psychiatry 1988;3:203-206.

Damian MS, Schilling $G$, Bachmann $G$, Simon $C$. White matter lesions and cognitive deficits: Relevance of lesion pattern? Acta Neurol Scand 1994a;6:430-436.

Damian MS, Bachmann G, Koch MC, Schilling G. Brain disease and molecular analysis in myotonic dystrophy. Neuroreport 1994b;8:2549-2552.

de Die-Smulders CEM, Höweler CJ, Mirandolle JF, Steyaert J, Willekens D, Goossens E, Nelemans P, Smeets HJM, Geraedts JPM, Fryns JP. The childhood type of myotonic dystrophy, clinical and genetic aspects. Submitted for publication, 1999.

Delaporte C. Personality patterns in patients with myotonic dystrophy. Arch Neurol $1998 ; 55: 635-640$.

Fiorelli M, Duboc D, Mazoyer BM, Blin J. Decreased cerebral glucose utilization in myotonic dystrophy. Neurology 1992;1:91-94

Franzese $\mathrm{A}$, Antonini $\mathrm{G}$, Iannelli $\mathrm{M}$, Leardi $\mathrm{MG}$. Intellectual functions and personality in subjects with non-congenital myotonic muscular dystrophy. Psychol Rep 1991;3:723-732.

Harper PS. Myotonic dystrophia. 2nd eds. W.B. Saunders, Philadelphia, 1989.

Harper PS. Myotonic Dystroplyy as a trinucleotide repeat disorder: a clinical perspective. In Wells RD, Warren ST (eds). Genetic instabilities and hereditary neurological diseases. Academic press, San Diego, 1998.

Hashimoto T, Tayama M, Miyazaki M, Murakawa K, Kawai H, Nishitani H, Kuroda $Y$. Neuroimaging study of myotonic dystrophy. [. Magnetic resonance imaging of the brain. Brain Dev 1995; 17:24-27.

Koch MC, Grimm T, Harley $\mathrm{HG}_{*}$ Harper PS. Genetic risks for children of women with myotonic dystrophy. Am J Hum Genet 1991;48:1084-1091.

Kortenbout Van der Sluijs MJ, De Levita DJ, Van Manen R, Defares PB. Amsterdams diagnostisch interview yoor kinderen en adolescenten, een bewerking wan de Diagnostic interview for children and adolescents. Swets and Zeitlinger BV, Lisse, 1993.

Rosman NP, Kakulas BA. Mental deficiency associated with muscular dystrophy. A neuropathological study. Brain 1966;89:769-787.

Steyaert J, Umans S, Willekens D, Legius E, Pijkels E, de Die-Smulders $C$, Van den Berghe $\mathbb{H}$, Fryns JP. A study of the cognitive and psychological profile in 16 children with congenital or juvenile myotonic dystrophy. Clin Genet 1997;52:135-141. 
Stinissen $J_{3}$, Willem PJ, Coetsier P. Hulsman WLL. Handleiding bij de Nederlandse bewerking van de Wechsler adult intelligence scale (WAIS). Swets and Zeitlinger BV, Lisse, 1970.

Vander Steene G, Van Haasen PP, De Bruyn EEJ, Coetsier P, PIj YJ, Poortinga YH, Spelberg $\mathrm{HC}$, Stinissen J. Wechsler intelligence scale for children-Revised, Nederlandstalige Uitgave. Swets and Zeitlinger BV, Lisse, 1986.

Van Spaendonck KPM, Ter-Bruggen JP, Weyn-Banningh EWA, Maassen BM. Cognitive function in edrly adult and adult onset myotonic dystrophy. Acta Neurol Scand 1995;6:456-461. Verhulst FC, Van der Ende J, Koot HM. Guide for the CBCL/ 14-18. Rotterdam: Department Child and Adolescent Psychiatry. University of Rotterdam, 1996.

Welner $Z$, Reich W, Herjanic B, Jung KG, Amado $H$. Reliability, validity and parent-child agreement studies of the Diagnostic Interview for Children and Adolescents (DICA). J Am Acad Child Adolese Psychiatry 1987;26:649-653. 
Chapter 2.3

\section{A study of the cognitive and psychological profile in $\mathbf{1 6}$ children with congenital or juvenile myotonic dystrophy}

J. Steyaert ${ }^{1,2}$, S. Umans ${ }^{2,3}$, D. Willekens ${ }^{2}$, E. Legius ${ }^{2}$, E. Pijkels ${ }^{2}$, C. de DieSmulders ${ }^{1}, H$. Van den Berghe ${ }^{2}$, J.P. Fryns ${ }^{2}$

${ }^{1}$ Centre for Clinical Genetics, Maastricht University, The Netherlands, ${ }^{2}$ Centre for Human Genetics and ${ }^{3}$ Department of Child Psychiatry, University of Leuven, Belgium

Clin Genet 1997;52:135-141 


\begin{abstract}
We report data on intelligence and on possibly associated psychopathology in 16 children and adolescents, between 7 and 18 years of age, with congenital or juvenile myotonic dystrophy. We found that all the subjects have an intelligence level below the population mean, four of them in the mentally retarded range. An unexpected number of subjects are in the clinical range on the Child Behaviour Checklist. In nine of the 16 subjects, a child psychiatric diagnosis was found using a standardized psychiatric interview. The most frequent child psychiatric diagnosis was Attention Deficit Hyperactivity Disorder.
\end{abstract}




\section{Introduction}

Myotonic dystrophy (DM) is a progressive neuromuscular disease characterised by a wide variation in neuromuscular symptoms and multisystem involvement. Besides myotonia and progressive muscular weakness, other symptoms can be present, depending on the affected organ system: cataract, smooth muscle disturbances (esophageal spasms, spastic colon, diarrhoea), gonadal dysfunction (subfertility), mental retardation, depression, somnolescence, diabetes, and cardiac conduction defects (bradycardia, arrhythmias) (Harper, 1989). DM is an autosomal dominant inherited disorder, caused by an expanded and unstable CTG repeat sequence in the $3^{\prime}$ untranslated region of a gene on chromosome 19. The sequence of this gene predicts its protein product to be a member of the protein kinase family (Aslanadis et al., 1992; Brook et al., 1992; Buxton et al., 1992; Fu et al., 1993; Harley et al., 1992; Johnson et al., 1995; Mahadevan et al., 1992; Shaw et al., 1993). The prevalence of the DM-mutation in the general population is estimated to be 1 in 8000 (Hunter et al., 1992).

Harley proposed a classification of four different categories of myotonic dystrophy in relation to age of onset and of clinical symptoms (Harley et al. 1993).

1. The mild form of DM with cataract and minimal or no neuromuscular symptoms in middle or older age.

2. The classical or adult form with typical neuromuscular symptoms in adolescence or (early) adult life.

3. The juvenile form: symptoms are present in childhood before the age of 10 years. Learning disabilities are often prominent, while neuromuscular symptoms are rather mild or sometimes even absent.

4. The congenital form with clinical symptoms present form birth on or in utero: hypotonic cerebral palsy, respiratory and/or feeding problems, and mild to moderate developmental delay in survivors.

The psychiatric and cognitive evolution of individuals with the adult form of DM has been well documented in the past, with controversial findings. Studies rather suggest an increased incidence of depression in the group of patjents with DM (Cuthill et al., 1988; Harper et al., 1989). It is equivocal whether or not a carefree temperament is typical of patients with DM (Harper et al., 1989). Some studies in adults suggested intellectual impairment and lower IQ as the age of onset of signs and symptoms is lower, but this was not confirmed in other studies (Broughton et al., 1990; Censori et al., 1990; Harper, 1989; Perini et al., 
1989; Ragazzoni et al., 1991; Tuikka et al., 1993; Tumpenny et al., 1994; Van Spaendonck et al., 1995). Apart from the fact that neuromuscular symptoms are frequently associated with developmental problems, not much is know about the cognitive and behavioural aspects of the infantile and juvenile forms of DM.

We studied intelligence and possibly associated psychopathology in 16 children and adolescents, between 7 and 18 years of age, with either the congenital (two patients), or the juvenile form (14 patients) of DM. The study is also the first phase of a longitudinal study on possible cognitive and developmental changes in subjects with infantile or juvenile DM.

\section{Subjects and methods}

\section{Subjects}

We studied a group of 16 children and adolescents, between the age of 7 and 18 years, nine girls and seven boys. Eleven were index patients in their respective families and all were referred to the centre for clinical genetics because of a great variety of neuromuscular problems (such as hypotonia and somnolescence), other somatic complaints (gastrointestinal problems) or developmental problems and learning difficulties. The other five subjects are affected brothers and sisters of the index patients. The clinical diagnosis of DM was confirmed by molecular studies and further family studies were performed. Table 1 gives a summary of the age of onset of clinical symptoms, the present age and the molecular data in the 16 children and adolescents and of the molecular data in the affected parents. All affected parents presented a classic, adult-onset DM.

History and clinical findings allowed us to classify the 16 subjects into two groups, following the classification we propose:

11. Congenital DM group (CDM) (two girls):

Severe hypotonia was noted at birth in the two children. A fetal hypokinesia sequence with reduced fetal movements and polyhydramnios was seen in one child. At birth one child presented a talipes equinovarus deformity of both feet, and another had respiratory distress syndrome; both children had serious feeding- and swallowing difficulties form the beginning. They had facial weakness with typical tented upper lip, myotonia, dysarthric speech and extremely slow movements. One is mildly mentally retarded (FSIQ between 50 and 70) and one has a borderline intelligence (FSIQ between 70 and 85 ). 
2. Juvenile DM group (JDM) (14 patients; seven boys and seven girls):

No major problems were noted in these children at birth. Five of them had feeding problems (slow suckers; bottle-feeding was started after birth because breast feeding was not possible), while pre- and perinatal history were normal in seven patients. The five patients with early feeding problems were diagnosed as having DM before the age of 8 , on the basis of the following symptoms: muscular hypotonia (one child), tiredness after physical exercise (one child), gastrointestinal symptoms (one girl with feeding difficulties with constipation and diarrhoea), and learning difficulties (all five). The others were diagnosed before the age of 15 years on the basis of the following: learning difficulties (four patients), muscular hypotonia (two patients), and somnolence (one patient).

Data on intelligence were as follows: mild mental retardation (three subjects), borderline intelligence (five subjects), learning difficulties with IQ's between 85-100 (five subjects). Nine of the 12 children are in a special education program. The 14 children with JDM presented facial weakness, and myotonia in the hands. Delayed fine motor development was noted in five of them and somnolence in four others. Most children in both groups needed a rather long night rest: 12 of the 16 children needed 10 or more hours of sleep a day.

\section{Methods}

Intelligence was tested with the Wechsler scales: WISC-R scale in the children and WAIS scale in the adolescents older than 16 years (Stinissen et al., 1970; Van Haasen et al., 1974). These scales are subdivided into performance and verbal subscales. Each subscale contains different subtests (verbal subscale: information, similarities, arithmetic, wocabulary, comprehension and digit span; performance subscale: picture completion, picture arrangement, block design, object assembly, substitution and mazes). The resulting data give us a total intelligence quotient (FSIQ), a verbal intelligence quotient (VIQ), a performance intelligence quotient (PIQ) and an intelligence profile. Differences over time in FSIQ in a single patient are present when the $95 \%$-reliability intervals of the first and the last IQ result do not overlap (Van Haasen et al., 1974). Thus, a decline in IQ can be demonstrated with a probability below 0.05 .

The Dutch versions of the Children's Behaviour Checklist (CBCL), a well validated checklist standardized in children with normal and borderline intelligence (IQ>70), was completed by the parents (Verhulst et al., 1990). The results from this checklist are transformed into a total problem score, in two 
subscores for, respectively, the internalising (withdrawn, somatic complaints and anxious/depressed) and externalising problem behaviour (delinquent and aggressive) and in a profile of chusters with specific problem behaviour (withdrawn, somatic complaints, anxious/depressed, social problems, thought problems, attention problems, delinquent behaviour and aggressive behaviour). The responses are transformed into $T$-scores $(X=50, s . d .=10)$. In the total problem score, and the internalising and externalising subscores, a T-score of 63 or higher (coinciding with 90 th centile or higher) is considered to be of concern and is called by the authors "in the clinical range". T-scores in the range of 70 or higher ( $>98$ th centile) are found in populations with severe behavioural or emotional problems. For the specific problem clusters, T-scores of 66 or higher ( $>93$ rd centile) are considered to be of concern (Verhulst et al., 1990).

Depressivity was assessed by two questionnaires, adapted for a Dutch population: the Child Depression Scale in nine children younger than 15 years, and the Beck Depression Inventory in five adolescents older than 15 years (Beck et al., 1961; Luteijn, 1981; Bouman et al., 1985).

Finally, the possible presence of clinical child psychiatric syndromes was assessed by means of a structured interview with the parents: the Dutch version of the Diagnostic Interview for Children and Adolescents (ADIKA) (Kortenbout et al., 1993). This instrument, based on the criteria of the DSM-III-R classification, has been adapted in Dutch, but the norm values for a Dutch population are not available yet. Therefore, we applied the DSM-III-R criteria and the US-norms of the Diagnostic Interview for Children and Adolescents (Reich et al., 1982; American Psychiatric Association, 1987; Welner et al., 1987).

The length of the insertion at the DM-site was assessed on peripheral lymphocytes. Genomic DNA was extracted and two Southern blots were performed: one to assess longer insertions, after digestion with EcoRI, and one to assess shorter insertions, after digestion with $B g / I$. Standard techniques were used, with p25B1.4 as a probe. Repeat lengths were measured and expressed as difference in repeat size with a normal control. 


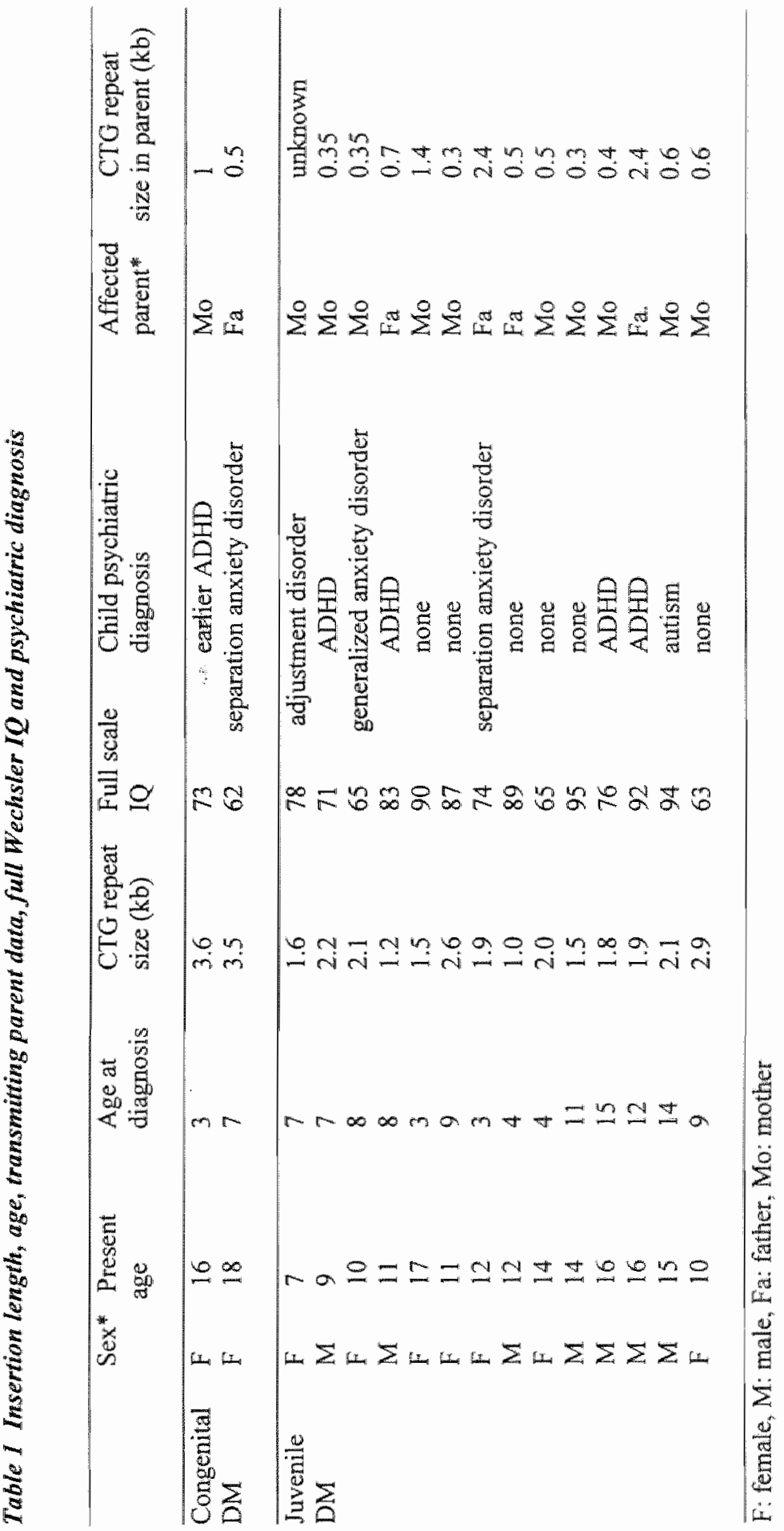




\section{Results}

\section{Molecular data}

The mean repeat size was $3.55 \mathrm{~kb}$ in the two subjects with congenital DM, and $1.88 \mathrm{~kb}$ in the groups of juvenile DM (Table 1). All affected parents presented a classical adult form of DM. The mean repeat size was $0.66 \mathrm{~kb}$ in the transmitting mothers and $2.3 \mathrm{~kb}$ in their affected children. The mean repeat size was $1.2 \mathrm{~kb}$ in the transmitting fathers and $1.5 \mathrm{~kb}$ in their affected children. ANOVA of repeat size between the two categories shows significant differences between the categories $\left(p=0.001\right.$, multiple $\left.r^{2}=0.61\right)$.

\section{Intelligence}

The full scale IQ (FSIQ) was below 100 in all 16 subjects; individual IQ's varied between 62 and 95, and the mean FSIQ was 79. Average FSIQ (Table 1) was 68 in the category congenital DM (CMD), and 80 in the category juvenile DM (JMD). ANOVA of FSIQ between the two categories of DM, with age as covariate, shows significant differences $(p=0.039)$ between these categories. Regression analysis of FSIQ as a function of the whole group of subjects, shows an inverse correlation $(p=0.025)$.

Analysis of the Wechsler subscales in all patients showed no significant difference between the average performance IQ (PIQ:82) and the average verbal IQ (VIQ:79). Kaufman's three-factor analysis of the Wechsler scales showed an average factor $1-\mathrm{IQ}$ (verbal reasoning) of 79, factor2-IQ (visuo-spatial reasoning) of 82 and factor3-IQ (attention) of 81 (Van Haasen et al., 1974). The differences between these three factors are not significant.

Longitudinal IQ data were available in two subjects. Results on the WISC R in two clitdren with juwenile DM showed a significant $(\mathrm{p}<0.05)$ decline of FSIQ over a period of 2 years (FSIQ's: from 94 to 71 and from 75 to 65).

\section{Behavioural and emotional functioning}

Results on the CBCL parent form (Figure 1), showed problem behaviour in the clinical range, in five of the 16 subjects: one of the two subjects with congenital DM and four of the 14 subjects with juvenile DM. Problems lay mainly in the internalising subscale of the CBCL: six subjects scored in the clinical range on the internalising subscale, while only one subject scored in the clinical range on the externalising subscale. On the separate symptom clusters, the clusters "withdrawal" (three subjects), "social problems" (four subjects) and "attention problems $^{\text {"1 }}$ (two subjects) are in the clinical range ( $T$-score $>70$, or above 98th centile). Two children scored in the clinical range of depression on the 
depression questionnaires: one girl with juvenile DM on the Chilldren"s Depression Scale, and one girl with congenital DM on the Beck Depression Inventory.

Child psychiatric syndromes

On the structured psychiatric interview (ADIKA), nine subjects showed a clinical syndrome (Table 1).

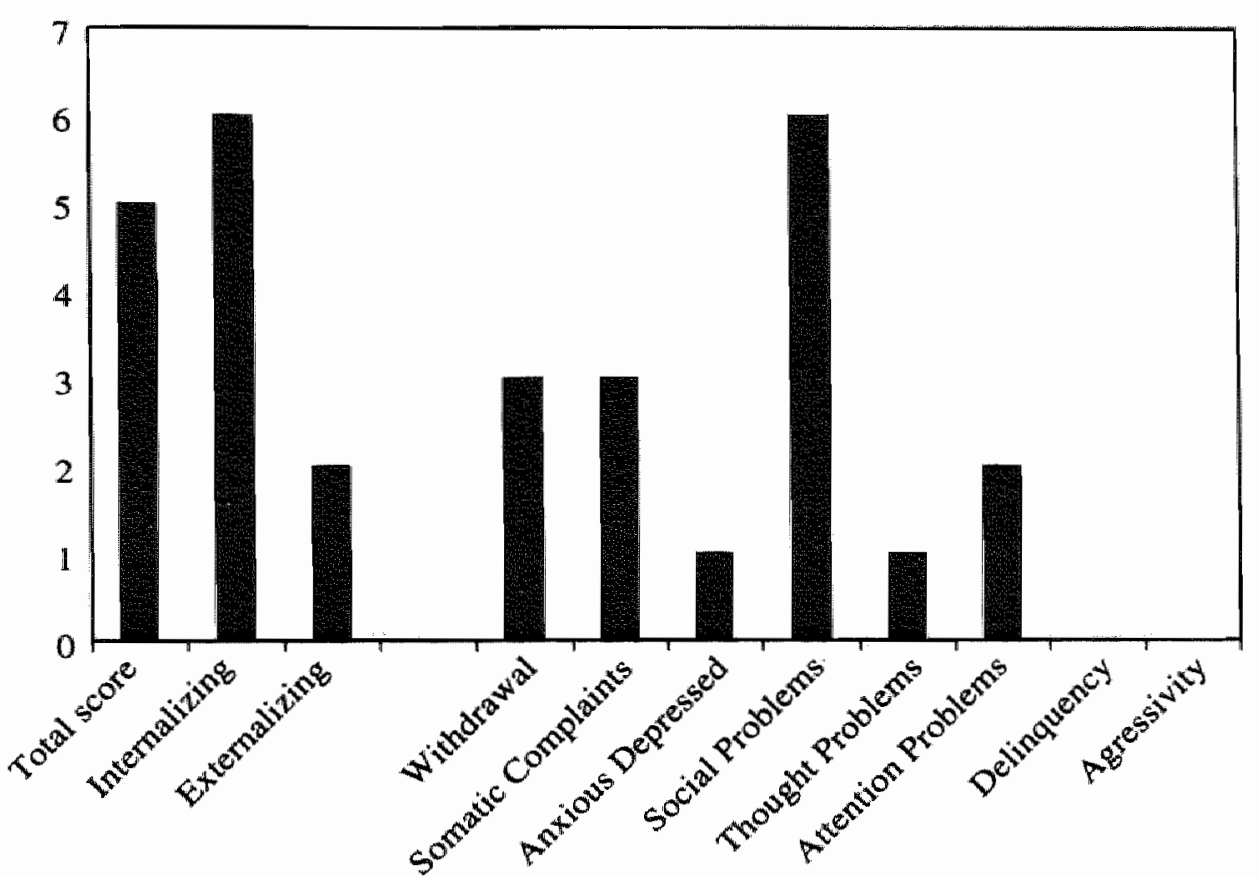

Figure 1 Scores on the different dimensions of the Child Behaviour Checklist (parents' questionnaire); Number of subjects scoring above +2 standard deviations on scale

Four subjects fulfilled the criteria for Attention Deficit and Hyperactivity Disorder (ADHD): all four have juvenile DM and normal or borderline intelligence. The diagnosis $\mathrm{ADHD}$ was clinically diagnosed by the child psychiatrist in three of these four subjects. One of the females, with congenital $\mathrm{DM}$, fulfilled the criteria for the diagnosis $\mathrm{ADHD}$ in childhood, but no longer fullfilled them at the time of the study.

One mildly mentally retarded female with congenital DM and one borderline intelligent female with juvenile DM manifested a separation anxiety disorder 
before the age of 15 years. Finally, one mildly mentally retarded female DM patients had a generalised anxiety disorder and one borderline intelligent female had an adjustment disorder with depressive mood. These two subjects have juvenile DM. One boy with normal intelligence and juvenile DM fulfils the criteria for autism on the Childhood Autism Rating Scale.

\section{Discussion}

We assessed 16 children and adolescents with congenital or juvenile DM, and with intelligence levels in the normal, borderline or mildly retarded range. In the two children with congenital DM, severe muscular hypotonia was present form birth on. In one subject a fetal hypokinesia sequence with polyhydramnios was already noted in the third trimester of pregnancy. Despite these obvious symptoms, the diagnosis DM was made only at age 3 and 7 years, respectively. This long interval period between the age at onset of the first symptoms and the age at diagnosis may be explained by the fact that the two subjects were index patients in their respective families. Further family studies showed that both inlherited the DM mutation from their mother, who presented a classical adult form of DM.

In the 14 subjects with juvenile DM, the mean age at diagnosis was 8.1. Although other symptoms were present in these children at the time of diagnosis, the first problem that alarmed the parents was learning difficulties. The fact that learning difficulties were the reason for seeking help in these patients, in whose families DM was not known, may be the reason why the age at which the diagnosis was made coincides with the beginning of primary school.

In the patients we describe, within each category of DM, there is an important variation in severity of symptoms and affected organ systems within each diagnostic group. Repeat length does not permit prediction of the variation within one diagnostic group, but there is a significant correlation between repeat length and FSIQ. In this study we found a significant difference in repeat length between the diagnostic groups juvenile DM and congenital DM. Moreover, further family studies showed that all affected parents (three fathers and eight mothers) presented a classical adult form of DM. As expected, the mean repeat size in the transmitting mothers was much smaller than in their affected children. Transmitting fathers had about the same repeat size as their affected 
children, although the differences in clinical severity between fathers and their children are important. Possible factors that may influence the phenotypic expression are somatic mosaicism, ongoing instability of the repeat expansion after birth, and the intrinsic characteristics of the protein kinase (DMPK) itself (Report on MDA workshop on DM (Johnson et al., 1995)).

On intelligence tests, all subjects in this study show a full scale IQ (FSIQ) below the population mean. The mean FSIQ of the group is 79 . This result may not be representative for the whole population of DM patients, as in this group there was an ascertainment bias because for several subjects the reason for consultation had been learning difficulties rather than somatic complaints. Previous studies performed in adult-onset DM showed higher mean FSIQ, ranging between 84 and 96 . These data are not very representative, as the subject group in these studies is always biased (Turnpenny et al., 1994). In the present study, the subjects with congenital DM have a significantly lower FSIQ than the subjects with juvenile DM. As the subjects in the study are a group of referred patients, we cannot demonstrate whether the lower mean intelligence that was found is due to ascertainment bias or reflects a truly lower intelligence in the population of children and adolescents with DM.

Several studies of cognitive functioning in adult DM have already demonstrated attention and concentration problems, and deficits in visuospatial and visuoconstructive abilities in affected individuals (Tumpenny et al., 1994). However, other studies showed hardly any evidence of cognitive dysfunction (Van Spaendonck et al., 1995). In the present study of 16 affected children and adolescents, the profile of the intelligence test did not suggest specific cognitive deficits in the verbal or visuospatial area. However, more specific neuropsychological testing should be performed to assess this issue.

Longitudinal data on IQ evolution with age were available in two children and they showed a significant decline with age. Results of IQ evolution with age of several studies in adult-onset DM are controversial (Bird et al., 1983 ; Portwood et al., 1984, 1986; Tuikka et al., 1993).

With regard to behaviour (results of the Child Behaviour Checklist, parents" form) we found that an unexpectedly high number of children scores in the clinical range (five of 16 children for total problem score). All these children are children with FSIQ>70 who are well in the range of intelligence for which the CBCL was designed. The pathological scores are mainly on the dimensions "withdrawal", "social problems" and "attention problems". 
Two subjects scored in the clinical range on the Depression Scale we used. This incidence may not be very different from the incidence of depression in a normal population ( 2 to $5 \%$ ) and a mentally retarded population ( 8 to $15 \%$ ), according to the numbers given by Lovell (Lovell and Reiss, 1993). Both these children reported being teased at school.

A structured child psychiatric interview (ADIKA) showed Attention Deficit and Hyperactivity Disorder (ADHD) in four subjects at present, and in one more subject in the past. The diagnosis was made in three of these subjects at clinical assessment by a child psychiatrist. The discrepancy between the higher number of subjects, who fulfilled the diagnostic criteria of the DSM-III-R (ADIKA), and the somewhat lower number diagnosed by the child psychiatrist, may be due to the fact that the subjects mainly present symptoms relating to attention deficit and impulsivity, and fewer relating to hyperactivity. This may prevent the child psychiatrist reaching the diagnosis, although the criteria are fulfilled. The prevalence of ADHD in a population with intelligence higher than 70 is estimated to be between 1 and 3\% (American Psychiatric Association, 1994). In our sample the prevalence was $25 \%$ (4/16). Attention problems were one of the most frequent complaints of the parents in the other subjects, as well as in the subjects in whom the full diagnosis of ADHD was made. Thus, attention problems, with or without hyperactivity and impulsivity, seem to be a frequent problem in the population of children with DM. It is not clear how much somnolence or problems of circadian rhythm in DM contribute to the attention problems in DM.

Another frequent diagnosis was that of anxiety disorders (three in 16 subjects). In two adolescents $(>16$ years, two juvenile DM) reduced initiative was reported and they presented more pronounced muscle weakness. In the other 14 subjects, there were no complaints that could refer to the presence of apathy. Apparently, the clinical diagnosis of "apathy" which is made in many DM children, may be a false impression caused by their expressionless face.

In conclusion, the observations made in the present group of $16 \mathrm{DM}$ children and adolescents are interesting and reveal an unexpected incidence of different child psychiatric syndromes (ADHD, anxiety disorders). 


\section{References}

American Psychiatric Association (APA). Diagnostic and statistical manual of mental disorders, 3rd edn. Revised (DSM-III-R). American Psychiatric Association, Washington DC, 1987.

American Psychiatric Association (APA). Diagnostic and statistical manual of mental disorders, IVth edn. (DSM-IV). American Psychiatric Association, Washington DC, 1994.

Aslanadis C, Jansen G, Amemiya C, Shutler G, Tsilfidis C, Mahadevan M, Chen C, Alleman J, Wormskamp NGM, Voojls M, Buxton J, Jonhson K, Smeets HJM, Lennon GG, Carrano AV, Korneluk RG, Wieringa B, de Jong PJ. Cloning of the essential myotonic dystrophy region: mapping of the putative defect. Nature 1992;355:548-551.

Beck AT, Ward CH, Mendelson M, Mock JE, Erbaugh I. An Inventory for measuring depression. Arch Gen Psychiatr 1961;4:561-571.

Bird TD, Follet C, Griep, E. Cognitive and personality function in myotonic dystrophy. J Neurol Neurosur Psychiatr 1983;46:9711-980.

Bouman $\mathrm{K}$, Luteijn $F$, Albersnagel FA, van der Ploeg FAE. Enige ervaringen met de Beck Depression Inventory. Tijdschr Psychol 1985;13:13-24.

Brook JD, Mc Currach ME, Harley HG, Buckler AJ, Church D, Aburatani H, Hunter K, Stanton VP, Thirion JP, Hudson T, Sohn R, Zemelman B, Snell RG, Rundle SA, Crow S, Davies J, Shelbourne P, Buxton $J$, Jones $C$, Juvonen $V$, Johnson $K$, Harper PS, Shaw DJ, Housman DE. Molecular basis of myotonic dystrophy." expansion of a trinucleotide (CTG) repeat at the $3^{\prime}$ end of a transcript encoding a protein kinase family member. Cell 1992;68:799-808.

Broughton R. Stuss D, Kates M, Roberts J, Dunham W. Neuropsychological deficits and sleep in myotonic dystrophy. Can J Neurol Sci 1990;17:410-415.

Buxton J, Shelboume P, Davies J, Jones C, Van Tongeren T, Aslanadis C, de Jong P, Jansen $\mathrm{G}$, Anvret M, Williamson R, Johnson $\mathrm{K}$. Detection of an unstable fragment of DNA specific to individuals with myotonic dystrophy. Nature 1992;355:547-548.

Censori B, Danni M, Del Pesce M, Provinciali L. Neuropsychological profile in myotonic dystrophy. J. Neurol 1990;237:251-256.

Cuthill J, Gattereau A, Viguie F. Myotonic dystrophy of Steinert: are anxiety and depression. necessarily concomitans? Can J Psychiatr 1988;33:203-206.

Fu YH Friedman DL, Richards S, Pearlman JA, Gibbs RA, Pizutti A, Ashizawa T, Perryman MB, Scarlato G, Fenwick RG, Caskey CT. Decreased expression of myotoninmprotein kinase messenger RNA and protein in adult form of myotonic dystrophy. Science 1993;260:235-238. Harley HG, Brook JD, Rundle SA, Crow S, Reardon W, Buckler AJ, Haper PS, Housman DE, Shaw DJ. Expansion of an unstable DNA region and phenotypic variation in myotonic dystrophy. Nature 1992,355:545-546.

Harley HG, Rundle SA, Mc Millan JC, Myring J, Brook JD, Crow S, Reardon W, Fenton L, Shaw DJ, Harper PS. Size of the unstable CTG repeat sequence in relation to phenotype and parental transmission in myotonic dystrophy. Am J Hum Genet 1993;52:1164-1174.

Harper PS. Myotonic dystrophy, 2nd edn. W.B. Saunders Company, Philadelphia, 1989.

Hunter AGW, Tsilfidis C, Mettler G, Jacob P, Mahadevan M., Surh L, Korneluk RG. The correlation of age of onset with $\mathrm{CTG}$ trinucleotide repeat amplification in myotonic dystrophy. J Med Genet 1992;29:774-779.

Johnson KJ, Siciliano MJ. Report on MDA workshop on myotonic dystrophy, 10 October 1994, Montreal, Quebec, Canada. J Med Genet 1995;32:662-665. 
Kortenbout Van der Sluijs MJ, De Levita DJ, Van Manen R, Defares PB. Amsterdams diagnostisch interview voor kinderen en adolescenten, een bewerking van de Diagnostic interview for children and adolescents. Swets and Zeiflinger BV, Lisse, 1993.

Lovell RW, Reiss AL. Dual diagnoses. Psychiatric disorders in developmental disabilities. Pediatr Clin North Am 1993,40:579.

Luteijn F. Kinder depressieschaal (Nederlandse bewerking van de Childrens depression scale). Swets and Zeitlinger BV, Lisse, 1981.

Mahadevan M, Tsilfidis C, Sabourin L, Shutler G, Amemiya C, Jansen G, Neville C, Narang M, Barcelo J, OHoy K, Leblond $\mathrm{S}$, Earle-Mc Donald $J$, de Jong PJ. Wieringa $B$, Korneluk RG. Myotonic dystophy mutation: an unstable CTO repeat in the 3 untranslated region of the gene. Science 1992;255:1253-1255.

Perini GI, Colombo G. Armani M, Pellegrini A, Ermani M, Miotti M, Angelini C. Intellectual impaiment and cognitive ewoked potentials in myotonic dystrophy. J Nerv Ment Dis $1989 ; 177: 750-754$.

Portwood MM, Wicks JJ, Lieberman JS, Fowler WM. Psychometric evaluation in myotonic dystrophy. Arch Phys Med Rehab 1984;65:533-536.

Portwood M, Wicks J, Lieberman J, Fowler W, Duveneck M. Longitudinal study of intellectual function in myotonic muscular dystrophy (abstract). Muscle Nerve 1986;9 (suppl): 99.

Ragazzoni A, Pinto F, Taiuti R, Silveri MC. Myotonic dystrophy: an electrophysiological study af cognitive deficits. Can J Neurol Sci 1991;18:300-306.

Reich W, Herjanic B, Welner Z, Gandhy PR. Development of a structures psychiatric interview for children: agreement on diagnosis comparing child and parent inteview, J Abn Child Psychol 1982;10:325-336.

Rostain AL. Attention-deficit disorders in children and adolescents. Pediatr Clin North Am 1991;38: 607.

Shaw DJ, Mc Curtach M, Rundle SA, Harley HG, Crow SR, Sohn R, Thirion JP, Hamshere $M G$, Buckler AJ, Harper PS, Housman DE, Brook DJ. Genomic organization and transcriptional units at the myotonic dystrophy locus. Genomics 1993;18:673-679.

Stinissen J, Willens PJ, Coetsier P, Hulsman WLL. Handleiding bij de Nederlandse bewerking van de Wechsler adult inteligence scale (WAIS). Swets and Zeitlinger BV, Lisse, 1970.

Tuikka RA, Lakksonen RK, Somer HVK. Cognitive function in myotonic dystrophy: a follow-up study. Eur Neurol 1993;33:436-441.

Turmpenny $\mathrm{P}$, Clark $\mathrm{C}$, Kelly $\mathrm{K}$. Intelligence quotient profile in myotonic dystrophy, intergenerational deficit, and correlation with CTG amplification. I Med Genet 1994;31:300305.

Van Haten PP, De Bruyn EEJ, Pijl YJ, Poortinga YH, Spelberg HC, Vander Steene $G_{\text {, }}$ Coetsier P, Spoelders-Claes R, Stinissen J. Wechsler intelligence scale for children - Revised, Nederlandstalige Uitgave. Swets and Zeitlinger BV, Lisse, 1974.

Van Spaendonck KPM, Ter Bruggen JP, Weyn Banningh EWA, Maassen BAM, Van de Biezenbos IBM, Gabreels FJM. Cognitive function in early adult and adult onset myotonic dystrophy. Acta Neurol Scand 1995;91:56-461.

Verhulst FC, Koot JM, Akkerhuis GW, Veerman JW. Praktische handleiding voor de CBCL. Van Gorcum, Assen/Mastricht, 1990.

Wehner $Z$, Reich W, Herjanic $\mathbb{B}$, Jung $K G$, Amado $\mathbb{H}$. Reliability, validity and parent-child agreement studies of the Diagnostic Interview for Children and Adolescents (DICA). J Am Acad Child Adolesc Psychiatry 1987;26:649-653. 
Chapter 3

\section{Age and causes of death in adult onset myotonic dystrophy}

C.E.M. de Die-Smulders ${ }^{1}$, C.J. Höweler ${ }^{2}$, C. Thijs ${ }^{3}$, J.F. Mirandolle ${ }^{4}$, H.B. Anten $^{5}$, H.J.M. Smeets ${ }^{6}$, K.E. Chandler ${ }^{1}$, J.P.M. Geraedts ${ }^{6}$

Departments of ${ }^{4}$ Clinical Genetics and ${ }^{2}$ Neurology, Academic Hospital Maastricht, ${ }^{3}$ Department of Epidemiology, Maastricht University, ${ }^{4}$ Department of Neurology, de Wever Hospital, Heerlen, ${ }^{5}$ Department of Neurology, Maasland Hospital, Sittard, ${ }^{6}$ Department of Molecular Cell Biology and Genetics, Division of Genetics, Maastricht University, the Netherlands

Brain 1998;121:1557-1563 


\section{Summary}

Myotonic dystrophy is a relatively common type of muscular dystrophy, associated with a variety of systemic complications. Long term follow-up is difficult because of the slow progression. The objective of this study was to determine survival, age at death and causes of death in patients with the adult-onset type of myotonic dystrophy. A register of myotonic dystrophy patients was set up in Southern Limburg (the Netherlands), using data longitudinally collected over a 47-year period (1950-1997). Survival for 180 patients (from the register) with adult-onset type myotonic dystrophy was established by the Kaplan-Meier method. The median survival was 59 years for males and 60 years for females. Survival of the patients was also estimated from the age of 15 years to the ages 25,45 and 65 years and compared with the expected survival of age- and sex matched birth cohorts from the normal Dutch population. The observed survival to the ages of 25,45 and 65 years, was $99 \%, 88 \%$ and $18 \%$, compared with an expected survival of $99 \%, 95 \%$ and $78 \%$, respectively. Thus, survival to the age of 65 in patients with adult-onset myotonic dystrophy is markedly reduced. A weak positive correlation between the CTG repeat length and younger age at death was found in the 13 patients studied $(r=0.50, P=0.08$ ). The cause of death could be determined in 70 of the 83 deceased patients. Pneumonia and cardiac arrhythmias were the most frequent primary causes of death, each occurring in $\sim 30 \%$, which was far more than expected for the general Dutch population. In addition, we assessed mobility in the years before death in a subgroup of 18 patients, as a reflection of the long-term physical handicap in myotonic dystrophy patients. Half of the patients studied were either partially or totally wheelchair-bound shortly before their death. 


\section{Introduction}

Myotonic dystrophy is an autosomal dominant muscular dystrophy, with a prevalence of 1-10 per 100000 (Emery, 1991). It is caused by an expanded CTG repeat in the myotonic dystrophy protein kinase (DMPK) gene on the long arm of chromosome 19 (Harley et al., 1992). The length of the repeat correlates with the age at onset and the severity of clinical symptoms. Four disease types have been recognized: late onset (mild) type; adult-onset (classical) type; childhood and congenital type (Harley et al., 1993). The muscular symptoms are associated with a variety of systemic complications, some of which can be life threatening, e.g. cardiac arrhythmias and aspiration pneumonias (Harper, 1989). The progression of muscle weakness in myotonic dystrophy is usually slow. Initially, only distal limb muscles are involved, but in the later stages the weakness extends more proximally. Owing to the slow progression of the disease, patients may survive for decades after the onset of symptoms. Consequently, prospective studies on the course of myotonic dystrophy are difficult to perform, and to date very little information exists on patients' overall survival and cause of death. The long-term clinical outcome and mortality have only been studied for congenital myotonic dystrophy (Reardon et al., 1993). The natural history of adult-onset myotonic dystrophy has not been studied. Only data on mean age at death for all disease types combined have been reported in older studies (Bell, 1948; Thomasen, 1948; Klein, 1958; Grimm, 1975).

Our study aimed to determine the long-term prognosis of patients with adultonset type myotonic dystrophy. We conducted a follow-up study by combining data collected by two generations of neurologists with a special interest in myotonic dystrophy. The age and causes of death were retrieved from the patients" records and a survival analysis performed. In order to get an impression of the physical handicap in the years preceding death, mobility was assessed in a subgroup of patients.

\section{Patients and methods}

The population of patients for this study was selected from the register of myotonic dystrophy families in Southern Limburg. This region is a geographically isolated part of the Netherlands, bordered by Germany and Belgium. Ascertainment of complete families and follow-up of patients is relatively straightforward because of limited population migration. Between 1950 and 1970, 85 myotonic dystrophy patients from 15 families living in this area were examined (de Jong, 1955). The 
collection of data was continued from 1970 by the next generation of neurologists, working in the three regional hospitals in Maastricht, Heerlen and Sittard. After 1987 the series of family records were collated by the Department of Clinical Genetics and a genetic register set up. Data on disease type, major complications, results of DNA examination and genealogical studies were documented.

The register presently contains data on 328 myotonic dystrophy patients from 56 families. For this study patients with the adult-onset type were selected from the register. This type is characterized by an age at onset between 10 and 50 years, myotonia and progressive weakness, and absence of mental retardation (Harley et al, 1992). Congenital and childhood-onset cases were excluded because they show a high neonatal and childhood mortality and their prognosis was recently determined (Reardon et al., 1993). Patients with mild disease (age at onset $>50$ years) were not included because their prognosis seems to be much better than that for adult-onset patients. In total, 180 patients with adult-type myotonic dystrophy were selected, of which 83 (47 males and 36 females) were deceased at the time of surveying (January 1997).

The age at death was ascertained by information from family members, medical records or from the registry office. The median and mean ages at death were determined for the whole population $(\mathrm{n}=83)$ and for males and females separately. We calculated the mean age at death in order to compare our data with those from previous studies. Survival of the patients was estimated by the Kaplan-Meier method with the attained age as the survival time. Patients still alive at the end of follow up were censored (in order to include follow-up information of all patients, deceased or still alive). Survival of the patients was also compared with the expected survival based on generation-survival tables from the Dutch population 1860-1989 (Tas, 1991). We calculated survival rates of the cohorts at risk from the age of 15 to age 25 years (cohort born before 1972), to the age of 45 years (cohort born before 1952), and to the age of 65 years (cohort born before 1932). It was assumed that all patients survived at least to the age of 15 years. The $95 \%$ confidence intervals around the observed survival rates were calculated by the exact method using the binomial distribution. Exact P-values were also calculated from this distribution.

The primary cause of death was known in 70 patients. Data on cause of death were obtained either from medical records, in the case of death in hospital, or from the general practitioner, in the case of death at home. Causes of death were grouped into two main categories: disease-related causes and causes not related to myotonic dystrophy. Sudden death, arrhythmias, pneumonia and postoperative death are well known systemic complications of myotonic dystrophy (Aldridge, 1985; Harper, 
1989; Mathieu et all, 1997). We also considered fractures following a spontaneous fall as a myotonic dystrophy associated complication, as they probably occurred as a result of the muscle weakness. Some patients died following a series of events, e.g. a fracture after a fall, complicated by a fatal pneumonia. In these cases the initial event was recorded as the primary cause of death and the final complication leading to death as the secondary. An autopsy was performed in 22 patients. All autopsy reports were carefully reviewed.

The observed frequencies of the different causes of death were compared with expected frequencies for the general Dutch population. The expected proportion of patients dying from a certain cause was calculated using Dutch population tables of causes of death from 1970 and 1990 (to represent, respectively, patients with median year of death 1965 and patients with median year of death 1991) and was further standardized for age and sex. The analysis was confined to primary causes of death that could be classified unambiguously by ICD (International Classification of Disease) number (ICD-8, World Health Organization, Geneva $1967 / 1969$ for 1970 and ICD-9, World Health Organization, Geneva 1978 for 1990). $P$-values were calculated from the binomial distribution.

The length of the CTG repeat was known for only 13 patients, as most patients died before 1.992, before the myotonic dystrophy gene was identified. Genomic DNA was isolated from peripheral blood cells. The molecular analyses were performed according to methods previously described (Shelbourne et al., 1993). In the samples where smears were detected, the middle of the smear was sized. The expansions are expressed in kilobases of additional DNA.

In a subgroup of 18 patients, mobility within 2 years of death was assessed during their regular visit to the outpatient clinic of neurology, and scored on a fourpoint scale (Hoffer et al., 1973).

\section{Results}

The ages at death for the 83 deceased patients with adult-type myotonic dystrophy are shown in Fig. 1 . The majority of patients $(63 \%)$ died between the ages of 50 and 65 years. Only $12 \%$ of patients died aged 65 years or older. Further characteristics regarding the age at death are summarized in Table 1 . Although mean and median ages at death were lower in malle patients than in female patients, the observed differences were not statistically significant. The median $(50 \%)$ survival for male patients was 59 years and for female patients 60 years (Table 1). 


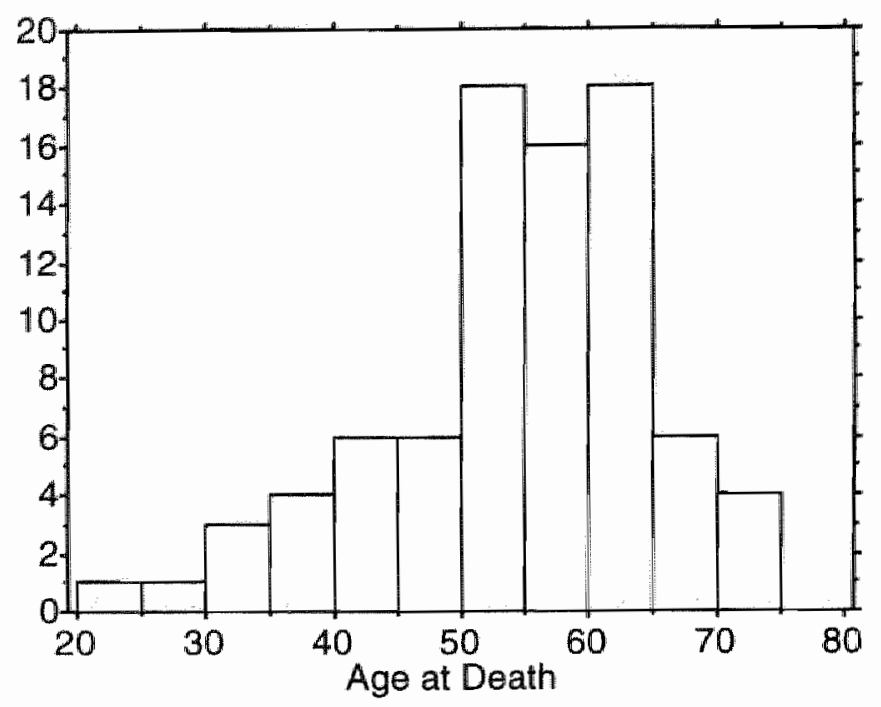

Figure 1 Age at death $(n=83)$

Table 1 Characteristics of the patients ( $n=180$, including 83 deceased)

All patients Malles Females

Age at death (years)

Median age*

Mean age +

(95\% Cl)

$\begin{array}{lll}83 & 47 & 36 \\ 56 & 54 & 58 \\ 54 & 52 & 56 \\ (52.0-56.7) & (48.2-55.0) & (55.2-60.8)\end{array}$

Survival time (years)

$\begin{array}{llll}n & 180 & 101 & 79 \\ \text { Median time } & 59 & 59 & 60 \\ (95 \% \mathrm{CD}) & (57.6-60.8) & (57.2-61.2) & (56.7-63.3) \\ \text { Mean } & 58 & 56 & 60 \\ (95 \% \mathrm{Cl}) & (56.1-59.7) & (53.8-58.8) & (57.5-62.4)\end{array}$

$\mathrm{Cl}=$ confidence interval

*Difference between males and females, $X^{2}$ test, $P=0.15$

TDifference between males and females, $t$ test, $\mathrm{P}=0.006$

tDifference between males and females, log-rank test, $\mathrm{P}=0.11$ 
The Kaplan-Meier curves (Fig. 2) show that survival in both sexes declined rapidly between the ages of 50 and 70 years, from $\sim 80 \%$ of the cohort to $\sim 10 \%$.

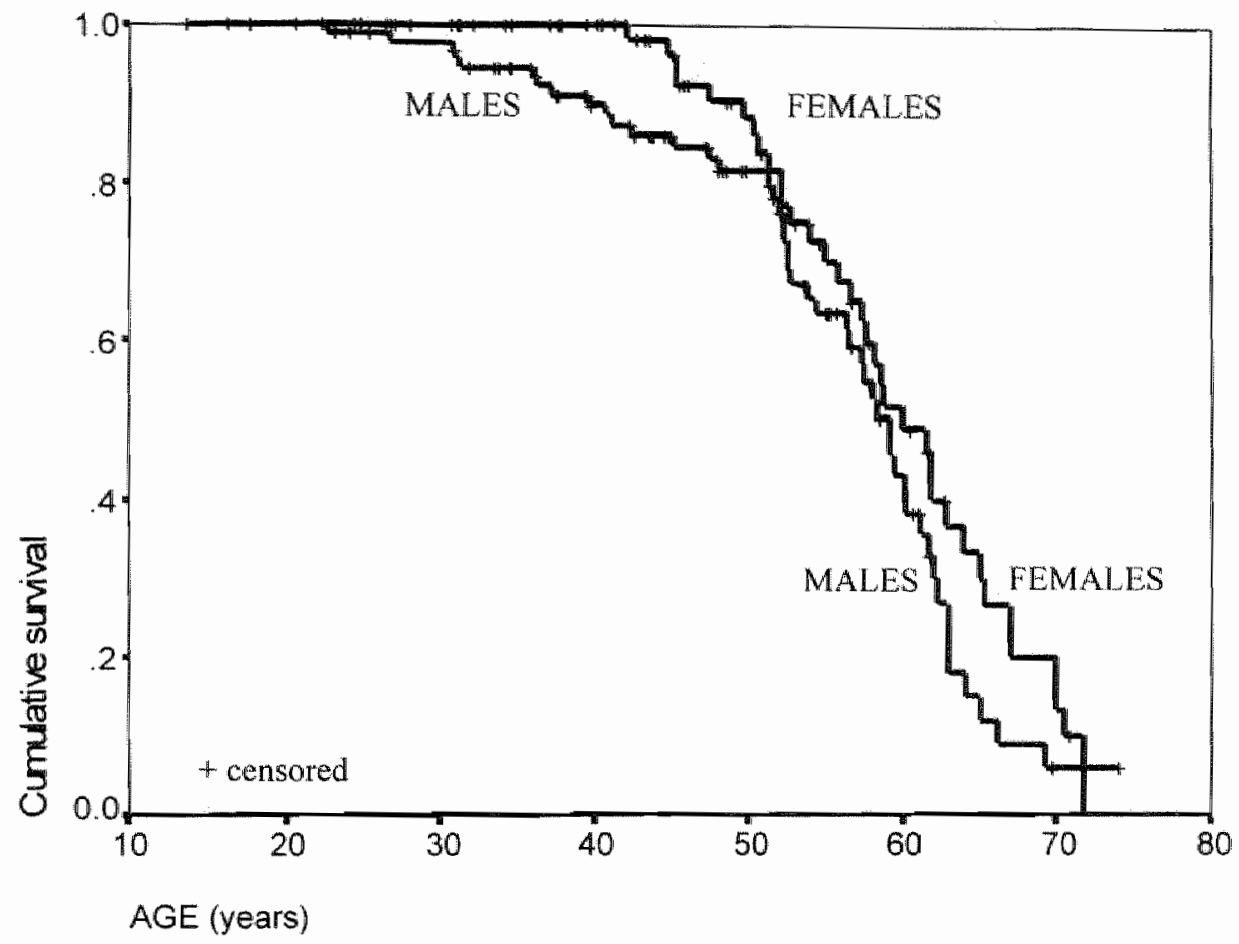

Figure 2 Kaplan-Meier survival curves of adult-onset myotonic dystrophy patients $(n=180) ;$ of the 101 males, 47 had died, 54 were censored; of the 79 women, 36 had died and the other 43 were censored

In Table 2, the observed survival from the age of 15 years in the 180 patients is compared with the expected survival. Survival of the patients to the age of 45 years was slightly, but significantly, lower than expected. Survival of patients to the age of 65 years was markedly reduced, only $18 \%$ compared with an expected survival of $78 \%$. The observed survival to the age of 65 years was lower in males $(11 \%)$ than in females $(29 \%)$, but this difference was not statistically significant (Fisher's exact test $\mathrm{P}=0.10$ ).

The molecular data for the 13 patients studied are given in Fig 3. The mean CTG repeat size was $1.8 \mathrm{~kb}$ (600 CTG repeats) (range $0.5-4.7 \mathrm{~kb}$ ). A weak inverse correlation between the CTG repeat length and survival was found $(r=0.50$, $\mathrm{P}=0.08$ ). 
Table 2 Survinal (from the age 15 ) of adult-onset minotonic dystrophy patients $(n=180)$, compared with the survival of normal subjects

Survival to the age of:

25 years 45 years 65 years

Birth cohorts

1889-1971

1889-1951 1889-1931

Survived $(n) /$ cohort $(n)$

$169 / 170$

$105 / 120 \quad 12 / 66$

Observed survival

$99 \%$

$88 \%$

$18 \%$

$(95 \% \mathrm{CI})$

$197 \%-100 \%)$

$(80-93 \%)$

$(10-30 \%)$

Expected survival*

$99 \%$

$95 \%$

$78 \%$

Survival ratio

1.01

0.92

0.23

P-value:

0.99

0.001

0.000

Cl= Confidence interval

* Calculated from survival tables of the general Dutch population, using the birth year of patients

tSurvival ratio $=$ observed survivalfexpected survival of normal subjects. \$Probability, to three decimal places, of observed value of survival (or smaller value) given the expected survival

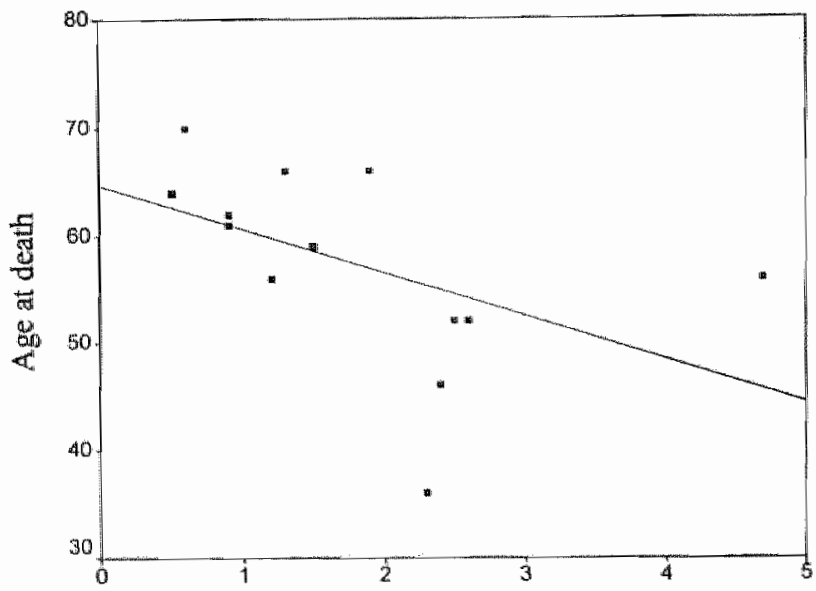

$\mathrm{kb}$

Figure 3 Correlation of CTG repeat length and age at death $(n=13)$

Medical documents on the cause of death were available for 70 patients; of these, $73 \%$ of the patients died from a complication related to myotonic dystrophy (Table 3). Pneumonia was the most frequent primary cause of death $(31 \%)$, and it was a secondary cause of death in eight patients (11\%) (three with fractures, three with 
embolic events and two with postoperative complications). Thus, pneumonia as the primary or secondary cause of death accounted for $42 \%$ (30 out of 70 ) of all deaths. Cardiac arrhythmias were the second most frequent primary cause of death $(29 \%)$.

Table 3 Primary and secondary causes of death in adultonset nyotonic dystrophy patients $(n=70)$

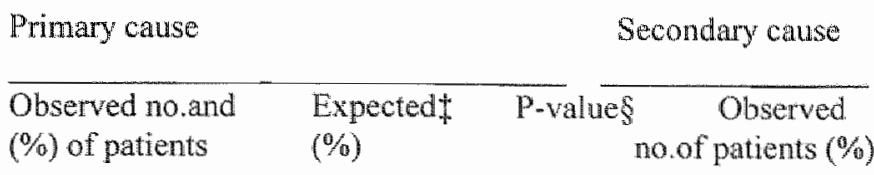

\begin{tabular}{lcccc}
\hline Causes related to myotonic dystrophy & & & \\
Pneumonia & $22(31 \%)$ & 1 & 0.000 & $8(11 \%)$ \\
Arrhythmias & $20(29 \%)$ & 2 & 0.000 & $3(4 \%)$ \\
Postoperative & $4(6 \%)$ & & & \\
Fractures & $5(7 \%)$ & & \\
Causes not related to myotonic dystrophy & & & \\
Malignancy* & $7(10 \%)$ & 37 & 0.000 \\
Other causes & $12(17 \%)$ & & & \\
Total & $70(100 \%)$ & &
\end{tabular}

* Two lung and two uterus carcinoma, and one breast, one brain carcinoma and one liver netastases, primary tumour not known

†Four traffic accidents, three cardiac infarction, two with tuberculosis, one cerebrovascular accident, one diabetic gangrene and one metachromatic leucodystrophy

f Calculated from causes of death tables of the general Dutch population, given birth year of patients. The causes included were: pneumonia (ICD 480-486), cardiac conduction disorders (ICD 426) and cardiac dysthythmias (ICD 427) combined with sudden death, cause unknown (ICD-9 798, data from 1990 extrapolated to 1970 because this category does not exist in ICD-8) and malignancies (ICD 140-239)

\$Probability, to three decimal places, of observed value (or smaller value) given the expected value

Iprimary cause of death: fracture (three), embolic event (three) and postoperative complications (two)

\#Primary cause of death: fracture (two) and postoperative complications (one)

For the purpose of this study we included in this group ventricular arrythmias documented shortly before death (three), embolic events secondary to atrial fibrillation (four), and patients with sudden death at home (13), assuming that sudden death in myotonic dystrophy patients is usually caused by a cardiac rhythm disturbance. Cardiac complications were the secondary cause of death in three patients (4\%) (one postoperative and two with fractures). Overall, cardiac complications as the primary or secondary cause of death were seen in $33 \%$ of patients. Pneumonias and cardiac 
complications were far more frequent primary causes of death than would be expected for this age group (expected 1\% and 2\%, respectively) (Table 3 ). The proportion of all deaths attributed to malignancies was $10 \%$ in the myotonic dystrophy patients. Allowing for age and sex, this frequency was strikingly lower than that found for the general Dutch population (37\%).

The autopsy results confirmed the clinical diagnosis in all patients with pneumonia as the primary or secondary cause of death, as well as in the patients with carcinoma, cardiac infarction, traffic accident and postoperative embolism of the lung. Autopsy in the eight patients from the group with arrhythmia as the primary (six) or secondary (two) cause of death confirmed the cause of death in two patients as being embolism of the intestines and cerebral embolism, respectively. Non-specific myocardial changes were seen in six patients with sudden death, but no coronary artery disease, cerebral haemorrhages or other causes for their sudden death were found.

Detailed information on independence and mobility in the 2 years preceding their death was available for 18 patients (Table 4 ). Half of these where wheelchairbound, either completely ( $22 \%)$ or only outdoors $(28 \%)$. Their mean age at death was 59.7 years (which is similar to the whole group of deceased patients) and mean disease duration was 28 years (range 18-45 years).

Table 4 Mobility in the years preceding death in a subgroup of 18 patients with adult-onset myotonic dystrophy

\begin{tabular}{|c|c|c|c|c|}
\hline Mobility & Grade* & $\begin{array}{l}\text { No. and } \\
(\%) \\
\text { of patients }\end{array}$ & $\begin{array}{l}\text { Mean age } \\
\text { at death } \\
\text { in years } \\
\text { (range) }\end{array}$ & $\begin{array}{l}\text { Mean } \\
\text { disease } \\
\text { duration } \\
\text { in years } \\
\text { (range) }\end{array}$ \\
\hline -No restrictions & 0 & $1(6)$ & 62 & 18 \\
\hline $\begin{array}{l}\text {-Community ambulator } \\
\text { (able to walk }>100 \mathrm{~m} \text { outside } \\
\text { without assistance, wheelchair } \\
\text { needed for long distances) }\end{array}$ & 1 & $8(44)$ & $\begin{array}{l}57.8 \\
(44-70)\end{array}$ & $\begin{array}{l}26 \\
(19-40)\end{array}$ \\
\hline $\begin{array}{l}\text { Household ambulator } \\
\text { (able to walk indoors, } \\
\text { wheelchair needed outdoors) }\end{array}$ & 2 & $5(28)$ & $\begin{array}{l}59.8 \\
(52-66)\end{array}$ & $\begin{array}{l}28.4 \\
(21-37)\end{array}$ \\
\hline $\begin{array}{l}\text {-Completely } \\
\text { wheelchair-bound }\end{array}$ & 3 & $4(22)$ & $\begin{array}{l}63 \\
(59-71)\end{array}$ & $\begin{array}{l}33.2 \\
(26-45)\end{array}$ \\
\hline
\end{tabular}

*Hoffer et al. (1973) 


\section{Discussion}

This is the first longitudinal study on mortality in the adult-onset type of myotonic dystrophy. The major findings are as follows. (i) Survival of patients to the age of 65 years is markedly reduced in comparison with the expected survival for the normal population ( $18 \%$ versus $78 \%$ ). Only half of the patients survived beyond the age of 60 years. (ii) Pneumonia and cardiac arrythmias are the most frequent primary causes of death (31\% and $29 \%$, respectively), and they are also a common secondary cause of death.

Previous studies on age at death in myotonic dystrophy were retrospective and made no distinction between the various disease types. They showed mean ages of death in myotonic dystrophy of 43.5, 44.7, 50.6, and 53 years in Bell (1948), Thomasen (1948), Klein (1958) and Grimm (1975), respectively. We found a mean age at death of 54.3 years. A recent preliminary report of a 10-year follow-up study on mortality showed a mean age at death of 55.4 years for late adult-onset patients and 47.8 years for early adult-onset patients (Mathieu and Potvin, 1996). Survival analysis is more appropriate for estimating the life span of patients than age at death, as it permits inclusion of follow-up information on all patients, dead or alive. Even patients who have been followed for a short time can provide valuable information. For the present population of patients, survival to the age of 45 years was slightly reduced in comparison with the normal population. However, the chance of survival to 65 years was small in comparison with the expected survival in the normal population (18\% and $78 \%$, respectively). We found a median survival of 59-60 years for the adult-type myotonic dystrophy. Reardon et al. (1993) found a median survival of 35 years for the congenital type. Thus, patients with the adult-type of myotonic dystrophy have a considerably better prognosis than those with the congenital type.

The CTG repeat sizes in the 13 patients studied are in accordance with the adult-onset disease type (Harley et al., 1993). A weak positive correlation was found between increased CTG repeat size and younger age at death. Our results suggest that repeat length may have some prognostic significance for premature death, but the limited number of patients prohibits a reliable estimation of its prognostic value.

Most patients $(73 \%)$ died from systemic complications of myotonic dystrophy. Pneumonia was the most frequent primary cause of death (31\%). Other studies also reported pneumonia to be the most common cause of death $-48 \%$ for all disease types and $66 \%$ for congenitally affected children (Reardon et al., 1993; Mathieu and Potvin, 1996). Pneumonia in myotonic dystrophy results from a 
multiplicity of problems: aspiration owing to pharyngeal weakness in combination with delayed gastric emptying, weakness of respiratory muscles and diaphragm and impaired central respiratory drive. With longer duration of the disease the vital capacity decreases and the risk of pneumonia increases (Harper, 1989; Zifko et al., 1996). Several of our patients had recurrent pneumonias in the 5-10 years before their death. Early and intensive treatment, including bronchoscopy and artificial respiration, often proved successful.

In our series, arrhythmia was the second most frequent primary cause of death (29\%). In congenitally affected patients cardiac arrhythmia accounted for $23 \%$ of deaths (Reardon et al., 1993). Cardiac arrhythmias in myotonic dystrophy are due to selective degeneration of the cardiac conducting system (Nguyen et al., 1988). Heart involvement was found to be progressive during the course of the disease (Fragola et al., 1994). However, sudden death is not confined to patients with advanced muscle disease, and serious cardiac anomalies may also be present at an early stage (Harper, 1989). To prevent the consequences of conduction defects, regular electrocardiographic monitoring and adequate treatment is important. Nevertheless, patients with a permanent pacemaker may also die suddenly and unexpectedly, as was the case in four of our patients.

Postoperative complications were the cause of death in $6 \%$ of patients in our series. This is similar to the frequency found in congenitally affected patients (Reardon et al., 1993). Mathieu et al. (1997) found that the risk of postoperative complications was higher with ages $>37$ years, as well as with severe, proximal limb weakness and after upper abdominal surgery. Fractures accounted for $7 \%$ of all deaths. Nearly all patients of these latter two groups ultimately died from pneumonia or cardiac problems after a long series of complications. Thus, a fracture and the postoperative period are vulnerable situations for myotonic dystrophy patients and special care is warranted. The number of patients dying from malignancies $(10 \%)$ is far lower than expected $(37 \%)$. So we found no evidence that myotonic dystrophy is associated with a general tendency to malignancies.

In conclusion, patients with adult-type myotonic dystrophy are particularly susceptible to pneumonia and cardiac arrhythmias when aged $>45$ years. These systemic complications can occur either primarily or as a fatal complication in riskbearing situations. Therefore, it may be wise to refrain from surgical intervention in myotonic dystrophy patients aged $>45$ years, for conditions that are not life threatening. The data for this study were collected between 1950 and 1997 and were analysed retrospectivelly. This approach offered the opportunity to gather long-term follow-up data of patients, but also entailed some disadvantages. First, not all 
currently desirable data, e.g. exact age at onset, were recorded in the past. Therefore we cannot give survival according to disease duration for all patients. Secondly, selective inclusion of patients who died young (in the group with complete data) may give a false impression of age at death. We think that this bias is limited, because patients were ascertained in several independent ways, e.g. by family studies and by regular follow-up. Selective follow-up was also limited: only three patients of the original cohort of 58 patients with adult-type myotonic dystrophy, examined by de Jong (1955), were lost to follow-up. Finally, we may have underor overestimated the frequency of fatal cardiac arrhythmias. Underestimation may arise because patients who die suddenly are usually at home (and not in hospital) and medical documents from hospital are generally more easily obtained than information from the general practitioner. However, this underestimation may be limited as the cause of death was unknown in only $16 \%$ (13 out of 83 ) of patients. The assumption that we made, that all sudden deaths are owing to cardiac arrhythmias, may give an overestimation of this cause of death. However, the autopsies of the eight patients who died suddenly did not uncover any other cause of their sudden death. Overall, we are fairly confident that our data represent a true picture of mortality in adult-onset myotonic dystrophy.

We have only preliminary data on mobility in the years before death. We found that nine out of 18 patients were partially or completely wheelchair-bound shortly before death (Table 4), which is far more than reported by Mathieu (Mathieu et al., 1992). In this latter cross-sectional study wheelchair dependence was found in only $4.4 \%$ of patients, although by the age of 50 years, or more, $14 \%$ of patients were wheelchair-bound. A possible explanation for the observed difference is that in the study of Mathieu et al. (1992) the proportion of patients with a disease duration $>20$ years is relatively small $(21 \%)$. The mean disease duration of the 18 patients we studied was 28 years (range 19-45). We presume that muscle weakness tends to progress to proximal muscles in the last years of patients' lives. Further prospective studies on progression of muscular weakness in the advanced stages of the disease may serve to answer the question of impairment of mobility in the years before death.

\section{Acknowledgements}

We wish to thank Carlo Marcelis for help in data collection, Fren Smulders for statistical support, Tineke Spaans-van der Bijl for genealogical studies and Connie 
Schrander-Stumpel and Henk Kerkhoff for their critical comment. The work was supported by the Dutch Beatrixfonds (Grant number 93.006).

\section{References}

Aldridge LM. Anaesthetic problems in myotonic dystrophy. Br J Anaesth 1985;57:11 19-1130. Bell J. Dystrophia myotonica and allied diseases. In: Fischer RA, ed. Treasury of human inheritance 4, part V. Cambridge University Press, Cambridge, 1948, p.351-357.

de Jong JGY. Dystrophia myotonica, paramyotonia and myotonia congenita. Thesis, University of Utrecht, 1955.

Emery AEH. Population frequencies of inherited neuromuscular diseases - a world survey. Neuromuscul Disord 1991;1:19-29.

Fragola PV, Luzi M, Callò L, Antonini G, Borzi M, Frongillo D et al. Cardiac involvement in myotonic dystrophy. Am J Cardiol 1994;74:1070-1072.

Grimm T. The age of onset and the age at death in dystrophia myotonica. J Genet Hum 1975; 23 (Suppl): 172.

Harley HG, Rundle SA, Reardon W, Myring $J$, Crow $\mathrm{S}$, Brook JD et al. Unstable DNA sequence in myotonic dystrophy. Lancet 1992;39:1125-1128.

Harley HG, Rundle SA, MacMillan JC, Myring J, Brook JD, Crow S, et al. Size of the unstable CTG repeat sequence in relation to phenotype and parental tranmission in myotonic dystrophy, Am J Hum Genet 1993;52:1164-1174.

Harper PS. Myotonic dystrophy, 2nd ed. WB Saunders, London, 1989.

Hoffer MM, Feiwell E, Perry R, Perry J, Bonnett C. Functional ambulation in patients with myelomeningocele. J Bone Joint Surg AM 1973;55A:137-138.

Klein D. La dystrophie myotonique (Steinert) et la myotonie congénitale (Thomsen) en Suisse: étude clinique, génétique et démogtaphique. J Génét Hum 1958; 7 (Supp]): 1-328.

Mathieu J, Potvin L. Mortality in myotonic dystrophy: a cohort study from the Saguenay-LacSaint-Jean region (Quebec, Canada) [abstract]. Neurology 1996; 46 (2 Suppl): A170.

Mathieu J, De Braekeleer M, Prévosi C, Boily C. Myotonic dystrophy: clinical assessment of muscular disability in an isolated population with presumed homogeneous mutation (published erratum appears in Neurology 1992; 42: 689). Neurology 1992:42:203-208.

Mathieu J, Allard P, Gobeil G, Girard M, De Braekeleer M, Begin P. Anesthetic and surgical complications in 219 cases of myotonic dystrophy. Neurology 1997:49:1646-1650.

Nguyen HH, Wolfe JT, Holmes DR Jr, Edwards WD. Pathology of the cardiac conduction system in myotonic dystrophy: a study of 12 cases. I Am Coll Cardiol 1988;11:662-671.

Reardon. W, Nawcombe R, Fenton 1 , Sibert $J_{3}$ Harper PS. The natural history of congenital myotonic dystrophy: mortality and long term clinical aspects. Arch Dis Child 1993;68:177-181. Shelbourne P, Davies J, Buxton J, Anvret M, Blennow E, Bonduelle M et al. Direct diagnosis of myotonic dystrophy with a disease-specific DNA marker. N Engl J Med 1993;328:471-475.

Tas RFJ. Generatie-overlevingstabellen naar geslacht en leeftijd afgeleid uit waarnemingen over de periode 1860-1989. In: maandstatistiek bevolking 91/6. 's Gravenhage: Centraal Bureau voor de Statistiek 1991:15-26.

Thomasen E. Myotonia. Universitetsforlaget, Aarhus, 1948.

Zifko UA, Hahn AF, Remtulla H, George CFP, Wihlidal W, Bolton CF. Central and peripheral respiratory electrophysiological studies in myotonic dystrophy. Brain 1996;1 19:1911-1922. 
Chapter 4

\section{Trinucleotide repeat disorders}

4.1 Introduction

4.2 Instability of trinucleotide repeats

4.3 Parental origin effects

4.4 Somatic mosaicism 


\subsection{Introduction}

The discovery of trinucleotide repeat expansions as the mutational basis for several, mainly neurological, diseases is of tremendous value, not only from a scientific point of view, but also for clinical practice. It has led to insight into several formerly unexplained unusual inheritance patterns, gave access to a variety of novel biological pathways, and has generated possibilities for the understanding of evolution of genomes. Clinical practice has benefited from the molecular progress as presymptomatic and prenatal testing have become a (better) possibility for several of these disorders (Rubinsztein and Hayden, 1998). In 199l the genes for fragile X mental retardation (FRAXA) and spinobulbar muscular atrophy (SBMA, Kennedy disease) were found to contain unstable trinucleotide repeats (La Spada et al., 1991; Oberlé et al., 1991; Verkerk et al., 1991; Yu et al., 1991). In 1992 myotonic dystrophy (DM) was found to be the result of an expanded CTG trinucleotide repeat (Brook et al., 1992; Fu et al., 1992; Harley et al., 1992; Mahadevan et al., 1992). Nowadays more than a dozen neurological diseases can be attributed to trinucleotide repeat expansion. A summary of diseases caused by trinucleotide repeat expansions is given in the table.

Four classes of trinucleotide repeat disorders can be recognised, based on the location and the structure of the expanded repeat within the affected genes (Rubinsztein and Hayden, 1998; Koob et al., 1999):

(1) - repeats located in the untranslated region (UTR) of a gene, either a CGG repeat in the $5^{\prime}$ UTRR, such as in fragile $\mathrm{X}$ syndrome or

(2) - a CTG repeat in the 3 UTR such as in myotonic dystrophy or SCA 8 (spinocerebellar ataxia type 8)

(3) - repeats in coding exonic sequences, CAG repeats such as in Huntington disease or most dominant ataxias

(4) - repeats in intronic sequences, such as the GAA repeat in Friedreich ataxia.

The repeats in non-coding parts of the gene (1), (2) are able to undergo very large expansions to several hundreds or thousands of repeats. In fragille- $\mathrm{X}$ syndrome the expanded repeat is associated with a folate-sensitive fragile site at Xq27.3. The mutational basis is expansion of a $\mathrm{CGG}$ repeat, which coincides with hypermethylation of a $\mathrm{CpG}$ island containing the promotor of the FRMI gene. Protein expression is suppressed when methylation has occurred, in general when the repeat length is expanded above 200 repeats. Severity of the phenotype is correlated with the degree of methylation and not with the length of the CGG expansion (Tapscott et al., 1998). The CTG repeat in DM is localised in the $3^{\prime}$ UTR 
of a gene predicted to encode a serine-threonine kinase (myotonic dystrophy protein kinase or DMPK). The pathophysiology of the expanded repeat in DM has not yet been elucidated (chapter 5). The repeats located in the coding sequences of genes (3) undergo only modest expansions up to a maximum of 90-100 repeats and lead to a gain of function at the protein level. These latter repeats are CAG repeats, coding for glutamine. The expanded CAG repeats lead to very large polyglutamine tracts in the respective proteins and are associated at the histological level with intranuclear inclusions, comprising aggregates of protein filaments and these aggregates are associated in some way with cell death (Paulson, 1999). The $\mathrm{CAG}$ /polyglutamine disorders all follow autosomal dominant inheritance, except for spinobulbar muscular atrophy, which is X-linked. Friedreich ataxia (4)), caused by an expanded GAA repeat in intron 1 of the so called frataxin gene, was the first autosomal recessive disorder with a trinucleotide repeat as the mutational basis. It was also the first disease with an expanded trinucleotide repeat located in an intronic sequence. Furthermore in Friedreich atexia a GAA repeat is involved whereas it was assumed earlier that expanded repeats were confined to CG-rich triplets (Campuzano et al., 1996).

\subsection{Instability of trinucleotide repeats}

In contrast to the classical monogenic diseases, trinucleotide repeat disorders show a number of unusual inheritance features. In monogenic disorders the mutated gene is transmitted unchanged from one generation to the next and affected individuals in subsequent generations show a more or less similar disease phenotype. Furthermore, there is in general no difference between maternal and paternal inheritance of the mutation. In contrast, the mutated trinucleotide repeats are unstable, can show large changes in size in transmission to subsequent generations, and parent-of-origin effects are common (see 4.3). In fragile $\mathrm{X}$ and myotonic dystrophy the intergenerational changes of the repeat are much larger than in the diseases with repeats in coding regions, such as Huntington disease or the dominant ataxias (Tapscott et al., 1998). Expansions are far more frequent than contractions on transmission. This size increase corresponds with an earlier age at onset and/or a more severe phenotype in successive generations (anticipation) (Rubinsztein and Hayden, 1998). Clinical anticipation was described in DM and fragile $X$ before the identification of the corresponding genes. Is has long been unexplained and was summarily dismissed as an ascertainment bias. A change in gene structure as the 
Table Summary of diseases caused by trinucleotide repeat expansions

Disorder Inheritance* Gene Chromosome Protein Repeat location product

\section{Fragile sites}

Fragile XA

XLD

FMR1

$\mathrm{Xq} 27.3$

FMRIP

CGG

Fragile XE

XLD

FMR2

$\mathrm{Xq} 28$

FMR2P

GCC

CTG repeat disorders

Myotonic

$\mathrm{AD}$

dystrophy

$\begin{array}{lll}\text { DMPK } 19 q 13.3 & \begin{array}{l}\text { Myotonic CTG } \\ \text { dystrophy } \\ \text { protein kinase }\end{array}\end{array}$

SCA8

$\mathrm{AD}$

SCA 8

$13 \mathrm{q} 21$

$?$

CTG

CAG/polyglutamine disorders

\begin{tabular}{|c|c|c|c|c|c|}
\hline M. Huntington & $\mathrm{AD}$ & IT15 & $4 p 16.3$ & Huntingtin & $\mathrm{CAG}$ \\
\hline SBMA (Kennedy) & XLR & AR & $X q 13-21$ & $\begin{array}{l}\text { Androgen } \\
\text { receptor }\end{array}$ & $\mathrm{CAG}$ \\
\hline DRPLA & $A D$ & DRPLA & $12 \mathrm{p} 13.3$ & $\begin{array}{l}\text { Atrophin-1 } \\
\text { (Drplap) }\end{array}$ & $\mathrm{CAG}$ \\
\hline SCA 1 & $\mathrm{AD}$ & SCA 1 & $6 \mathrm{p} 23$ & Ataxin-1 & $\mathrm{CAG}$ \\
\hline $\mathrm{SCA} 2$ & $\mathrm{AD}$ & SCA 2 & $12 \mathrm{q} 24.1$ & Ataxin-2 & $\mathrm{CAG}$ \\
\hline $\begin{array}{l}\text { SCA 3/Machado } \\
\text { Joseph disease }\end{array}$ & $\mathrm{AD}$ & $\begin{array}{l}\text { SCA 3/ } \\
\text { MJD }\end{array}$ & $14 q 32.1$ & Ataxin-3 & $\mathrm{CAG}$ \\
\hline
\end{tabular}

SCA 6

$\mathrm{AD}$

CACNA1A 19p13

$\alpha_{1 \mathrm{~A}}$-voltage- CAG dependent calcium channel subunit

$\mathrm{SCA} 7$

$\mathrm{AD}$

SCA 7

3p12-13

Ataxin-7

CAG

Friedreich's araxia

AR

X25

9p13-21.1 Frataxin

GAA

\footnotetext{
*AD: autosomal dominant, AR: autosomal recessive, XLR: $\overline{X \text {-linked recessive, }}$ XLD: X-linked dominant.
} 
Normal Disease range Repeat Mechanism Parental Anticipation range location of disease* sex bias

\begin{tabular}{|c|c|c|c|c|c|}
\hline $6-52$ & $\begin{array}{l}60-2000^{\text {(premutation) }} \\
200-1000^{\text {(fulll) }}\end{array}$ & 5'UTR & LOF & Maternal & Yes \\
\hline $7-35$ & $\begin{array}{l}43-200 \text { (premutation) } \\
200-800^{\text {(full) }}\end{array}$ & 5'UTR & LOF & $\mathrm{ND}$ & Yes \\
\hline $5-40$ & $\begin{array}{l}50-80^{\text {(protomutation) }} \\
80-4000^{\text {(full) }}\end{array}$ & 3'UTR & $\begin{array}{l}\mathrm{P} \\
\mathrm{r} \\
1\end{array}$ & \multicolumn{2}{|c|}{$\begin{array}{l}\text { Paternal small Yes } \\
\text { repeats, maternal } \\
\text { large repeats }\end{array}$} \\
\hline $16-37$ & $107-127$ & Non-coding & & Maternal & Yes \\
\hline $6-39$ & $36-121$ & Coding & GOF & Paternal & Yes \\
\hline $11-33$ & $38-66$ & Coding & $\begin{array}{l}\text { GOF } \\
\text { LOF (partial) }\end{array}$ & Paternal & Yes \\
\hline $3-35$ & $49-88$ & Coding & GOF & Paternal & Yes \\
\hline $6-39$ & $41-81$ & Coding & GOF & Paternal & Yes \\
\hline $14-31$ & $35-64$ & Coding & GOF & Paternal & Yes \\
\hline $12-41$ & $40-84$ & Coding & GOF & $\begin{array}{l}\text { Paternal } \\
\text { and maternal }\end{array}$ & $\begin{array}{l}\text { Yes } \\
1\end{array}$ \\
\hline $4-18$ & $20-30$ & Coding & GOF? & ND & No (?) \\
\hline $4-35$ & $38-130$ & Coding & GOF & Paternal & Yes \\
\hline $6-34$ & $\begin{array}{l}80^{\text {(premutation) }} \\
112-1700^{\text {(fully) }}\end{array}$ & Intron 1 & LOF (partial) & ) Maternal (? & )Yes (?) \\
\hline
\end{tabular}

* LOF: loss of function, GOF: gain of function, ND: not determined 
biological explanation has been suggested only carefully (Pembrey et al., 1985; Höweler, 1989). The finding of the dynamic mutations was the definite explanation for anticipation (Sutherland et al., 1991).

In general there is a good correlation between trinucleotide repeat size and clinical severity. The number of trinucleotide repeats can show a value intermediate between normal alleles and full mutations. These so called premutations (fragile $\mathrm{X}$ ) or protomutations (DM) are not associated with apparent clinical features or associated with only minor anomalies (de Vries et al., 1998; Barceló et al., 1993). Pre- or protomutations also tend to increase when transmitted and exhibit a high probability of expansion into disease related alleles (full mutation). In general there is a strong relationship between size of the pre- or protomutation and the chance of intergenerational expansion of the repeat. In fragile $\mathrm{X}$ normal $\mathrm{CGG}$ repeats contain between 10 and 50 repeats, premutations are between 50 and 200 repeats long and are not associated with clear clinical abnormalities, and full mutations contain more than 200 repeats (de Vries et al., 1998). Females who carry a premutation $<60$ repeats have a probability of $<1 \%$ of having fragile $\mathrm{X}$ affected offspring, whereas in females with a CGG repeat length $>90$ the chance of transition to a full mutation in offspring is almost 100\% (Eichler and Nelson, 1998). In myotonic dystrophy repeats in the range of 50-80 (protomutations) result in no or only mild symptoms. Although stable transmission over several generations is possible, intergenerational increase of a DM protomutation is more frequent than transmission without a change (chapter 5; Barceló et al., 1993). In Huntington disease the occurrence of intermediate alleles, with a repeat size of $27-35$, is rare. Expansion of such intermediate alleles is responsible for de novo expression of Huntington disease in a family (American College of Medical Genetics, 1998).

In contrast to mutated trinucleotide repeats, the repeats on non-disease chromosomes, which are shorter than on the mutated chromosomes, are passed on stable from one generation to the next. Only rarely the normal repeats show changes of usually one repeat. These normal length trinucleotide repeats are polymorphic in the population (Rubinsztein and Hayden, 1998).

\subsection{Parental origin effects}

Pedigree studies on the trinucleotide repeat disorders have shown some remarkable parent of origin effects. Fragile X premutations only show a strong tendency to expansion into a full mutation when transmitted through the female germline (de 
Vries et al., 1998). In CAG expansion disorders the expansion is usually more unstable with paternal transmission. In Huntington disease, for example, the severe juvenile form is mainly paternally transmitted, and furthermore expansion of an intermediate allele into a full mutation has been contributed almost exclusively to male transmissions (Kremer et al., 1995). In myotonic dystrophy there are two striking departures from the sex ratio (chapter 5). Firstly, there is a preponderance of (protomutation carrying) males in the generation before the disorder is clinically recognisable (Brunner et al., 1993). Secondly, the most severe form of DM, the congenital form, is almost exclusively transmitted by an affected mother (Harper, 1989). What appears a paradox at first sight - paternal transmission of the severe juvenile phenotype in Huntington disease versus maternal transmission of severe myotonic dystrophy combined with paternal anticipation in mild cases - resolves itself when looking closer to repeat sizes in the two disorders. The repeat length in juvenile Huntington disease (maximum 100 CAG's) is comparable to that seen in the mildest cases of myotonic dystrophy, and completely different from that of congenitall myotonic dystrophy. Thus both disorders show a greater tendency of the short repeats to expand by transmission through the male germ line (Harper, 1998).

Studies of the expanded repeat in sperm cells of patients have given further insight in the above mentioned parent of origin effects. Males affected with Huntington disease show expansions in sperm that are on average larger than in blood from the same individual, but also exhibit a greater range, thereby creating the possibility of expansion or reduction of repeat size in the next generation, depending on the properties of the particular sperm responsible for fertilisation (MacDonald et al., 1993). In DM the situation is similar for males with short repeats. Their sperm shows an increased average allele size with extensive variation in repeat length, compared to blood (Mockton et al., 1995). However as repeat sizes in DM get longer and further expansions more inevitable, a mechanism of negative selection of sperm with long repeats becomes apparent (Jansen et al., 1994; Monckton et al., 1995). As a result of this selection against sperm carrying very large expansions, the repeat expansion in sperm cells of males with large expansions in their blood, are smaller than in somatic tissues. In fragile X sperm selection is even more extreme, as carrier males only transmit premutation alleles, regardless of their repeat length in somatic tissue. Correspondingly in the sperm cells of fragile $\mathrm{X}$ patients with a full mutation in their blood, only a premutation is present (Reyniers et al., 1993, de Graaff et al., 1995). Apparently germ line selection includes that large expansion persist through oogonial, but not in spermatogonial cells (Reyniers et al., 1993; Tapscott et al., 1998). 


\subsection{Somatic mosaicism}

Instability of trinucleotide repeats is not only observed in the transmission from one generation to the next, but also within and between tissues of an affected individual. In general the spread in repeat expansion and thus the somatic variability increases with the size of the repeat (Waring and Komeluk, 1998). Somatic instability occurs particularly in those diseases with extreme expansions, such as fragile $X$ and myotonic dystrophy. Analysis of blood lymphocytes shows the expanded repeat as a "smear" or diffuse band, rather than a sharply defined band (Harley et al., 1992). These smears are composed of multiple mutant alleles of different length (Monckton et all, 1995). In fragile X, mosaicism in somatic cells involves the presence of both a full mutation and a premutation in $20-40 \%$ of patients (Nolin et al., 1994).

The size of the trinucleotide repeat also varies from tissue to tissue, as has been shown in DM and in fragile X by comparing repeat sizes in blood, muscle biopsies, sperm (chapter 4.3) and in autopsy studies (Anvret et al., 1993; Jansen et al., 1994; de Graaf et al., 1995). For instance the CTG expansion in myotonic dystrophy patients is greater in muscle than in blood (Anvret et al., 1993). One may wonder which tissue is best suited to predict severity of the disease. At least for DM, expansion status in muscle appears to have little prognostic value (Waring and Korneluk, 1998). The expanded repeat in Huntington disease shows no somatic instability in a comparison of blood, lymphoblasts and brain (MacDonald et al., 1993).

Also of relevance in relation to somatic instability is the question of the moment of repeat instability and the change over time. As referred above the trinucleotide repeat disorders apparently exhibit a meiotic short expansion mutational mechanism. Evidence suggest that the long expansions are postmeiotic events (Wöhrle et al., 1993; Nelson and Warren, 1993; Monckton et al., 1995). It is likely that in fragile $\mathrm{X}$ and DM, the expanded repeat may undergo continued mitotic expansion, which may result in very large repeats (Jansen et al., 1994). Analysis of blood samples of DM patients taken at intervals of several years showed increased spread of the repeat size in later samples (Martorell et al., 1998). These data suggest an increase of the degree of somatic mosaicism with time. The clinical relevance of somatic heterogeneity is unclear, it is still under debate if the irregular mitotic behaviour of the repeats provides an explanation for the clinical variations in some of these disorders, and also the significance for the pathogenesis of the diseases is yet unclear. 


\section{References}

American College of Medical Genetics/American Society of Human Genetics/Huntington Disease Genetic testing Working Group. Laboratory guidelines for Huntington disease genetic testing. ACMG/ASHG statement. Am J Hum Genet 1998;62:1243-1247.

Anvret M, Ahlberg G, Grandell U, Hedberg B, Johnson K, Edstrom L. Larger expansions of the CTG repeat in muscle compared to lymphocytes from patients with myotonic dystrophy. Hum Mol Genet 1993:2:1397-1400.

Barceló JM, Mahadevan MS, Tsilfidis C, ManKenzie AE, Korneluk RG. Intergenerational stability of the myotonic dystrophy protomutation. Hum Mol Genet 1993;2:705-709.

Brook JD, Mc Currach ME, Harley HG, Buckler AJ, Church D, Aburatani H, Hunter KI, Stanton VP, Thirion J-P, Hudson T, Sohn R, Zemelman B, Snell RG, Rundle SA, Crow S, Davies J, Shelbourne $\mathrm{P}$, Buxton $\rrbracket$, Jones $\mathrm{C}$, Juvonen $\mathrm{V}$, Johnson $\mathrm{K}$, Harper PS, Shaw DI, Housman DE. Molecular basis of myotonic dystrophy: expansion of a trinucleotide (CTG) repeat at the 3'end of a transcript encoding a protein kinase family member. Cell 1992;68:799-808.

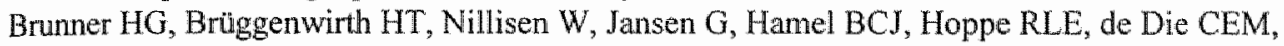
Howeler CJ, van Oost BA, Wieringa B, Ropers HH, Smeets HJM. Influence of sex of the transmitting parent as well as of parental allele size on the CTG expansion in myotonic dystrophy. Am J Hum Genet 1993;53:1016-1023.

Campuzano V, Montermini L, Moltó MD, Pianese L, Cossée M, Cavalcanti F, Monros E, Rodius F, Duclos F, Monticelli A, Zara F, Canizares J, Koutnikova H, Bidichandani S, Gellera C, Brice A, Trouillas P, De Michele G, Filla A, de Frutos R, Palau F, Patel PI, Di Donato S, Mandel JL, Cocozza $S$, Koenig M, Pandolfo M. Friedreich ataxia: antosomal recessive disease caused by an intronic GAA triplet repeat expansion. Science 1996;271:1423-1427.

Eichler EE and Nelson DL. The FRAXA fragile site and fragile X syndrome. In: Rubinsztein DC, Hayden MR. Analysis of triplet repeat disorders. Bios scientific publishers, Oxford, 1998.

Fu Y-H, Pizzuti A, Fenwick Jr RG, King J, Rajnarayan S, Dumne PW, Dubel J, Nasser GA, Ashizawa T, de Jong P, Wieringa B, Korneluk R, Perryman MB, Epstein HF, Caskey CT. An unstable triplet repeat in a gene related to myotonic muscular dystrophy. Science 1992;255:12561258.

Graf de E, Willemsen R, Zhong N, de Die-Smulders CEM, Brown WT, Freling G, Oostra B. Instability of the CGG repeat and expression of the FMR 1 protein in a male fragile $X$ patient with a lung tumor. Am J Hurm Genet 1995;57:609-618.

Harley HG, Rundle SA, Reardon W, Myring J, Crow S, Brook JD, Harper PS, Shaw DJ. Unstable DNA secuence in myatonic dystrophy. Lancet 1992;339:1125-1128.

Harper PS. Myotonic dystrophy, 2nd edn. WB Saunders, London and Philadelphia, 1989.

Harper PS. Myotonic dystrophy as a trinucleotide repeat disorder-a clinical perspective. In: Wells RD, Warren ST (eds). Genetic instabilities and hereditary neurological disorders. Academic Press, San Diego, 1998.

Höweler CJ, Busch HFM, Geraedts JPM, Niermeijer MF, Staal A. Anticipation in myotonic dystrophy: fact or fiction? Brain 1989;112:779-797.

Jansen $G$, Willems P, Coerwinkel M, Nillesen W, Smeets $H$, Vits L., Höweler C, Brunner $H$, Wieringa B. Gonosomal mosaicism in myotonic dystrophy patients: involvement of mitotic events in $(\mathrm{CTG})_{\mathrm{n}}$ repeat variation and selection against extreme expansion in sperm. Am J Hum Genet 1994;54:575-585.

Koob MD, Moseley ML, Schut LJ, Benzow KA, Bird TD, Day JW, Ranum LPW. An untranslated CTG expansion causes a novel form of spinocerebellar ataxia (SCA8). 
Nature Genet $1999: 21: 379 \cdot 384$

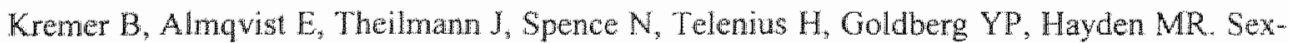
dependent mechanisms for expansions and contractions of the CAG repeat on affected Huntington disease chromosomes. Am J Hum Genet 1995;57:343-350.

La Spada $A R$, Wilson EM, Lubahn DB, Harding AE, Fischbeck KH. Androgen receptor gene mutations in X-linked spinal and bulbar musculat atrophy. Nature 1991;352.77-79.

MacDonald ME, Bames $\mathrm{G}$, srinidhi $\mathrm{J}$, Duya MP, Ambrose CM, Myers $\mathrm{RH}$, Gray J, Conneally PM, Young A, Penney J, Shoulson I, Hollingworth Z, Koroshetz W, Bird E, Vonsattell IP, Bonilla $\mathbb{E}_{\text {, Moscowiz }} \mathrm{C}$, Penchaszadeh $\mathrm{G}$, Brzustowitz L, Alvir J, Bickham Conde $J$, Cha $I_{\text {, }}$ Dure L, Gomez F, Ramos-Arroyo M, Sanchez-Ramoz J, Snodgrass SR, Young de M, Wexler NS, MacFarlane H, Anderson MA, Jenkins B, Gusella JF. Gametic but not somatic instability of CAG repeat length in Huntington disease. I Med Genet 1993;30:982-986.

Mahadevan M, Tsilfidis C, Sabourin L, Shutler G, Amemiya $C$, Jansen $G$, Neville $C$, Narang M. Barceló J, O'Hoy $\mathrm{K}$, Leblond $\mathrm{S}$, Earle-MacDonald J, De Jong PJ, Wieringa $\mathrm{B}$, Korneluk RG. Myotonic dystrophy mutation: an unstable CTG repeat in the 3 ' untranslated region of the gene. Science $1992 ; 255: 1253-1255$.

Martorell L, Monckton DG, Gamez J, Johnson KJ, Gich I, Lopez de Munain A, Baiget M. Progression of somatic CTG repeat length heterogeneity in the blood cells of myotonic dystrophy patients. Hum Mol Genet 1998; 7:307-312.

Monckton DG, Wong L-JC, Ashizawa T, Caskey CT. Somatic mosaicism, gemline expansions, germline reversions and intergeneretional reductions in myotonic dystrophy males: small pool PCR analyses. Hum Mol Genet 1995;4:1-8.

Nelson DL, Warren ST. Trimcleoticle repeat instability: when and where? Nature Genet $1993,4: 107-108$

Nolin SL, Glicksman A, Houck G JR, Brown WT, Dobkin CS. Mosaicism in fragile X affected males. Am J Med Genet 1994;51:509-512.

Oberlé I, Rousseau F, Heitz D, Kretz C, Devys D, Hanauer A, Boue J, Bertheas MF, Mandel JL. Instability of a 550-base pair DNA segment and abnormal methylation in fragile $X$ syndrome.

Science 1991;252:1097-1102

Paulson HL. Human genetics '99: trinucleotide repeats. Protein fate in neurodegenerative

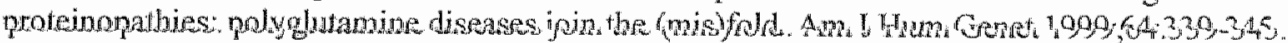
Pembrey $M$. Winter $R$, Davies $K$. A premutation that generates a defect at crossing over explains the inheritance of fragile $X$ mental retardation. Am J Med Genet 1985;21:709.

Reyniers E, Vits L, De Boulle K, Van Roy B, Van Velzen D, de Graaff E, Verkerk AJMH, Jorens HZJ, Darby JK, Oostra B, Willems PJ. The full mutation in the FMR-1 gene of male fragile X patients is absent in their spem. Nature Genet 1993;4:143-146.

Rubinsztein DC, Hayden MR. Analysis of triplet repeat disorders. Bios scientific publishers, Oxford, 1998.

Sutherland GR, Haan EA, Kremer E, Lynch M, Pritchard M, Yu S, Richards Rl. Hereditary unstable DNA: a new explanation for some old genetic questions. Lancet 1991;338:289-291.

Tapscott SJ, Klesert TR, Widrow RJ, Stöger R, Laird CD. Fragile-X syndrome and myotonic dystrophy: parallels and paradoxes. Current Opinions in Genetics and Development 1998;8:245253.

Verkerk AJ, Pieretti M, Sutcliffe JS, Fu YH, Kuhl DPA, Pizutti A, Reiner O, Richards S, Victoria $\mathrm{MF}$, Zhang $\mathrm{F}$, Eussen BE, van Ommen GJB, Blomden LAJ, Riggins GJ, Chastain $\mathbb{I L}$, Kunst $\mathrm{CB}$, Galjaard H, Caskey CT, Nelson DL, Oostra BA, Waren ST. Identification of a gene (FMR-I) containing a $C G G$ repeat coincident with a breakpoint cluster region exhibiting length variation in fragile X syndrome. Cell 1991;65:905-914. 
Vrues de BBA, Halley DJJ, Oostra BA, Niermeijer MF. The fragile X syndrome. II Med Genet 1998:35:579-589.

Waring JD, Komeluk RG. Genetic studies of the myotonic dystrophy CTG repeat. In: Wells RD, Warren ST (eds). Genetic instabilities and hereditary neurological disorders. Academic Press, San Diego, 1998.

Wöhrle D, Hennig I, Vogel W, Steinbach P. Mitotic stability of fragile X mutations in differentiated cells indicates early post-conceptional trimucleotide repeat expansion. Nat Genet $1993 ; 4: 140-142$.

Yu S, Pritchard M, Kremer E, Lynch M, Nancarrow J, Baker E, Holman K. Mulley JC, Warten ST, Schlessinger D, Sutherland GR, Richards RI. Fragile X genotype characterized by an unstable region of DNA. Science 1991;252:1179-1181. 

Chapter 5

\section{Genetic aspects of myotonic dystrophy}

5.1 Introduction

5.2 Anticipation in myotonic dystrophy

5.3 Clinical-molecular correlation's

5.4 Intergenerational repeat instability and parent of origin effects

5.5 Hypotheses for the molecular basis of myotonic dystrophy

5.6 Genetic counselling, prenatal diagnosis and preimplantation genetic diagnosis

5.7 Other mutations, other genes or other diseases 


\subsection{Introduction}

Myotonic dystrophy (DM) results from expansion of a CTG repeat in the $3^{\prime}$ untranslated region (UTR) of the DM protein kinase gene (DMPK) (Aslanides et al., 1992; Buxton et al., 1992; Harley et al., 1992a; Harley et al., 1992b). Over 99\% of DM cases show the same molecular basis. Also, the expanded repeat is specific to myotonic dystrophy and has not been seen in normal individuals or in other disorders (Groenen and Wieringa, 1998). The repeat is transmitted unstable through generations. The intergenerational transmission of the CTG repeat is marked by length increase, which explains several previously unresolved clinical observations, such as anticipation. However, the role of the repeat in the pathogenesis of the disease process is still an enigma. Many mechanisms for the causes and consequences of repeat expansion have been proposed, but none of them has enjoyed prolonged support (Groenen and Wieringa, 1998).

\subsection{Anticipation in myotonic dystrophy}

Anticipation is the term given to the apparent occurrence of a genetic disorder with progressively earlier age at onset in successive generations (Harper et al., 1992). This earlier age at onset is usually accompanied by a more severe course of the disease. Historically the description of anticipation in DM dates back to the beginning of the 20th century, when Fleischer (1918) described the progressive severity of symptoms in subsequent generations in DM families. Bell (1947) confirmed that the occurrence of cataract is often found in one or two generations prior to the clinical manifestations of DM. Penrose (1948) dismissed the concept of anticipation and stated that the observations of Bell and others were due to ascertainment bias and this view was generally accepted. Anticipation remained a neglected phenomenon until the end of the eighties, when Höweler $(1986,1989)$ showed convincingly that anticipation in DM was reality and not an artefact. Finally, the finding of unstable DNA was found to be the molecular basis to be responsible for anticipation (Harper et al., 1992).

\subsection{Clinical-molecular correlation's.}


The CTG repeat in the DMPK gene is highly polymorphic within the normal population, ranging in size from 5 to 37 triplets. Over $45 \%$ of normal alleles in the European population contain 5 repeats, $50 \%$ contain between 11 and 14 repeats, and the remaining $5 \%$ of individuals have between 19 and 37 repeats. It is estimated that over $75 \%$ of the population is heterozygous for different sized alleles (Brook et al., 1992; Davies et al., 1992; Groenen and Wieringa, 1998). These normal alleles are transmitted stable to subsequent generations. The threshold length for repeat instability is estimated to be around 35 to 40 CTG's (Wieringa, 1994). CTG repeats in the 35-50 range are believed to be a "premutation" state of the gene, infrequently these alleles are passed on unstable to the next generation.

In DM affected individuals the number of repeats ranges from 50 to several thousands. In general the size of the expanded repeat shows a broad inverse correlation with the age at onset of disease. Repeats in the range of 50-80 result in no of minimal disease, generally cataracts at an advanced age (Barceló et al., 1993). Repeat lengths in patients with the adult onset (classical) type may range from 100150 to approximately $1000 \mathrm{CTG}$ repeats, with the majority being around 500 repeats (Harley et al., 1993, Lavedan et al., 1993a). Congenitally affected cases have on average the largest repeat sizes, mostly in the 1500-2000 CTG range, but they may greatly exceed this limit and be as long as 5000 repeats (Lavedan et al., 1993b). However, also some congenital cases with alleles in the 500-1000 range have been reported (Tsilfidis et al., 1992; Harley et al., 1993; Redman et al., 1993). Relatively few data are available on repeat size in the childhood type. They are expected to be intermediate between adult-onset and congenital type, but preliminary data showed that they show great overlap with the congenital type (Harley et al., 1993; Redman et al., 1993; Passos-Bueno et al., 1995). In conclusion, the overall differences between the disease types are obvious, but there is large overlap in repeat length between the different clinical types and a wide range of expansion within each clinical type. Therefore CTG repeat length measurement, at least in blood, cannot be reliably used as a prognostic criterion and caution is given to use this information for prognosis of an individual case (Harper, 1996).

\subsection{Intergenerational repeat instability and parent of origin effects}

As expected for autosomal dominant inheritance the overall parental sex ratio in DM is $50 \%$ (Harper, 1989). However, some remarkable sex-specific influences can be 
observed in the transmission pattern. In the past few years these sex dependent effects on transmission have been explained, at least partly, at the molecular level.

Firstly, there is a male bias in the generation of new alleles causing DM. It has been noted for some time that the transmitting grandparent of affected DM patients is more often male (Bell, 1947). Brunner et al. (1993a) confirmed that the onset of clinical expression in DM is preferentially associated with paternal transmission and that for DM mutation carriers with less than 80-100 CTG repeats a large increase in CTG number is much more likely with male than with female transmission. Barceló et al. (1993) extended the study on the transmission of small mutations. She designated these small mutations in the 50-80 CTG repeat range, as "protomutations" (Barceló et al., 1993). Protomutations of 50-70 repeats were transmitted stable in approximately $25 \%$ of cases, whereas repeats of $70-80$ CTG's were stable on transmission in only $5 \%$ of cases and larger alleles were inevitable unstable (Barceló et al., 1993). The stable transmission of a protomutation was strongly associated with female transmission, while for patemally derived alleles a positive correlation between protomutation length and the degree of amplification in the next generation was observed.

However, as the parental repeat size increases ( $>$ 80-100 CTG's), intergenerational amplification becomes greater for maternal than for paternal transmissions. In several studies a gradual decrease of intergenerational repeat expansion with increasing paternal repeat length was demonstrated while the average expansion in offspring increases with maternal repeat length (Cobo et al., 1993; Lavedan et al., 1993b; Redman et al., 1993; Ashizawa et al., 1994a). Moreover, repeat contractions begin to appear in paternal transmission from long alleles. In a large multicenter study it was shown that these repeat contractions occur in $6-7 \%$ of parent-child transmissions and it was confirmed that they preferentially occur in paternal transmission (Ashizawa et al., 1994b). In a few cases, all resulting from paternal transmission, reverse mutation with correction of the CTG repeat into the normal range was demonstrated (Shelbourne et al., 1992; Brunner et al., 1993b; Hunter et al., 1993; O'Hoy et al., 1993). The apparently limited ability of males to expand has been explored further by studying repeat length in sperm (Jansen et al., 1994; Monckton et al., 1995). Males with small repeats showed on average larger repeats in their sperm (Monckton et al., 1995). However males with large allele expansions in blood cells, and consequently adult-onset DM, had similar or smaller repeats in their sperm with a maximum observed size in sperm of $1000 \mathrm{CTG}$ repeats (Jansen et al., 1994). Also sperm alleles $>1000 \mathrm{CTG}$ 's were not seen by small pool 
PCR (Monckton et al., 1995). Thus apparently there is selection during spermatogenesis against sperm carrying very large expansions.

Even more striking is the observation that almost all congenitally affected cases originate from an affected mother (Dyken and Harper, 1973; Pearse and Höweler, 1979). Only recently a few cases of paternal transmission of DM have been reported (Bergoffen et al., 1994; Ohya et al., 1994; Nakagawa et al., 1994; Laforet et al., 1995). The explanation for the almost exclusive transmission of congenital DM is still not fully clear. The congenital type is associated with very large expansions. These large expansion are usually derived from mothers with repeat lengths $\geq 300 \mathrm{CTG}$ 's, showing adult-onset disease type (Cobo et al., 1995). This is in accordance with the fact that at higher CTG-lengths the degree of expansion is clearly greater for maternally than for patemally transmitted mutations (Lavedan et al., 1993b; Wieringa, 1994). Furthermore, long paternal CTG repeats are prone to contraction rather than to expansion, while maternal transmissions do not show such an upper limit to expansion. So, apparently paternal transmission does not result in the large expansions necessary for congenital DM (Mulley et al., 1993). The fact that malles with the adult type DM have, on average, less children than women with the same disease type also contributes to the lower frequency of paternal transmission of congenital DM (Höweler, 1989).

In summary: at the minimal end of the severity range male-transmitted expansion and anticipation is predominant, but the final stages of anticipation are a consequence of predominant female-transmitted expansions (Harper, 1996).

\subsection{Hypotheses for the molecular basis of myotonic dystrophy}

Disease causing mechanism in DM is complex and is nowadays far from clear. On the basis of the dominant transmission of DM, one could expect the mutation to affect protein structure, but it is difficult to see how a CTG expansion outside the gene's open reading frame could affect the structure of the protein. Current evidence suggests that the CTG repeat affects cellular functions at the DNA, RNA and protein level.

\subsubsection{Genes from the DM area}

By far the best candidate gene for DM is the DMPK (myotonic dystrophy protein kinase) gene, also called MtPK (myotoninPK). It belongs to the protein kinase family and encodes a putative serine-threonine kinase (Brook et al., 1992; Fu et al., 
1992; Mahadevan et al., 1992). It is located on human chromosome 19q13.3, has a size of $13 \mathrm{~kb}$ and contains 15 exons (Figure). Several different isoforms exist due to alternative RNA splicing (Jansen et al., 1992). Such isoforms could result in the presence of different protein isoforms in the various DM affected tissues and may be important in relation to the multisystem nature of the disorder (Fu et al., 1993). The expanded CTG repeat is located in the $3^{\prime}$ untranslated region of DMPK (exon 15). Highest levels of DMPK expression are found in cardiac and skeletal muscle and in organs containing smooth muscle linings, but the gene is also expressed in particular central nervous system regions and in the retina. This distribution of expression corresponds with the tissues that are most prominently involved in DM. DMPK has a putative role in signal cascades and/or ion homeostasis in striated, smooth and cardiac muscle (Jansen et al., 1994; Groenen and Wieringa, 1998).

The CTG repeat expansion is located in a very gene-rich region and it is conceivable that repeat expansion also leads to the change in expression of other, neighbouring genes.

The DMAHP (DM associated homeodomain protein) gene or SIX5 gene is located immediately $3^{\prime}$ (downstream) to the DMPK gene, with its promotor $<1 \mathrm{~kb}$ downstream of the CTG repeat (Figure). The gene belongs to the SIX gene family, which were initially identified on the basis of their homology to Drosophila melanogaster sine oculis. It contains 3 exons, of which the first encodes the homeobox segments and the middle exon can be alternatively spliced. DMAHP encodes a putative transcription factor and is expressed in skeletal muscle, eye, heart, liver, brain, fibroblasts, lymphocytes and at several fetal locations (Groenen and Wieringa, 1998; Korade-Mirnics et al.,1999; Winchester et al., 1999). Thus the expression patterns of DMPK and DMAHP overlap significantly. It has been suggested that the expression of DMAHP is tissue dependent (Korade-Mirnics et al.,1999).

The DMWD gene, formerly called the 59 gene, identified in the mouse as $D M R-N 9$, lies immediately $5^{\prime}$ (upstream) to the DMPK gene (Figure). The gene contains 5 exons and codes for a putative protein of 650 amino acids, which is strongly conserved among species. Part of the gene is possibly engaged in signal transduction or cell regulatory functions. There have been reports indicating that the 3 'end of its mRNAs can extend beyond its region, and it has been suggested that the two transcriptional units of DMWD and DMPK could become "contiguous", thereby creating the possibility that DMWD transcription could open up the DMPK transcriptional unit (Mahadevan et al., 1993; Shaw et al., 1993a). The gene normally 
in

㟧

嘼

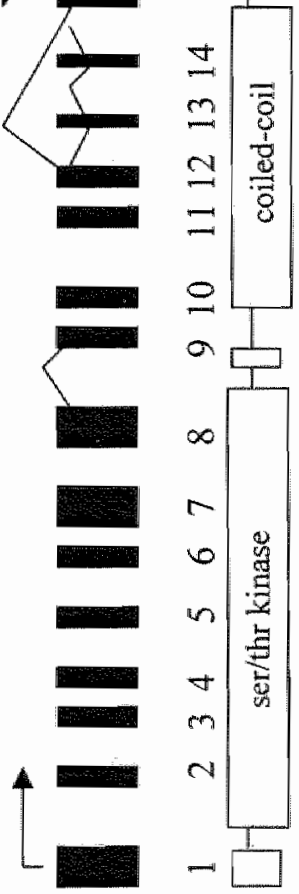

*

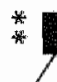

的气

욜

ชั

논

$\stackrel{5}{5}$

s 는

60

ษัญ

을

ปี

so

ช

$\Phi \div$

की

ชั้

ㄴำ

.

ร

혹ำ

ช

ปรี้

8

ง.

$\exists \pm$

ชั้

\& 5

ริ) 3

$5 \bar{y}$

จริ

ป 5

- है 5

. 5 ป

(4) 00

5 เै

논

s

1 5

อิ

5

540

ป

을

马ํํㄴ

ㅎํㄴ

เू

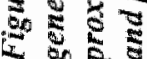


shows strongest expression in brain, liver, and testis, and there is a low level of expression in several other tissues (Groenen and Wieringa, 1998).

\subsubsection{Expression of DMPK and neighbouring genes}

Several lines of evidence indicate that expression of the DMPK gene is altered in DM. Initial studies on DMPK levels in DM patients were equivocal. Decreased DMPK mRNA levels were shown in adult DM patients and also in congenitally affected patients (Fu et al., 1993; Hofmann-Radvanyi et al., 1993; Timchenko et al., 1995). In contrast, Sabourin et al. (1993) found that total DM transcript levels in patients were increased over controls, at moderately elevated levels in muscle tissue, and even up to 14-fold in brain, although appropriate age-matched controls were not available. It may be significant to note that the various groups used different methodology for RNA-analysis. Further studies compared the amounts of total mRNA, precursor (unspliced, localised nuclear) mRNA and mature (spliced, localised cytoplasmatically) mRNA of DMPK. Wang et al. (1995) found a reduction to approximately $50 \%$ of control levels for total RNA in patients" muscle, and an even more pronounced loss (10-20\% of normal) of transcripts of mature mRNA. The level of mature mRNA from the expanded allele was very low, but also the mature mRNA processed from the normal allele was reduced. According to their findings the expanded $\mathrm{CTG}$ repeat inhibits the processing of $\mathrm{mRNA}$, in cis as well as in trans manner, thereby explaining the dominant nature of the mutation. Krahe et al. (1995) studied levels of unspliced and spliced mRNA and found that similar levels of unspliced DMPK mRNA are being produced from wild type and disease alleles in skeletal muscle and cell lines of patients. However, a reduction of $50 \%$ of mature mutant transcripts in comparison with transcripts from the normal allele was observed, and this reduction was correlated with the expansion size. Hamshere et al. (1997) confirmed the presence of reduced levels of cytoplasmatic DMPK transcripts in fibroblasts from DM patients, and moreover showed that the transcripts of the DM expansion allele were retained at an increased level in the nucleus. Contrary to the results of Wang et al. (1995), they found no evidence for a change in the level of expression of the normal allele. However, the observations of Hamshere et al. (1997) were made on fibroblasts, whilst Wang et al. (1995) used muscle tissue from patients.

Analysis of DMPK knockout mice showed that heterozygous mice did not show an abnormal phenotype and even complete deletion of the gene causes only a mild, late onset myopathy, but none of the other hallmarks of the disease such as 
myotonia or cataracts (Jansen et al., 1996; Reddy et al., 1996). Thus, loss of DMPK activity is not sufficient to cause the complete DM phenotype in mice.

Decreased DMAHP expression, resulting in decreased levels of mRNA, has been reported in fibroblast cell lines from DM patients (Klesert et al., 1997) Allele specific RT-PCR studies on myoblast cultures showed that the reduced level of DMAHP was due to decreased expression of the allele in cis with the CTG expansion, and proportional to the size of the expanded repeat (Thomton et al., 1997). In contrast to these results, Hamshere et al. (1997) found no reduced cytoplasmatic levels of DMAHP in fibroblast cell lines. These latter data were reanalysed by Alwazzan et al. (1999), who compared the nuclear and cytoplasmatic fractions from the normal and the DM allele, using RT-PCR. The findings of this latter study were broadly similar to those of Klesert et al. (1997) and Thornton et al. (1997), with a 20-50\% reduction in the RNA level from the DMAHP allele, both in the nuclear and in the cytoplasmatic fraction.

Alwazzan et al. (1999) also showed reduced levels of cytoplasmatic RNA from the expanded allele of the DMWD gene, compared with the level of the wildtype allele. No such reduction was found in the nuclear fraction of these DM cell lines. There was no obvious correlation between repeat length and level of DMWD reduction, in contrast with the results of Eriksson et al. (1999), who showed that DMWD expression is inversely correlated with CTG repeat expansion in skeletal muscle.

\subsubsection{Effects at the RNA level}

A disruption of RNA processing might play a role in the pathogenesis of DM. Firstly, expression studies of the different DM candidate genes have shown reduced levels of RNA, with differences between the nuclear and cytoplasmatic fractions (see 5.5.2)

A second indication for DM being an RNA-processing disease came from the study of Taneja et al. (1995). They found that transcripts of the DM allele of the DMPK gene accumulated at foci within the nucleus in DM cell lines and in biopsied tissues (muscle) from patients (Taneja et al., 1995). Normally, the mature, spliced and polyadenylated, mRNA is transported through nuclear pores to the cytoplasm, where it is translated. The mRNAs with expanded CUG repeats were found to accumulate in the nucleus after polyadenylation and splicing are completed. This process of foci formation was more extensive with longer CTG repeats. It was proposed that this accumulation of DMPK mRNAs with expanded CUG segments may lead to nuclear clogging and disrupt other nuclear functions, such as the 
processing of other mRNAs (Groenen and Wieringa, 1998). The reduced levels of DMPK transcripts found in previous studies can now be explained, to some extent, by this mechanism of retention of RNA in the nucleus, which may lead to an increase of transcripts in the nucleus and a reduction of transcripts in the cytoplasm. A possible explanation for the different results of those studies is that with the different methods of purifying RNA, varying amounts of DMPK RNA were extracted from the different cell compartments (Fu et al., 1993; Hofmann-Radvanyi et al., 1993; Sabourin et al., 1993; Krahe et al., 1995; Timchenko et al., 1995; Wang et al., 1995).

A third explanation for the effects at the RNA level was provided by Timchenko et al. (1999). They proposed that the DMPK mRNA might affect the processing of other mRNAs through intervention of so-called RNA binding proteins. Indeed, they identified several proteins that specifically recognise and bind to the CUG repeat in (DMPK) mRNA. One of these proteins, CUGBP1 (CUG binding protein 1), is normally cytosolic, but was found to be sequestered into the nuclei of DMPK cells with large repeats. The relationship between DMPK and CUGBP1 is complex. It is still debated whether the nuclear accumulation of DMPK mRNAs is the cause or the consequence of CUGBP1 related anomalies. The original model of Timchenko et al. (1996) held that expanded CUG repeats in the mutated mRNA bind excessively to CUGBP1, thereby preventing the normal binding of CUGBP1 to other mRNAs. An alternarive hypothesis is that the increase in CUG repeat length leads to induction of excessive CUGBP1 formation. These CUGBPS may cause altered splicing of other genes containing a few CUG repeats near an exon, such as abnormal splicing of cardiac troponine $T$ (Timchenko et al., 1999). As a significant amount of CUGBPI was also found in cytoplasm, it has been suggested that this protein may also play a role in translation of the other CUG containing genes. According to this model altered processing of different (CUG containing) mRNAs and/or tissue specific responses to CUG repeat expansions may contribute to the tissue-specific features of DM.

\subsubsection{Alteration of chromatin structure}

The mechanism by which the repeat expansion might suppress the expression of DMPK and other genes is not known. Based on theoretical grounds the expanded $\mathrm{CTG}$ repeat may have a direct effect on its immediate surrounding and may compromise protein binding and transcriptional activity.

It has been demonstrated in vivo that a large triplet repeat expansion creates a condensed chromatin structure that obscures a DNAse hypersensitive site, located 
between the DMPK and DMAHP genes (Otten and Tapscott, 1995). This hypersensitive site normally functions as an enhancer for transcriptional activity. It was shown indeed that the elimination of this hypersensitive site leads to reduced DMAHP expression (Klesert et al., 1997).

In analogy with the fragile $X$ syndrome (chapter 4.1 ), it was suggested that altered methylation may play a role in the expression of DM. Initial DNA methylation studies, undertaken to give a possible explanation for the differences between patemal and maternally transmitted alleles and the exclusive maternal origin of congenital DM, gave no evidence for effects of this type (Jansen et al., 1993; Shaw et al. 1993b). These results seem to be in contrast to a recent study (Steinbach et al., 1998). They studied the methylation pattern of the disease allele in patients with different disease severity. Hypermethylation of a gene segment upstream (5") of the CTG repeat was found in young severely affected, mostly congenital onset patients with repeat lengths between 3 and $5.5 \mathrm{~kb}$, whereas less severely affected patients with later onset and shorter repeat lengths (0.6-4.2 kb) showed no specific methylation of the disease allele. Hypermethylation was only found in patients with a maternally transmitted expanded allele, which may be explained by the exclusive maternal origin of these congenitally affected DM. Theories on the origin of this hypermethylation are speculative. As noted before, repeat expansion may convert the region surrounding the repeat to a more condensed chromatin structure, thereby leading to a reduced accessibility of transcription factors. This disturbed protein-DNA interaction may lead to hypermethylation of $\mathrm{CpG}$ islands.

\subsection{Genetic counselling, prenatal diagnosis and preimplantation genetic diagnosis}

Prior to the identification and characterisation of the DM mutation, linkage analysis was the only possible approach to the molecular diagnosis of DM. The current feasibility of a highly specific and sensitive DNA-test for DM has changed previous approaches to prediction and genetic counselling. From a laboratory point of view a combination of PCR (polymerase chain reaction) analysis and Southern blotting can detect virtually all DM mutations (Pizzuti et al., 1993; Shelbourne et al., 1993). Small repeats are best examined by PCR analysis, whilst the large expansions are best analysed by Southern blotting as PCR techniques may sometimes fail to amplify such large repeats (Mahadevan et al., 1992). If DM is suspected on clinical 
grounds, the diagnosis can now reliably be confirmed or excluded by molecular analysis.

The situation for asymptomatic at risk individuals was formerly often complicated: even in the absence of any clinical signs or symptoms of DM, the remaining risk of being a gene carrier was around $8 \%$, which posed much uncertainty upon these individuals (Brunner et al., 1991a). Now a normal molecular result allows a high degree of reassurance both in terms of developing DM in the future as of transmitting the disorder. However, the uncertainty has now shifted to the prognosis for those who are clinically normal but shown to have an expanded repeat. Since there is only a broad correlation between repeat length and phenotypic expression, prognosis needs to be very cautious (Harper, 1996). Therefore in all cases of presymptomatic (DNA) testing extensive pre-test counselling is warranted. A further recommendation is to refrain from genetic analysis in young healthy children at risk, in order to give them the opportunity to make their own decisions in the future as an autonomous adult (Clarke, 1997).

For genetic counselling of patients the sex-related effects on transmission of the repeat have to be taken into account. Fathers with a small repeat expansion $(<80$ repeats), have a greater chance of significant expansion (up to 1000-1500 repeats) in their offspring than mothers with a small repeat (Barceló et al., 1993; Ashizawa et al., 1994a; Wieringa, 1994). Fathers with longer repeats show a strong tendency to reduced amplification or even contraction of the repeat on transmission (repeat length in their offspring usually not exceeds 1000 repeats (Ashizawa et al., 1994b). In mothers with a small DM mutation ( $<80$ repeats), the repeat is often transmitted relatively stable to the next generation (Barceló et al., 1993; Wieringa, 1994). Transmission of the repeat by mothers with longer repeats results in large average increments, and the risk of a congenitally affected child increases with maternal repeat length (Koch et al., 1991; Cobo et al., 1995).

Prenatal diagnosis can now be offered to all future parents with a high risk of producing affected offspring (Myring et al., 1992). It is particularly useful in those families in which a severely affected child has been born, with a high risk of a subsequent child being similarly affected (Harper, 1996). Although the overlap between repeat lengths in the different disease types makes it impossible to give an accurate prognosis on the basis of the size of the expansion prenatally, it is certainly possible to discriminate between small mutations (up to 80-100 CTG repeats) and consequently minimal symptoms, and large repeats and severe disease.

Preimplantation genetic diagnosis (PGD) is an alternative for prenatal testing for high risk couples, especially for those who had one or more conventional 
prenatal diagnoses with subsequent selective abortion or for those who have principle objections to prenatal diagnosis (Sermon et al, 1997). In particular PGD can be a good option for couples with male factor infertility, due to DM related oligozoospermia, who are already candidates for IVF/CSI (in vitro fertilisation/intracytoplasmatic sperm injection). The main disadvantage of PGD is the limited success rate of obtaining a pregnancy (15-30\% per cycle). A point of special concern in PGD for DM is the safety of the affected women, and their possibly increased risk of IVF related complications.

\subsection{Other mutations, other genes or other diseases}

So far, the unstable and expanded CTG repeat has been the only mutational mechanism found in myotonic dystrophy. No case of DM has had a different type of site of mutation identified. The cases in which no repeat expansion can be found are mostly explained by misdiagnoses (Harper, 1996). A significant portion of atypical DM patients are now proven to be affected with proximal myotonic myopathy (PROMM). This newly recognised disorder shows clinical overlap with DM (Ricker et al,. 1994; Moxley et al., 1996). The combination of myotonia, progressive muscle weakness and cataract is similar to DM, as is the autosomal dominant inheritance. However, the preferentially proximal located muscle weakness, the absence of systemic complications apart from cataract, the presence of muscle pain and stiffness, the late onset and relatively mild course and the absence of anticipation in families clearly distinguishes PROMM from DM. Recently, Ranum et al. (1998) reported a large 5 generation family with a disorder that they named DM2. However, a further description of the clinical features in this family revealed that DM2 is more like PROMM, although some affected members of the DM2 familly were reported to have exclusively distal limb weakness, which has not been observed in PROMM families (Day et al., 1999). The patients of the DM2 family did not have the CTG expansion in the DMPK gene and the disease locus in this family was mapped to chromosome $3 q$. Shortly after, it was shown that PROMM is linked to the same $3 q$ region as DM type 2 (Ricker et al., 1999). So DM2 and PROMM may be caused by the same mutation or may be alllelic disorders. An alternative is that they are caused by two closely linked and functionally related genes. Elucidation of the specific gene in PROMM/DM2 may be highly relevant as the pathophysiology of DM and PROMM/DM2 may be related. A comparison of $\mathrm{DM}, \mathrm{PROMM}$ and $\mathrm{DM} 2$ is given in the table. 
Table Similarities and differences between myotonic dystrophy (DM), proximal myotonic myopathy (PROMM) and myotonic dystrophy type 2 (DM2) (adapted from Moxley et al., 1996)

\begin{tabular}{|c|c|c|c|}
\hline & DM & PROMM & $\mathrm{DM} 2$ \\
\hline \multicolumn{4}{|l|}{ Core features } \\
\hline myotonia & +1 & + & + \\
\hline weakness & + & + & + \\
\hline cataract & \pm & + & + \\
\hline \multicolumn{4}{|l|}{ Muscle symptoms } \\
\hline weakness of facial and jaw muscies & +4 & - & \pm \\
\hline distal limb weakness & +1 & - & \pm \\
\hline proximal limb weakness & + & ++ & +4 \\
\hline muscular atrophy & +1 & \pm & \pm \\
\hline muscle pain and stiffness & - & +4 & $+t$ \\
\hline Cardiac arrhythmias & +4 & + & \pm \\
\hline Other systemic complications & +4 & - & - \\
\hline \multicolumn{4}{|l|}{ Genetics } \\
\hline autosomal dominant & + & + & + \\
\hline anticipation & +1 & - & - \\
\hline congenital type & + & - & - \\
\hline CTG repeat expansion $19 \mathrm{q}$ & + & - & - \\
\hline linked to $3 \mathrm{q}$ & - & + & + \\
\hline
\end{tabular}

The peculiar association of DM and hereditary motor and sensory neuropathy (HMSN) was described by Spaans et al. (1986). Fifteen members of this family presented with HMSN, eight of them showed more or less prominent signs of DM. The DM affected family members showed myotonic discharges on EMG examination, and cataract presumably related to DM, was present in four of them. Although a number of studies have shown mild peripheral nerve involvement in DM, this family shows unique clinical features because of the early and severe neuropathy, predating the onset of DM features (Brunner et al., 1991b). Genetic studies showed linkage with the DM locus on chromosome 19 (Brunner et all, 1991b). Recently we had the opportunity to reinvestigate some affected familly members. Muscular weakness was relatively mild in the affected patients and only slowly progressive. Anticipation was not observed in three generations. Interestingly, the expanded CTG repeat in these patients could only be identified by Southern bloth analysis, PCR failed repeatedly (personal communication $\mathrm{dr}$. H. Smeets, 1999). One may speculate that a different type of mutation or a different site of the expanded CTG repeat is responsible for the disorder in this family. Further 
molecular studies in this family are pending. The results may be of great importance in understanding the mutational mechanism and the pathophysiology of DM.

\section{References}

Alwazzan M, Newman E, Hamshere MG, Brook JD. Myotonic dystrophy is associated with a reduced level of RNA from the DMWD allele adjacent to the expanded repeat. Hum Mol Genet 1999:8:1491-1497.

Aslanidis C, Jansen G, Amemiya C, Shutler G, Mahadevan M, Tsilfidis C, Chen C, Alleman J, Wormskamp NGM, Vooijs M, Buxton J, Johnson K, Smeets HJM, Lennon GG, Carrano AV, Korneluk RG, Wieringa $\mathrm{B}$, de Jong PJ. Cloning of the essential myotonic dystrophy region and mapping of the putative defect. Nature 1992;355:548-551

Ashizawa T, Dunne PW, Ward PA, Seltzer WK, Richards CS. Effects of the sex of myotonic dystrophy patients on the unstable triplet repeat in their affected offspring. Neurology 1994a; 44:120-122.

Ashizawa T, Anvret M, Baiget M, Barceló JM, Brunner H, Cobo AM, Dallapiccola B, Fenwick RG, Grandell U, Harley H, Junien C, Koch MC, Komeluk RG, Lavedan C, Miki T, Mulley JC, López de Munain A, Novelli G, Roses AD, Seltzer WK, Smeets H, Shaw DJ, Sutherland GR, Yamagata H, Harper PS. Characteristics of intergenerational contractions of the CTG repent in myotonic dystrophy. Am J Hum Genet 1994b;54:414-423.

Barceló JM, Mahadevan MS, Tsilfidis C, ManKenzie AE, Korneluk RG. Intergenerational stability of the myotonic dystrophy protomutation. Hum Mol Genet 1993;2:705-709.

Bell J. Dystrophia myotonica and allied diseases. In: Penrose LS (ed). Treasury of human inheritance. Cambridge University Press, 1947.

Bergoffen J, Kant J, Sladky J, McDonald-McGinn D, Zackai EH, Fischbeck KH. Paternal. transmission of congenital myotonic dystrophy. J Med Genet 1994;31:518-520.

Brook JD, Mc Currach ME, Harley HG, Buckler AJ, Church D, Aburatani H, Hunter KI, Stanton VP, Thirion J-P, Hudson T, Sohn R, Zemelman B, Snell RG, Rundle SA, Crow S, Davies J, Shelbourne P, Buxton J, Jones C, Juvonen V, Johnson K, Harper PS, Shaw DJ, Housman DE. Molecular basis of myotonic dystrophy: expansion of a trinucleotide (CTG) repeat at the 3'end of a transcript encoding a protein kinase family member. Cell 1992;68:799-808.

Brunner HO, Smeets HJM, Nillesen W, van Oost BA, van den Biezenbos BM, Joosten EMG, Pinckers AJLG, Hamel BCJ, Theeuwes AGM, Wieringa B, Ropers HH. Myotonic dystrophy. Predictive value of normal results on clinical examination. Brain 1991a;114:2303-2311.

Brunner HG, Spaans F, Smeets HJM, Coerwinkel-Driessen M, Hulsebos T, Wieringa B, Ropers HH. Genetic linkage with chromosome 19 but not chromosome 17 in a family with myotonic dystrophy associated with hereditarymotor and sensory neuropathy. Neurology 1991b;41:80-84. Brunner HG, Brüggenwirth HT, Nillisen W, Jansen G, Hamel BCJ, Hoppe RLE, de Die CEM, Höweler CJ, van Oost BA, Wieringa B, Ropers HH, Smeets HJM. Influence of sex of the transmitting parent as well as of parental allele size on the CTG expansion in myotonic dystrophy. Am J Hum Genet 1993a;53:1016-1023.

Brunner HG, Jansen G, Millesen W, Nelen MR, de Die CEM, Höweler CJ, van Oost BA, Wieringa B, Ropers HH, Smeets HMM. Reverse mutation in myotonic dystrophy. New Engl J Med $1993 b ; 328: 476-480$. 
Buston J, Shelboume P, Davies J, Jones J, Van Tongeren T, Aslanidis C, de Jong P, Jansen G, Anvet M, Riley B, Williamson $R$, Johnson $K$. Detection of an unstable fragment of DNA specific to individuals with myotonic dystrophy. Nature 1992;355:547-548.

Clarke AJ. The genetic testing of children. In: Genetics, society and clinical practice. Harper PS, Clarke AJ. Bios scientific publishers, Oxford, 1997.

Cobo AM, Baiget M, Lopez de Munain A, Poza JJ, Emparanza JI, Johnson K Sex-related difference in intergenerational expansion of myotonic dystrophy gene. Lancet 1993;341:1159. 1160

Cobo AM, Poza JJ, Martorell L, López de Munain A, Emparanza II, Baiget M. Contribution of molecular analyses to the estimation of the risk of congenital myotonic dystrophy. I Med Genet $1995 ; 32: 105-108$

Davies $J$, Yamagata $H$, Shelbourne $P$, Buxton I, Ogihara $T$, Nokelainen P, Nakagawa M, Williamson R, Johnson $\mathrm{K}$, Miki T. Comparison of the myotonic dystrophy associated CTG repeat in European and Japanese populations. I Med Genet 1992;29:766-769.

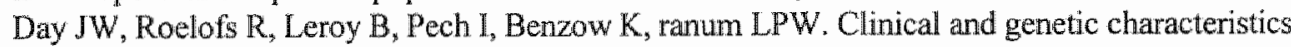
of a five-generation family with a novel form of myotonic dystrophy (DM2). Neuromusc Disord 1999;9:19-27.

Dyken PR, Harper PS. Congenital dystrophia myotonica. Neurology $1973 ; 23: 465-473$.

Eriksson M, Ansved T, Edstrom L, Anvret M, Carey N. Simultaneous analysis of the three myotonic dystrophy locus genes in adult skeletal muscle samples: the CTG expansion correlates inversely with DMPK and 59 expression levels, but not DMAHP levels. Hum Moll Genet 1999;8:1053-1060.

Fleischer B. Über myotonische dystrophie mit katarakt: eine heriditäre, familiäre degeneration. Archiv fir ophthalmologie, Berlin 1918;96:91-133.

Fu Y-H, Pizzuti A, Fenwick Jr RG, King J, Rajnarayan S, Dunne PW, Dubel J, Nasser GA, Ashizawa $T$, de Jong P, Wieringa B, Korneluk R, Perryman MB, Epstein HF, Caskey CT. An unstable triplet repeat in a gene related to myotonic muscular dystrophy. Science $1992 ; 255: 1256-$ 1258.

Fu YH, Friedman DL, Richard S, Pearlman JA, Gibbs RA, Pizzuti A, Ashizawa T, Perryman MB, Scarlato G, Fenwick RG, Caskey CT. Decreased expression of myotonin-protein kinase messenger RNA and protein in adult form of myotonic dystrophy. Science 1993;260:235.

Groenen P, Wieringa B. Expanding complexity in myotonic dystrophy. BioEssays 1998;20:901912 .

Hanshere $\mathrm{MG}_{3}$ Newman EE, Alwazzan M, Athwal BS, Brook JD. Transcriptional abnormality in myotonic dystrophy affects DMPK but not neighboring genes. Proc Natl Acad Sci 1997;94:7394-7399.

Marley HG, Brook ID, Rundle SA, Crow S, Reardon W, Buckler AJ, Harper PS, Housman DE, Shaw DI. Expansion of an unstable DNA region and phenotypic variation in myotonic dystrophy. Nature 1992a;355:545-546.

Harley HG, Rundle SA, Reardon W, Myring J, Crow S, Brook JD, Harper PS, Shaw DJ. Unstable DNA sequence in myotonic dystrophy. Lancet 1992b;339:1125-1128.

Harley HG, Rundle SA, MacMillan JC, Myring J, Brook JD, Crow S, Reardon W, Fenton I, Shaw DJ, Harper PS. Size of the unstable repeat sequence in relation to phenotype and parental tranmission in myotonic dystrophy. Am J Hum Genet 1993;52:1164-1174.

Harper PS. Myotonic dystrophy, 2nd edn. WB Saunders, London and Philadelphia, 1989.

Harper PS, Harley HG, Reardon W, Shaw DJ. Anticipation in myotonic dystrophy: new light on an old problem. Am J Hum Genet 1992;51:10-16. 
Harper PS. Myotonic dystrophy. In: Rimoin DL, Connor JM, Pyeritz RE (eds). Emery and Rimoin's principles and practice of medical genetics. Churchill Livingstone, New York, 1996. Hoffmann-Radvayi H, Lavedan C, Rabes JP Savoy D, Duros C, Johnson K. Junien C. Myotonic dystrophy:absence of CTG enlarged transcripts in congenital forms, and low expression of the normal allele. Hum Mol Genet 1993;2:1263-1266.

Höweler CJ. A clinical and genetic study in myotonic dystrophy. Thesis, University of Rotterdan, 1986.

Höweler CJ, Busch HFM, Geraedts JPM, Niermeijer MF, Staal A. Anticipation in myotonic dystrophy: fact or fiction? Brain 1989;112:779-797.

Hunter AGW, Jacob P, OHoy K, MacDonald I, Mettler G, Tsilfidis C, Koneluk RG. Decrease in the size of the myotonic dystrophy CTG repeat during transmission from parent to child: implications for genetic counselling and genetic anticipation. Am II Med Genet 1993;45:401 407. Jansen G, Mahadevan M, Amemiya C, Wormskamp N, Segers B, Hendriks W, O'Hoy K, Baird $S$, Sabourin L, Lennon G, Jap PL, lles D, Coerwinkel M, Hofker M, Carrano AV, de Jong PJ, Korneluk RG, Wieringa B. Characterization of the myotonic dystrophy region predicts multiple protein isoform-encoding mRNAs. Nature Genet 1992;1:261-266.

Jansen G, Bartolomei M, Kalscheuer V, Merkx G, Wormskamp N, Mariman E, Smeets D, Ropers $\mathrm{HH}$, Wieringa $\mathrm{B}$. No imprinting involved in the expression of DM-kinase mRNAs in mouse and human tissues. Hum Mol Genet 1993;2:1221-1227.

Jansen G, Willems P, Coerwinkel M, Nillesen W, Smeets H, Vits L, Höweler C, Brumer H, Wieringa $\mathrm{B}$. Gonosomal mosaicism in myotonic dystrophy patients: involvement of mitotic events in $(\mathrm{CTG})_{\mathrm{n}}$ repeat variation and selection against extreme expansion in sperm. Am J Hum Genet 1994;54:575-585.

Jansen G, Groenen PJTA, Bächner D, Jap PHK, Coerwinkel M, Oerlemans $\mathbb{H}^{-1}$, van den Broek W, Gohlsch B, Pette D, Plomp JJ, Molenaat PC, Nederhoff MGJ, van Echteld CIA, Dekker M, Berns A, Hameister $\mathrm{H}$, Wieringa $\mathrm{B}$. Abnormal nyotonic dystrophy protein kinase levels produce only mild myopathy in mice. Nature Genet 1996;13:316-324.

Klesert TD, Otten AD, Bird TD, Tapscott SJ. Trinucleotide repeat expansion at the myotonic dystrophy locus reduces expression of DMAHP. Nature Genet 1997;16:402-406.

Koch MC, Grimm T, Harley HG, Harper PS. Genetic risks for children of women with myotonic dystrophy. Am J Hum Genet 1991;48:1084-1091.

Korade-Mirnics Z, Tarleton J, Servidei S, Casey RR, Gennarelli M, Pagoraro E Angelini C. Hoffman EP. Myotonic dystrophy: tissue-specific effect of somatic CTO expansions in allelespecific DMAHP/SIX5 expression. Hum Mol Genet 1999;8:1017-1023.

Krahe R, Ashizawa T, Abbruzzese C, Roeder E, Carango P, Giacanelli M, Funanage V. Effect of myotonic dystrophy trinucleotide repeat expansion on DMPK transcription and processing. Genomics 1995;28:1-14.

Laforet P, Heron D, Gourdon G, Radvanyi H, Harpey JP, Fardeau M, Eymard B. A new case of paternally inherited congenital myotonic dystrophy. Eur J Neurol, suppl 1, 1995;2:29.

Lavedan C, Hofmann-Radvanyi H, Shelboume P, Rabes JP, Duros C, Savoy D, Dehaupas I, Luce $S$, Johnson K, Junien C. Myotonic dystrophy: size- and sex-dependent dynamics of CTG meiotic instability, and somatic mosaicism. Am J Hum Genet 1993a;52:875-883.

Lavedan C, Hofmann-Radvanyi $H$, Rabes JP, Roume $J$, Junien C. Different sex-dependent. constraints in CTG length variation as explanation for congenital myotonic dystrophy. Lancet $1993 b ; 341: 237-238$.

Mahadevan M, Tsilfidis C, Sabourin L, Shutler G, Amemiya C, Jansen G, Neville C, Narang M, Barceló J, O'Hoy K, Leblond S, Earle-MacDonald J, De Jong PJ, Wieringa B, Korneluk RG. 
Myotonic dystrophy mutation: an unstable CTG repeat in the $3^{\prime \prime}$ untranslated region of the gene. Science $1992 ; 255: 1253-1255$.

Mahadevan MS, Amemiya C, Jansen $G$, Sabourin L, Baird S, Neville CE, Wormskamp N, Segers $B$, Batzer $M$, Jamerdin $J_{\text {, de Jong }}$, Wieringa $B$, Komelul RG. Structure and genomic sequence of the myotonic dystrophy (DM kinase) gene. Hum Mol Genet 1993;2:299-304.

Monckton DG, Wong LJ Je, Ashizawa T, Caskey CT. Somatic mosaicism, germline expansions, germline reversions and intergeneretional reductions in myotonic dystrophy males: small pool PCR analyses. Hum Mol Genet 1995;4:1-8.

Moxley RT. Proximal myotonic myopathy: mini-review of a recently delineated clinical disorder. Neuromusc Disond 1996;2:87-93.

Mulley JC, Staples A, Domnelly A, Gedeon AK, Hecht BK, Nicholson GA, Haan EA, Sutherland GR. Explanation for exclusive maternal origin for congenital form of myotonic dystrophy. Lancet $1993 ; 341: 236-237$.

Myring $J_{3}$ Meredith AL, Harley HG, Kohn G, Norbury G, Harper PS, Shaw DJ. Specific molecular prenatal diagnosis for the CTG mutation in myotonic dystrophy. J Med Genet $1992 ; 29: 785-788$.

Nakagawa M, Yamada H, Higuchi $\mathbb{I}$, Kaminishi Y, Miki T, Johnson K, Osame M. A case of paternally inherited congenital myotonic dystrophy. I Med Genet 1994;31:397-400.

O'Hoy KL, Tsilfidis C, Mahadevan MS, Neville CE, Barceló J, Hunter AGW, Komeluk RG. Reduction in size of the myotonic dystrophy trinucleotide repeat mutation during transmission. Nature 1993;259:809-811.

Ohya K, Tachi N, Chiba S, Sato T, Kon S, Kickuchi K, Imamura S, Yamagata H, Miki T. Congenital myotonic dystrophy transmitted from an asymptomatic father with a DM-specific gene. Neurology 1994;44:1958-1960.

Otten AD, Tapscott S.J. Triolet repeat expansion in myotonic dystrophy alters the adjacent chromatin structure. Proc Natl Acad Sci 1995;92:5465-5469.

Passos-Bueno MR, Cerqueira A, Vainzof M, Marie SK. Zatz M. Myotonic dystrophy: genetic, clinical and molecular analysis of patients from 41 Brazilian families. J Med Grenet 1995;32:14 18.

Pearse RG, Höweler CJ. Neonatal form of dystrophia myotonica. Five cases of preterm babies and review of earlier reports. Arch Dis Child 1979;54:331-338.

Penrose LS. The problem of anticipation in pedigrees of dystrophia myotonica. Ann Eugen $1948 ; 14: 125-132$.

Pizzuti A, Friedman DL, Caskey CT. The myotonic dystrophy gene. Arch Neurol 1993;50:11731179.

Ranum LPW, Rasmussen PF, Benzow KA, Koob MD, Day JW. Genetic mapping of a second myotonic dystrophy locus. Nature Genet 1998;19:196-198.

Reddy S, Smith DBJ, Rich MM, Leferovich JM, Reilly P, Davis BM, Tran K, Rayburn H, Bronson $\mathbb{R}$, Cros D, Balice-Gordon RJ, Housman D. Mice lacking the myotonic dystrophy protein kinase develop a late onset progressive myopathy. Nature Genet 1996;13:325-335.

Redman JB, Fenwick RG, Fu Y-H, Pizzuti A, Caskey $T$. Relationship between parental trinucleotide GCT repeat length and severety of myotonic dystrophy in offspring. JAMA $1993 ; 269: 1960-1965$.

Ricker K, Koch MC, Lehmann-Horn F, Pongratz D, Otto M, Heine R, Moxley RT. Proximal myotonic myopathy; a new dominant disorder with myotonia, muscle weakness, and cataracts. Neurology $1994 ; 44: 1448-1452$. 
Ricker K, Grimm T, Koch MC, Schneider C, Kress W, Reimers CD, Schuite-Mattler W, MuellerMyhsok B, Toyka KV, Mueller CR. Linkage of proximal myotonic myopathy to chromosome $3 \mathrm{q}$. Neurology 1999;52:170-171.

Sabourin LA, Mahadevan MS, Narang M. Lee DSC, Surh LC Korneluk RO. Effect of the myotonic dystrophy (DM) mutation on mRNA levels of the DM gene. Nature Genet 1993;4:233238.

Sermon K, Lissens W, Joris H, Seneca S, Desmyttere S, Devroey P, Van Steirteghem A, Liebaers 1. Clinical application of preimplantation diagnosis for myotonic dystrophy. Prenat Diagn $1997 ; 17: 925-932$.

Shaw DJ, McCurrach M, Rundle SA, Harley HG, Crow SR, Sohn R, Thirion JP, Hamshere MG, Buckler AJ, Harper PS, Housman DE, Brook JD. Genomic organization and transcriptional units at the myotonic dystrophy locus. Genomics 1993a;19:673-679.

Shaw DJ, Chaudhary S, Rundle SA, Crow S, Brook JD, Harper PS, Harley HG. A study of DNA methylation in myotonic dystrophy. J Med Genet 1993b;30:189-192.

Shelbourne $P$, Winqvist $R$, Kunert $E$, Davies J, Leisti J, Thiele $H$, Bachmann H, Buxton J, Willamson $B$, Johnson $\mathrm{K}$. Unstable DNA may be responsible for the incomplete penetrance of the myotonic dystrophy phenotype. Hum Mol Cenet $1992 ; 1: 467-473$.

Shelboume P, Davies J, Buxton J, Anvret M, Blennow E, Bonduelle M, Schmedding E, Glas 1 , Lindenbaum R, Lane $R$, Williamson $R$, Johnson $K$. Direct diagnosis of myotonic dystrophy with a disease-specific DNA marker. N Engl J Med 1993;328:471-475.

Spaans $F_{\text {s }}$ Jennekens FGI, Mirandolle JF, Bijlsma JB, de Gast GC. Myotonic dystrophy associated with hereditary motor and sensory neuropathy. Brain 1986;109:1 1.49-1 1.68.

Steinbach P, Gläser D, Vogel W, Wolf M, Schwemmle S. The DMPK gene of severely affected myotonic dystrophy patients is hypermethylated proximal to the largely expanded CTG repeat. Am JHum Genet 1998;62:278-285.

Taneja KJ, McCurrach M, Schalling M, Housman D, Singer RH. Foci of trimucleotide repeat transcripts in nuclei of myotonic dystrophy cells and tissues. J Cell Biol 1995:128:995-1002.

Thomton CA, Wymer JP, Simmons Z, McClain C, Moxley RT. Expansion of the myotonic dystrophy CTG repeat reduces expression of the flanking DMAHP gene. Nature Genet $1997 ; 16: 407-409$.

Timchenko LT, Monckton DG, Caskey CT. Myotonic dystrophy: an unstable repeat in a protein kinase gene. Senin Cell Biol 1995;6:13-19.

Timchenko LT, Miller JW, Timchenko NA, DeVore DR, Datar $K$ V, Lin $L$, Roberts R Identification of a (CUG)n triplet repeat RNA-binding protein and its exprossion in myotonic dystrophy. Nucleic Acids Res $1996: 24: 4407-4414$.

Timchenko LT: Myotonic dystrophy: the role of RNA CUG triplet repeats. Am J Hum Genet $1999 ; 64: 360-364$.

Tsilfidis C, Mckenzie AF, Mettler G, Barceló J, Komelluk RG. Cortelation between CTG trinucleotide repeat length and frequency of severe congenital myotonic dystrophy. Nature Genet $1992 ; 1: 192-195$.

Wang J. Pegoraro E, Menegazo E, Genaareli M, Hoop RC, Angelini C, Hoffinas EP. Myotonic dystrophy: evidence for a possible dominant-negative RNA mutation. Hum Mol Genet $1995 ; 4: 599-606$

Wieringa B. Myotonic dystrophy reviewed: back to the future. Hurn Mo! Genet 1994:3:1-7.

Winchester CL, Femier RK, Sermoni A. Clark BJ, Johnson KI. Characticrization of the expression of DMPK and SIXS in the human eye and implications for pathogenesis in myotonic dystroply. Hum Mol Genet 1999;8:481-492. 
Chapter 6

\section{Epidemiology and origin of the myotonic dystrophy mutation}

6.1 Epidemiology

6.2 The origin of the myotonic dystrophy mutation

6.3 The origin of myotonic dystrophy in families

6.4 The genetic paradox 


\subsection{Epidemiology}

Myotonic dystrophy is the most prevalent inherited neuromuscular disease in adults and has been reported from many countries and ethnic groups. The prevalence ranges from 1 in 8000 in Western Europeans and North Americans to 1 in 20.000 among the Japanese (Davies et al., 1992; Harper, 1989). In some populations, such as the sub-Saharan Africans, there is a striking absence of the disease (Goldman et al., 1994). On the other hand the disease appears to be particularly common in some populations that have undergone rapid expansion, such as the Saguenay-Lac St Jean region of Quebec, Canada. The estimated prevalence of DM in this region is one in 500 individuals (Harper, 1989; Mathieu, 1990). This high prevalence is presumed to be due to genetic founder effect. The observed differences between populations, especially the near absence of the disease in ethnic Africans, have led to hypotheses about the origin of the DM mutation.

\subsection{The origin of the myotonic dystrophy mutation}

The studies on the initial origin of the expansion in DM are now centred at the molecular level. Prior to the identification of the DM gene in 1992, linkage disequilibrium between the putative DM locus and several extragenic markers was found, suggesting a conserved structure on disease chromosomes (Waring and Korneluk, 1998). Further characterisation of closer polymorphic markers, such as D19S63, confirmed the strong association of DM with these alleles. This linkage disequilibrium was observed in different populations, indicative of a genetic founder effect (Harley et al., 1991; Cobo et al., 1992). After the identification of the DM gene, it was determined that the DM expansion is in complete association with the insertion allele of an Alu repeat insertion/deletion polymorphism (D19S95), in intron 8 of the DMPK gene (Harley et al., 1992; Yamagata et al., 1992; Mahadevan et al., 1993). The normal frequency of this insertion allele varies between 0.45 in Japanese, 0.52 in Europeans and 0.71 in South African Negroids (Waring and Korneluk, 1998). The fact that all disease chromosomes contain the insertion allele, in Caucasian as well as in Japanese populations, suggests a common origin of the DM mutation. Neville et al. (1994) extended previous linkage studies and showed that a single haplotype (haplotype A, including the Alu insertion allele) composed of nine polymorphism's within and flanking the DM locus, spanning a physical distance of $30 \mathrm{~kb}$, is in complete linkage disequilibrium with DM. Haplotype A 
represented approximately $50 \%$ of the normal French Canadian population studied. The frequency of the other eight haplotypes found in the normal population, varied from $27 \%$ to less than $1 \%$ (Neville et al., 1994). Only one exception to this association has been reported to date: in a Nigerian DM family the disease chromosome was not associated with haplotype $\mathrm{A}$, including the insertion allele (Krahe et al., 1995).

The issue of the origin of the DM mutation was further examined by analysing the associations of normall length CTG repeats in populations. Firstly, it was shown that the Alu insertion polymorphism was in strong linkage disequilibrium with the normal 5 allele, and with large normal alleles (16-36 CTG's), while intermediate alleles (11-16 repeats) were almost always associated with the deletion allele. On the basis of this observation Imbert et al. (1993) proposed that through a few initial events the 5-allele expanded to an allele of 19 to 30 repeats and, in turn, this latter group of alleles formed a reservoir for recurrent mutations to the expanded disease alleles. In contrast to the findings of Imbert et al. (1993), Zerylnick et al. (1995), in their study on the distribution of normal CTG repeats in global human populations, found several exceptions to the observation that the 5 and 19-30 allele are exclusively associated with the insertion allele, and therefore suggested that the occurrence of a group with high repeat numbers may antedate the origin of the insertion-deletion polymorphism. This might indicate that expanded alleles are derived from more than one ancestral allele, and that the variable population frequencies may reflect distinct frequencies of such predisposing alleles (Zerylnick et al., 1995; Harper, 1996a).

It has also been suggested that the frequency of DM in a population might be related to the distribution of normal alleles, possibly a higher frequency of large normal alleles predisposes to a higher frequency of the disorder. It has indeed been shown that South African Negroids, where DM has not been observed so far, have significantly fewer large normal repeats than Caucasians (Goldman et al., 1994). The above mentioned findings led to two hypotheses: (1) the predisposition for CTG instability results from a founder effect that occurred only once or a few times during human evolution (2) the disease haplotype itself predisposes to CTG instability. The fact that in the Nigerian DM family the disease is not associated with haplotype A, supports the idea that the expanded CTG in this family is the result of an independent mutational event, and is an argument against the theory that a single ancestral haplotype predisposes to repeat expansion (hypothesis (2)) (Krahe et al., 1995). 
So current theory implies that DM is probably the result of one or a few ancestral mutations, and that the original change(s) that eventually lead(s) to most cases of DM may have occurred many thousands of years ago, with a gradual increase over many generations until the number of repeats reaches a critical threshold where the altered gene becomes unstable (Harper, 1996a). However the mechanism(s) by which the normal (premutated) alleles lengthen, subsequently become unstable ( $>=50$ repeats, protomutation) and ultimately expanded, remains elusive. Also, the frequency of the transition from a large normal allele (premutation) to a protomutation is unknown (Thornton, 1999).

The studies on the initial origin of the DM mutation are also relevant as part of the analysis of the human evolutionary history. Linkage studies have shown similar associations for the Europeans and Japanese people, supporting the idea of a common Eurasian origin of the DM mutation (Imbert et al., 1993; Yamagata et al., 1996). Combined with the fact that DM is common in European and Asiatic populations, including Japan, and extremely rare in African populations, it is thus possible that the original mutation occurred after the migration of early humans from Africa, but before any separation of Asiatic and Caucasian populations. Presumably the Eurasian mutation represents a more ancient event than the recently identified African mutation.

\subsection{The origin of myotonic dystrophy in families}

In fact the discussion on the origin of DM focuses not only on the ultimate origin of the initial expansion, but allso on the origin of clinically identifiable cases (Harper, 1996b). Observations in families have shown that DM patients never arise "de novo" and that all cases can be derived from a (minimally affected) parent with an expanded repeat (Harper, 1996a). Furthermore in family studies, using registers dating from the Napoleontic time, common ancestors 3 to 6 generations ago were shown, suggesting that in these families the DM allele may be at least several generations old (Fleischer, 1918; de Jong, 1955; Klein, 1958; Höweler, 1986; Brunner et al., 1993a). The most remarkable example was found in the Saguenay region, where genealogical studies showed that all 750 patients living in this region could be traced back to a common ancestor couple that migrated from France to Quebec in the 17th century, 10-14 generations ago, suggesting that the disease was transmitted through many generations without apparent clinical signs or symptoms (Mathieu, 1990). 
Genealogical studies in DM families descending from Limburg

We wondered for how many generations the DM gene could be traced back in the families, known to be descending from the Southern part of the province of Limburg. A total of 20 pedigrees were studied: 9 families originating from the city of Maastricht and 11 families from the South-Western part of Limburg. The 9 families from Maastricht were all linked to at least one other family. In three instances, two families were linked together. Once, three pedigrees were connected by descent. The 4 pairs of common ancestors were born between 1790 and 1818 , on average 6 generations ago. An attempt to find a connection between these 4 common ancestor pairs was not successful, as the family files dating from the period before 1880 had to be derived from church registers, which were hardly accessible and largely incomplete. The pedigrees of the 11 families from the South-Western part of Limburg were also traced back to the beginning of the 19 th century. None of the families were linked.

The question how far back the instability of the expanded DM repeat extends in families, remains largely unanswered. The preliminary conclusion from our genealogical studies and those of others, is that the immediate origin of DM in families is incremental with a gradual increase in repeat size across a limited number of generations, until a critical value is reached and instability, accompanied with clinical anticipation, commences. However, the factors causing the transition from a (relatively) stable to an unstable allele are largely unknown. Gender of the transmitting parent may play a role, as it was shown previously that the onset of clinical expression of DM in pedigrees is preferentially associated with male transmission (Brunner et al., 1993a).

\subsection{The genetic paradox}

The genetic "paradox", why is DM still a relatively common disease despite its high gene loss and the absence of identifiable new mutations, can only be answered. provisionally. A number of genetic processes may contribute to the maintenance of the gene in the population. Firstly, segregation distortion has been documented in healthy individuals, with preferential transmission of the larger allele to offspring (Carey et al., 1994; Shaw et al., 1995, Chakraborty et al., 1996). This so called meiotic drive may enrich the proportion of large normal alleles in the population (Thornton, 1999). They may be passed down through many generations and so spread through the population, as discussed before. These large normal alleles are 
the presumed source for new (proto)mutations. Secondly, the relative stable transmission of protomutations by individuals with no or only minor manifestations, may contribute to the further dissemination of disease alleles. However, this stable transmission of protomutations is thought to be limited, although transmission of a minimally expanded allele with minimal or no amplification over several generations has been observed (Barceló et al., 1993; Simmons et al., 1998). Finally, the maintenance of the DM allele in the population can be explained by the occurrence of intergenerational contractions of the repeat, which returns the process of anticipation to an earlier point in the cascade. However, these reductions of the number of CTG repeats are not very frequent. Unexpectedly, they are usually accompanied by clinical anticipation. So, they may prolong the anticipation cascade with only a few generations (Barceló et al, 1993; Ashizawa et al., 1994; Thornton, 1999). The presumably rare occurrence of true reverse mutations into the normal range, may also contribute (Shelbourne et al., 1992; Brunner et al., 1993b; Hunter et al., 1993; O'Hoy et al., 1993).

\section{References}

Ashizawa T, Anvret M, Baiget M, Barceló JM, Brunner H, Cobo AM, Dallapiccola B, Fenwick RG, Grandell U, Harley H, Junien C, Koch MC, Korneluk RG, Lavedan C, Miki T, Mulley JC, López de Munain A, Novelli G, Roses AD, Seltzer WK, Smeets H, Shaw DJ, Sutherland GR, Yamagata H, Harper PS. Characteristics of intergenerational contractions of the CTG repeat in myotonic dystrophy. Am J Hum Genet 1994;54:414-423.

Barceló JM, Mahadevan MS, Tsilfidis C, ManKenzie AE, Korneluk RG. Intergenerational stability of the myotonic dystrophy protomutation. Hum Mol Genet 1993;2:705-709.

Brunner HG, Brüggenwirth HT, Nillisen W, Jansen G, Hamel BCJ, Hoppe RLE, de Die CEM, How weler $\mathrm{CJ}$, van Oost BA, Wieringa B, Ropers $\mathrm{HH}$, Smeets HJM. Influence of sex of the transmitting parent as well as of parental allele size on the CTG expansion in myotonic dystrophy. Am J Hum Genet 1993a;53:1016-1023.

Brunner HG, Jansen O, Millesen W, Nelen MR, de Die CEM, Höweler CJ, van Oost BA, Wieringa B, Ropers HH, Smeets HJM. Reverse mutation in myotonic dystrophy. New Engl I Med $1993 b ; 328: 476-480$.

Carey N, Johnson K, Nokelainen P, Peltone L, Savontaus ML, Juvonen V, Anvret M, Grandell U, Chotai K, Robertson E, Middleton Price H, Malcolm S. Meiotic drive at the myotonic dystroplyy locus? Nature Genet 1994;6: 117-118.

Chakraborty R, stivers DN, Deka R, Yu LM, Shriver MD, Ferrell RE. Segregation distortion of the CTG repeats at the myotonic dystrophy locus. Am J Hum Genet 1996;59:109-118.

Cobo A, Grinberg D, Balcells S, Vilageliu L, Gonzàlez-Duarte R, Baiget M. Linkage disequilibrium detected between myotonic dystrophy and the anonymous marker D19S63 in the Spanish population. Hum Genet 1992;89:2287-291.

Davies J, Yamagata $\mathrm{H}$, Shelbourne $\mathrm{P}$, Buxton $\mathrm{J}$, Ogihara T, Nokelainen $\mathbb{P}$, Nakagawa $\mathrm{M}$, Williamson R, Johnsosn K, Miki T. Comparison of the myotonic dystrophy associated CTG repeat in European and Japanese populations. J Med Genet 1992;29:766-769. 
Fleischer B. Über myotonische dystrophie mit katarakt: eine heriditäre, familtiare degeneration. Archiv für Ophthalmologie, Berlin 1918;96:91-133.

Goldman A, Ramsay M, Jenkins T. Absence of myotonic dystrophy in southern African Negroids is associated with a significantly lower number of CTG trinucleotide repeats. I Med Genet $1994 ; 31: 37-40$.

Harley HG, Brook JD, Floyd J, Rundle SA, Crow S, Walsh KV, Thibault MC, Harper PS, Shaw DI. Detection of linkage disequilibrium between the myotonic dystrophy locus and a new polymorphic DNA marker. Am J Hum Genet 1991;49:68-75.

Harley $H_{G}$, Brooi JD, Rundle SA, Crow S, Reardon W, Buckler AJ, Harper PS, Housman DE, Shaw DJ. Expansion of an unstable DNA region and phenotypic variation in myotonic dystrophy. Nature 1992;355:545-546.

Harper PS. Myotonic dystrophy, 2nd edn. WB Saunders, London and Philadelphia. 1989.

Harper PS. New genes for old diseases: the molecular basis of myotonic dystrophy and Huntington's disease. J Royal Coll Physicians of London 1996a;30:221-231.

Harper PS. Myotonic dystrophy. In: Rimoin DL, Connor JM, Pyeritz RE (eds). Emery and Rimoin's principles and practice of medical genetics. Churchill Livingstone, New York, 19966. Höweler CJ. A clinical and genetic study in myotonic dystrophy. Thesis, University of Rotterdam, 1986.

Hunter AGW, Jacob P, OHoy K, MacDonald I, Mettler G, Tsilfidis C, Komeluk RG. Decrease in the size of the myatonic dystrophy CTG repeat during transmission from parent to child: implications for genetic counselling and genetic anticipation. Am J Med Genet 1993:45:401-407. Imbert $\mathrm{G}$, Rretz $\mathrm{C}$, Johnson $\mathrm{K}$, Mandel J-L. Origin of the expansion mutation in myotonic dystrophy. Nature Genet 1993;4:72-76.

Jong de JCYY. Dystrophia myotonica, paramyotonia and myotonia congenita. Thesis, University of Utrecht, 1955.

Klein D. La dystrophie myotonique (Steinert) et la myotonie congénitale (Thomsen) en Suisse: étude clinique, génétique et démographique. J. de Génétique Humaine 1958;7, Supplement:1-328. Krahe R, Eckhart M, Ogunniyi AO, Osuntokun BO, Siciliano MJ, Ashizawa T. De novo myotonic dystrophy mutation in a Nigerian kindred. Am J Flum Genet 1995;56:1067-1074.

Mahadevan MS, Foitzik MA, Surh LC, Korneluk RG. Characterization and polymerase chain reaction (PCR) detection of an ALU deletion polymorphism in total linkage disequilibrium with myotonic dystrophy. Genomics $1993 ; 15: 446-448$.

Mathieu J. Genealogic reconstruction of myotonic dystrophy in the Saguenay-Lac-Saint-Jean area (Quebec, Canada). Neurology 1.990;40:839-842.

Neville CE, Mahadevan MS, Barceló JM, Korneluk $R$ G. High resolution genetic analysis suggests one ancestral predisposing haplotype for the origin of the myotonic dystrophy mutation. Hum Molec Genet 1994;3:45-51.

O'Hoy KL, Tsilfidis C, Mahadevan MS, Neville CE, Barceló J, Hunter AGW, Korneluk RG. Reduction in size of the myotonic dystrophy trinucleotide repeat mutation during transmission. Nature 1993;259:809-811.

Shaw AM, Barnetson RA, Phillips MF, Harper PS, Harley HG. Evidence for meiotic drive at the myotonic dystrophy locus. I Med Genet 1995;32:145.

Shelbourne $P$, Winqvist $R$, Kunert E, Davies J, Leisti J, Thiele $H_{3}$, Bachmann $H$, Buxton J, Williamson $\mathrm{B}$, Johnson $\mathrm{K}$. Unstable DNA may be responsible for the incomplete penetrance of the myotonic dystrophy phenotype. Hum Mol Genet 1992;1:467-473.

Simmons Z, Thornton CA, Seltzer WK, Richards CS. Relative stability of a minimal CTG repeat expansion in a large kindred with myotonic dystrophy. Neurology 1998;50:1501-1504.

Thomton C. The myotonic dystrophies. Semin Neurol 1999;19:25-33. 
Waring JD, Koneluk RG. Genetic studies of the myotonic dystrophy CTG repeat. In: Wells RD, Warren ST (eds). Genetic instabilities and hereditary neurological disorders. Academic Press, San Diego, 1998.

Yamagata H, Miki T, Ogihara T, Nakagawa M, Higushi I, Osame M, Shelbourne $\mathrm{P}$, et al. Expansion of unstable DNA region in Japanese myotonic dystrophy patients. Lancet $1992 ; 339: 692$.

Yamagata $\mathrm{H}$, Miki $T$, Nakagawa $M$, Johnson $\mathrm{K}$, Deka $\mathrm{R}$, Ogihara T. Association of CTG repeats and the 1-kb. Alu insertion/deletion polymorphism at the myotonin protein kinase gene in the Japanese population suggests a common Eurasian origin of the myotonic dystrophy mutation. Hum Genet 1996:97:145-147.

Zerylnick C, Torroni A, Sherman SL, Warren ST. Normal variation at the myotonic dystrophy locus in global human populations. Am J Hum Genet 1995;56:123-130. 
Chapter 7

\section{Anticipation resulting in elimination of the myotonic dystrophy gene: a follow-up study of one extended family}

C.E.M. de Die-Smulders' ${ }^{1}$, C.J. Höweler ${ }^{2}$, J.F. Mirandolle ${ }^{3}$, H.G. Brunner ${ }^{4}$, V. Hovers $^{\sharp}$, H. Brüggenwirth ${ }^{4}$, H.J.M. Smeets ${ }^{4}$, J.P.M. Geraedts ${ }^{1}$

Departments of ${ }^{1}$ Clinical Genetics, ${ }^{2}$ Neurology, University Hospital Maastricht, ${ }^{3}$ Department of Neurology, de Wever Hospital, Heerlen, ${ }^{4}$ Department of Human Genetics, University Hospital Nijmegen, the Netherlands

J Med Genet 1994;31:595-601 


\begin{abstract}
We have re-examined an extended myotonic dystrophy (DM) family, previously described in 1955, in order to study the long term effects of anticipation in DM and in particular the implications for families affected by this disease. This follow up study provides data on 35 gene carriers and 46 asymptomatic at risk family members in five generations. Clinical anticipation, defined as the cascade of mild, adult, childhood, or congenital disease in subsequent generations, appeared to be a relentless process, occurring in all affected branches of the family. The cascade was found to proceed asynchronously in the different branches, mainly because of an unequal number of generations with mild disease. The transition from the mild to the adult type was associated with transmission through a male parent. Stable transmission of the asymptomatic/mild phenotype showed a female transmission bias.

We further examined the extent and causes of gene loss in this pedigree. Gene loss in the patient group was complete, owing to infertility of the male patients with adult onset disease and the fact that mentally retarded patients did not procreate. Out of the 46 at risk subjects in the two youngest generations, only one was found to have a full mutation. This is the only subject who may transmit the gene to the sixth generation. No protomutation carriers were found in the fourth and fifth generations. Therefore it is highly probable that the DM gene will be eliminated from this pedigree within one generation. The high population frequency of DM can at present not be explained by the contribution of asymptomatic cases in the younger generations of known families, but is probably caused by the events in the ancestral generations.
\end{abstract}




\section{Introduction}

Myotonic dystrophy (DM) is an autosomal dominant disorder with myotonia and muscular weakness as diagnostic features. Apart from the muscular manifestations, it is characterised by multiple systemic effects including cataract, mental retardation, cardiac involvement, and testicular atrophy. Extreme variability is one of the hallmarks of the disease; clinical studies have led to the recognition of four disease types on the basis of age at onset and core symptoms: late onset (mild) type, adult onset (classical) type, childhood and congenital type. ${ }^{\mathrm{I}-3}$

Anticipation, increasing severity and earlier age at onset in successive generations, has been observed in DM since the beginning of this century, but remained unexplained and controversial until recently. ${ }^{4-7}$ With the discovery of an unstable CTG trinucleotide repeat in the $3^{\prime}$ untranslated region of a protein kinase gene on chromosome $19 q$, a biological explanation for this phenomenon has emerged. ${ }^{8-14}$ The repeat length correlates with the severity of clinical symptoms and increases with transmission to subsequent generations. ${ }^{3} 7_{15} 16$ However, most of the dynamics of the unstable CTG trinucleotide repeat are not yet fully understood. The exact implications of anticipation for DM families are still unclear. As a rule the anticipation cascade proceeds and the phenotype changes from mild type to adult type to childhood/congenital type in subsequent generations. However, it is not known which events precede the cascade, which factors trigger the start of the cascade, and what happens after the childhood/congenital onset generation. Fleischer ${ }^{4}$ argued that the disease would become extinct in families because of gene loss in severely affected patients owing to celibacy, childless marriages, mental retardation, and high infant mortality. Follow up studies to determine whether the disease indeed disappears from a given family have not been performed. We had the opportunity to reexamine a large DM family, the first three generations of which were described by de Jong ${ }^{17}$ in 1955, and so we could gain data on five generations. The aim was to study the consequences of anticipation over more generations than can be studied in transverse studies. The inter- and intragenerational phenotypic variation was studied by combining clinical and DNA data. The reproductive fitness of male and female patients was compared. To examine whether progressive severity leads to the extinction of the disease from a given pedigree, descendants of the third and fourth symptomatic generations were studied, and the extent and causes of gene loss in the youngest generations were evaluated. 


\section{Methods}

Family

In 1955 de Jong ${ }^{17}$ described an extended DM family with three symptomatic generations (pedigree $G$ ). He gave detailed information on 50 family members, 16 of whom were designated as affected. Neurological examination and slit lamp examination by an ophthalmologist were used as diagnostic methods. Electromyography was not available then. We carefully reviewed his data and only subjects showing definite signs of DM were classified as affected. We added data on the descendants of III. 12, who were examined by de Jong in 1958 (figure). 11.2 and her descendants are not included in this follow up study, because she was not examined by de Jong. III.8, III.9 and III.10 and their children were found to be normal in 1955. They live abroad and were excluded from the present study. The living members of generations IV and $\mathrm{V}$ were reexamined and so we were able to obtain data on five generations.

This follow up study was started with the patients and at risk family members already known to the Departments of Clinical Genetics and Neurology of the University Hospital Maastricht and the Department of Neurology of the De Wever Hospital in Heerlen, the Netherlands. They were asked to approach their relatives. Most family members were visited and examined in their own homes, which turned out to have a significant advantage in terms of cooperation in the study.

The total study comprises data on 81 family members: initially there were 35 symptomatic patients or obligate gene carriers (including de Jong's patients) and 46 at risk subjects. The at risk group comprised asymptomatic first degree relatives of DM patients. Second and third degree relatives were defined as at risk if the disease status of the intermediate family member(s) was unknown. One at risk subject (V.20) was included in the group of gene carriers after DNA examination showed that she had inherited the expanded CTG repeat from her affected father. Eighteen out of the 36 gene carriers were no longer alive at the time of the study.

\section{Examinations}

Careful histories from the patients or their family members or both were obtained to document the age of onset and current clinical symptoms. When available, clinical records were reviewed. Muscular weakness or myotonia or both, myotonic cataract, neonatal symptoms or mental retardation defined the onset of disease. Neurological examination was performed using a standardised form. Ophthalmological assessments were carried out using a portable slit lamp. 
EMG examination was only performed when examination took place in hospital.

\section{Cinical classification}

To compare the disease types within and between generations four clinical categories were used, adapted from the classification of Harley et al. ${ }^{3}$ : mild, adult, childhood, and congenital types (table 1 ). We added a category of additional later symptoms, because several of the present patients have had symptomatic DM for over 40 years (table 1). Conclusions regarding the disease type were made on the basis of the results of our recent examination in combination with the data from medical records and de Jong's descriptions.

Table I Disease types in DM related to age at onset and core symptoms

\begin{tabular}{|c|c|c|c|}
\hline $\begin{array}{l}\text { Disease } \\
\text { type }\end{array}$ & $\begin{array}{l}\text { Age at } \\
\text { onset }\end{array}$ & Initial symptoms & $\begin{array}{l}\text { Additional later } \\
\text { symptoms }\end{array}$ \\
\hline Mild & $>50 \mathrm{yr}$ & $\begin{array}{l}\text { Cataract or } \\
\text { iridescent lens opacities }\end{array}$ & $\begin{array}{l}\text { Myotonia } \\
\text { Mild weakness }\end{array}$ \\
\hline Adult & $10.50 \mathrm{yr}$ & $\begin{array}{l}\text { Myotonia } \\
\text { Muscular weakness }\end{array}$ & $\begin{array}{l}\text { Progressive weakness } \\
\text { Inertia, hypersomnia } \\
\text { Cataract } \\
\text { Testicular atrophy }\end{array}$ \\
\hline Childhood & $1-10$ yr & $\begin{array}{l}\text { Neonatal symptoms } \\
\text { absent } \\
\text { Speech/learning } \\
\text { difficulties } \\
\text { or mental retardation }\end{array}$ & $\begin{array}{l}\text { Muscular weakness } \\
\text { Varying degree of } \\
\text { mental retardation } \\
\text { No myotonia before } \\
\text { school age } \\
\text { Abdominal symptoms }\end{array}$ \\
\hline Congenital & $<1 \mathrm{yr}$ & $\begin{array}{l}\text { Reduced fetal } \\
\text { movements } \\
\text { Polyhydramnios } \\
\text { Neonatal problens: } \\
\text { hypotonia, } \\
\text { facial diplegia, } \\
\text { joint immobility, } \\
\text { respiratory insufficiency }\end{array}$ & $\begin{array}{l}\text { Initial improvement } \\
\text { of weakness } \\
\text { Psychomotor retardation } \\
\text { No myotonia before } \\
\text { school age } \\
\text { Abdomiral symptoms }\end{array}$ \\
\hline
\end{tabular}

\section{DNA analysis}

Chromosomal DNA was isolated from peripheral blood cells from 16 patients and 39 at risk subjects. Molecular analyses were performed according to methods described previously. ${ }^{912141819}$ Southern blot analysis was performed using restriction enzyme HindIII and probe pGB2.6 respectively. In those 
samples where smears were detected, the middle of the smear was sized. Expansions $<0.35 \mathrm{~kb}$ were also sized on polyacrylamide gels, after PCR amplification using primers flanking the CTG repeat. ${ }^{14}$ All molecular results were expressed in terms of kilobases of additional DNA.

\section{Results}

\section{Pedigree}

The abbreviated pedigree is depicted in the figure; only gene carriers and their descendants and at risk persons are shown. The disease types are given in the pedigree. Generations II, III and most members of generation IV were studied in 1955 or 1958. All subjects of generations I, II and III are dead. The common ancestor of generation II (I.1) was born in 1833 and died at the age of 84 . According to his children he never had visual or muscular complaints. Thus he was probably an asymptomatic gene carrier. In generation II, two subjects have had cataract operations (II.3, II.4). When examined aged 80 and 76 years respectively, they showed no muscular signs. Subject II. 1 died at the age of 26 , a few days after the birth of her sixth child. In generation III, four patients had mild disease and two had the adult type, transmitted by their father. III.12 had no muscular signs when examined at the age of 54. Slit lamp examination, however, was not performed. Patients still alive in generation IV are now aged 38 to 69 years. The most frequent type in generation IV is adult onset disease, with a few exceptions: one male is congenitally affected (IV.40) and three patients have the childhood form (IV.23, IV.29, IV.38); in all four cases the disease was transmitted by their affected mother. These four patients with early onset disease are aged $46,64,47$ and 56 years respectively. They are still able to walk with walking aids, despite having had symptoms for more than 40 years. They are moderately mentally retarded and not able to live independently. One gene carrier in generation IV (IV.46) has minor symptoms. This 52 year old man was found to be normal on clinical and slit lamp examination. However, DNA-analysis revealed that he carried the DM mutation, containing a $0.3 \mathrm{~kb}$ expansion. Electromyography, that happened to be performed some years previously, showed myotonic discharges. Based on these results he was classified in the mild group. This is in sharp contrast to his five affected sibs, who have (early) adult onset disease with expansions of 2 to $2.5 \mathrm{~kb}$. 


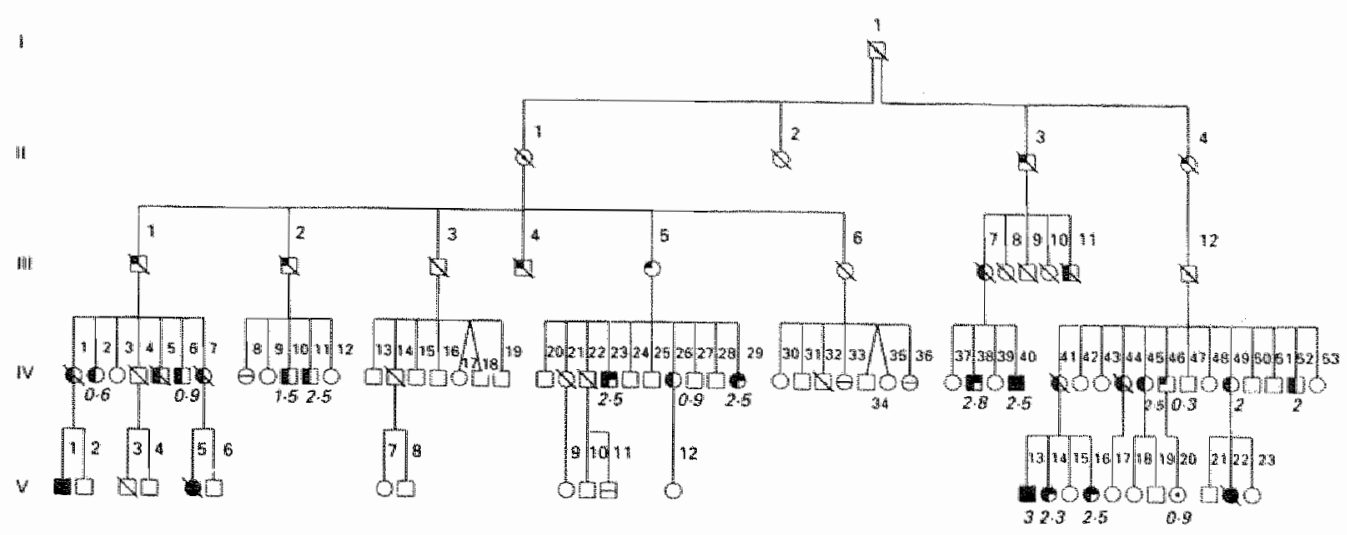

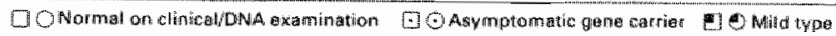

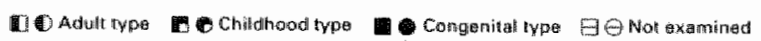

Figure Pedigree of the family. The numbers beneath the symbol denote the size (kb) of CTG repeat expansion by Southern blot analysis

The age of the living patients in generation $\mathrm{V}$ is between 31 and 41 years. In this generation, four patients had congenital disease, two of whom died in the neonatal period, and two patients have childhood onset disease. The 16 year old daughter of IV.46 (V.20) was asymptomatic on clinical and slit lamp examination, but DNA studies showed that she has inherited the mutated paternal chromosome, containing an expansion of $0.9 \mathrm{~kb}$. She is of normal intelligence and is attending secondary school; we presume she will develop (late) adult onset disease.

Intergenerational differences in phenotype

In the different branches a variable number of generations with mild disease was observed. The mild type was most frequently present in two generations and the transition from the mild to the classical type occurred from generation III to IV; $72 \%$ of the gene carriers in generation IV had the adult onset type. In one branch this transition occurred one generation earlier (offspring of II.3). In another case the transition was one generation later (transmission line II.4III.12-IV.46-V.20). This unequal number of generations with mild disease in the different branches resulted in the occurrence of the adult type in three different 
generations: III, IV, V (assuming V.20 will have adult type disease). Also as a result of this asynchronous anticipation a large intragenerational variation in disease types was found, becoming most obvious in generation IV, in which patients with four different disease types are present. Disease types were compared in 32 parent child pairs in generations II to $\mathrm{V}: 16$ mother-child pairs and 16 father-child pairs. For this analysis we combined the asymptomatic and mild patients and designated them as having the mild type, because inclusion in one group or the other strongly depends on the age at which a subject was examined. We also combined the childhood and congenital onset groups, because the prognosis of these patients is essentially determined by their mental retardation. Parental disease type was mild/asymptomatic in 24 . Six children of a parent with mild disease also had mild disease; in five of these six stable transmissions of the mild type the mother was the transmitting parent. Sixteen children of a parent with mild disease had the adult type. In 15 of these 16 mild to adult transitions the gene was transmitted by a male gene carrier. In two cases maternal transmission of the mild type results in direct transition to childhood disease in her offspring (III.5-IV.23 and III.5-IV.29). III.5 was 50 years old when examined by de Jong in 1955. At that time her only symptoms were a slightly myopathic face and iridescent lens opacities on slit lamp examination. Unfortunately DNA studies could not be performed in this woman. There were eight parent-child pairs in which the parent had adult onset disease. These parents were all female. These women had no offspring with adult onset disease; all their children were normal or had childhood/congenital disease. None of the males with adult onset disease had offspring.

Correlation of disease type and repeat size

DNA data were obtained from 17 DM gene carriers, with the following disease types: mild (1), adult (8), childhood (5), congenital (2) and asymptomatic (1). The repeat sizes are given in the pedigree (figure). Congenitally and childhood affected patients showed the largest bands. Patients with repeat sizes of approximately $2.5 \mathrm{~kb}$ were found in the adult group and in the childhood and congenital onset group. Vertical transmission of the CTG repeat could only be studied in one father-daughter pair (IV.46 and V.20); repeat lengths were 0.3 and $0.9 \mathrm{~kb}$ respectively.

\section{At risk group}

Forty six asymptomatic at risk persons were examined. Their status is given in table 2. Thirty eight of these 46 subjects were proven not to be gene carriers; they showed no clinical abnormalities and DNA analysis showed that they had 
inherited the normal allele from their affected (grand)parent.

Table 2 Residual risk of being a gene carrier in at risk group $(N=46)$

\begin{tabular}{llllll}
\hline Risk: & Excluded & Affected & $50 \%$ & $25 \%$ & $8 \%$ \\
No. & 38 & 1 & 1 & 3 & 3 \\
\hline
\end{tabular}

One at risk subject (V.20) was found to be carrying the DM gene with an expansion of $0.9 \mathrm{~kb}$. Four subjects (IV.8, IV.33, IV.36, V.11) refused to cooperate in the study. In three subjects (V.2, V.15, V.19) DNA analysis could not be performed. As they were normal on clinical examination, including slit lamp examination and electromyography, their residual risk was $8 \%{ }^{20}$

Causes of gene loss

We found three causes of gene loss: infertility, infant mortality, and the fact that mentally retarded patients did not procreate. The fertility of the patients, as defined by disease type and by sex of the transmitting parent is given in table 3 .

Table 3 Number of children of DM gene carriers aged over 20 years $(N=35)$, by disease type and sex of the transmitting parent.

\begin{tabular}{llclc}
\hline Sex of parent: & $\begin{array}{l}\text { Female } \\
\text { no. patients }\end{array}$ & no. children & $\begin{array}{l}\text { Male } \\
\text { no. patients }\end{array}$ & no. children \\
Disease type of parent: & & 6 & 2 & 17 \\
Asymptomatic & 1 & 11 & 5 & 18 \\
Mild & 2 & 19 & 6 & 0 \\
Adult & 9 & 0 & 2 & 0 \\
Childhood & 3 & 0 & 3 & 0 \\
Congenital & 2 & 36 & 18 & 35 \\
Total & 17 & & & \\
\hline
\end{tabular}

A remarkable difference between the sexes was observed in the adult onset group. Only one of the nine women with adult onset DM was childless, while the other eight women had a total of 19 children. These females are now all middle aged and have completed their families. In contrast none of the six adult onset males has produced children; they are between 39 and 63 years of age and are all single, which makes it unlikely that they will produce offspring in the future.

Childlessness of the male patients with adult onset disease accounted for $35 \%$ 
of the gene loss in generations IV and V. Infertility of the female patients with adult onset disease accounted for only $6 \%$ of gene loss. Patients with congenital or childhood disease are all mentally retarded, unable to live independently, and childless. They are beyond the age of 30 and are also unlikely to have offspring in the future. Childlessness owing to mental retardation was responsible for $47 \%$ of the total gene loss. Infant mortality in this family involved two children with congenital DM in generation $\mathrm{V}$ and accounted for $12 \%$ of the gene loss.

The effects of the different causes of gene loss are also reflected in the number of patients in each generation, as given in table 4.

\section{Table 4 Namber of gene carriers by generation.}

Generation I II $\quad$ III IV $\quad$ V $\quad$ VI

\begin{tabular}{lllllll}
\hline Number of gene carriers & 1 & 3 & 7 & 18 & 7 & 1 or 2 expected
\end{tabular}

The largest number of patients is found in the third symptomatic generation (generation IV). The first decline in the number of gene carriers, after generation IV, is mainly owing to infertility of the male patients with adult type DM. The second expected decline, after generation V, is because of the childlessness of childhood/ congenitally affected patients of both sexes. Only one female gene carrier in generation V (V.20) will be able to transmit the gene to generation VI.

If the anticipation proceeds in her descendants as in the rest of the family, her children may have childhood or congenital onset disease. Therefore the gene may be expected to be eliminated from this family within one or two generations.

\section{Discussion}

We re-examined an extended myotonic dystrophy family previously documented in 1955, and analysed the effects of anticipation in a larger number of generations then can be studied in transverse studies. We collected clinical information on five generations and DNA data on the fourth and fifth generations, in order to examine the probability of transmission of DM to the sixth generation. 
Anticipation can be defined at two levels. At the clinical level it is a cascade of mild, adult and childhood or congenital disease types in subsequent generations. At the molecular level it can be defined as a stepwise increase of the CTG repeat number. A broad correlation between clinical anticipation and DNA expansion has been shown by several authors. ${ }^{321-23}$

In this extended family clinical anticipation occurred in all 21 vertical transmission lines descending from the common ancestor 1.1. No protomutations ( 50 to 80 repeats) were found in the asymptomatic members of the fourth and fifth generations. Thus the presumed protomutation of the common ancestor must have been unstable to such a degree that anticipation was a relentless process in all affected branches of the family.

However, the anticipation cascade developed asynchronously in the different branches, mainly depending on the number of generations with mild disease. The start of the cascade, that is, the transition from mild to adult type disease was most frequently seen after two generations with mild disease. An earlier start, after only one generation with mild disease, was seen in one branch (descendants of II.3), while in another vertical transmission line (descendants of II.4) anticipation was postponed, because 3 generations with asymptomatic/mild disease preceded the cascade.

The sex of the transmitting parent appeared to be the main influence on the transition from mild to adult type. Fifteen out of the 16 transitions from mild to adult onset disease resulted from male transmission. In contrast, in five out of six stable transmissions of the mild type a female was the transmitting parent. An exception was a mildly affected woman (III.5) who had two children with childhood onset disease as well as a daughter with adult onset disease. This was the only direct transition from the mild to the childhood type observed in this family. Another exception was the asymptomatic male III.12 who had one son with mild disease as well as five children with adult onset disease. It can be concluded from these observations that gender is an important, but not the only, factor determining the start of the cascade.

In eight transmission lines the classical three step anticipation cascade was observed with mild, adult and childhood/congenital type in subsequent generations. A two step cascade, present 13 times, occurred for two reasons. Firstly, because of the absence of the last step of the cascade (childhood/congenital type). This was the case in all six male patients with adult onset disease and was because of infertility. There were also five females with adult onset disease who had no offspring with childhood/congenital onset disease. Three of 
these women had only normal children and two were single (so far). The second reason for a two step cascade was the above mentioned direct conversion of the mild type into the childhood type.

Our observations on anticipation in a five generation DM family are unique, as longitudinal studies of DM familles have not been previously reported. Transverse studies have shown anticipation in the clinical sense or at the DNA level or both in the great majority of parent-child pairs studied. ${ }^{462124-}$ ${ }^{26}$ Asynchronous anticipation occurred in some of the reported pedigrees as ages of onset of patients in the same generation differed considerably. ${ }^{6} 212527$ However, the course of the cascade and the ultimate effects of continuing anticipation can be studied more completely in longitudinal studies. In the transverse study of Barceló et al, ${ }^{24}$ the stable transmission of a protomutation ( \pm 60 repeats) through four successive generations was described, where symptomatic DM occurred in other branches of their family. The authors concluded that a protomutation may be passed down relatively stably through many generations and may contribute to the genetic reservoir of DM in the population. ${ }^{24}$ Our study does not support this supposition. We found clinical anticipation in all affected branches of the family. We therefore presume that once anticipation starts in offspring of a given gene carrier, anticipation will occur in all affected branches descending from this gene carrier within a limited number of generations. As our results are based on only one extended family, more follow up studies are needed to confirm these findings.

The gender differences we found with regard to transmission are in agreement with the results of others. ${ }^{2324}$ Our clinical observation that the transition from mild to adult type is strongly associated with male transmission confirms previous data from molecular and genealogical studies that the probability of initial expansion of the CTG repeat is greater for paternally then for maternally transmitted small mutations. ${ }^{2328}$ As an exception we twice observed a direct transition from the mild to the childhood type DM after maternal transmission. Similar direct mild to childhood transitions have been described previously. ${ }^{21126}$ In all cases the mother was the transmitting parent. This finding seems to contradict the hypothesis that maternally transmitted small mutations are more stable. One may speculate that as a rule small mutations remain relatively stable during transmission in the female germline, but if a small maternal mutation becomes unstable the risk of larger amplification, resulting in childhood or congenital disease in her offspring, is greater. $^{162126}$ An alternative explanation in the present case might be that a 
larger expansion, with a greater propensity for further expansion in offspring, was present in III. 5 and was associated with relatively mild symptoms.

The absent paternal transmission of congenital DM can be explained in this particular family by decreased fertility of males with adult onset disease. Another factor contributing to this phenomenon is the presumed selection against sperm bearing large mutations. ${ }^{23} 29$

In conclusion, anticipation in this family was, once started, a relentless process occurring in all affected branches. The start of the process was asynchronous, because the transition from mild to adult type occurred in different generations, and was mainly but not exclusively influenced by the sex of the transmitting parent. The classical three step cascade is often shortened to two steps because of different reasons, the most frequent being infertility of males with adult onset disease.

We further studied DM patients and their descendants in the fourth and fifth symptomatic generations to examine the probability of transmission of the gene to the sixth generation. Gene loss in the patient group was complete, owing to infertility of the male patients with adult onset disease (35\%) and childlessness of the mentally retarded patients with childhood or congenital disease $(47 \%)$. In the nearly completely studied group of at risk asymptomatic family members, we found no carriers of a protomutation. One at risk person (V.20) was found to be carrier of a full mutation and she is the only one who may transmit the gene to the next generation. We therefore conclude that there will be complete loss of the DM gene from this family within one or two generations.

It has already been suggested by Fleischer ${ }^{4}$ that progressively increasing severity of DM leads to the elimination of the disease from a given pedigree. Systematic follow up studies to prove this hypothesis have not been performed before. On the other hand several authors presume that undetected cases may exist in the younger generations of symptomatic DM families and contribute to the maintenance of the DM gene in the population. ${ }^{3524}$ It is important to stress that these minimal cases in younger generations of known families have not yet been observed. If our results on elimination of the gene are confirmed in other follow up studies this implies that the gene loss from known DM families is complete and that the high population frequency of DM cannot be explained by the contribution of asymptomatic cases in the younger generations of known families. A more likely source of new symptomatic DM families is the class of (CTG) ${ }^{19-30}$ alleles, with an overall frequency of $5-10 \%$, which probably possess 
predisposing properties for expansion. ${ }^{728}$ These metastable protomutations may be passed down through many generations, and in this way can spread through the population, before the accelerated cascade of anticipation starts. ${ }^{728}$ Studies on linkage disequilibrium and extensive genealogical studies, such as those in Northern Quebec, support this hypothesis as they strongly suggest that one, or at most a few, ancestral mutations have been responsible for most cases of the disorder. ${ }^{31-35}$ A third possible source of new DM families are the contracted repeats in known families. Recently, Ashizawa et $a^{36}$ found, in a large multicentre study, that contraction of the CTG repeat, even to a normal length, occurred in approximately $6 \%$ of parent-child pairs studied and was preferentially associated with male transmission. ${ }^{36}$ Surprisingly, clinical anticipation occurred in $48 \%$ of these pairs. At present it is unclear whether these contracted repeats can be the starting-point of a new anticipation cascade. ${ }^{36}$ Follow up studies of patients with contracted repeats and of asymptomatic families with small mutations may give valuable information on the factors causing instability and hence the start of the anticipation cascade.

\section{Acknowledgements}

We wish to thank the members of the family for their kind cooperation, Dr. J.G.Y. de Jong, former neurologist in Heerlen, for providing his family data, and Mrs. T. Spaans-van der Bijl for performing the genealogical studies.

\section{References}

1 Harper PS. Myotonic dystrophy, 2nd ed. W B Saunders, London, 1989.

2 Koch MC, Grimm T, Harley HG, Harper PS. Genetic risks for children of women with myotonic dystrophy. Am J Hum Genet 1991;48:1084-1091.

3 Harley HG, Rundle SA, MacMillan JC, et al. Size of the unstable repeat CTG sequence in relation to phenotype and parental transmission in myotonic dystrophy. Am J Hum Genet 1993;52:11164-1174.

4 Fleischer B. Uber myotonische dystrophie mit katarakt: eine heriditäre, familiäre degeneration. Arch Ophthalmol 1918;96:91-133.

5 Penrose LS. The problem of anticipation in pedigrees of dystrophia myotonica. Ann Eugen $1948 ; 14: 125-132$.

6 Höweler CJ, Busch HFM, Geraedts JPM, Niermeijer MF, Staal A. Anticipation in myotonic dystrophy: fact or fiction? Brain 1989;112:779-797.

7 Harper PS, Harley HG, Reardon W, Shaw DJ. Anticipation in myotonic dystrophy: new 
light on an old problem. Am J Hum Genet 1992;51:10-16.

8 Aslanidis $C$, Jansen $G_{3}$ Amemiya $C_{3}$ et al Cloning of the essential myotonic dystrophy region and mapping of the putative defect. Nature 1992;355:548-551.

9 Brook JD, McCurrach ME, Harley $\mathrm{HG}$, et al. Molecular basis of myotonic dystrophy: expansion of a trinucleotide (CTG) repeat at the 3 ' end of a transcript encoding a protein kinase family member. Cell 1992;68:799-808.

10 Buxton J, Shelbourne P, Davies J, et al Detection of an unstable fragment of DNA specific to individuals with myotonic dystrophy. Nature 1992;355:547-548.

11 Fu YH, Pizzuti A, Fenwick Jr RG, et al. An unstable triplet repeat in a gene related to myotonic muscular dystrophy. Science 1992;255:1256-1258.

12 Harley HG, Brook JD, Rundle SA, et al. Expansion of an unstable DNA region and phenotypic wariation in myotonic dystrophy. Nature 1992;355:545-546.

13 Jansen $G$, Mahadevan $M$, Amemiya $C$, et al. Characterization of the myotonic dystrophy region predicts multiple protein isoform-encoding mRNAs. Nature Genet 1992;1:261-266.

14 Mahadevan M, Tsilfidis C, Sabourin L, et al. Myotonic dystrophy mutation: an unstable CTG repeat in the 3 ' untranslated region of the gene. Science 1992;255:1253-1255.

15 Harley HG, Rundle SA, Reardon W, et al. Unstable DNA sequence in myotonic dystrophy. Lancet 1992;339:1125-1128.

16 Lavedan $\mathrm{C}$, Hofmann-Radvanyi $\mathrm{H}_{3}$ Shelbourne $\mathrm{P}$, et al. Myotonic dystrophy: size- and sex-dependent dynamics of CTG meiotic instability, and somatic mosaicism. Am J Hum Genet 1993;52:875-883.

17 De Jong JGY. Dystrophia myotonica, paramyotonia and myotonia congenita. Thesis, University of Utrecht, 1955.

18 Brumer $\mathrm{HG}$, Nillisen $\mathrm{W}$, van Oost $\mathrm{BA}$, et al. Presymptomatic diagnosis of myotonic dystrophy. I Med Genet 1992;29:780-784.

19 Shelbourne P, Davies J, Buxton I, et al. Direct diagnosis of myotonic dystrophy with a disease-specific DNA marker. N Engl J Med 1993;328:471-474.

20 Brunner HG, Smeets HJM, Nillesen W, et al Myotonic dystrophy. Predictive value of normal results on clinical examination. Brain 1991:11:4:2303-2311.

21 Ashizawa T, Dubel JR, Dunne PW, et al. Anticipation in myotonic dystrophy. II. Complex relationships between clinical findings and structure of the GCT repeat. Neurology $1992 ; 42: 1877-1883$.

22 Hunter $\mathrm{A}$, Tsilfidis $\mathrm{C}$, Mettler $\mathrm{G}$, et al. The correlation of age of onset with CTG trinucleotide repeat amplification in myotonic dystrophy. J Med Genet 1992;29:774-779.

23 Brunner $\mathrm{HG}$, Bruggenwirth $\mathrm{H}^{\top} \mathrm{T}$, Nillisen $\mathrm{W}$, et al. Influence of sex of the transmitting parent as well as of parental allele size on the CTG expansion in myotonic dystrophy. Am J Hum Genet 1993;53:1016-1023.

24 Barcelơ JM, Mahadevan MS, Tsilfidis C, Mackenzie AE, Komeluk RG. Intergenerational stability of the myotonic dystrophy protomutation. Human Molecular Genetics $1993 ; 2: 705-79$.

25 Howeler CJ. A clinical and genetic study in myotonic dystrophy. Thesis, University of Rotterdam, 1986.

26 Redman JB, Fenwick Jr RG, Fu YH, Pizzuti A, Caskey T. Relationship between parental trinucleotide GCT repeat length and severity of myotonic dystrophy in offspring. JAMA $1993 ; 269: 1960-1965$.

27 Cobo AM, Baiget M, López de Munain A, Poza JJ, Emparanza JI, Johnson K. Sex related difference in intergenerational expansion of myotonic dystrophy gene. Lancet 1993;- 
341:1159-1160.

28 Wieringa B. Myotonic dystrophy reviewed: back to the future? Hum Molec Genet $1994 ; 3: 1-7$.

29 Jansen $G$, Willems $P$, Coerwinkel $M$, et al. Gonosomal mosaicism in myotonic dystrophy patients: involvement of mitotic events in (CTG) repeat variation and selection against extreme expansion in sperm. Am J Hum Genet, 1994,54:575-585.

30 Harper PS, Harley HG, Shaw DJ. Detection of minimal mutation carriers in myotonic dystrophy. Lancet 1992;340:238-239.

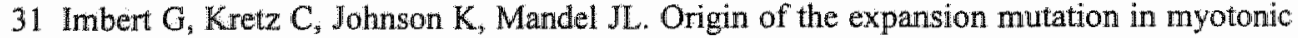
dystrophy. Nature Genet 1993;4:72-76.

32 Harley $\mathrm{HG}$, Brook JD, Floyd $\mathrm{J}$, et al. Detection of linkage disequilibrium between the myotonic dystrophy locus and a new polymorphic DNA marker. Am J Hum Genet. 1991:49:68-75.

33 Neville CE, Mahadevan MS, Barceló JM, Korneluk RG. High resolution genetic analysis. suggests one ancestral predisposing haplotype for the origin of the myotonic dystrophy mutation. Hum Molec Genet 1994;3:45-51.

34 Eckhart $M$, Krahe R, Ogunniyi AO, Siciliano MJ, Osuntokun BO, Ashizawa $T$, Dissociation of the CTG repeat expansion and the $1-\mathrm{kb}$ Alu insertion within the myotonic dystrophy (DM) protein kinase gene in a Nigerian DM family. Am J Hum Genet (Suppl) $1993 ; 53: 796$.

35 Mathieu J. Geneallogic reconstruction of myotonic dystrophy in the Saguenay-Lac-SaintJean area (Quebec, Canada). Neurology 1990;40:839-842.

36 Ashizawa T, Anvret M, Baiget M, et al. Characteristics of intergenerational contractions of the CTG repeat in myotonic dystrophy. Am J Hum Genet 1994;54:414-423.

37 Brunner $\mathrm{HG}_{*}$ Jansen $\mathrm{G}$, Nillesen $\mathrm{W}$, et al Reverse mutation in myotonic dystrophy. $\mathrm{N}$ Engl J Med 1993;328:476-480. 
Chapter 8

\section{Paternal transmission of the myotonic dystrophy gene}

8.1 Paternal transmission of congenital myotonic dystrophy (J Med Genet 1997;34:930-933)

8.2 Reverse mutation in myotonic dystrophy (N Engl J Med 1993;328:476-480) 
.

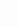
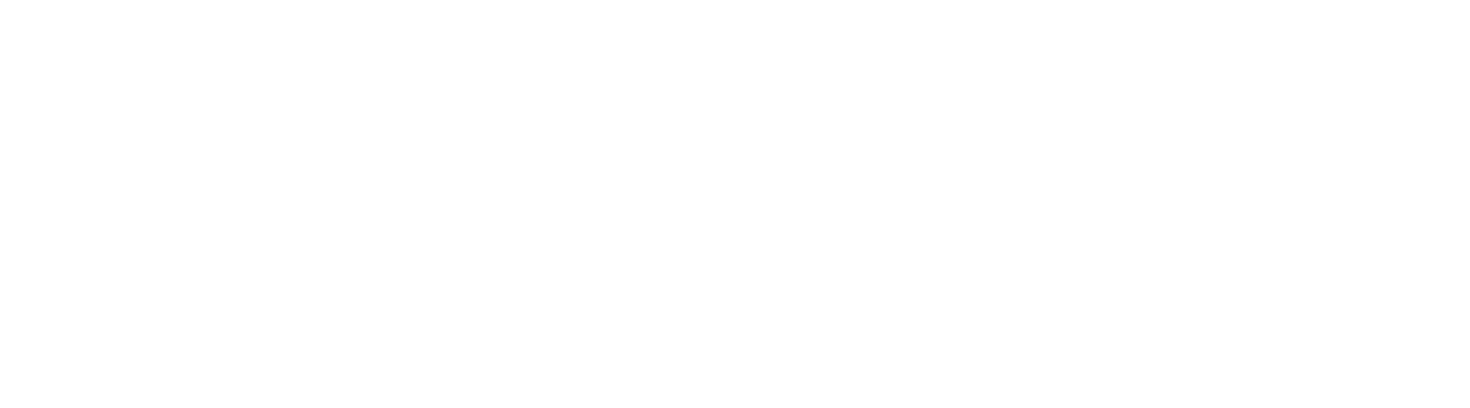

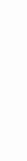

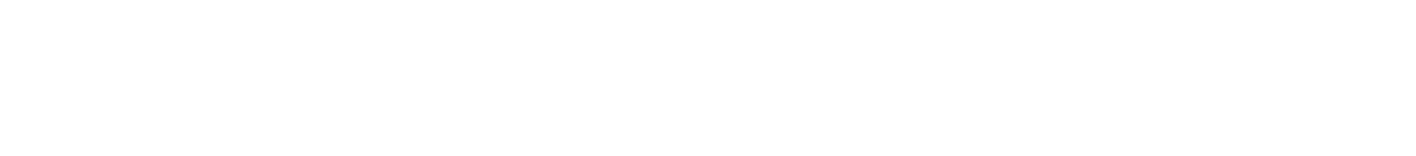


Chapter 8.1

\section{Paternal transmission of congenital myotonic dystrophy}

Christine E.M. de Die-Smulders ${ }^{1}$, H.J.M. Smeets ${ }^{2}$, W. Loots ${ }^{2}$, H.B.M. Anten ${ }^{3}$, J.F. Mirandolle, J.P.M. Geraedts', C.J. Höweler ${ }^{5}$

'Department of Clinical Genetics, Maastricht University, Maastricht, the Netherlands, ${ }^{2}$ Department of Molecular Genetics, Maastricht University, 'Department of Neurology, Maasland Hospital, Sittard, ${ }^{4}$ Department of Neurology, de Wever Hospital, Heerlen, ${ }^{5}$ Department of Neurology, University Hospital Maastricht, Maastricht

JMed Genet 1997;34:930-933 


\section{Abstract}

We report a rare case of paternally transmitted congenital myotonic dystrophy (DM). The proband is a 23 year old, mentally retarded male who suffers severe muscular weakness. He presented with respiratory and feeding difficulties at birth. His two sibs suffer from childhood onset DM. Their late father had the adult type of DM, with onset around 30 years. Only six other cases of paternal transmission of congenital DM have been reported recently. We review the sex related effects on transmission of congenital DM. Decreased fertility of males with adult onset DM and contraction of the repeat upon male transmission contribute to the almost absent occurrence of paternal transmission of congenital DM. Also the fathers of the reported congenitally affected children showed, on average, shorter CTG repeat lengths, and hence less severe clinical symptoms than the mothers of children with congenital DM.

We conclude that paternal transmission of congenital DM is rare and preferentially occurs with onset of DM past 30 years in the father. 


\section{Introduction}

Myotonic dystrophy (DM) is an autosomal dominant disorder characterised by myotonia and muscle weakness and complicated by multisystem manifestations. Four separate disease types are recognised based on age at onset and predominant symptoms: mild, adult, childhood and congenital DM. ${ }^{1-3}$ The clinical picture of congenital DM is characterised by neonatal hypotonia and generalised muscle atrophy with potentially life threatening respiratory and feeding difficulties. Typically, the baby has bilateral facial weakness with a tent shaped mouth. Congenital talipes or other joint contractures are other commonly associated findings. Polyhydramnios and reduced fetal movements are often noted in the preceding pregnancy. If the congenitally affected baby survives beyond the first weeks, the muscle weakness improves, but mental retardation is very common. The childhood type of DM is less well defined. The age at onset is usually between 1 and 10 years. Speech and learning difficulties are the only early signs in most cases. Some children present with myotonia and muscle weakness, but usually not before school age. ${ }^{15}$

DM occurs as a result of expansion of the number of CTG-trinucleotides in the $3^{\prime}$ untranslated region of the DMPK gene. ${ }^{6}$ CTG repeat length usually increases with transmission to subsequent generations, explaining the phenomenon of anticipation at the clinical level. ${ }^{37}$ A general, but not absolute correlation is seen between CTG repeat length and age of onset and severity of clinical symptoms. ${ }^{2}$ Sex differences in transmission are well recognised. Most notably, congenital DM almost exclusively originates from the mother. ${ }^{4}$ Childhood and adult onset type DM, on the other hand, may be transmitted by an affected parent of either sex. Paternally transmitted congenital DM is a rare event. Its infrequent occurrence, therefore, is of interest and suggests some significant difference in the mechanism of paternal as opposed to maternal transmission. Six cases have been published recently. ${ }^{8-11}$ In this paper, we report on a seventh case of paternal transmission of congenital DM.

\section{Case reports}

Patient 1 was born at term by spontaneous vaginal delivery. He was hypotonic at birth and received supplemental oxygen because of respiratory difficulties. Artificial ventilation, however, was not required. Nasogastric feeding was 
necessary owing to his poor sucking and swallowing problems. He had a talipes deformity of his left foot. His hypotonia and feeding problems gradually improved over the first few months of life but developmental delay was noted in later years. He sat unsupported at 10 months and walked at 18 months of age. At the age of 13 he was found to have a tented mouth, dysarthria, a nasal voice, a high arched palate, and myotonia of his hands (fig 1).
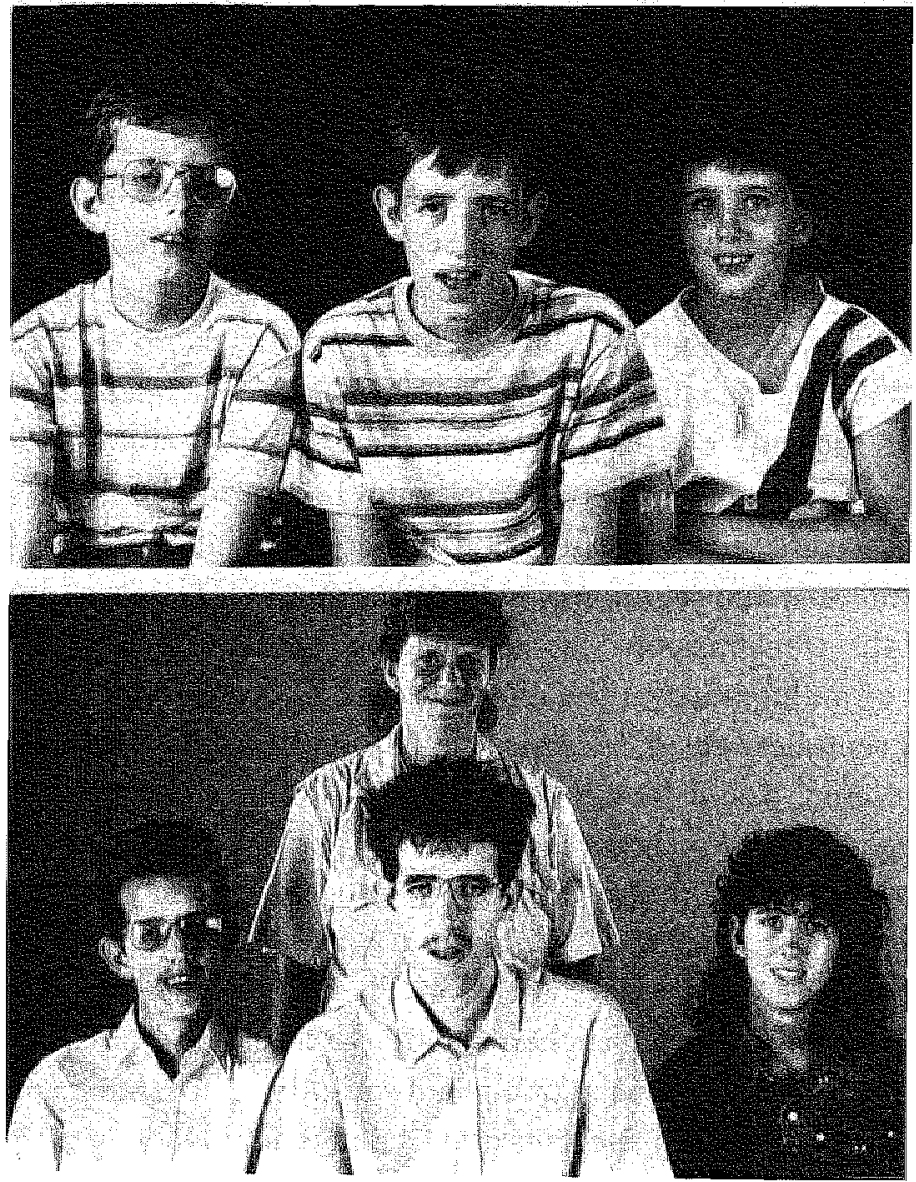

Figure 1 Upper row, from left to right: patients 2,1 and 3 at the ages of 14,13 and 10 years, respectively. Lower row, from left to right: patients 2,1 and 3 photographed 10 years Jater, with their normal mother. Note progression of facial weakness, especially in patients I and 2 (All photographs reproduced with permission) 
His mental development was borderline (IQ 75, WISC) and he needed special education from the age of 7 . On recent review at the age of 23 , he was severely dysarthric. He complained of swallowing difficulties, recurrent abdominal pains, and diarrhoea. He had a myopathic face with severe weakness and atrophy of his facial and neck muscles (fig 1). In addition, his distal and proximal arm muscles and lower leg muscles were similarly affected giving bilateral foot drop. Testicular atrophy was also evident. He works in sheltered employment.

Patient 2 is the older brother of patient 1 . He was born at term with no neonatal hypotonia or respiratory or feeding difficulties reported. His developmental milestones were within the normal range. At the age of 8 years he presented with a shuffling gait. Over the next few years his muscular symptoms worsened. By the age of 14 he had severe dysarthria, facial weakness, and mild atrophy of the calf and anterior tibial muscles. He was found to be of low/normal intelligence (IQ $=90$, WISC). In addition he had stigmata of neurofibromatosis type I, from which his mother also suffered. On recent review, aged 24 years, he showed facial weakness, atrophy of the facial and neck muscles, and grip myotonia (fig 1). Distal limb weakness was relatively mild.

Patient 3 is the younger sister of cases 1 and 2 . She first presented at the age of 7 years with learning difficulties and needed special education. By 9 years of age she was clumsy and slow and was found to have myotonia. Evaluation at the age of 20 showed a mildly retarded girl with normal speech. Neurological examination showed only mild facial and neck muscle weakness and a high arched palate (fig 1). Severe myotonia was evident in her hands. Walking on her heels was difficult, but otherwise her extremities were not affected.

The father of the three affected children was of normal intelligence. He presented at the age of 30 when he noticed weakness of the hands because he could not hold his newborn daughter for long without tiring. In addition his voice had altered, becoming more nasal and, when asleep, he had a lid lag. Neurological examination at that time showed mild weakness of his facial muscles and hands and myotonia was confirmed by electromyogram. At the age of 31 he died from a malignant brain tumour. Six of his 13 sibs showed definitive symptoms of adult onset DM.

The mother was examined at the age of 45 and was found to have no signs or symptoms of DM. She was known to suffer from neurofibromatosis type I. 


\section{DNA analysis}

Chromosomai DNA was isolated from peripheral blood cells and analysed for expansion of the CTG repeat, according to methods previously described. ${ }^{3 / 213}$ The polymorphic markers used were the extragenic CA repeat D19S112 and the intragenic RFLP's Hhal and Hinfl. ${ }^{14} 15$ Patients 1,2 , and 3 showed an expansion of the CTG repeat, varying from $5-6 \mathrm{~kb}(\mathrm{n}=1700-2000 \mathrm{CTG}$ repeats) for cases 1 and 3 , to $2-3 \mathrm{~kb}(\mathrm{n}=700-1000)$ for case 2 (fig 2).

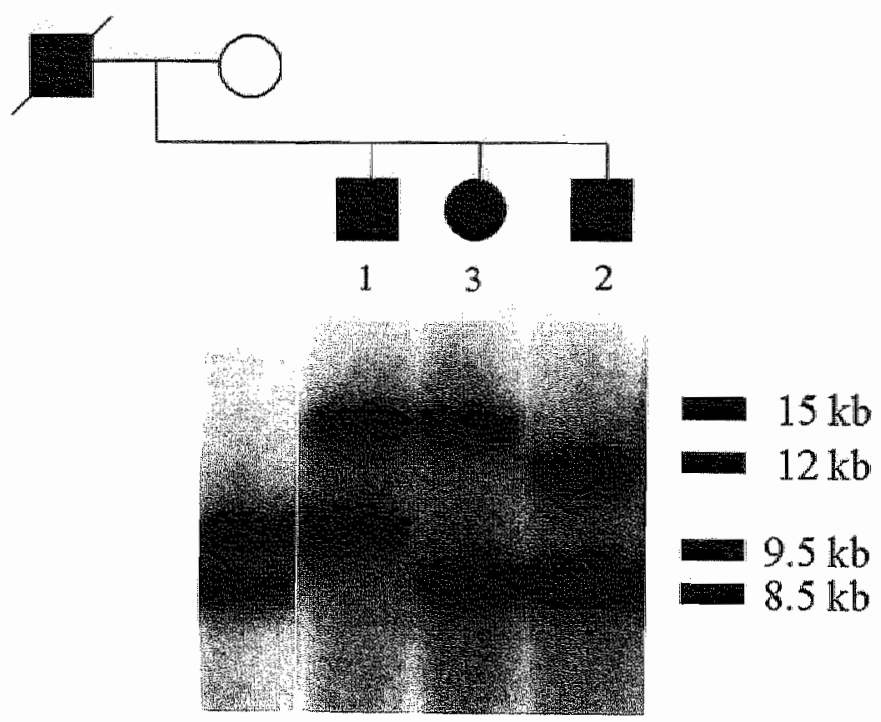

Figure 2 Southern blot analysis of patients 1,3 , and 2 and their mother. The Southern blot analysis with probe p GPI.5 was performed on HindIII digested DNA from peripheral blood lencocytes. Normal fragments are 8.5 and $9.5 \mathrm{~kb}$. Expansions are calculated respective to the larger normal fragment, 5-6 $\mathrm{kb}$ for patients 1 and 3 and 2-3 kb for patient 2 , respectively

The repeat sizes fall within the overlap region of adult onset and congenital myotonic dystrophy. Their mother was unaffected and had two normal CTG alleles ( $n=5$ and $n=14$ ). Their affected father had died and could not be tested. Therefore we tested the family with intragenic RFLP's and the CA repeat DI9S112 to determine the risk haplotype. ${ }^{15} 16$ All affected paternal family members, including patients 1,2 and 3, carried the same haplotype (data not shown). We concluded that all three had inherited the expanded CTG repeat from their affected father. 


\section{Discussion}

In this paper we report on a patient with paternally inherited congenital DM. His two sibs had the childhood type of DM and their father suffered from the adult type of DM, with age at onset around 30 years. Congenital DM is almost exclusively maternally transmitted. ${ }^{4}$ Six cases of patemally transmitted congenital DM have recently been reported. ${ }^{811}$ Ohya et al ${ }^{10}$ described a father of two congenitally affected children who was still asymptomatic at the age of 42 and showed minimal expansion of the CTG trinucleotide. Nakagawa et al ${ }^{9}$ reported two sibs with congenital DM whose father first developed symptoms of DM at 39 years. The father of the patient described by Bergoffen et al ${ }^{8}$ showed mild symptoms at the age of 53. The father of the 11 year old patient reported by Laforet et al" had "typical" DM at the age of 40 (age at onset not mentioned). All these congenitally affected patients were severely affected at birth or showed signs associated with DM in utero. Their affected fathers had mild or adult type DM, with age at onset beyond 30 years. In an earlier series of 132 congenitally affected children, reported by Harper, ${ }^{4}$ two certain cases and six probable instances of paternal transmission were found. However neither of these children had severe problems in the neonatal period or evidence of intrauterine abnormalities.

Imprinting, mutations of mitochondrial DNA, and transmission of a transplacental factor have been suggested to play a role in the maternal transmission of congenital DM. ${ }^{17-19}$ New insights have emerged with the recognition that an unstable CTG repeat is the mutational basis underlying DM and is the molecular explanation for anticipation in families. ${ }^{20}$ Patients with congenital DM have been shown, on average, to have longer CTG repeat sizes than those with adult and mild types of DM. ${ }^{21}$ However, considerable variation exists, with the shortest repeat size found in congenital DM being about 500 CTG repeats, and the longest repeat size found in the adult type being about 2000 CTG repeats. ${ }^{2223}$

The sex and the repeat length of the transmitting parent are the main influences on the length of the CTG repeat in offspring. ${ }^{2024}$ Fathers with a small repeat expansion ( $<100$ repeats) have a greater chance of significant expansion (up to 1000-1500 repeats) in their offspring than mothers with a small repeat. ${ }^{20}{ }^{26}$ Fathers with longer repeats show a strong tendency to reduced amplification or even contraction of the repeat on transmission (repear length in their offspring usually does not exceeds 1000 repeats), presumably owing to 
negative selection of large DM alleles during spermatogenesis. ${ }^{142} 28$ The fact that males with the adult type DM have, on average, fewer children than women with the same disease type also contributes to the lower frequency of patemal transmission of congenital DM. ${ }^{3}$

In mothers with a small DM mutation ( $<100$ repeats), the repeat is often transmitted relatively stably to the next generation. ${ }^{20}$ However, a few asymptomatic women (with presumed CTG repeat sizes $<100$ ) have also been described who have given birth to children with congenita】 DM. ${ }^{25}$ Cobo et $\mathrm{al}^{30}$ found that the risk of a congenitally affected child is considerably higher if the maternal allelle is greater than 300 repeats. Only $10 \%$ of the affected children of mothers with a repeat length $<300$ showed the congenital form, while $60 \%$ of the affected offspring of mothers with a repeat length $>300$ were congenitally affected. ${ }^{30}$

Most of the published data are based upon measurements of repeat lengths in peripheral blood cells. Tissue heterogeneity for the DM mutation has been found, with larger expansions in muscle than in blood. ${ }^{1431}$ The impact of these observations on the inheritance pattern of congenital DM is not clear.

In conclusion the number of parental repeats, the sex of the transmitting parent, and the repeat size of the child are all important factors, but not the only features determining the congenital onset of the disease. Tissue heterogeneity is also hypothesised to play a role. The fact that sib 1 of the present family is congenitally affected, while sib 3 is not, despite having identically sized repeat expansions, cannot be fully explained on the basis of current knowledge about the characteristics of the unstable repeat in DM.

The reported observations of paternal transmission of congenital DM are of clinical importance, especially with regard to genetic counselling. Although patemal transmission of congenital DM is rare, a fertile man with DM has a snall, but not negligible risk of producing a child with congenital DM. What is more, a man with age at onset $>30$ years, and hence the mild or late adult onset type, may have a greater chance of having a congenitally affected child than a father with earlier onset disease. The situation is complicated by the fact that the father himself may still be asymptomatic at the time of birth of the affected child. This is in contrast with the situation in affected women where the risk of a congenitally affected baby increases as the mother is more severely affected. Therefore myotonic dystrophy should be considered in either parent when a baby presents with severe muscular weakness and clinical and molecular studies of both parents should be carried out. 


\section{References}

1 Koch MC, Grimm T, Harley HG, Harper PS. Genetic risks for children of women with. myotonic dystrophy. Am J Hum Genet 1991;48:1084-1091.

2 Harley HG, Rundle SA, MacMillan JC, et al. Size of the unstable repeat sequence in relation to phenotype and parental tranmission in myotonic dystrophy. An J Hum Genet 1993;52:1164-1174.

3 De Die-Smulders CEM, Höweler CJ, Mirandolle JF, et al. Anticipation resulting in elimination of the myotonic dystrophy gene: a follow up study of one extended family. $\mathrm{J}$ Med Genet 1994;31:595-601.

4 Harper PS. Myotonic dystrophy, 2nd ed. London: WB Saunders, 1989.

5 O'Brien TA, Harper PS.Course, prognosis and complications of childhood-onset myotonic dystrophy. Dev Med Child Neurol 1984;26:62-67.

6 Fu YH, Pizzuti A, Fenwick RG Jr, et al. An unstable triplet repeat in a gene related to myotonic muscular dystrophy. Science 1992;255:1256-1258.

7 Höweler CJ, Busch HFM, Geraedts JPM, et al. Anticipation in myotonic dystrophy: fact or fiction? Brain 1989;112:7797-97.

8 Bergoffen J, Kant $\mathrm{J}$, Sladky $\mathrm{J}$, et al. Paternal transmission of congenital myotonic dystrophy. J Med Genet 1994;31:518-520.

9 Nakagawa $M$, Yamada $H$, Higuchi 1 , et al. A case of paternally inherited congenital myotonic dystrophy. J Med Genet 1994;31:397-400.

10 Ohya $\mathrm{K}$, Tachi $\mathrm{N}$, Chiba $\mathrm{S}$, et al. Congenital myotonic dystroplyy transmitted from an asymptomatic father with a DM-specific gene. Neurology 1994;44:1958-1960.

11 Laforet $P$, Heron D, Gourdon G, et al. A new case of paternally inherited congenital myotonic dystrophy. Eur J Neurol suppl 1995;2(suppl 1):29A.

12 Aslanidis C, Jansen G, Amemiya C, et al. Cloning of the essential myotonic dystrophy region and mapping of the putative defect. Nature 1992;355:548-551.

13 Mahadevan M, Tsilfidis C, Sabourin L, et al. Myotonic dystrophy mutation: an unstable CTG repeat in the 3' untranslated region of the gene. Science 1992;255:1253-1255.

14 Jansen $G$, Willems $P$, Coerwinkel $M$, et al. Gonosomal mosaicism in myotonic dystrophy patients: involvement of mitotic events in (CTG) repeat variation and selection against extreme expansion in sperm. Am J Hum Genet 1994;54:575-585.

15 OHoy KL, Tsilfidis C, Mahadevan MS, et al. Reduction in size of the myotonic dystrophy repeat mutation during transmission. Science $1993 ; 259: 809-811$.

16 Jansen $G$, Mahadevan $M$, Amemiya $C$, et al. Characterization of the myotonic dystrophy region predicts multiple protein isoform-encoding mRNAs. Nature Genet 1992;1:261266.

17 Harper PS, Dyken PR. Early onset dystrophia myotonica: evidence supporting a maternal environmental factor. Lancet 1972ii:53-55.

18 Jansen $\mathrm{G}$, Smeets $\mathrm{H}$, Kahisheuer $\mathrm{V}$, et al. Myotonic dystrophy kinase (DM-kinase) gene expression in man and mouse. Am J Hum Genet (suppl) 1993;53:233.

19 Poulton $J$, Harley $\mathbb{H G}$, Dasmahapatra $J$, et al. Mitochondrial DNA does not appear to influence the congenital onset type of myotonic dystrophy. J Med Genet 1995;32:732735.

20 Wieringa B. Myotonic dystrophy reviewed: back to the future. Hum Mol Genet $1994 ; 3: 1-7$.

21 Tsilfidis C, Mackenzie AE, Mettler G, et al. Correlation between CTG trinucleotide repeat length and frequency of severe congenital myotonic dystrophy. Nature Genet 
$1992 ; 1: 192-194$.

22 Hunter $A$, Tsilfidis $C$, Mettler $G$, et al. The correlation of age of onset with $C T G$ trinucleotide repeat amplification in myotonic dystrophy. J Med Genet 1992;29:774-779.

23 Barcelo $\mathrm{MM}$, Pluscauskas M, Mackenzie AE, et al. Additive influence of matemal and offspring DM-kinase CTG repeat lengths in the genesis of congenital myotonic dystrophy. Am J Hum Genet 1994;54:1124-1125.

24 Brunner $\mathrm{HC}$, Bruggenwirth HT, Nillesen, et al. Influence of sex of the transmitting parent as well as of parental allele size on the CTG expansion in myotonic dystrophy. Am J Huim Genet 1993a;53:1016-1023.

25 Redman JB, Fenwick RG Jr, Fu YH, et al. Relationship between parental trinucleotide GCT repeat length and severity of myotonic dystrophy in offspring. JAMA 1993;269:1$960-1965$.

26 Ashizawa T, Dumne PW, Ward PA, et al. Effects of the sex of myotonic dystrophy patients on the unstable triplet repeat in their affected offspring. Neurology $1994 ; 44: 120$ 2.

27 Ashizawa $T$, Anvret $M$, Baiget $M$, et al. Characteristics of intergenerational contractions of the CTG repeat in myotonic dystrophy. Am J Hum Genet 1994;54:414-423.

28 Brunner $\mathrm{HG}_{\text {, Jansen }} \mathrm{G}_{3}$ Nillesen $\mathrm{W}$, et al. Reverse mutation in myotonic dystrophy. $\mathrm{N}$ Engl J Med 1993;328:476-480.

29 Goodship J, Gibson DE, Burn J, et al. Genetic risk for children of women with myotonic dystrophy. Am J Hum Genet 1992;50:1341.

30 Cobo AM, Poza JJ, Martorella $\mathrm{L}$ et al. Contribution of molecular analyses to the estimation of the risk of congenital myotonic dystrophy. J Med Genet 1995;32:105-108.

31 Zatz M, Passos-Buenos MR, Cerquira A, Vainzof M. CTG repeat length in muscle from patients with myotonic dystrophy. J Med Genet 1996;33:173-176. 
Chapter 8.2

\section{Reverse mutation in myotonic dystrophy}

Han G. Brunner ${ }^{1}$, Gert Jansen ${ }^{2}$, Willy Nillesen', Marcel R. Nelen ${ }^{1}$, Christine E.M. de Die-Smulders ${ }^{3}$, Chris J. Höweler ${ }^{4}$, Bernard A. van Oost ${ }^{1}$, Bé Wieringa ${ }^{2}$, Hans-Hilger Ropers ${ }^{1}$, Hubert J.M. Smeets ${ }^{1}$

${ }^{1}$ Department of Human Genetics, University Hospital and Medical Faculty, Nijmegen, the Netherlands, ${ }^{2}$ Department of Cell Biology and Histology, University Hospital and Medical Faculty, Nijmegen, ${ }^{3}$ Department of Human Genetics, University Hospital Maastricht,

${ }^{4}$ Department of Neurology, University Hospital Maastricht

N Engl J Med 1993;328:476-480 
Myotonic dystrophy is a multisystem disorder that is transmitted in an autosomal dominant fashion and is characterized by muscular weakness and atrophy, clinical and electromyographic evidence of myotonia, ocular cataract, and various other abnormalities, such as cardiac conduction disturbances, testicular atrophy in males, premature balding, increased risk from anesthesia, and mental retardation in cases with early onset. 'It is the most common inherited muscular dystrophy of adulthood, with an incidence of approximately 1 per 7500 people. The clinical expression of myotonic dystrophy is variable, ranging from neonatal mortality to a complete absence of symptoms. Recently, the disorder has been shown to be caused by an increased number of cytosine-thymidine-guanine (CTG) trinucleotide repeats in the 3' untranslated region of a protein kinase gene located in the $\mathrm{q} 13.3$ band of chromosome $19 .{ }^{2-8}$ The normal gene has between 5 and 40 CTG trinucleotide repeats, whereas myotonic dystrophy alleles have from approximately 50 to several thousand such repeats. The severity of the clinical symptoms of myotonic dystrophy usually increases with transmission to subsequent generations, a phenomenon that has been termed "anticipation"." This is paralleled by an increase in the length of the CTG repeat sequence. ${ }^{2,5,7} \mathrm{It}$ has been suggested that the progressively increasing severity of myotonic dystrophy eventually leads to the extinction of the disease from a given pedigree. $^{10}$

Genetic theory assumes that there is equilibrium between the incidence of new deleterious gene mutations and their subsequent loss from the population through the reduced viability and fertility of their carriers. No allowance is made in human genetic epidemiology for mechanisms that change the mutation itself from abnormal to normal. Reverse mutation - i.e., the spontaneous correction of a deleterious mutation upon transmission to unaffected offspring - has not been reported in humans, allthough it has been observed at low frequencies in bacteria and cultured mammalian cells.

We report here on two families with myotonic dystrophy in which a reverse mutation has occurred. In the first family, an expanded CTG trinucleotide repeat found in a clinically affected man decreased in size to a normal allele of 24 CTG trinucleotide repeats in his healthy infant daughter. Similarly, in the second family the expanded allele found in the clinically affected father changed to a normal-sized allele containing 19 CTG trinucleotide repeats in his healthy 25-year-old son. The normalization of the mutated myotonic dystrophy gene in these offspring can be explained by the mitotic and (possibly) meiotic instability of the expanded CTG repeat sequence. 


\section{Case Reports}

\section{Family 1}

In Family 1 (Fig.1), prenatal diagnosis was requested by a 25 -year-old woman (Subject II-4) and a 27-year-old man (Subject II-3). Myotonic dystrophy had been diagnosed in the man two years earlier on the basis of mild muscular weakness, clinical and electrical evidence of myotonia, and a family history of the disorder. The family was studied with genetic markers closely linked to the myotonic dystrophy gene. All clinically affected family members carried the same haplotype for the APOC2-VSSM and X75b-VSSM markers, which flank the myotonic dystrophy locus. The proband was heterozygous for these markers. Prenatal diagnosis was therefore considered feasible. The first pregnancy was terminated after DNA-marker analysis performed on a sample of chorionic villus obtained by biopsy indicated that the fetus (Subject III-1) had inherited the myotonic dystrophy mutation. Examination of fetal tissues confirmed the results. The second pregnancy was terminated when intrauterine death was diagnosed by ultrasonography six days after a transcervical chorionic-villus biopsy had been performed. DNA analysis indicated that this fetus (Subject III-2) would have been unaffected. In the third pregnancy, genetic-marker analysis again indicated that the fetus (Subject III-3) had received the abnormal DNA-marker haplotype. In view of the small genetic distances between markers in the region of the myotonic dystrophy gene, ${ }^{11-13}$ the chance that the fetus carried the myotonic dystrophy mutation was estimated to be greater than 99 percent. Mutation analysis ${ }^{7}$ was subsequently performed to determine the size of the CTG repeat in the myotonic dystrophy gene of this fetus in order to obtain more reliable prognostic information.

\section{Family 2}

In Family 2 (Fig. 1), a 23-year-old man (Subject II-2) and his 24-year-old sister (Subject II-1) were examined for signs of myotonic dystrophy because of a history of the disease in several relatives, including their father (Subject I-1). Clinical examination, including electromyography and slit-lamp examination, was normal in both Subject II-1 and Subject II-2. However, analysis with genetic markers flanking the myotonic dystrophy locus showed that the son (Subject II-2) had inherited the paternal chromosome 19 that carries the myotonic dystrophy gene in this family. 

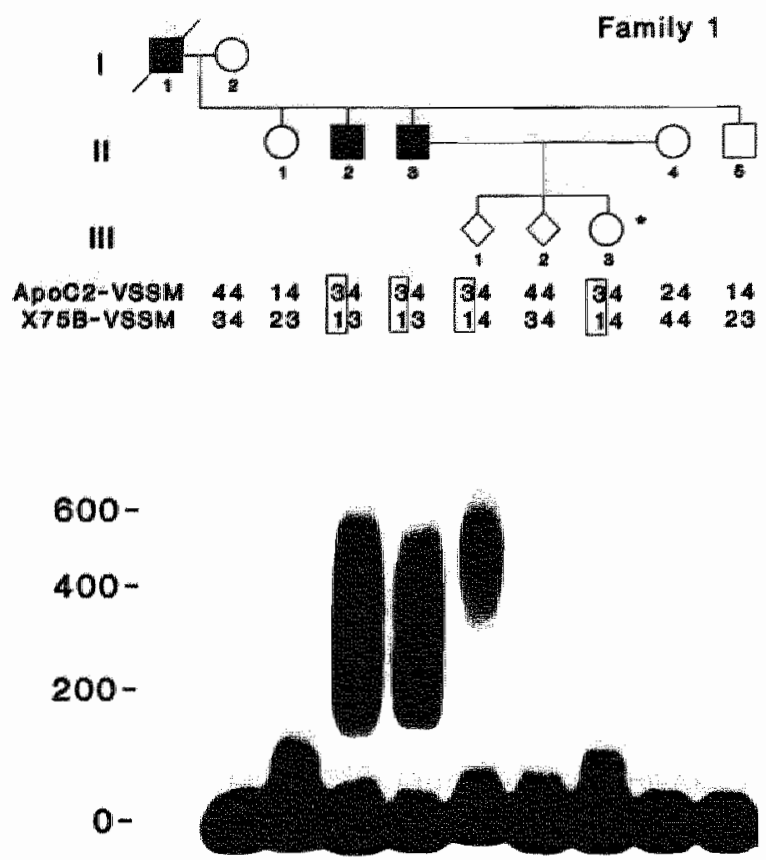

Family 2

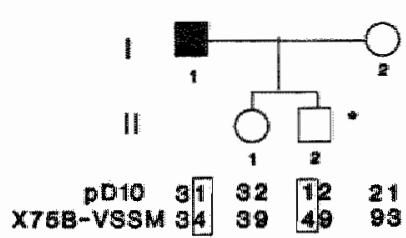

Figure I Linkage Analysis and Mutation analysis in Two Families with Myotonic Dystrophy

The squares denote male family members, and the circles female family members. The slash denotes a deceased family member. Prenatal diagnoses are indicated by diamonds. The shaded symbols indicate clinically affected subjects. Subjects carrying a reverted myotonic dystrophy gene are marked by an asterisk. In Family 1, all the affected subjects carry the 3 allele for the APOC2-VSSM marker and the 1 allele for the X75b-VSSM marker at locus D 195112 (boxed). Subject III-3 has also received these alleles from her father. In Family 2, Subject II-2 has inherited the $\mathbb{1}$ allele for the pD10 marker at locus D19S63 and the 4 allele for the X75bVSSM marker at locus DI9S112. This haplotype (boxed) carries the myotonic dystropliy mutation in several affected family members, including the father (Subject I-2). Mutation analysis (lower panel) detected both normal alleles (with 5 to 40 CTG trinucleotide repeats) and abnormal alleles (with $>50 \mathrm{CTG}$ trinucleotide repeats). The size of the alleles, expressed as the number of CTG trinucleotide repeats, is shown beside the blots. In Family 1 , Subject III-3 does not have an expanded allele. However, the marker haplotype suggests that she has inherited the myotonic dystrophy mutation from her father. In Family 2, Subject I-1 has an abnomal expanded allele of 150 to $500 \mathrm{CTG}$ trinucleotide repeats, whereas his son (Subject II-2) does not have an expanded allele, although this would be expected on the basis of the marker haplotype. 
Because Subject II-2 was now considered to be a carrier of the myotonic dystrophy gene, the clinical examination, including electromyography of 10 muscles was repeated when he was 25 years old. This reexamination revealed no signs of myotonic dystrophy. Because of the discrepancy between the clinical findings and the results of the DNA analysis final diagnosis was deferred until direct detection of the myotonic dystrophy mutation was possible.

\section{Methods}

Chromosomal DNA was isolated from peripheral-blood cells, cultured fibroblasts, or chorionic villi. ${ }^{14}$ Spermatozoa were isolated from semen by single-layer Percoll centrifugation, and DNA was isolated from the sperm pellet. $^{15}$ The genetic markers flanking the myotonic dystrophy mutation and their respective detection methods have been previously described. ${ }^{1-13}$ All the markers were tested at least twice. Using a recently described polymerase-chainreaction assay, ${ }^{7}$ we tested the expansion of the CTG trinucleotide repeat in genomic DNA. The CTG trinucleotide repeat was amplified with flanking primers, and the resulting DNA fragments were separated by electrophoresis on 1 percent and 4 percent agarose gels. A Southern blot, made from the 1 percent gel, was probed with a (CTG) 10 oligonucleotide end-labeled with phosphorus32 , and the hybridizing fragments were visualized by autoradiography. Normal alleles were identified by the same polymerase-chain-reaction assay, with a ${ }^{32} \mathrm{P}$ end-labeled amplification primer. The amplification product was separated by electrophoresis on a 6 percent polyacrylamide- $7 \mathrm{M}$ urea sequencing gel and visualized by autoradiography. For the purposes of paternity testing, several highly polymorphic loci were tested on chromosomes $3,15,17$ and $19 .^{12,16-23}$ The sizes of alleles were determined for each locus by comparison with control samples of known size, as well as by measurement on an automated sequencing system with Gene Scanner software (Applied Biosystems, Foster City, Calif.). An internal-lane size standard (Gene Scan-2500 Rox, Applied Biosystems) was added as a reference control for aligning peak data. The paternity index and the probability of paternity were calculated as previously described. ${ }^{24}$ The research plan was approved by the medical ethics committee of the Nijmegen University Hospital. 


\section{Results}

In Family 1 , genetic markers flanking the myotonic dystrophy mutation indicated that the third fetus (Subject III-3) had received the abnormal chromosome 19 from the father. Analysis of the causative myotonic dystrophy mutation showed an abnormal expanded allele in the father, but not in a sample of chorionic villus from the fetus (Fig.1). The fetus had two normal alleles (Fig. 2 ), the larger of which (with $24 \mathrm{CTG}$ trinucleotide repeats) was apparently inherited from the father.
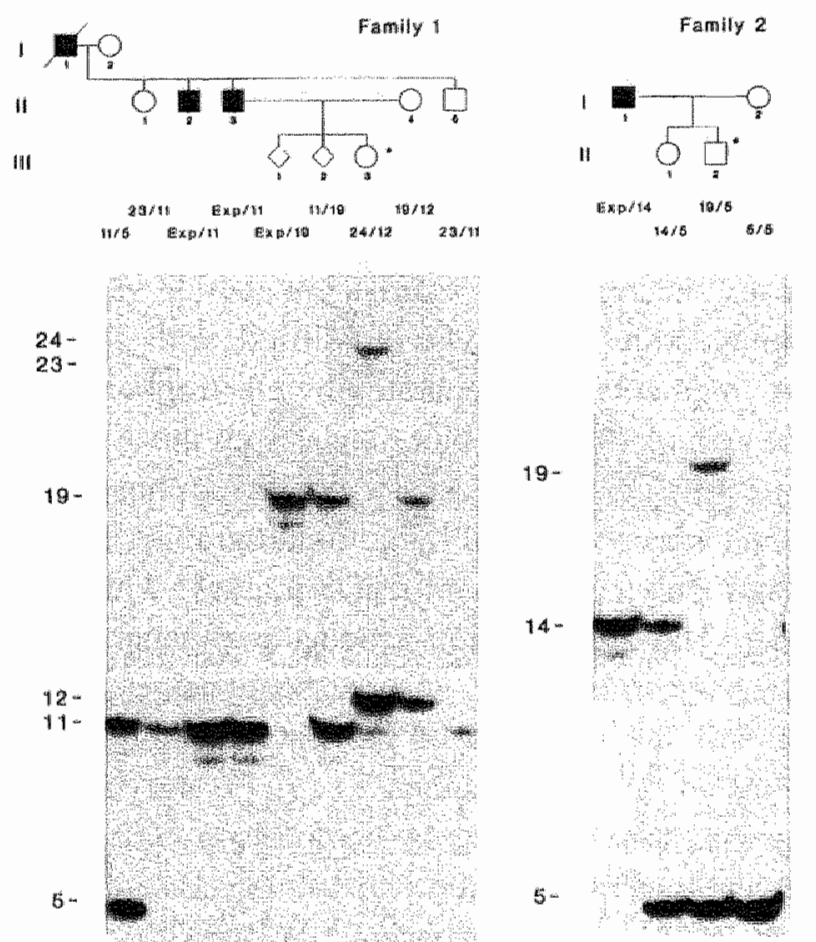

Figure 2 Precise Sizing of CTG Trinucleotide Repeats in Two Families with Myotonic Dystrophy

Only normal alleles (with 5 to 40 CTG trinucleotide repeats) are visualized on 6 percent polyacrylamide-gel electrophoresis. The abnormal expanded (Exp) alleles fall outside the range of fragments detected in this assay. Affected subjects (Subjects II-2, II-3, and TII- 1 in Family 1 and Subject $I m 1$ in Family 2) have only a single band, representing their single normal chromosome 19. Normal subjects (Subjects I-2, II-1, II-4, II-5, and IIJ-2 in Family $I$ and Subject II- 1 in Family 2) have two bands; Subject $1-2$ in Family 2 has only a single band, since she inherited identical normal alleles of five CTG trimucleotide repeats from both her parents. In Family 1 . Subject III-3 inherited a new normal altele of 24 CTG trinucleotide repeats from her affected father. In Family 2 , the mutated allele has decreased in size, from approximately 150 to $500 \mathrm{CTG}$ trinucleotide repeats (Fig. I) in the affected father (Subject I-1) to 19 trinucleotide repeats in his son (Subject III-2). The pedigree symbols are as described in Figure $\Perp$. 
However, this allele was clearly different from the father's normal chromosome 19 , which carried an allele of 11 CTG trinucleotide repeats. This suggested that a reverse mutation had occurred, through which the abnormal expanded CTG trinucleotide repeat in the father (approximately 150 to $600 \mathrm{CTG}$ trinucleotide repeats) (Fig. 1) had decreased in size to a normal allele of $24 \mathrm{CTG}$ trinucleotide repeats in the fetus. After the birth of a normal girl, identical results were obtained in a sample of cord blood and in fibroblasts from the umbilical cord. Attempts to detect mosaicism for the reverted allele were unsuccessful in other tissues from the father. We did not find additional reverted alleles after analyzing DNA from cultured skin fibroblasts and sperm from Subject II-3 (Fig. 3). We used several highly polymorphic systems from chromosomes $3,15,17$, and 19 to exclude the possibility that Subject II-3 was not the girl's father. The probability that Subject II-3 was the biologic father of Subject III-3 was greater than 0.99998 (Table 1).

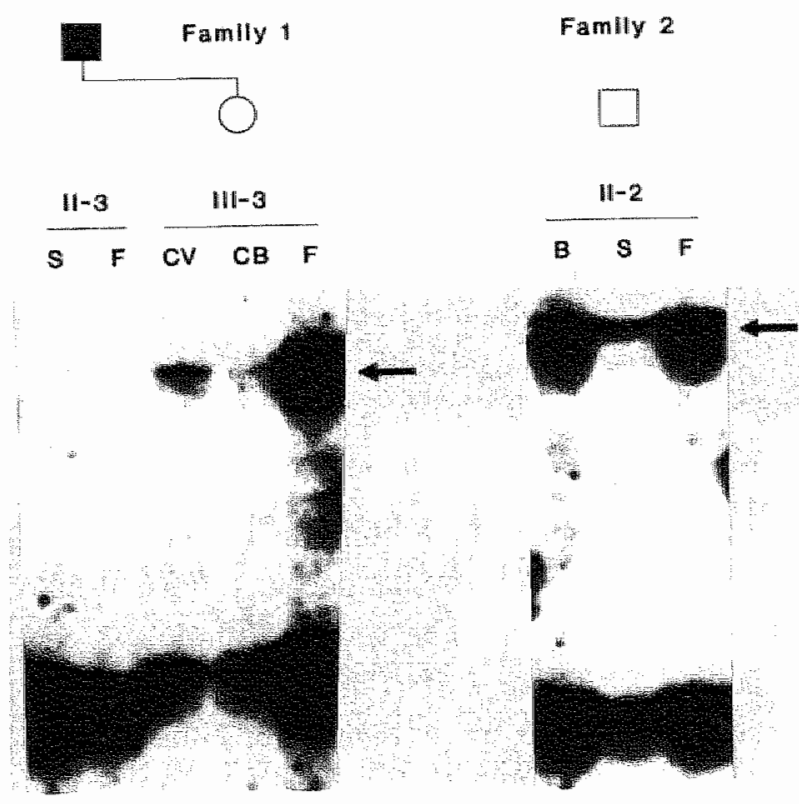

Figure 3 Tissue Testing in Two Families with Reversal of the Myotonic Dystrophy Mutation The pedigree symbols ane as described in Figure 1. The reverted (normal) allele is indicated by arrows. In Family 1. the reverted allele was not found in either sperm (S) or cultured fibroblasts (F) from the father (Subject II-3). In both families the reverted allele was present in various tissues from the healliy offspring. These included a chorionic-villus sample $(\mathrm{CV})$, umbilical-cord blood (CB), and umbilical-cord fibroblasts (CF) from Subject III-3 in Family $I$ and peripheral-blood cells $(B)$, cultured skin fibroblasts, and sperm from Subject $11-2$ in Family 2. 
In Family 2, an asymptomatic 25-year-old man (Subject II-2) had inherited the abnormal chromosome 19 from his father. Expansion of the CTG trinucleotide repeat could not be demonstrated, however (Fig. 1). Instead, there were two normal alleles (Fig. 2), the larger of which (19 CTG repeat units) was inherited from the affected father.

Table I Paternity testing un two families with a reversal of the myotonic dystrophy mutation

\begin{tabular}{|c|c|c|c|c|c|c|c|}
\hline \multirow[b]{3}{*}{ Locus } & & \multicolumn{3}{|c|}{ Family 1} & \multicolumn{3}{|c|}{ Family 2} \\
\hline & & $\begin{array}{l}\text { Nucl } \\
\text { pater } \\
\text { trans } \\
\text { allele }\end{array}$ & $\begin{array}{l}\text { otides in } \\
\text { ally } \\
\text { hitted }\end{array}$ & $\begin{array}{l}\text { Patermity } \\
\text { index }\end{array}$ & $\begin{array}{l}\text { Nucleotides } \\
\text { paternally } \\
\text { transmitted } \\
\text { allele }\end{array}$ & $\begin{array}{l}\text { Pat } \\
\text { ind }\end{array}$ & ernity \\
\hline & Ref. & & $\begin{array}{l}\text { Allele } \\
\text { frequency }\end{array}$ & & & $\begin{array}{l}\text { Allele } \\
\text { frequency }\end{array}$ & \\
\hline D17S513 & 18 & 183 & 0.36 & 1.4 & 193 & 0.33 & 1.5 \\
\hline IL $2 \mathrm{RB}$ & 16 & 149 & 0.18 & 2.4 & 163 & 0.09 & 5.6 \\
\hline D3S11 & 17 & 135 & 0.15 & 3.3 & 135 & 0.15 & 6.7 \\
\hline $\mathrm{HO} \times 2 \mathrm{~B}$ & 19 & 130 & 0.1 & 5 & 132 or 136 & 037 or 0.15 & 1.3 \\
\hline APOC2 & $\begin{array}{l}20 \\
21\end{array}$ & 80 & 0.1 & 5 & 96 & 0.04 & 12.5 \\
\hline D15S\1 & 22 & 253 & 0.07 & 7.6 & 243 & 0.5 & 2 \\
\hline GABRB3 & 23 & $\mathbb{1 9 9}$ & 0.05 & 10 & 183 & 0.09 & 5.7 \\
\hline D $19 S 112$ & 12 & $\mathbb{1 3 2}$ & 0.19 & 2.6 & 128 & 0.05 & 10 \\
\hline $\begin{array}{l}\text { Probability } \\
\text { of paternity }\end{array}$ & & & & $>0.99998$ & & $>0.99$ & 999 \\
\hline
\end{tabular}

The father's mutated myotonic dystrophy gene, which contained approximately 150 to 500 CTG trinucleotide repeats, had therefore changed to a normal-sized allele of $19 \mathrm{CTG}$ trinucleotide repeats in the son. The reverted allele was also present in skin fibroblasts and semen from the son (Fig. 3). There were no abnormal expanded alleles in these tissues. Thus, no evidence for either somatic or germline mosaicism was found in this subject. We used several highly polymorphic DNA markers from chromosomes 3,15,17 and 19 to exclude the possibility that Subject I-1 was not the man's father. The probability that Subject I-1 was the biologic father of Subject II-2 was greater than 0.99999 (Table 1). 


\section{Discussion}

A new class of genetic disease mutations has recently been described that is characterized by the amplification of preexisting trinucleotide-repeat units. ${ }^{25}$ Apart from myotonic dystrophy, ${ }^{2-8}$ the fragile $X$ syndrome ${ }^{26.27}$ and $X$-linked spinal and bulbar muscular atrophy ${ }^{28}$ have been shown to be associated with this type of mutation. In both the fragile $X$ syndrome and myotonic dystrophy, the length of the respective trinucleotide repeats tends to increase in subsequent generations, and there is a positive correlation between the length of a repeat and the severity of the disease. Although transmission of the fragile $X$ mutation is occasionally accompanied by a reduction in repeat length, ${ }^{27}$ this has never resulted in an allele of normal size. In our analysis of more than 100 carriers of the myotonic dystrophy mutation, a decreasing repeat length has been found in only one other family. A complete reversal of the mutated allele that yields a CTG trinucleotide repeat of normal size must therefore be an exceptional event. The mechanism that causes the change from an abnormal expanded allele to a normal-sized allele is unknown. The possibility of single genetic recombination is excluded in these cases, since it would change the DNA-marker haplotype surrounding the mutation. Double recombinants are also highly unlikely, given the small genetic distances in this segment of chromosome 19. Either gene conversion (the substitution of one parental allele for the other ${ }^{29}$ ) or direct deletion of the expanded repeat could explain the reversal of the mutation that we found in these two families.

We considered the possibility that the instability of the expanded CTG trinucleotide sequence in somatic tissues was also present in the father's germlines in the form of a large array of different-sized alleles that included some normal-sized alleles. However, DNA analysis of cultured skin fibroblasts and a sperm sample from the father in Family 1 (Subject II-3) showed a distribution of expanded repeats that was similar (although not identical) to that found in his peripheral blood. Moreover, this analysis failed to detect the presence of reverted alleles (Fig. 3), indicating that if germline mosaicism is present in Subject II-3, the frequency of reverted myotonic dystrophy mutations is very low. Alternatively, the reversal of the mutation in his daughter (Subject III-3) may have occurred in the early embryo.

The fact that the allele lengths in the two subjects described here are entirely within the range found in nomal subjects suggests that they should not have myotonic dystrophy in the future. They thus represent true reverse mutations, 
rather than the nonpenetrance of an abnormal gene. Yet it remains to be established whether their chromosomes have regained the normal stable state, since we do not know whether the expanded trinucleotide-repeat sequence is the onlly cause of the DNA instability in myotonic dystrophy. Analysis of cultured skin fibroblasts and a sperm sample from Subject II-2 in Family 2 showed 5 and 19 CTG trinucleotide repeats, identical to those detected in his peripheral-blood cell (Fig. 3). This suggests that the reverted allele containing 19 CTG trinucleotide repeats is stable in this subject's somatic tissues as well as in his germline.

In conclusion, the two subjects described here are examples of complete spontaneous corrections of myotonic dystrophy mutations. These results should be taken into account when one uses flanking DNA markers for genetic diagnosis, ${ }^{30}$ since it is possible that other genetic conditions in which the phenotype is highly variable will also prove to be associated with the inheritance of unstable DNA sequences. ${ }^{31}$

We are indebted to Dr. R.J. van Kooy and Dr. G.C.M.L. Christiaens, Department of Obstetrics and Gynecology, University Hospital, Utrecht, the Netherlands, for obtaining sperm and chorionic-villus samples; and to Dr. F. Spaans, Department of Clinical Neurophysiology, University Hospital, Maastricht, for performing additional neurophysiologic examinations.

\section{References}

1. Harper PS. Myotonic dystrophy. 2nd ed. W.B. Saunders, London, 1989.

2. Harley HG, Brook JD, Rundle SA, et al. Expansion of an unstable DNA region and phenotypic variation in myotonic dystrophy. Nature 1992;355:545-546.

3. Aslanidis C, Jansen G, Amemiya C, et al. Cloning of the essential myotonic dystrophy region and mapping of the putative defect. Nature 1992;355:548-551.

4. Buxion J, Shelbourne P, Davies $J$, et al. Detection of an unstable fragment of DNA specific to individuals with myotonic dystrophy. Nature 1992:355:547-548.

5. Brook JD, McCurrach ME, Harley HG et al. Molecular basis of myotonic dystrophy: expansion of a trinucleotide (CTG) repeat at the 3 "end of a transcript encoding a protein kinase family member. Cell 1992;68:799-808.

6. Fu Y-H, Pizzuti A, Fenwixk RG Jr. et al. An unstable triplet repeat in a gene related to myotonic muscular dystrophy. Science 1992;255:1256-1258.

7. Mahadevan M, Tsilfidis C, Sabourin L, et al. Myotonic dystrophy mutation: an unstable CTG repeat in the 3'untranslated region of the gene. Science 1992;255:1253-1255.

8. Jansen $\mathrm{G}$, Mahadevan $\mathrm{M}$, Amemiya $\mathrm{C}$, et al. Chacterisation of the myotonic dystrophy region predicts multiple protein isoform-encoding mRNAs. Nature Genet 1992;1:261-266. 
9. Höweler CI, Busch HF, Geraedts JPM, Niermeijer ME, Staal A. Anticipation in myotonic. dystrophy: fact or fiction? Brain 1989:112:779-797.

10. Fleischer B. Uber myotonische Dystrophie mit Katarakt: eine hereditare fumiliare Degeneration. Albrecht von Graefe Arch Opthalmol 1918;96:91-133.

11. Smeets HJ, Hermens R, Brumer HG, Ropers HH, Wieringa B. Identification of variable simple sequence motifs in 19q13.2-qter: markers of the myotonio dystrophy locus. Genomics 1991;9:257-263.

12. Jansen $\mathrm{G}$, de Jong $\mathrm{PJ}$, Amemiya $\mathrm{C}$, et al. Physical and genetic characterization of the distal segment of the myotonic dystrophy area on 19q. Genomics 1992:13:509-517.

13. Harley HG, Brook JD, Floyd J, et al. Detection of linkage disequilibrium between the myotonic dystrophy locus and a new polymorphic DNA marker. Am I Hum Genet 1991;49:68-75.

14. Miller SA, Dykes DD, Polesky HF, A simple salting out procedure for extracting DNA from human nucleated cells. Nucleic Acids Res 1988;16:1215.

15. van Kooij RI, van Oost BA. Determination of sex ratio of spermatozoa with a deoxyribonucleic acid-probe and quinacrine staining: a comparison. Fertil Steril $1992 ; 58: 384-386$.

16. Brewster ES, Brenman MB, Vissing H. Dinucleotide repeat polymorphism in the IL-2RB gene. Nucleic Acids Res 1991;19:4022.

17. Brett PM, Melmer G, Gurling HMD. A microsatellite polymorphism at the D3S11 locus. Nucleic Acids Res 1991;19:6978.

18. Oliphant AR, Wright EC, Swensen J, Gruis NA, Goldgar D, Skolnick MH. Dinucleotide repeat polymorphism at the D17S513 locus. Nucleic Acids Res 1991;19:4794.

19. Deinard AS, Ruano G, Kidd KK. A dinucleotide repeat polymorphism at the HOX2B locus. Nucleic Acids Res 1992;20:1171.

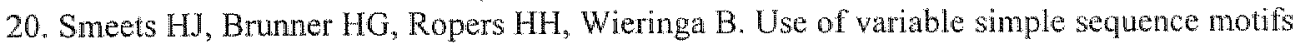
as genetic markers: application to study of myotonic dystrophy. Hum Genet 1989;83:245 251.

21. Fornage $M$, Chan L, Siest $G$, Boerwinkle E. Allele frequency distribution of the (TG)n(AG)m microsatellite in the apolipoprotein C-ll gene. Genomics $1992 ; 12: 63-68$.

22. Mutirangura $A$, Kuwano $A$, Ledbetter $S A$, Chinault $A C$, Ledbetter DH. Dinucleotide repeat polymorphism at the DI5S11 locus in the Angelman/Prader-Willi region (AS/PWS) of chromosome 15. Hum Mol Genet 1992;1:139.

23. Mutrangura A, Ledbetter SA, Kuwano A, Chinault AC, Ledbetter DH. Dinucleotide repeat polymorphism at the GABA, receptor $\beta 3$ (GABRB3) locus in the Angelman/Prader-Willi region (AS/PWS) of chromosome 15. Hum Mol Crenet 1992;1:67.

24. Nijenhuis LE. Paternity case analysis. In: Walker RH, ed. Inclusion probabilities in parentage testing. Arlington, Va.: American Association of Blood Banks, 1983;551 557.

25. Richards RI, Sutherland GR. Heritable unstable DNA sequences. Nature Genet 1992:1:7. 9.

26. Verkerk AJMH, Pierett M, Sutcliffe JS, et al. ldentilication of a gene (FMR-1) containing a $\mathrm{CGG}$ repeat coincident with a breakpoint cluster region exhibiting length variation in fragile $X$ syndrome. Cell 1991;:65:905-914.

27. Rousseau $F$, Heitz D, Biancalana $V$, et al. Direct diagnosis by DNA analysis of the fragile X syndrome of mental retardation. N Engl J Med 1991;325:1673-1681.

28. La Spada AR, Wilson EM, Lubahn DB, Harding AE, Fischbeck KH. Androgen receptor gene mutations in X-linked spinal and bulbar muscular atrophy. Nature 1991;352:77-9.

29. Kourilsky P. Molecular mechanism for gene conwersion in higher cells. Trends Genet $1986 ; 2: 60-63$. 
30. Antonarakis SE. Diagnosis of genetic disorders at the DNA level. N Engl J Med $1989 ; 320: 153-163$

31. Sutherland GR, Haan EA, Kremer $\mathrm{E}_{\mathrm{y}}$ et al. Hereditary unstable DNA: a new explanation of some old genetic questions? Lancet 1991;338:289-292. 
Chapter 9

\section{General discussion}

9.1 Clinical aspects of the study

9.2 Genetic aspects of the study

9.3 Final remarks and future prospects 
Myotonic dystrophy (DM) is a challenging disorder, because of its variable nature with involvement of many tissues and organs, its slow progression as well as the remarkable genetic characteristics, such as anticipation and the exclusive maternal inheritance of the congenital form. From the beginning of this century, elaborate clinical and family studies identified the extent of the clinical picture and the special features of the inheritance. In 1992 the molecular basis for DM was discovered to be an unstable trinucleotide repeat, providing a molecular mechanism for anticipation. The length of the CTG repeat expansion in the DMPK gene appeared to correlate broadly with age at onset and severity of symptoms (Harper et al., 1992). Based on this fact, the classification of patients in disease types became clinically more relevant and generally accepted.

For obvious reasons, research has shifted from clinical to molecular topics during the past 10 years. However, there are still many clinical questions. The knowledge of the symptomatology in the different phases of life is still incomplete. In particular the childhood-onset type is not sufficiently delineated and the differences from the congenital type are not clear. The prognosis for individual patients with the childhood, adult onset or mild type is obscure. Finally, for genetic counselling it is important to get further insight into the behaviour of the mutated gene in families.

Fifty years ago $15 \mathrm{DM}$ families, living in Southern Limburg, were examined and documented by de Jong (1955). These patients and their descendants were the basis for our data collection of DM patients, which was later extended with other families. It offered us the unique opportunity for the long-term clinical and genetic follow-up studies, described in this thesis.

In this way we gained insight in:

- the symptomology of DM in the different age of onset groups, particularly in the childhood-onset type

- the course and prognosis of the childhood and adult onset types

- the long-term consequences of anticipation in one extended family

- aspects of the irregular inheritance of the DM gene, especially the sex differences in transmission

Here we discuss the main conclusions and implications of our study. 


\subsection{Clinical aspects of the study}

\subsubsection{Myotonic dystrophy in children}

Myotonic dystrophy can present from birth to senility, obviously with very different consequences for the patient concerned. The childhood type has been delineated only recently as a separate disease type apart from the congenital type, although it was noted previously that DM may present in childhood without neonatal symptoms (O'Brien and Harper, 1984; Koch et al., 1991). The present study on the childhood-onset type (chapter 2) was undertaken on request of the Dutch organisation for myotonic dystrophy patients. They made us aware that these children had a lot of problems at school and in their social life. Their parents experienced a paucity of professional help and support, due to lack of knowledge and understanding of this disease type. We examined 52 patients with the childhood-onset type of DM, 20 children and 32 adults. Learning and speech problems are the main symptoms in the childhood-onset type. The learning difficulties are due to borderline or mild mental retardation combined with other problems, such as slowness and extreme tiredness (chapters 2.1 and 2.3). Also previously unrecognised behavioural and psychiatric problems, such as attention deficit hyperactivity disorder (ADHD) and anxiety disorder, appeared to be part of the clinical picture (chapter 2.2).

The childhood-onset type shares the presence of mental retardation with the congenital type. However, the initial absence of muscular weakness distinguishes it from congenital DM. It is still not known how the expanded CTG repeat causes the brain symptoms in the congenital and childhood types and whether the mental retardation results from cerebral developmental abnormalities. Neuroimaging and pathological studies of the brain have revealed abnormalities in some cases, such as ventricular dilatation, hypoplasia of the corpus callosum and malformations of the cerebral cortex (Rosman and Kakulas, 1966; Harper, 1989; Hashimoto et al., 1995). However, more research is needed on the "brain phenotype" in DM affected children, and we should advance the frontier of research in molecular brain pathophysiology in order to get better understanding in the etiology of the mental impairment in these children (Ashizawa, 1998).

It is important for clinical practice to distinguish childhood DM as a separate disease type, apart from the congenital type. The clinical presentation of the two disease type differs, but also the prognosis and transmission pattern. In general the prospects for childhood affected children are more favourable as 
for congenital onset patients (chapter 2.1, further discussed in 9.1.2). In contrast to the congenital type, childhood-onset DM can be transmitted by parents of both sexes (further discussed in 9.2.2). Finally, the childhood type is probably as frequent as congenital DM, as $12 \%$ of the subjects in our data collection of 370 patients had this type, compared with $9 \%$ with the congenital type. Matthieu et al. (1999) found similar frequencies for the childhood and congenital type.

\subsubsection{Prognosis}

An important issue for most (parents of) DM patients is their prognosis, and this concerns as well the course of the disease as their life expectancy. Most studies on DM are transversal, which is not suitable to study the natural history of a disease with such a variable age at onset and slow progression. Only recently, a long-term follow-up study of patients with congenital DM and a longitudinal study of mortality in DM patients with different ages at onset were published (Reardon et al., 1993; Mathieu et al,, 1999). By distinguishing the four disease types it is now possible to give some indication for a prognosis.

Prognosis of children with DM

The prognosis for congenital and childhood DM is mainly determined by their mental retardation: patients are not able to live an independent life and to be gainfully employed (chapter 2; O'Brien and Harper, 1984; Reardon et al., 1993). Physical disabilities, in particular walking problems, are less severe in childhood DM, compared with the congenital type (chapter 2.1). Life expectancy for the childhood type is also more favourable than for the congenital type. Only $50 \%$ of congenitally affected patients survive into the mid-30s, whereas the majority of the childhood onset cases reach the age 35 (chapter 2.1; Reardon et al., 1993) In the study of Mathieu et al. (1999) the mean age at death for the childhood type was 44.7 years.

Prognosis of adult-onset DM

In adult-onset DM patients disability occurs later in life and is determined more by muscular weakness and organ complications than by mental symptoms. Walking problems occur in a late phase of the disease, when distal limb weakness progresses to the proximal muscles. We found that half of the patients became wheelchair-bound in the years before death, which is far more than the $4.4 \%$ wheelchairdependence reported previously in a cross-sectional study of DM patients of all disease types (chapter 3; Mathieu et al., 1992). Survival to the age of 45 is nearly normal (chapter 3). However, only $50 \%$ of the patients with the adult-onset type reach the age of 60 years, and $18 \%$ reach the age of 65 
years, which is far less than expected. Cardiac rhythm disturbances and pneumonia were the most frequent causes of death (chapter 3). In the mild (late onset) type disability occurs only at old age, but the prognosis has not been documented systematically.

In conclusion, it has now become clear that the prognosis of DM is related to the age at onset and thus to the DM disease type. Survival in DM affected patients is reduced, at least in the congenital, childhood and adult-onset types. Interestingly, Thornton (1999) suggested that DM is possibly a genetic model for accelerated ageing because of the shortened lifetime of patients and the similarity of some features, such as cataract, muscle wasting, balding and cardiac rhythm disturbances, with normal senescence.

Consequences for management

Many patients perceive that not only the disorder is incurable but also that there is nothing that can be done to help improve quality of life or to reduce the morbidity and mortality associated with the condition. Because this view is also held by most clinicians, often no regular follow-up arrangements are made (Hilton-Jones, 1997). Surveillance of cardiac conduction defects by annual ECG control is strongly warranted (chapter 3, Philips and Harper, 1997). Life threatening complications as aspiration pneumonia should be managed in time. Preventive measures, particularly avoidance of obstetric complications and surgical and anaesthetic hazards in patients with advanced disease, should be given priority (chapter 3, Harper, 1998; Mathieu et al., 1997). Finally, the importance of giving patients and families full information regarding their condition should not be underestimated. Also patient support groups are of great value in the guidance of patients and their relatives.

\subsection{Genetic aspects of the study}

The genetic aims of this study concentrated on the long term consequences of anticipation and the sex differences in transmission.

\subsubsection{The anticipation cascade}

The transmission of DM is characterised by anticipation, which can be explained by the progressive expansion of the unstable CTG repeat (Brook et al., 1992; Harper et al., 1992). However, the complete pattern of clinical anticipation in conjunction with the changes of the CTG repeat expansion over several 
generations has not yet been examined. Only a number of parent-child pairs and 3-4 generation families have been reported (Ashizawa et a!., 1992; Brunner et al., 1992; Myring et al., 1992; Barceló et al., 1993; Redman et al., 1993; Shelbourne et al., 1993; Ashizawa et al., 1994; Cobo et al., 1995; Passos-Bueno et al., 1995; Simmons et al., 1998). In a follow-up study of a large family of 5 generations (chapter 7) we showed that anticipation is a relentless process, occurring in all affected branches of this family. The anticipation cascade was found to proceed asynchronously in the different branches, mainly because of an unequal number (2-4) of generations with mild disease. As a consequence of this unequal course of the cascade, we found asymptomatic gene carriers as well as severely affected patients in the same generation. The classical three step cascade (mild-adult-childhood/congenital type) was often shortened to two generations, because of infertility of males with adult-onset disease or direct conversion of the mild type into the childhood type. We found that the mutated gene will probably be eliminated from this pedigree in the near future, owing to ongoing clinical and molecular anticipation. Gene loss in the patient group was due to infertility of males with adult onset disease and lack of reproduction of mentally retarded patients with congenital and childhood-onset disease (chapter 7).

Assuming that the gene loss from known families is complete, one may wonder why DM is still so frequent in the population. It has been suggested that asymptomatic protomutation carriers from known families may spread the gene to the next generations. (Barceló et al., 1993). However, we proved that clinical and molecular anticipation are inevitable in a family, once the mutated gene has reached a certain critical grade of instability. Consequently, we found no protomutations in the youngest generations. A second possible source of new DM patients are the contracted repeats in known families. However, these reductions of the number of CTG are infrequent ( $6 \%$ of transmissions) and are usually not associated with a milder phenotype in the offspring (Ashizawa et al, 1994). Although the long-term consequences of these contracted repeats have not yet been studied, it is unlikely that they will prolong the reproductive fitness of a DM kindred with more than a few generations. The most likely origin of new mutations is the pool of normal individuals with high normal (premutated) repeat lengths, who may gradually increase over many generations, until the critical limit of instability is reached (chapter 6). Additional multigenerational family studies will be required to get further insight into the dynamics of the unstable CTG repeat, the clinical expression patterns and the possible factors 
determining instability. Moreover, genealogical studies combined with molecular data, may give a further clue to the origin of DM in families and in the population.

\subsubsection{Sex effects on transmission}

Clear sex differences in the transmission of DM are well known. Most strikingly, the congenital type is exclusively of maternal origin, with only a few exceptions recently reported. In chapter $8 . \|$ we describe a rare case of paternally transmitted congenital DM and review the six previously reported cases. All children with paternally derived congenital DM showed large repeat expansions in the DM gene, similar to maternally transmitted cases. In contrast to congenital DM, the childhood type is transmitted almost equally by male $(43 \%)$ and female $(57 \%)$ gene carriers (chapter 2.1$)$. Furthermore, we found that these childhood cases showed large CTG repeats in their DM gene, in the same range as in congenitally affected children (chapter 2.1), which is in accordance with the results of others (Harley et al., 93; Redman et al., 1993; Barceló et al., 1994.

The near absence of paternal transmission of congenital DM is usually explained by the behaviour of the unstable repeat on transmission. Males with large repeat expansion show a limited ability for repeat expansion in sperm, whereas females show greater intergenerational amplification, with larger parental repeat length. Therefore, sperm may be unable to support the large expansions necessary for congenital DM, as opposed to some mechanism(s) which allow for large expansions in female transmissions. (Chapter 5; Mulley et al., 1993; Jansen et al., 1994; Monckton et al., 1995). A diminished fertility of males with (early) adult-onset disease may further contribute to the near absence of paternally derived long alleles with concomitant congenital DM (Jansen et al., 1994; Harper, 1996).

However, we found that large alleles in offspring can wery well be paternally inherited (chapter 2.1), and that they usually originate from fathers with mild or (late) adult onset disease. These paternally transmitted large expansions only rarely result in congenital DM. As a rule childhood DM is the consequence. Cases of very large transmissions from males, resulting in childhood DM but not in congenital DM, were also reported by others (PassosBueno et al., 1995). In contrast, maternally transmitted large repeats may result either in congenital òr childhood onset disease in offspring.

At present these sex-of-parent effects on disease severity in offspring, can neither be explained by differences in the repeat length of the children nor by the 
sex related differences in behaviour of the CTG repeat. One might propose a modifying factor on the disease phenotype in offspring, dependent on the sex of the transmitting parent. Such an effect may stem from direct influences exerted by the uterine environment, in case of an affected mother (Harper and Dyken, 1972; Barceló et al., 1994; Harper, 1996). The presence of a familial predisposition was suggested by Lavedan et al. (1993) as they noticed that transmitting sisters usually gave birth to children with the same disease type. Alternatively, genetic factors, such as a differential expression of the gene in different tissues, dependent on the sex of the transmitting parent or sexdependent methylation differences, may be involved. Although initial studies gave no evidence for methylation differences between maternally and paternally derived alleles (Jansen et al., 1993; Shaw et al., 1993) Steinbach et al. (1998) found hypermethylation in young severely affected, mostly congenital onset patients, with a maternally transmitted disease allele. Also in our patient with paternally derived congenital DM (chapter 8 ) this hypermethylation was shown, refuting the proposition of sex-dependent methylation (Steinbach, personal communication 1998).

A second remarkable sex effect in the transmission of DM, is the predominance of male gene carriers in the last generation before the disease becomes clinically recognisable in a family. At the molecular level it was confirmed that the transition from protomutation to mutation is preferentially associated with male transmission (Brunner et al., 1993). In our large DM family we also found that 15 of the sixteen transmission from mild to adult onset disease resulted from male transmission (chapter 7). The explanation for this increased tendency to instability on male transmission is unknown. One possibility is that it simply reflects the larger number of cell divisions in spermatogenesis than in oogenesis, thereby increasing the chance of expansion of small repeats through male transmission (Brunner et al., 1993; Waring and Korneluk, 1998). Sex-specific differences in mutational rates of small alleles were also found in transgenic mice (Monckton et al., 1997).

Finally, a sex related effect is observed in the intergenerational contractions of the repeat. In chapter 8.2 we describe two exceptionall cases of a reverse mutation of a paternally inherited expanded DM allele into the normal range. Ashizawa et al. (1994) showed that reductions of the CTG repeat number are predominantly (three to one) associated with male transmission. An explanation for the mechanism of these contractions is still lacking, but it is 
possibly due to the general tendency to repeat contraction in spermcells of males with large somatic repeats (chapter 5).

In conclusion, parent-of-origin effects upon transmission of the DM gene may be explained only partly by the behaviour of the unstable gene on transmission. The discussion on sex and disease type might well become more clear when studies of the distribution of the CTG repeat length and the expression of the gene in different cell types and tissues become available, and can be compared in paternally and maternally derived congenital and later onset cases.

\subsection{Final remarks and future prospects}

By combining long-term clinical and genetic data we extended the knowledge on the different DM disease types, in particular the childhood onset type. Also, the prognosis of adult-onset and childhood type has been clarified. The genetic data presented in this thesis contribute to the understanding of the behaviour of the unstable gene and the consequences for families. However, many clinical as well as basic research questions remain to be investigated. More studies on DM in childhood are needed to further delineate the clinical spectrum and its variability, and to note the changes with time. Special attendance for the behavioural phenotype and the management of psychological and childpsychiatric problems is recommended. Long-term follow-up studies, taking into account the age at onset and/or the disease type may further clarify the course of the disease, in particular the progression of muscle weakness and the extent and timing of the systemic complications. Furthermore, an attempt should be made to the identification of possible predictive factors. Finally, a better insight into the complex pathophysiology of DM is of importance to explain the unusual genetic features and to get a better understanding of the variability and the multisystem nature of DM. Studies of the degree of expansion of the CTG repeat in different tissues of humans and in animal models and the report of families with unusual clinical presentation of DM might be of great importance in that light. Prior to this probably long-term aim we should now concentrate on the development of optimal strategies for support of the patients and their families. 


\section{References}

Ashizawa T, Dubel JR, Dunne PW, Dume CJ, Fu YH, Pizzuti A, Caskey CT, Boerwinkle E, Perryman MB, Epstein HF, Hejtmancik JF. Anticipation in myotonic dystrophy. II. Complex relationships between clinical findings and structure of the GCT repeat. Neurology $1992 ; 42: 1877-1883$.

Ashizawa T, Anvret M, Bäget M, Barceló JM, Brunner $H$, Cobo AM, Dallapiccola $B$, Fenwick RG, Grandell U, Harley H, Junien C, Koch MC, Komeluk RG, Lavedan C, Miki T, Mulley IC, Lopez de Munain A, Novelli G, Roses AD, Seltzer WK, Smeets H, Shaw DJ, Sutherland GR, Yamagata H, Harper PS. Characteristics of intergenerational contractions of the CTG repeat in myotonic dystrophy. A.m J Hum Genet 1994;54:414-423.

Ashizawa T. Myotonic dystrophy as a brain disorder. Arch Neurol 1998;55:291-293.

Barceló JM, Mahadevan MS, Tsilfidis C, ManKenzie AE, Korneluk RG. Intergenerational stability of the myotonic dystrophy protomutation. Hum Mol Genet 1993;2:705-709.

Barceló $\mathrm{M}$, Pluscauskas $M$, MecKenzie AE, Tsilfidis $C$, Naranc M, Komeluk RG. Additive influence of maternal and offspring DM-kinase gene CTG repeat length in the genesis of congenital myotonic dystrophy. Am ff Hum Genet 1994:54:1124-1125.

Brook JD, Mc Currach ME, Harley HG, Buckler AJ, Church D, Aburatani H, Hunter KI, Stanton VP, Thirion J-P, Hudson T, Sohn R, Zemelman B, Snell RG, Rundle SA, Crow S,

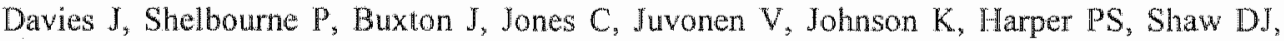
Housman DE. Molecular basis of myotonic dystrophy: expansion of a trinucleotide (CTG) repeat at the 3 'end of a transcript encoding a protein kinase family member. Cell 1992;68:799808.

Brunner $\mathrm{HG}$, Nillesen $W$, van Oost $B A$, Jansen $G_{6}$ Wieringa $B$, Ropers HH, Smeets HJM. Presymptomatic diagnosis of myotonic dystrophy. J Med Genet 1992;29:780-784.

Brunner HG, Brüggenwirth HT, Nillisen $W$, Jansen $G$, Hamel BCJ, Hoppe RLE, de Die CEM, Höweler CJ, van Oost BA, Wieringa B. Ropers HH, Smeets HJM. Influence of sex of the transmitting parent as well as of parental allele size on the CTG expansion in myotomic dystrophy. Am J Hum Genet 1993;53:1016-1023.

Cobo AM, Poza JJ, Martorell L, López de Munain A, Emparanza JI, Baiget M. Contribution of molecular analyses to the estimation of the risk of congenital myotonic dystrophy. I Med Genet 1995;32:105-108.

Hatley HG, Rundle SA, MacMillan JC, Myring J, Brook JD, Crow S, Reardon W, Fenton I, Shaw DJ, Harper PS. Size of the unstable repeat sequence in relation to phenotype and parental tranmission in myotonic dystrophy. Am J Hum Genet 1993;52:1164-1174.

Harper PS and Dyken PR. Early onset dystrophia myotonica-evidence supporting a maternal environmental factor. Lancet 1972;2:53-55.

Harper PS. Myotonic dystrophy, 2nd edm. WB Saunders, London and Philadelphia, 1989.

Harper PS, Harley HG, Reardon W, Shaw DV. Anticipation in myotonic dystrophy: new light on an old problem. Am J Hum Genet 1992;51:10-16.

Harper PS. Myotonic dystrophy. In: Rimoin DL, Connor JM, Pyeritz RE (eds), Emery and Rimoin's principles and practice of medical genetics. Churchill Livingstone, New York, 1996.

Harper PS. Myotonic dystrophy as a trinucleotide repeat disonder-a clinical perspective. In: Wells RD, Warren ST (eds). Genetic instabilities and hereditary neurological disorders. Acadenic Press, San Diego, 1998. 
Hashimoto T, Tayama M, Miyazaki M, Murakawa $K_{n}$ Kawai $H$, Nishitani $H$, Kuroda $\Upsilon^{r}$. Neuroimaging study of myotonic dystrophy. I. Magnetic resonance imaging of the brain. Brain Dev 1995; 17: 24-27.

Hilton-Jones D. Myotonic dystrophy-forgotten aspects of an often neglected condition. Current Opinion in Neurology 1997;10:300-401.

Jansen $\mathrm{G}$, Bartolomei $\mathrm{M}$, Kalscheuer $\mathrm{V}$, Merkx $\mathrm{G}$, Wormskamp $\mathrm{N}$, Mariman E, Smeets D, Ropers HH. Wieringa B. No imprinting involved in the expression of DM-kinase mRNAs in mouse and human tissues. Hum Mol Genet 1993;2:1221-1227.

Jansen $G$, Willems $P$, Coerwinkel $M$, Nillesen $W$, Smeets $H$, Vits L, Höweler $C$, Brunner $H$, Wieringa $\mathrm{B}$. Gonosomal mosaicism in myotonic dystrophy patients: involvement of mitotic events in $(\mathrm{CTG})_{\mathrm{n}}$ repeat variation and selection against extreme expansion in sperm. Am J Hum Genet 1994;54:575-585.

Jong de JGY. Dystrophia myotonica, paramyotonia and myotonia congenita. Thesis, University of Utrecht, 1955.

Koch MC, Grimm T, Harley HG, Harper PS. Genetic risks for children of women with myotonic dystrophy. Am J Hum Genet 1991;48:1084-1091.

Lavedan C, Hofmann-Radvanyi H, Shelboume P, Rabes JP, Duros C, Savoy D, Dehaupas I, Luce $\mathrm{S}$, Johnson $\mathrm{K}$, Junien C. Myotonic dystrophy: size- and sex-dependent dynamics of CTG meiotic instability, and somatic mosaicism. Am J Hum Genet 1993;52:875-883.

Mathieu J, De Braekeleer M, Prévost C, Boily C. Myotonic dystrophy: clinical assessment of muscular disability in an isolated population with presumed homogeneous mutation. Neurology $1992 ; 42: 203-208$.

Mathieu J, Allard P, Gobeil G, Girard M, De Braekeleer M, Bégin P. Anaesthetic and surgical complications in 219 cases of myotonic dystrophy. Neurology 1997,49:1646-1650.

Mathieu J, Allard P, Potvin L, Prévost C, Bégin P. A 10-year study of mortality in a cohort of patients with myotonic dystrophy. Neurology 1999;52;1658-1662.

Monckton DG, Wong L-Jc, Ashizawa T, Caskey CT. Sonatic mosaicism, germline expansions, germline reversions and intergeneretional reductions in myotonic dystrophy males: small pool PCR analyses. Hum Mol Genet 1995;4:1-8.

Monckton DG, Coolbaugh MI, Ashizawa KI", Siciliano MJ, Caskey CT Hypermutable myotonic dystrophy CTG repeats in transgenic mice. Nature Genet 1997; 15:193-196.

Mulley JC, Staples A, Donnelly A, Gedeon AK, Hecht BK, Nicholson GA, Haan EA, Sutherland GR. Explanation for exclusive maternal origin for congenital forn of myotonic dystrophy, Lancet 1993;341:236-237.

Myring J, Meredith AL, Harley HG, Kohn $G$, Norbury $G$, Harper PS, Shaw DJ. Specific molecular prenatal diagnosis for the CTG mutation in myotonic dystrophy. I Med Genet $1992 ; 29: 785-788$.

O'Brien TA, Harper PS. Course, prognosis and complications of childhood-onsel myotonic dystrophy. Dev Med Child Neurol 1984;26:62-67.

Passos-Bueno MR, Cerqueira A, Vainzof M. Marie SK, Zatz M. Myotonic dystrophy: genetic, clinical and molecular analysis of patients from 41 Brazilian families. J Med Genet $1995 ; 32: 14-18$.

Philips MF, Harper PS. Cardiac disease in myotonic dystrophy. Cardiovascular Research 1997;33:13-22.

Reardon W, Newcombe R, Fenton I, Sibert J. Harper PS. The natural history of congenital myotonic dystrophy: mortality and long term clinical aspects. Arch Dis Child 1993;68:177181. 
Redman JB, Fenwick RG, Fu Y.H, Pizzuti A, Caskey T. Relationstip between parental trinucleotide GCT repeat length and severety of myotonic dystrophy in offspring. JAMA $1993 ; 269: 1960-1965$.

Rosman NP, Kakulas BA. Mental deficiency associated with muscular dystrophy. A neuropathological study. Brain 1966;89: 769-787.

Shaw DJ, Chaudhary S, Rundle SA, Crow S, Brook JD, Harper PS, Harley HG. A study of DNA methylation in myotonic dystrophy. J Med Genet 1993b-30:189-192.

Shelboume P, Davies J, Buxton J, Anvret M, Blennow E, Bonduelle M, Schmedding E, Glas 1, Lindenbaum $R$, Lane $R$, Williamson $R$, Johnson $K$. Direct diagnosis of myotonic dystrophy with a disease-specific DNA marker. N Engl J Med 1993;328:471-475.

Simmons $Z$, Thornton CA, Seltzer WK, Richards CS. Relative stability of a minimal CTG repeat expansion in a large kindred with myotonic dystrophy. Neurology 1998;50:1501-1504.

Steinbach P, Gläser D, Voge』W, Wolf M, Schwemmle S. The DMPK gene of severely affected myotonic dystrophy patients is hypermethylated proximal to the largely expanded CTG repeat. Am J Hum Genet 1998;62:278-285.

Thornton C. The myotonic dystrophies. Semin Neurol 1999;19:25-33.

Waring JD, Korneluk RG. Genetic studies of the myotonic dystrophy CTG repeat.In: Wells RD, Warren ST (eds). Genetic instabilities and hereditary neurological disorders. Academic Press, San Diego, 1998. 


\section{Summary}

Myotonic dystrophy (DM) is an autosomal dominant disorder, characterised by the occurrence of myotonia and muscle weakness in conjunction with systemic complications. The severity of DM is extremely variable and related to the age at onset and duration of symptoms. Follow-up studies are difficult to perform, due to the slow progression of the disease. In 1955 several DM patients and their families, originating from the Southern part of Limburg, were described by the neurologist de Jong. This data-collection was extended and continued and was the basis for the long-term clinical and genetic studies described in this thesis.

In chapter 1 a summary of the clinical features in DM is given. Muscular weakness primarily involves the facial, neck and distal limb muscles. In time, the proximal muscles of the extremities will also be affected. Complications of various organ systems may occur, such as cataract, cardiac rhythm disturbances, respiratory problems and gastrointestinal symptoms. These systemic difficulties are of main importance in management and prognosis of the disease. In children with DM mental retardation is common. Based on age at onset and predominant symptoms four disease types can be recognised: mild, adult, childhood-onset and congenital type.

Chapter 2 deals with the results of a study on the childhood type of DM. In Chapter 2.1 the clinical and genetic aspects are discussed. The childhood type is characterised by learning and speech problems in combination with various somatic problems, such as chronic fatigue, slowness and abdominal complaints. The general outlook was poor with respect to independent living and working. After the age of 40 walking problems and serious dysarthria became evident. The childhood type was transmitted by mothers $(57 \%)$ or fathers $(43 \%)$, one third of the parents were either asymptomatic or only mildly affected. In chapters 2.2 and 2.3 the cognitive and behavioural profile is described. Mean full-scale IQ was 80 , without significant difference between verbal and performal IQ. Behavioural problems, such as withdrawal, social - and attention difficulties, were present in $1 / 3$ of the subjects. In half of the children a childpsychiatric diagnosis was made, attention deficit hyperactivity disorder (ADHD) and (separation) anxiety disorder were most frequent. 
Chapter 3 addresses the results of a study on age and causes of death in 83 patients with adult-onset type of DM. The survival to the age of 65 years was markedly reduced, with a median survival of 60 years. Pneumonia and cardiac arrhythmias were the most frequent causes of death $(31 \%$ and $29 \%$ respectively). Half of the patients were wheelchairbound shortly before death.

In chapter 4 an overview of the trinucleotide repeat disorders is given. The recently delineated mechanism of trimucleotide repeat expansion is responsible for a number of (mainly neurological) diseases, such as fragile $\mathrm{X}$ syndrome, myotonic dystrophy, Huntington's disease or the dominant ataxias. Instability and parental sex effects are characteristic upon transmission.

Literature data on the genetics of DM are summarised in chapter 5. DM is caused by an expanded CTG repeat in the DMPK (myotonic dystrophy protein kinase) gene on the long arm of chromosome 19. The inheritance of DM is characterised by anticipation, a progressive earlier age at onset in successive generations, accompanied by increasing expansion of the CTG repeat. The molecular mechanism by which the CTG expansion causes DM is still unknown. Various hypotheses including alterations in DMPK expression, a negative effect on the transcription of neighbouring genes, or alterations in RNA metabolism are all being actively pursued, without definitive solutions.

Chapter 6 comprises a summary on the literature of the epidemiology and the origin of the DM mutation. The prevalence of DM differs considerably between various ethnic groups. Linkage studies point to a common origin of most DM cases. It has been suggested that all cases originate from just a few ancestral mutations. Normal sized "premutated" repeats may gradually increase over many generations until a critical limit for instability and clinical expression is reached. The explanation for the high prevalence of DM, despite its low reproductive fitness, is presumably due to this continued supplement of new cases from the "gene pool".

Chapter 7 concerns a follow-up study of a 5 generation DM family. Clinical anticipation appeared to be a relentless process, occurring in all affected branches of the family. Gene loss in the patients of the youngest generations was complete, owing to infertility of the male patients with adult-onset disease and the lack of procreation of mentally retarded patients. We conclude that it is 
highly likely that the gene will be eliminated from this family within one generation.

In chapter 8 aspects of the unusual inheritance of DM are discussed. A rare case of paternal transmission of congenital DM is described (chapter 8.1), completed by an overview of the sex related effects on transmission of the congenital type. The almost exclusive maternal inheritance of congenital DM can only partly be explained by the behaviour of the unstable repeat upon transmission. Two cases of complete reversal of the DM mutation into the normal range, are presented in chapter 8.2 . In both cases the father was the transmitting parent.

Finally, in chapter 9 the results of the study are discussed and some future perspectives are given. 


\section{Samenvatting}

Myotone dystrofie is een autosomaal dominant overervende spierziekte, die gekenmerkt wordt door het optreden van myotonie (een vertraagde relaxatie van de spieren na aanspanning) en spierzwakte, in combinatie met afwijkingen van diverse andere organen. De ernst van de aandoening kan van patiënt tot patiënt sterk verschillen en hangt onder andere af van de beginleeftijd en de ziekteduur. Vervolgstudies zijn moeilijk uit te voeren, omdat de aandoening zeer langzaam progressief is. In 1955 werden een groot aantal myotone dystrofie patiënten en hun familieleden, allen afkomstig uit Zuid-Limburg, beschreven in het proefschrift van de Jong, destijds neuroloog te Heerlen. Deze gegevens verzameling is sindsdien voortgezet en uitgebreid, en vormt de basis voor het klinisch en genetisch vervolgonderzoek, wat in dit proefschrift beschreven wordt.

In hoofdstuk 1 wordt een samenvatting van de klinische verschijnselen gegeven. In de beginfase van de ziekte zijn met name de gelaatsspieren, de halsspieren en de distale arm- en beenspieren aangedaan. Later worden ook de bovenbeen- en bovenarmspieren zwak. Symptomen van andere orgaansystemen, zoals staar, hartritmestoornissen, ademhalings- en darmproblemen, treden vaak op. Deze orgaancomplicaties zijn meestal bepalend voor de prognose en dienen adequaat behandeld te worden. Kinderen met myotone dystrofie hebben vaak een verstandelijke handicap. Men kan myotone dystrofie onderverdelen in 4 typen, elk met hun eigen beginleeftijd en symptomatologie: het milde type, het volwassen type, het kindertype en het congenitale type.

Hoofdstuk 2 is een verslag van een onderzoek naar het kindertype van myotone dystrofie. De klinische en genetische aspecten worden bellicht in hoofdstuk 2.1. Leer- en spraakproblemen zijn kenmerkend voor de kindervorm. In combinatie hiemee komen een aantal andere problemen voor, zoals chronische moeheid, traagheid en buikklachten. Ook de toekomstverwachtingen werden nagegaan. Geen van de oudere patiënten bleek in staat tot een zelfstandig leven of had een normale baan. Loopproblemen en ernstige spraakproblemen traden op na het $40^{\text {ste }}$ levensjaar. De ziekte kon zowel door aangedane moeders $(57 \%)$ als door aangedane vaders $(43 \%)$ worden overgedragen. Opvallend daarbij was dat $1 / 3$ van de aangedane ouders wel gendrager waren, maar geen of slechts milde symptomen had. Ook het cognitief functioneren werd onderzocht en de 
kinderen ondergingen een psychologisch onderzoek. Het gemiddelde intelligentiequotiënt (IQ) was 80 , er werd geen verschil gevonden tussen verbaal en performaal IQ. Eenderde van de onderzochte kinderen had gedragsproblemen, zoals zich terugtrekken, sociale- en concentratieproblemen. Daarnaast kon bij de helft van de kinderen een kinderpsychiatrische diagnose worden gesteld. Attention deficit hyperactivity disorder (ADHD) en angststoornissen kwamen het meest frequent voor.

In hoofdstuk 3 worden de resultaten beschreven van een onderzoek naar de leeftijd en de oorzaak van overlijden bij de volwassen vorm van myotone dystrofie. De overleving tot 65 -jarige leeftijd is duidelijk korter. Slechts de helft van de patiënten werd 60 jaar of ouder. De meest voorkomende doodsoorzaken waren pneumonie (longontsteking) en acute hartdood door hartritmestoomissen ( $31 \%$ en $29 \%$ respectievelijk). De helft van de patiënten was rolstoelgebonden in de jaren voor hun overlijden.

In hoofdstuk 4 wordt een overzicht gegeven van de zogenaamde trinucleotiderepeatziekten. Bij deze aandoeningen is er sprake van een "verlenging" van een gedeelte van het gen, door toename van het aantal trinucleotiden. Dit mechanisme is pas vanaf het begin van de jaren 90 bekend, en komt vooral voor bij neurologische ziekten, zoals het fragiele X syndroom, myotone dystrofie, de ziekte van Huntington en de dominante ataxiën. De trinucleotide repeats erven instabiel over van generatie op generatie, meestal worden zij langer. Daarnaast is er vaak een verschil tussen moederlijke en vaderlijke overerving.

Hoofdstuk 5 betreft een overzicht van de huidige genetische kennis over myotone dystrofie. Myotone dystrofie wordt veroorzaakt door een expansie (toename) van het aantal CTG repeats in het myotone dystrofie-gen. Dit gen wordt ook wel myotone dystrofie-proteine-kinase genoemd, en is gelegen op de lange arm van chromosoom 19. Karakteristiek bij de overerving van myotone dystrofie is het optreden van anticipatie, d.w.z. een vroeger ziektebegin gepaard gaande met ernstiger ziekteverschijnselen in opeenvolgende generaties, wat wordt veroorzaakt door een toename van het aantal CTG repeats in elke volgende generatie. Hoe de CTG repeat myotone dystrofie veroorzaakt, dus de aard van het moleculaire mechanisme, is nog niet opgehelderd. Men veronderstelt dat de toename van het aantal CTG repeats leidt tot een vermindering van de eiwitaanmaak. Andere hypotheses zijn dat de activiteit van 
naburige genen beïnloed wordt of dat er veranderingen optreden van het RNA metabolisme.

In hoofdstuk 6 wordt een samenvatting gegeven van de epidemiologische aspecten en de theoretische kennis omtrent de origine van myotone dystrofie. De prevalentie van myotone dystrofie is heel verschillend, wanneer men een aantal rassen vergelijkt. Bij genetisch koppelingsonderzoek zijn er aanwijzingen gevonden dat de meeste myotone dystrofie patiënten afstammen van 1 of enkele voorouders. Verondersteld wordt dat "gepremuteerde" normale genen geleidelijk langer worden, wat vele generaties in beslag neemt, totdat een kritische grens wordt bereikt en het gen instabiel wordt, met als gevolg dat er klinische verschijnselen zullen gaan optreden. De meest waarschijnlijke verklaring voor het frequente voorkomen van myotone dystrofie in de populatie, ondanks de beperkte voortplanting van patiënten, is dat er steeds nieuwe patiënten ontstaan uit dit "genetische reservoir".

In hoofdstuk 7 wordt een vervolgonderzoek beschreven van een grote familie met myotone dystrofie. Het bleek mogelijk de gegevens te verzamelen van 5 generaties patiënten. Anticipatie trad op in alle aangedane takken van de familie. De patiënten in de jongere generaties bleken zich niet voort te planten ten gevolge van hun verstandelijke handicap (47\%) of onvruchtbaarheid van mannen met het volwassen type (35\%). Dit zal hoogstwaarschijnlijk leiden tot het verdwijnen van het gen uit deze familie binnen 1 generatie.

Aspecten van de bijzondere overerving van myotone dystrofie zijn het onderwerp van hoofdstuk 8 . Het congenitale type wordt vrijwel altijd door een aangedane moeder doorgegeven. Een familie waarin een vader met myotone dystrofie een kind kreeg met het congenitale type wordt beschreven in hoofdstuk 8.1. Er is op dit moment nog geen sluitende verklaring voor het vrijwel niet voorkomen van deze vaderlijke overdracht, de beperkte mogelijkheid tot verlenging van de CTG repeat bij vaderlijke transmissie speelt een rol. Twee casus van een terugmutatie van het myotone dystrofie gen, tot in de normale range, zijn het onderwerp van hoofdstuk 8.2 . In beide gevallen was de vader de ouder die het gen doorgaf:

In hoofdstuk 9 worden de resultaten van de studie besproken en bediscussieerd, tevens worden een aantal nog openstaande vragen en mogelijkheden voor toekomstig onderzoek aangegeven. 


\section{Dankwoord}

Allerbeste Chris, Dr. C.J. Höweler, initiator en stimulator van het myotone dystrofie onderzoek. Ik vind het een hele eer dat ik jouw "levenswerk" heb mogen voortzetten. Veel dank voor je enthousiasme, en je niet aflatende steun en kritiek.

Beste Joep, Prof. dr. J.P.M. Geraedts, dank voor je geduld en voor de vrijheid om in mijn eigen tempo dit proefschrift te kunnen voltooien.

Beste Jean Pierre, Prof. dr. J.P. Fryns, enthousiasme voor wetenschappelijk onderzoek heb jij me bijgebracht, dank voor het in mij gestelde vertrouwen.

Beste Connie, dr. C.T.R.M. Schrander-Stumpel, je stimulans, je bereidheid om in te springen en het feit dat je me ook op deze dag bijstaat, zijn voor mij van grote waarde.

Beste Bert, dr. H.J.M. Smeets, bedankt voor de kritische discussies; je medewerkers van het DNA-lab wil ik bedanken voor alle extra analyses.

Beste Liesbeth, Monique, Jolanda, Petra, Nicole en Yvonne, secretaresses, bedankt voor de zeer prettige samenwerking in de afgelopen jaren en al jullie hulp bij de definitieve afronding van het manuscript.

Beste Francis, dank voor het vele donkere kamer werk en je wijze lessen om dit boekje mooi te kunnen maken.

Beste overige en onmisbare collegae uit Maastricht, dank voor jullie dagelijkse steun en samenwerking.

Beste Leuvense collegae, ik hoop dat de goede relatie Maastricht-Leuven nog lang zo zal blijven.

Beste Nijmeegse collegae, jullie hulp was een goed begin.

Beste Jan Frans en Bert, dr. J.F. Mirandolle en dr. H.B. Anten, zonder jullie gegevens was dit werk niet compleet geweest.

Beste Frans en Herman, Prof. dr. F.J. Jennekens en prof. dr. H.F.M. Busch, de kennismaking met jullie en het schrijven van ons "Nederlandse DM boekje" zijn voor mij een stimulans geweest om dit "Engelse boek" af te maken.

Beste medewerkers en leden van de Vereniging Spierziekten Nederland, patienten en ouders van patienten, de inspiratie voor dit werk komt ook van u.

Lieve Leendert, vanaf nu is de computer weer van jou.

Lieve Sara, controleren met jou was heel leuk, dankjewel.

Lieve Tony, jouw vrolijkheid hielp me er steeds weer bovenop.

Lieve Jan, de enige echt onmisbare. 


\section{Curriculum Vitae}

Christine Smulders werd geboren op 6 september 1956 te Rotterdam. Zij woonde daarna in Almelo en Vlissingen, en vanaf 1968 in Middelburg. In 1974 werd het diploma gymnasium $\beta$ behaald aan de Stedelijke Scholengemeenschap te Middelburg. Het kandidaatsexamen Biologie werd met succes afgelegd in 1975 aan de Rijksuniversiteit Utrecht. Vanaf 1975 studeerde zij Geneeskunde aan de Rijksuniversiteit Utrecht. In 1982 werd het artsexamen behaald. In 1983 1984 volgde zij de beroepsopleiding tot huisarts aan de Rijksuniversiteit Utrecht (opleider mw. drs. J. van Buuren, huisarts te Haaften). In juli 1984 werd zij aangesteld bij de Stichting Klinische Genetica Limburg (SKGL) te Maastricht. Zij werd opgeleid tot klinisch geneticus door drs. B.G.A. ter Haar, kinderarts te Nijmegen, en na diens overlijden in 1986, door dr. B.C.J. Hamel, hoofd sectie klinische genetica van de afdeling Anthropogenetica, Radboud ziekenhuis Nijmegen. Op 12 oktober 1988 werd zij als klinisch geneticus ingeschreven in het specialistenregister. Een belangrijke bijdrage aan de verdere vorming werd geleverd door Prof dr. J.P. Fryns, hoofd afdeling klinische genetica van het Cenrtum voor Menselijke Erfelijkheid te Leuven, en sinds 1988 als bijzonder hoogleraar vanwege de SKGL verbonden aan de Universiteit Maastricht.

Christine Smulders is waarnemend hoofd van de afdeling Klinische Genetica van de Stichting Klinische Genetica Zuid Oost Nederland (SKGZON), en sedert oktober 1992 waarnemend opleider voor het specialisme klinische genetica (opleider dr. C.T.R.M. Schrander- Stumpel). Het onderzoek wat in dit proefschrift wordt beschreven werd uitgevoerd binnen het Instituut Groei en Ontwikkeling van de Universiteit Maastricht (divisieleider Prof. dr. J.P.M. Geraedts, anthropogeneticus). 


\section{Publications}

Hamers AJH, Vaes-Peeters GPM, Jongbloed RJE, Millington-Ward AM, Meyer $\mathrm{H}$, de Die-Smulders CEM, Geraedts JPM. On the origin of recurrent trisomy 21: determination using chromosomal and DNA-polymorphisms. Clin Genet 1987;32: 409-413

Ploos van Amstel HK, Reitsma PH, Hamulyàk K, de Die-Smulders CEM, Mannucci PM, Bertina RM: A mutation in the protein S pseudogene is linked to protein $S$ deficiency in a thrombophilic family. Thrombosis and Haemostasis $1989 ; 62: 897-901$.

Floor E, De Jong RO, Fryns JP, de Die-Smulders CEM, Vles ISH : Spondylocostal dysostosis: an example of autosomal dominant transmission in a large family. Clin Genet 1989;36:236-241.

Schrander-Stumpel CTRM, de Die-Smulders CEM, Fryns JP, da Costa J, Bouckaert P: Limb reduction defects and renal dysplasia: Confirmation of a new, apparently lethal, autosomal recessive MCA syndrome. Am J Med Genet 1990;37:133-135.

de Die-Smulders CEM, Vonsée HJ, Zandvoort JA, Fryns JP. The lethal multiple pterygium syndrome: prenatal ultrasonographic and postmortem findings. A case report. Eur J Obstet Gynecol Reprod Biol 1990;35:283-289.

de Die-Smulders CEM, Schrander-Stumpel CTRM, Fryns JP: The lethal multiple pterygium syndrome: a nosological approach. Genetic Counseling 1990;1:13-23.

Spaepen A, Schrander-Stumpel CTRM, Fryns JP, de Die-Smulders CEM, Borghgraef $M$, van de Berghe $H$. Hallermann-Streiff syndrome: clinical and psychological findings in children. Nosologic overlap with oculodigitodental dysplasia? Am J Med Genet 1991;41:517-520.

Fryns JP, Schrander-Stumpel C, de Die-Smulders C, Borghgraef M, van den Berghe H. MASA syndrome: delineation of the clinical spectrum at prepubertal age. Am J Med Genet 1991;43:402-407.

de Die-Smulders CEM, Donk JM, Engelen JJM, Fryns JP: Further evidence for the location of the BPES gene at 3q2 Letter to the Editor. Clin Genet 1991;10:725.

de Die-Smulders CEM, Theunissen P, Schrander-Stumpel CTRM, Fryns JP. On 
the variable expression of the Brachmann-de Lange syndrome. Clin Genet 1992;41:42-45.

Schrander-Stumpel CTRM, de Die-Smulders CEM, Hennekam RCM, Fryns JP, Bouckaert PXGM, Brouwer OF, da Costa J, Lommen E, Maaswinkel-Mooy P. Oculoauriculovertebral spectrum and cerebral anomalies. J Med Genet 1992;29:326331.

Schaap C, de Die-Smulders CEM, Kuyten RH, Fryns JP. Kaufmann-Mc Kusick syndrome: the diagnostic challenge of abdominal distension. Eur $J$ Pediatr 1992;151:583-585.

de Die-Smulders CEM, Fryns JP. Smith-Lemli-Opitz syndrome: the changing phenotype with age. Genetic Counseling 1992;3:77-89.

Roelofsen JMT, de Die-Smulders CEM, de Haan MW, Havenith MG, Smits F. Dicephalus dipus dibrachius: een zeldzaam geval van een siamese tweeling. Nederlands Tijdschrift voor Obstetrie \& Gynaecologie 1992;105:237-238.

de Die-Smulders CEM, Vles H, Fryns JP. Characteristic facial dysmorphism, arachnodactyly and mental handicap in two unrelated girls: a distinct MCA/MR syndrome? Genetic Counselling 1993;4:165-167.

Brunner HG, Jansen G, Nillesen W, Nelen MR, de Die-Smulders CEM, Höweler $\mathrm{CJ}$, van Oost BA, Wieringa B, Ropers HH, Smeets HJM. Reverse mutation in myotonic dystrophy. N Engl J Med 1993;328:476-480.

Brunner HG, Brüggenwirth HT, Nillesen W, Jansen G, Hamel BCJ, Hoppe RCL, de Die-Smulders CEM, Höweler CJ, van Oost BA, Wieringa B, Ropers $H H$, Smeets HJM. Influence of sex of the transmitting parent as well as of parental allele size on the CTG expansion in myotonic dystrophy. Am J Hum Genet 1993, $53: 1016-1023$.

Smits APT, Dreesen JCFM, Post JG, Smeets DFCM, de Die-Smulders CEM, Spaans-van der Bijl T, Govaerts LCP, Warren S, Oostra BA, van Oost BA. The fragile-X syndrome: no evidence for any recent mutations. J Med Genet 1993;30:9497.

de Die-Smulders CEM, Droog RP, van Dijk M, Fryns JP. Severe intrauterine growth retardation, blepharophimosis, cylindrical nose with midline groove: a variant or severe expression of Dubowitz syndrome? J Med Genet 1993;30:525. 
Schrander-Stumpel C, de Die-Smulders C, de Krom M, Schyns-Fleuren S, Hamel $B$, Jaeken D, Fryns JP. Marden-Walker syndrome: case report, literature review and nosologic discussion. Clin Genet 1993;43:303-308.

Schrander-Stumpel CTRM, de Groot-Wijnands JBG, de Die-Smulders CEM. Type III syndactyly and oculodental dysplasia: a clinical spectrum. Genetic Counseling $1993 ; 4: 271-276$.

Vles JSH, de Die-Smulders CEM, van der Hoeven M, Fryns JP. Corpus callosum agenesis in two male infants of a heterozygotic triplet pregnancy. Genetic Counseling 1993;4:239-240.

Schrander-Stumpel CTRM, de Groot-Wijnands JBG, de Die-Smulders CEM. Type III syndactyly and oculodental dysplasia: a clinical spectrum. Genetic Counseling $1993 ; 4: 271-276$.

de Die-Smulders CEM, Schrander-Stumpel CTRM, Fryns JP. Familial occurence of renal and müllerian duct hypoplasia, craniofacial anomalies, severe growth and developmental delay: a $4 \mathrm{p}$ Deletion? Letter to the Editor. Am J Med Genet 1993;47:936.

Moog U, Engelen JJM, de Die-Smulders CEM, Albrechts JCM, Loneus WH, Haagen AAM, Raven EJM, Hamers AJH. Partial trisomy of the short arm of chromosome 18 due to inversion duplication and direct duplication. Clin Genet 1994;46:423-429.

de Die-Smulders CEM, van Schrojenstein Lantman-de Valk H, Fryns JP. Confirmation of a new $\mathrm{mr} /$ male pseudohermaphroditism syndrome, Verloes type. Genetic Counseling 1994;5:73-75.

Willekes C, Roumen FME, van Elsacker-Niele AMW, Weilend HT, Vermey-Keers C, van Krieken JHJM, de Die-Smulders CEM, Hamers GJH, Vaes-Peeters GPM. Human parvovirus B1.9 infection and unbalanced translocation in a case of hydrops fetalis. Prenat Diagn 1994;14:181-185.

Meijer H, de Graaff E, Merckx DML, Jongbloed RJE, de Die-Smulders CEM, Engelen JJM, Fryns JP, Curfs PMG, Oostra BA. A deletion of $1.6 \mathrm{~kb}$ proximal to the CTG repeat of the FMRI gene causes the clinical phenotype of the fragile-X syndrome. Hum Mol Genet 1994;3:613-620.

Bartstra HJL, Hulsmans RFHJ, Steijlen PM, Ruige M, de Die-Smulders CEM, 
Cassiman JJ. Mosaic expression of hypohydrotic ectodermal dysplasia. Report of a family with an isolated affected female. Arch Dermatol 1994;130:1421-1424.

Legius E, Habex E, Fryns JP, Cassiman JJ, de Die-Smulders CEM, Verbraak F. Genetic heterogeneity in Rieger syndrome. J Med Genet 1994;31:340-341.

Engelen J, de Die-Smulders CEM, Hoovers JMN, Jakobs ME, Fryns JP, Loots WJG, Albrechts JCM, Hamers AJH. Partial trisomy and monosomy $8 p$ due to inversion duplication. Clin Genet 1994;45:203-207.

de Die-Smulders CEM, Höweler CJ, Mirandolle JF, Brunner HG. Hovers V, Brüggenwirth $\mathrm{H}$, Smeets HIM, Geraedts JPM. Anticipation resulting in elimination of the myotonic dystrophy gene. A follow-up study of one extended family. J Med Genet 1994;31:595-601.

de Die-Smulders CEM, Theunissen P, Schrander-Stumpel CTRM, Fryns JP. Exclusively maternal transmission of autosomal dominant Brachmann-de Lange syndrome. Letter tot the Editor. Am J Med Genet 1994;52:363.

de Die-Smulders CEM, Sturkenboom MCJM, Veraart J, van Katwijk C, Sastrowijoto $P$, van der Linden $E$. Severe limb defects and craniofacial anomalies in a fetus conceived during acitretin therapy. Teratology 1995; 52:215-220.

de Die-Smulders CEM, Engelen JMM, Schrander-Stumpel CTRM, Govaerts LCP, de Vries B, Vles JSH, Wagemans A, Schijns-Fleuren S, Gillessen-Kaesbach G, Fryns JP. Trisomy $8 \mathrm{p}$ due to interstitial inverted duplication: clinical data on seven patients and review of the literature. Am J Med Genet 1995;59:369-374.

Schell U, Hehr A, Feldman GJ, Robin NH, Zackai EH, de Die-Smulders C, Viskochil DH, Stewart JM, Wolff G, Ohashi H, Price RA, Cohen MM, Muenke M. Mutations in FGFR1 and FGFR2 cause familial and sporadic Pfeiffer syndrome. Hum Mol Genet 1995;4:323-328.

de Graaff E, Willemsen R, Zhong N, de Die-Smulders CEM, Ted Brown W, Freling G, Oostra B. Instability of the CGG repeat and expression of the FMRI protein in a male fragile $X$ patient with a lung tumor. Am J Hum Genet $1995 ; 57: 609-618$.

Plomp AS, de Die-Smulders CEM, Meinecke P, Ypma-Verhulst JM, Lissone DA, Fryns JP. Coffin-Lowry syndrome: clinical aspects at different ages and symptoms in female carriers. Genetic Counseling 1995;6:259-268. 
Engelen JJM, de Die-Smulders CEM, Sijstermans JMJ, Meers LEC, Albrechts JCM, Hamers AJH. Familial partial trisomy $8 \mathrm{p}$ without dysmorphic features and only mild mental retardation. J Med Genet 1995;32:792-795.

Schrander-Stumpel CTRM, van der Meer S, de Die-Smulders CEM, Meinecke P, Rupprecht E, Maroteaux P, Schrander JJP, Fryns JP. Cerebro-costo-mandibular syndrome: a follow-up study with 7 patients. Letter to the Editor. Genetic Counseling 1996;7:71-72.

de Die-Smulders CEM, van der Meer S, Spaapen L, Fryns JP. Confimation of defective cholesterol biosynthesis in 2 previously described adult sibs with SmithLemli-Opitz syndrome. Letter to the Editor. Genetic Counseling 1996;7:161-162.

de Die-Smulders CEM, Engelen J. 11q duplication in a patient with Pitt-RogersDanks phenotype. Letter to the Editor. Am J Med Genet 1996;66:116-117.

Dreesen JCFM, Dumoulin JCM, Coonen E, Hopman AWN, Land JA, Dunselman GAJ, de Die-Smulders CEM, de Wert G, Evers ILH, Geraedts JPM. A test system for preimplantation diagnosis of the Fragile-X syndrome. TFO 1996,10:27-29

Moog U, Krüger G, Stengel B, de Die-Smulders CEM, Dijkstra $\$$, BleekerWagemakers E. Oculocerebrocutaneous syndrome: a case-repon, a follow-up and differential diagnostic considerations. Genetic Counseling 1996;7.257-265.

de Die-Smulders CEM. Hoe kan dragerschap voor hemochromatose worden opgespoord? Internistenvademecum, augustus 1996.

Moog U, de Die-Smulders C, Systermans PA, Cobben JM. Oculocerebrocutaneous syndrome: report of three additional cases and aetiological considerations. Clin Genet 1997;53:219-225.

de Die-Smulders CEM, Smeets HJM, Loots W, Anten HBM, Mirandolle IF, Geraedts JPM, Höweler CJ. Paternal transmission of congenital myotonic dystrophy. J Med Genet 1997;34:930-933.

Chandler KE, de Die-Smulders CEM, Engelen JJE, Schrander JJP. Severe feeding problems and congenital laryngostenosis in a patient with $3 q 23$ deletion. Eur $J$ Pediatr 1997;156:636-638.

Steyaert J, Umans S, Willekens D, Legius E, Pijkels E, de Die-Smulders C, van den Berghe H, Fryns JP. A study of the cognitive and psychological profile in 16 
children with congenital or juvenile myotonic dystrophy. Clin Genet 1997;52:135141.

Janssen EAM, Kemp S, Hensels GW, Sie OG, de Die-Smulders CEM, Hoogendijk $\mathrm{JE}$, de Visser $\mathrm{M}$, Bolhuis PA. Connexin32 gene mutations in X-linked dominant Charcot-Marie-Tooth disease (CMTX1). Hum Genet 1997;99:501-505.

Zwamborn-Hanssen AMN, Bijlsma JB, Hennekam EFAM, Lindhout D, Beemer F, Bakker E, Kleijer WJ, de France HF, de Die-Smulders CEM, Duran M, van Gennip AH, wan Mens JT, Pearson PL, Mantel G, Verhage RE, Geraedts JPM. The Dutch uniform multicenter registration system for genetic disorders and malformation syndromes. Am J Med Genet 1997;70:444-447.

de Die-Smulders CEM, Plomp A, Meijer H. Mutaties in het HLA-H gen: een doorbraak in de diagnostiek van haemochromatose. Internistenvademecum, maart 1997.

Plomp AS, Hamel BCJ, Cobben JM, Verloes A, Offermans JP, Lajeunie E, Fryns IP, de Die-Smulders CEM, Fryns JP. Pfeiffer syndrome type 2: further dellineation and review. Am J Med Genet 1998;75:245-251.

Martini E, van Bergh ARM, Coonen E, de Die-Smulders CEM, Hopman AHN, Ramaekers FCS, Geraedts JPM. Detection of structural abnormalities in spermatozoa of a translocation carrier $t(3 ; 11)(\mathrm{q} 27.3 ; 24.3)$ by triple FISH. Hum Genet 1998;102:157-165.

de Die-Smulders CEM, Höweler CI, Thijs C, Mirandolle JF, Anten HBM, Smeets HJM, Chandler KE, Geraedts JPM. Age and causes of death in adult onset myotonic dystrophy. Brain 1998;121:1557-1563.

Vandevijver N, De Die-Smulders CEM, Offermans JPM, van der Linden $\mathbb{E S}$, Arends JW, Sastrowijoto SH, Moerman PH, Fryns JP. Lethal hypophosphatasia, spur type: case report and fetopathological study. Genetic Counseling 1998;9:205209.

Dreesen JCFM, Bras M, de Die-Smulders CEM, Dumoulin JCM, Cobben JM, Evers JLH, Smeets HJM, Geraedts JPM. Pre-implantation genetic diagnosis (PGD) of spinal muscular atrophy (SMA). Mol Hum Reprod 1998;4:881-885.

Van den Enden $\int J$, Schrander-Stumpel C, Rupprecht E, Meinecke P, Marotaux P, de Die-Smulders C, Hamel BCJ. The cerebro-costo-mandibular syndrome: seven 
patients and review of the literature. Clin Dysmorphol 1998;7:87-96.

Plomp AS, Engelen JJM, Albrechts JCM, de Die-Smulders CEM, Hamers AJH. Two cases of partial trisomy $8 \mathrm{p}$ and monosomy $21 \mathrm{q}$ in a family with a reciprocal translocation (8;21)(p21.1;q22.3). J Med Genet 1998;35:604-608.

de Die-Smulders CEM, Geraedts JPM, Dreesen JCFM, Coonen E, Land JA. Genetische diagnostiek bij IVF-embryo's: eerste ervaringen met 'preimplantatie genetische diagnostiek' in Nederland. Ned Tijdschr Geneeskd 1998;142:2441-2444.

Frints SGM, de Die-Smulders CEM, Hasaart THM. Anencephaly in monozygotic twins and recurrence risk. Letter to the Editor. Prenat Diagn 1998; 18:867-868.

de Die-Smulders CEM. Pre-implantatie genetische diagnostiek: hoe eerder hoe beter? Tijdschr Verloskd 1998;23:264-267.

Moog U, Schoonbrood-Lenssen AMJ, Wagemans A, Spaapen LJM, de DieSmulders CEM. De ziekte van Sanfilippo type B: ondergediagnostiseerd bij verstandelijk gehandicapten? Ned Tijdschr voor de Zorg aan verstandelijk gehandicapten 1998;24:161-166.

Plomp AS, de Die-Smulders CEM, Smeets H. Hoe kan dragerschap voor hemochromatose worden aangetoond? Rheumatologen vademecum, nr 2, 1998.

de Die-Smulders CEM, Engelen JJM, Albrechts JCM, Hamers AJH. Detection of a cryptic translocation $t(13 ; 20)(q 34 ; p 13)$ in an unexplained case of MCA/MR: the value of FISH over high resolution chromosome banding. Am $J$ Med Genet $1999 ; 86: 385-388$.

Claeys M, van der Hoeven M, de Die-Smulders CEM, Bakker JA, Offermans JPM, Forget $\mathrm{Ph}$. Groener JEM, Spaapen LJM. Early infantile type of galactosialidosis as a cause of heart failure and neonatal ascites. J Inher Metab Disease 1999;22:666667.

Moog U, de Die-Smulders CEM, Scheffer H, van der Vlies P, Henquet CJM, Jonkman MF. Epidermolysis bullosa simplex with mottled pigmentation: clinical aspects and confirmation of the P24L mutation in the KRT5 gene in further patients. Am J Med Genet 1999;86:376-379.

Engelen JJM, de Die-Smulders CEM, Vos PTH, Meers LEC, Albrechts JCM, Hamers AJH. Characterization of a partial trisomy 16q with FISH. Ann Génét 
$1999 ; 42: 101-104$

Janssen HCJP, Schaap C, Vandevijver N, Moerman P, de Die-Smulders CEM, Fryns JP. Two sibs with microcephaly, hygroma colli, renal dysplasia, and cutaneous syndactyly: a new letha] MCA syndrome? J Med Genet 1999;36:481-484.

Curfs LMG, Didden R, Sikkema SPE, de Die-Smulders CEM. Management of sleeping problems in Wolf-Hirschhorn syndrome. Genetic Counseling 1999;10:345350.

de Die-Smulders CEM, Waterham H, Fryns JP. Unexpected molecular findings in 2 previously described brothers with Smith-Lemli-Opitz syndrome. Letter to the editor. Genetic counseling 1999;10:403. 